\title{
CONFLICT-AFFECTED WOMEN'S DISCOURSES ABOUT ACCESS TO HIGHER EDUCATION
}

A Dissertation
presented to
the Faculty of the Graduate School
at the University of Missouri-Columbia
In Partial Fulfillment
of the Requirements for the Degree
Doctor of Philosophy
HEATHER J. MACCLEOUD
Dr. Lisa Dorner, Dissertation Supervisor

DECEMBER 2019 
(C) Copyright by Heather J. MacCleoud 2019

All Rights Reserved 


\section{APPROVAL PAGE}

The undersigned, appointed by the dean of the Graduate School, have examined the dissertation entitled

\section{CONFLICT-AFFECTED WOMEN'S DISCOURSES ABOUT ACCESS TO HIGHER EDUCATION}

presented by Heather J. MacCleoud, a candidate for the degree of Doctor of Philosophy, and hereby certify that, in their opinion, it is worthy of acceptance.

Professor Lisa Dorner

Professor Pilar Mendoza

Professor Emily Crawford

Professor Stephanie Potochnick 


\section{DEDICATION}

This dissertation is dedicated to the 10 amazing women featured in this study, and to their countless peers around the world. These resilient women have fought valiantly for second chances in their lives and have inspired so many with their stories of bravery and persistence in the face of seemingly unsurmountable obstacles to their pursuit of higher education. 


\section{ACKNOWLEDGEMENTS}

Dissertations by design are collaborative efforts. There are no more important collaborators than the members of one's dissertation committee who have each given generously of their time and expertise. I would like to thank Dr. Lisa Dorner for encouraging me down a new road of inquiry, and for her guidance on the use of critical discourse analysis to understand the complexities and inherent power structures within even seemingly mundane pieces of text. I would like to thank Dr. Pilar Mendoza for her insights into global higher education policies and trends, and her recommendations for consideration of important research and policy materials. I would like to also thank Dr. Emily Crawford and Dr. Stephanie Potochnick for the critical questions they have asked and the insights they have shared.

The focus of this research has been on 10 applicants to the Asherah Foundation's Second Chance Scholarship program. I would like to thank Dr. Kristen Sorenson and Dr. Gabrielle Malfatti for helping become "the change we wished to see" by founding the Asherah Foundation with me, and for Dr. Özlem Özyon and DeAnna Alonso, MSSW for helping the organization truly become global. I would also like to thank the many Executive Board and Advisory Board members who have helped further shape the organization, and the interns who have kept building its capacity to serve women around the world who need a second chance.

I also would like to thank two professional colleagues for the many engaging conversations they have held with me about the many academic, political, and practical considerations of this research: Dr. Sara Woodruff of the Asherah Foundation and Dr. Shanna Saubert of NAFSA: Association of International Educators. 
Finally, I would like to thank the countless people in my life who have provided inspiration and feedback throughout the process. Participants in conferences where I have presented aspects of this work, editors who have reviewed earlier iterations of this research, and friends, family, and colleagues who have engaged in critical conversation with me have all provided valuable guidance and support. 


\section{TABLE OF CONTENTS}

\section{Contents}

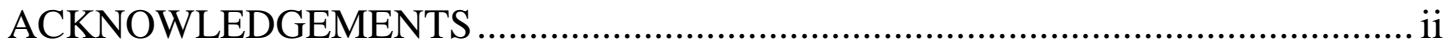

LIST OF FIGURES ………………………………...................................... vi

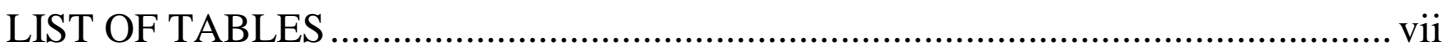

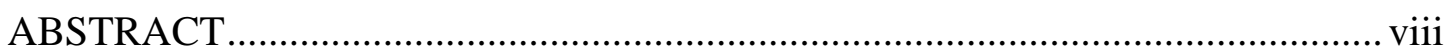

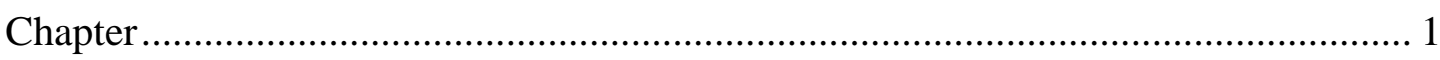

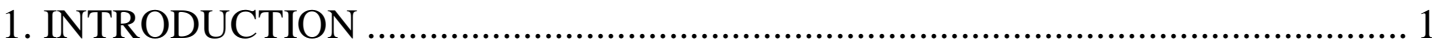

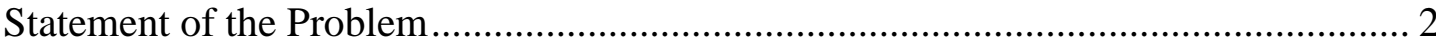

Purpose of the Study ................................................................................................ 4

Research Design and Questions...................................................................... 4

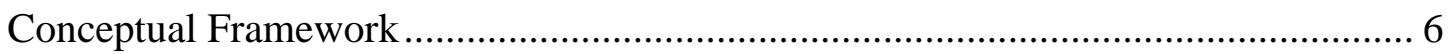

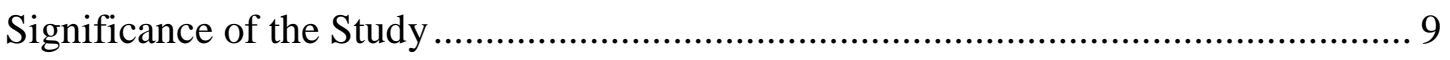

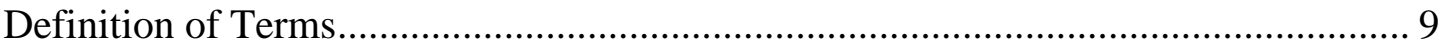

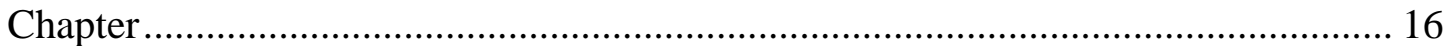

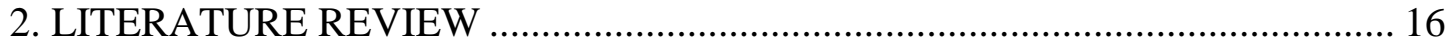

Discourses about Global Access to Higher Education ............................................... 18

Common Critiques of IO-related Global Discourses (e.g. UN, World Bank) ............. 30

Discourses: Role of Education and Identities of Students ......................................... 48

Theoretical Framework: Critical Discourse Analysis (CDA) ...................................... 64

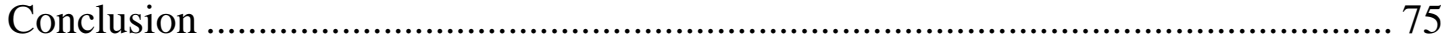

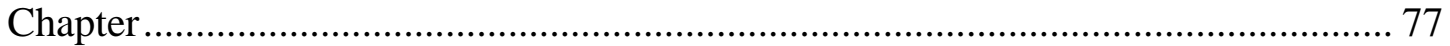

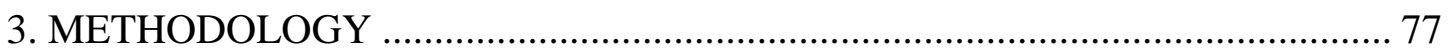

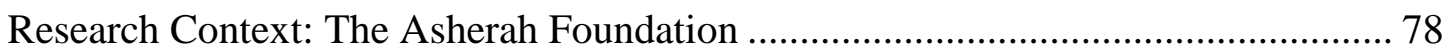

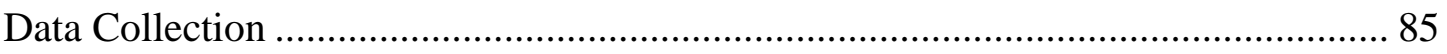

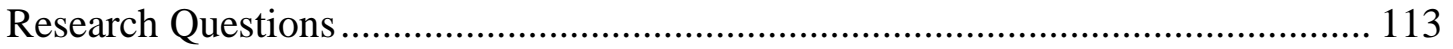

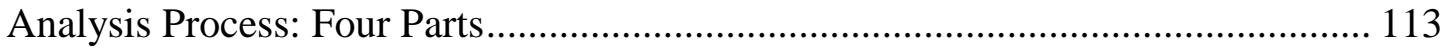

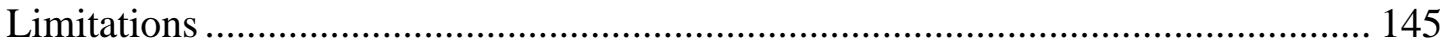

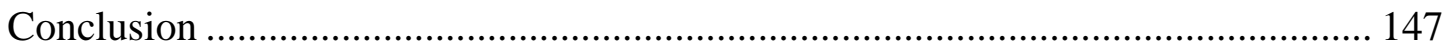




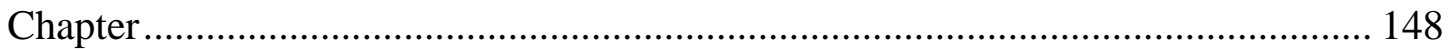

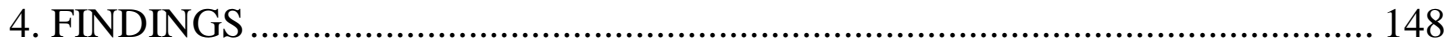

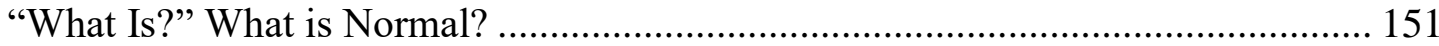

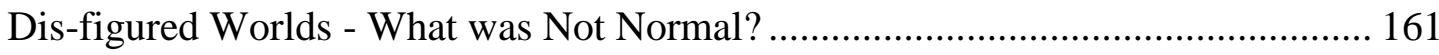

Conversations: Alignment with Discourses? …………………………………..... 167

Findings for Part III: Wider Societal Context (What Might Be?) ............................. 189

Findings for Part VI: What else is possible?........................................................ 192

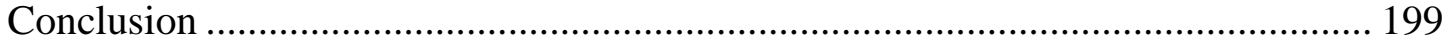

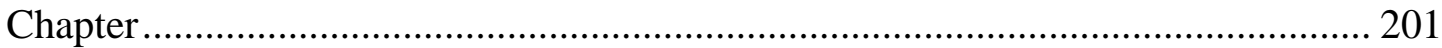

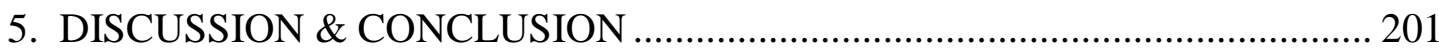

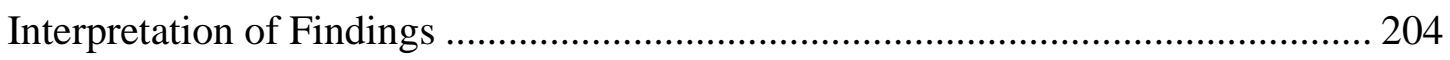

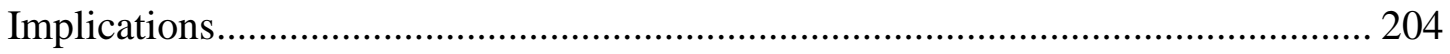

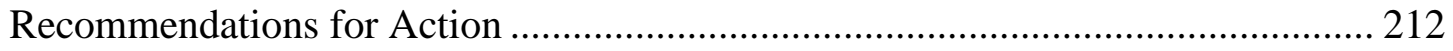

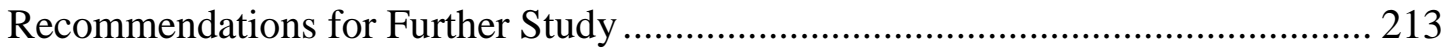

Reflection on Researcher's Experience ……………………………………….... 216

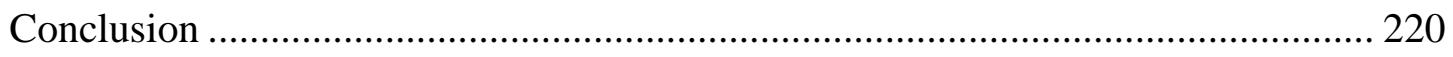

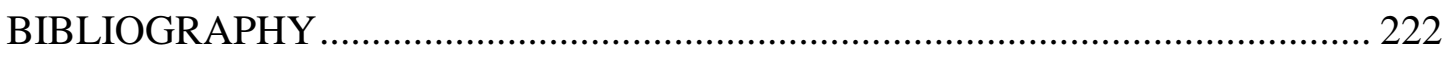

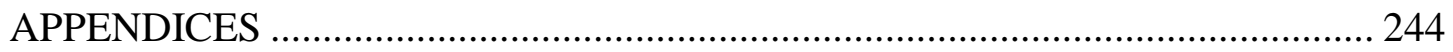

Appendix 1: Figures and Tables ..................................................................... 245

Appendix 2: SDG \#4 Targets.............................................................................. 287

Appendix 3: Education Levels (ISCED levels 4-8) .............................................. 290

Appendix 4: Comparison of World Bank and UIS Country Classifications ............ 292

Appendix 5: Fragile and Conflict-affected Situations ............................................ 296

Appendix 6: Scholarship Policy \& Application Form ................................................ 298

Appendix 7: Building Task Codes - Comparisons of Major Categories.................... 308

Appendix 8: Chart of Four Discourses: Applicants vs. Others.................................. 310

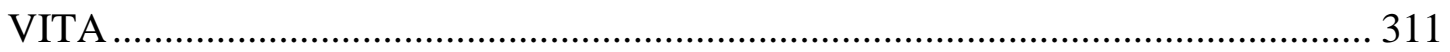




\section{LIST OF FIGURES}

Figure

Page

Figure 1: 2016 Gross enrolment ratio, tertiary, female $(\%)$..................................... 247

Figure 2. Building Task Codes by Top Categories - Normal Scenarios....................... 248

Figure 3. Top Categories by Building Task - Applicants in Normal Scenarios ............ 249

Figure 4. Normal Scenarios: Applicants vs. Others ............................................. 250

Figure 5. Top Categories of Building Task Codes for Others in Normal Scenarios ...... 251

Figure 6. Top Categories for Building Tasks in Dis-figured Worlds - Both Applicants

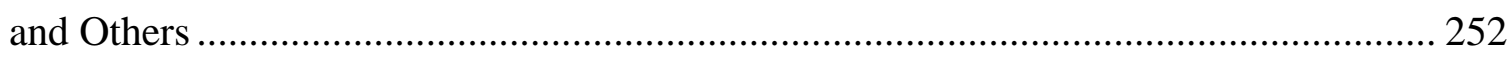

Figure 7. Top Categories for Three Building Tasks - Applicants' Dis-figured Worlds 253

Figure 8 Top Categories for Others in Dis-figured Worlds ...................................... 254

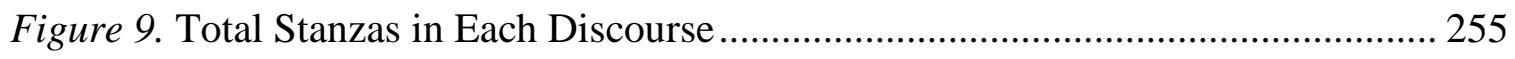

Figure 10. Discourse Ratios: Percentage of Normal : Not Normal ............................. 256

Figure 11. Discourses by Each Analytical Group .................................................... 257

Figure 12. Transactional Victim Discourse Distribution ........................................... 258

Figure 13. Transformative Victim Discourse Distribution.......................................... 259

Figure 14. Transactional Victor Discourse Distribution ........................................... 260

Figure 15. Transformative Victor Discourse Distribution ....................................... 261

Note: Not all figures are shown throughout the body of the text. All figures are found in Appendix 1. 


\section{LIST OF TABLES}

Table

Page

Table 1: How Education is Typically Linked with Other Sustainable Development Goals . 263

Table 2: Completion rates by education level, income group, sex and wealth, 2008$2014(\%)$ 265

Table 3: Tertiary education participation indicators 266

Table 4: Definitions and Components of D/discourse and Critical Discourse Analysis (CDA) 267

Table 5: Characteristics of Inaugural Executive Board 268

Table 6: Applicants by Region 269

Table 7: Applicants by Income Classification Level ........................................... 270

Table 8: Applicants by UIS Level of Development............................................. 271

Table 9: Primary and Alternative Samples ......................................................... 272

Table 10: Characteristics of Primary Population of Study .................................... 273

Table 11: Components of Discourse, CDA, and Parts of Analysis ......................... 275

Table 11: Components of Discourse, CDA, and Parts of Analysis ........................ 275

Table 12: Building Tasks \& Tools: Analysis Round Two...................................... 277

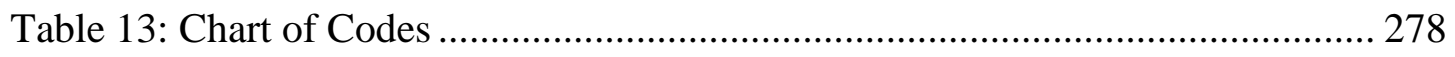

Table 14: Distribution of Building Task Codes .................................................. 279

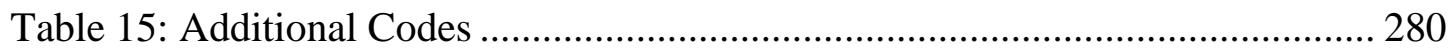

Table 16: Building Task Code Distribution........................................................... 281

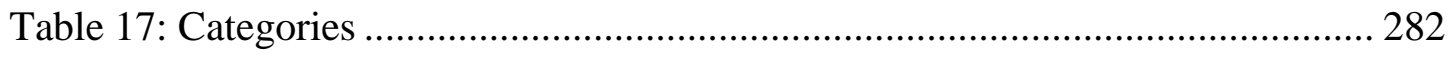

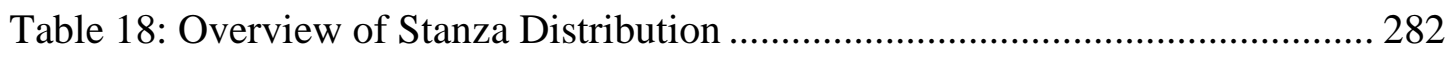

Table 19: Categories for Each Building Task in Example Stanzas......................... 283

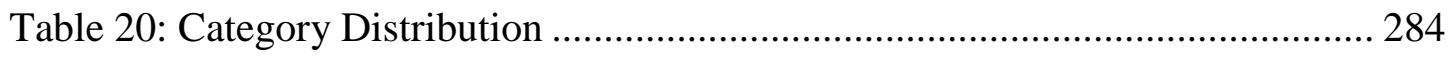

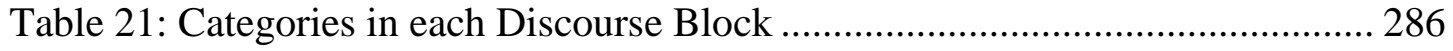

Note: Not all tables are shown throughout the body of the text. All tables are found in Appendix 1. 


\begin{abstract}
This dissertation examined the discourses of 10 underserved women working to access higher education, in relation to the discourses of formal efforts to provide education access via international organizations (IOs) such as the United Nations. The purpose of this dissertation was to better understand whether and how the discourses of these women were aligned with those of these international organizations, with a focus on the purposes of higher education, and the roles of these women in relation to these purposes. The primary source of data for this analysis were essays these women had written as part of an application to an international scholarship program. The study was shaped by a review of literature on access to higher education for nontraditional students including refugees, women, and those in low- and lower-middle-income countries. Critical Discourse Analysis (CDA) provided both the theoretical framework and the method of analysis.
\end{abstract}

The analysis highlighted the complex nature of these 10 women's relationships with higher education. Findings suggested that efforts by IOs to improve access to underserved populations should consider that students may be simultaneously victimized and victorious, and that education plays both transactional and transformational roles in their experiences.

The use of their scholarship essays provided a means through which their voices could be heard, as they have not traditionally been involved in shaping the educational research and policies that impact their experiences. Their experiences fall outside of most research on nontraditional students, refugees, and students from lower income countries. The complexity of their experiences as outlined through this research may help shape 
additional research about how underserved populations at the intersection of multiple underserved groups. 
WOMEN'S DISCOURSES

\section{Chapter}

\section{INTRODUCTION}

Access to higher education for women in lower income countries and in conflict affected and fragile states is extremely low. In 2016, the United Nations Educational, Scientific and Cultural Organization (UNESCO $)^{1}$ reported that only seven percent of eligible women were enrolled in tertiary education in low-income countries. In fragile and conflictaffected states, this percentage increased to $11 \%$, while in lower-middle-income countries, that number rose to $24 \%$. In 2016 , the world average for such tertiary enrollment was $40 \%$, while the average for high-income countries was 86\% (see Figure 1: 2016 Gross Enrolment Ratio: Tertiary, Female (\%)). These extreme disparities highlight the need to understand more about how and why these inequities exist.

Global agendas to improve access to education in the lower income countries have been around for decades. The United Nations' (UN's) Sustainable Development Goals (SDGs) represent the latest version. These goals were adopted in 2015 after years of consultation with millions of constituents around the world. Despite the immense effort put into developing the goals, identifying indicators, collecting data on progress towards these indicators, and working with international organizations to publish a 600+ page comprehensive report on Goal \#4, the UN fell short in its efforts. The 2016 GEM Report noted that "Forcibly displaced populations are among the most neglected" (UNESCO, 2016a, p. 254) and that "forced displacement tends to lead to gross violations of the right to education" (p. 271). The report asks readers to consider ways in which to collect information "that identifies individuals as members of other vulnerable groups such as people... who are

\footnotetext{
${ }^{1}$ For readability, all documents by the United Nations Educational, Scientific and Cultural Organization will be identified as "UNESCO" in citations.
} 
forcibly displaced" (p. 256). This research is a part of that effort. This introduction will provide an overview of the reasons for this study, the questions it seeks to answer, and ways in which this research may be useful. It will conclude with definitions of key terms.

\section{Statement of the Problem}

In the summer of 2016, recognizing the extraordinary challenges to underserved students' access to higher education, two very different organizations sought to improve access to higher education for them. The first was the United Nations (UN), which produced a preliminary report that aimed to measure progress towards ambitious global education targets: the 2016 Global Education Monitoring (GEM) Report. These targets were developed under Sustainable Development Goal (SDG) \#4, which was to "ensure inclusive and quality education for all and promote lifelong learning" (UNESCO, 2016a, p. 6). It included 10 primary targets which had been developed alongside global efforts to promote access to higher education by other international organizations such as the United Nations High Commissioner for Refugees (UNHCR) and the World Bank (see Appendix 2: SDG\#4 Targets). The second organization was a much smaller non-profit organization called the Asherah Foundation, which announced its first set of scholarships for women around the world who needed a "second chance" at accessing higher education.

While the UN's 2016 GEM Report was announced with great fanfare and symbolized the efforts of millions of people around the world coming together to provide access to education for underserved populations, the Asherah Foundation's scholarship program was more quietly announced through personal networks of a few board members. Nonetheless, the Asherah Foundation's efforts to support a small number of underserved and 
nontraditional women around the world were trying to support access to women overlooked in the policies and reports from these international organizations (IOs).

The 2016 GEM Report was an impressive first attempt at measuring progress and continuing the conversations around how to achieve SDG \#4. However, the report itself noted that there were significant gaps in data collected and thus used to inform policy. While there were new concentrated efforts to measure the reach of efforts to educate underserved women across the globe, relatively little was known about how women themselves viewed their access to higher education; this was especially the case for those who have been forcibly displaced due to violence, despite the fact that the UN has called for better measurement and understanding of such experiences. In parallel, research in the Global North focused on the challenges and strategies of nontraditional students accessing higher education in high-income countries. However, in 2016 this research seemed to be disconnected from the SDGs, particularly as it focused on students living and working in high-income countries without the stressors of significant violent conflict.

This research sought to illuminate an area of the UN's education goals that was left out of the GEM Report by engaging in a critical discourse analysis (CDA) of the scholarship essays of nontraditional, conflict-affected women from lower income countries who applied for the Asherah Foundation's Second Chance Scholarship between 2016-2018. Alongside the efforts of IOs like the UN, scholars have begun to research best practices to provide educational access for nontraditional students, for women, and for those affected by conflict, often critiquing the UN's SDGs along the way. Many of the critiques of the SDGs highlight the lack of voice from those that the UN seeks to serve through the SDGs. 
This analysis sought to highlight some of these voices. Many of the applicants to the Asherah Foundation were nontraditional women from low and lower-middle income countries which were also conflict-affected or considered to be "fragile states." Their ability to access higher education despite the odds against them is remarkable. Their stories about their educational journeys may provide valuable insight into how they were able to overcome the challenges of conflict and provide information to further the goals of SDG \#4. In addition, their stories may speak to empirical literature on access to higher education for nontraditional students, students from lower income countries, and women more broadly.

\section{Purpose of the Study}

The purpose of this study was to understand the experiences of women who were from some of the most underserved populations in the world (in terms of access to higher education). They were from lower income countries, were adult females, and were affected by conflict, yet were able to somehow access higher education despite it all. The 2016 GEM Report noted that in the lowest-income countries, just $1 \%$ of the poorest girls completed upper secondary school and were thus eligible for higher education (UNESCO, 2016a, p. 185). This rises to $17 \%$ in lower-middle-income countries. This means that those women who were from low- and lower-middle-income countries had very little chance to access higher education. Those who endured violent conflict faced even greater obstacles.

\section{Research Design and Questions}

This study sets out to examine the experiences of a select group of women seeking to access higher education using the theories and methods of Critical Discourse Analysis or CDA (Gee, 2014a, 2014b). CDA allows for a deep exploration of the ways in which language is used to socially construct realities. These realities determine what is acceptable 
or not acceptable to discuss, and what actions are appropriate to take. These realities are constructed through language as it creates and perpetuates meta-narratives (or "Discourses"). These Discourses shape the "Conversations" (or thematic debates) that are acceptable. The exploration enabled via CDA enables researchers to better understand who has the power to construct these realities, the boundaries of these realities, who does not have this power, and thus "what else is possible" (Gee, 2014a, 2014b). Understanding all of this is an important part of efforts to effect change, which is why CDA was chosen as both the conceptual framework and methodology of this research.

\section{Sample}

Out of the 175 applications to the Asherah Foundation's Second Chance Scholarship from 2016 - 2018, 101 came from a "conflict-affected or fragile situation" (UNESCO, 2016a, p. 399; The World Bank, 2018a). However only 33 self-identified as having had their educational journeys explicitly interrupted due to conflict. Ten of the applicants to the Asherah Foundation's Second Chance Scholarship self-identified as conflict-affected, were from a low, or lower-middle-income country, and fit additional criteria as "nontraditional" students (and also submitted applications in English). The experiences of these 10 women are particularly valuable in terms of shedding light on how they overcame substantial obstacles in order to access higher education. This sample of remarkable women was able to access higher education despite being from poor countries and despite having their educational journeys interrupted by conflict. Their stories provide insight into the ways in which they were able to succeed despite the odds against them. They are the focus of this study. 


\section{Questions}

In order to examine how they did so, the overarching question for this research was: How do nontraditional women from lower income countries and conflict-affected regions describe their journeys to higher education despite tremendous obstacles including violence and poverty? Specifically, how do applicants to the Asherah Foundation Second Chance Scholarship talk about themselves and the role of education in their lives? Overall, the questions of this study examined "what is," "what might be" and "what else is possible" through a critical discourse analysis of the women's application essays:

- What is: How do the women identify themselves and the role of education in their experiences?

- What might be: How do these discourses compare to women in similar situations?

- What else is possible: How might critiques regarding inequities be addressed?

\section{Conceptual Framework}

Critical Discourse Analysis (CDA), especially the theories and methods articulated by Norman Fairclough (1992, 1995, 2001, 2013) and James Paul Gee (2014a, 2014b), is the primary framework for this research. In addition, the project was shaped by a review of literature on access to higher education for nontraditional students including refugees, women, and those in lower income countries.

\section{Critical Discourse Analysis (CDA)}

Critical Discourse Analysis (CDA) is based on theories around social constructionism, viewing reality as constantly being constructed based on interpretations of various social factors. The "critical" aspect seeks to understand that various structures of power involved in producing discourses, and thus shaping the Discourses (meta-narratives) 
surrounding this discourse production. The scholarship application essays submitted by the women who were the focus of the analysis are considered to be works of discourse, or language-in-use, that is, language being used to construct reality, including identities, relationships, and arguments regarding the appropriate distribution of social goods (Gee, 2014a, 2014b). Analysis of these discourses seeks to understand the larger Discourses (or meta-narratives) in which they are produced, and to understand what Conversations (debates within the meta-narratives [e.g. what is the purpose of education for women?]) in which women are engaging. The critical aspect of this discourse analysis is concerned with looking at the politics involved in the production of these discourses (e.g. essays). Assumptions about the distribution of social goods, including the role of education for women, the responsibilities for funding this education, and what constitutes a "good" education are all assumptions that uphold and privilege certain power structures, viewpoints, and individuals over others.

\section{Review of Literature}

This study draws upon reports from International Organizations (IOs) such as the United Nations and the World Bank. Empirical research on access to higher education for women, for conflict-affected, and for nontraditional students provides the foundation for understanding the discourses of 10 women seeking to access higher education from the least developed countries. Critiques of global educational goals from IOs provide the lens to critically analyze the discourses of these women in conjunction with the Discourses of these organizations.

Organizations such as the UN and the World Bank have done tremendous work over the past few decades in helping to expand access to education. They have developed 
extensive data collection and reporting mechanisms, and used this data to develop policies, inform practices, and create broad global goals for the access and pursuit of education. The global reach of these IOs means that they have access to data reporting and tracking mechanisms around the world and can align policies to contexts.

As will be highlighted in Chapter Two, there is a growing body of empirical research developed around nontraditional students' access to higher education, focused on adults with familial and financial responsibilities in the Global North. IOs have provided insight into educational access for underserved populations - including those from lower income countries, girls, and refugees. However, there is very little research on educational access for students who find themselves at the intersections of these groups, or even excluded.

Adult females who have been affected by conflict, and who are from developing countries have not typically been represented in the existing body of research on educational access. They are generally considered to be too old to be counted among the girls for whom the IOs offer support. They do not always have formal recognition as refugees, leaving them out of conversations about how to support those with the official legal definition of "refugee." Although they share characteristics with the growing numbers of nontraditional students in the Global North, they often access their education in the Global South.

Discussions about these underserved women rarely involve their participation. When they are discussed, they are portrayed as victims, mothers, and/or untapped resources (Andersson, \& Hatakka, 2017). They are victims as they have been prevented from accessing education. They are mothers whose primary role is to make sure the rest of their family and community are transformed. They are untapped resources as they are sources of human capital to be developed in efforts to promote economic growth. 


\section{Significance of the Study}

The significance of this study is that there is currently little research on the experiences of underserved women, particularly those who are nontraditional, from lower income countries, and who have successfully accessed higher education despite having their educational journeys affected by conflict. The authors of the 2016 GEM Report explicitly asked readers to find and use data on these underserved populations. The data that the Asherah Foundation Second Chance Scholarship applications provided was a crucial step to developing strategies to obtain data about these women's experiences, with the hopes that eventually this data can be used by IOs to monitor and encourage progress so that more of them will be able to successfully access higher education.

\section{Definition of Terms}

This section will provide brief definitions and outlines of the following: Education Levels, Country Classifications, Nontraditional Students, and concepts related to the term Global.

\section{Education Levels}

As this research seeks to provide guidance to those involved with the GEM Report series, the terminology used in this paper will follow the definitions used by this report where appropriate. Education levels in the GEM Report follow "the International Standard Classification of Education (ISCED), which is the classification system designed to serve as an instrument for assembling, compiling and presenting comparable indicators and statistics of education both within countries and internationally" (UNESCO, 2016a, p. 493). Much of the discourse relied upon for this research is in reference to tertiary education (levels 5-8 in the GEM Report). It should be noted that the Asherah Foundation uses post-secondary to 
refer to levels 4-8. To avoid confusion, this paper will refer to ISCED levels 4-8 as "higher education" in general. This will be done, in large part, as one of the goals of this research is to inform the dialogue about access for women to tertiary education including post-secondary education opportunities (level 4). For further information distinguishing the various levels of post-secondary and tertiary education, see Appendix 3: Education Levels (ISCED levels 4-8).

\section{Country Classifications}

Most of the data on access to education comes from either the UN, primarily through the United Nations Institute of Statistics (UIS) and the GEM Reports, or from the World Bank. The UN and the World Bank have slightly different methods of classifying countries by region, income levels, and conflict status. A comprehensive list of how each country is classified is provided in Appendix 4: Comparison of World Bank and UIS Country Classifications. When reporting on country- and region-specific data, the classification provided will be that of the organization providing the data (e.g. percentage of education expenditure for low-income countries from the UN will use the UN's low-income classification).

Regions. The UN and World Bank also classify countries regionally in slightly different ways. Please see Appendix 4: Comparison of World Bank and UIS Country Classifications for list of countries by region according to both methodologies. In general, the World Bank's Middle East and North Africa (MENA) region overlaps substantially with the UIS's West Asia region.

Palestine. A significant number of applicants for the Asherah Foundation scholarship self-identified as being from the State of Palestine. The Asherah Foundation does not have an official position on the legal status of this 
country/territory. As will be noted throughout the document, the UIS and World Bank have different ways of addressing Palestine.

Income levels. The UN and World Bank have slightly different categorizations of income levels as indicated, most of which have increased between the start of this study in 2016 and the present (most recent data is for the 2020 fiscal year). The World Bank's categories for 2020 are as follows:

- Low-income group aggregate. Low-income economies are those in which 2018 [Gross National Income] GNI per capita was $\$ 1,025$ or less.

- Lower-middle-income group aggregate. Lower-middle-income economies are those in which 2018 GNI per capita was between $\$ 1,026$ and \$3,995.

- Upper-middle-income group aggregate. Upper-middle-income economies are those in which 2018 GNI per capita was between $\$ 3,996$ and $\$ 12,375$.

- High-income group aggregate. High-income economies are those in which 2017 GNI per capita was greater than $\$ 12,376$ (The World Bank, 2019).

The UIS does not provide definitions for either the income or development level classifications (personal communication, UN Statistics Division, 2017). As will be noted within Chapter Three: Methodology, this means that certain countries (e.g. Jordan) are classified differently by the two organizations (The World Bank, 2018c). For the purposes of this study, when referring to groups with members from both low-income and lower-middleincome countries, the classification will be simplified to "lower income." For example, the 10 women in the primary population of study are from lower income countries, as some are from low-income countries and some from lower-middle-income countries. Additionally, seven of the 10 women featured in this research came from countries that had been classified 
as lower-middle-income but had been re-categorized as low-income during the course of this study as their economies had deteriorated.

Fragile and conflict-affected situations. Most refugees, asylum seekers, internallydisplaced and forcibly displaced individuals are from countries and situations where there is ongoing conflict. Those living in such situations may generally considered to be "affected by conflict" as there is often significant disruption to their lives (e.g. becoming orphaned) even if they are not forced to relocate. International Organizations such as the United Nations and the World Bank have similar definitions, and thus similar lists of those countries/situations which are deemed fragile and/or conflict-affected.

The 2016 GEM Report considers "conflict-affected" countries in its analysis. As much of the focus is on those women who were affected by conflict, this classification is worth considering. The report notes that

For a given year, any country with 1,000 or more battle-related deaths (including fatalities among civilians and military actors) over the preceding 10 -year period and/or more than 200 battle related deaths in any one year over the preceding 3-year period, according to the Uppsala Conflict Data Program Battle-Related Deaths Dataset. (UNESCO, 2016a, p. 493)

The World Bank's designation includes eligibility for certain types of international development attention and/or the presence of "a UN or regional peacebuilding and political mission ...or peacekeeping mission...during the last three years." (The World Bank, 2018a). Appendix 5: Fragile and Conflict-affected Situations contains additional information on these definitions as well as a list of those countries/situations designated as fragile and conflictaffected by one of these two organizations. 
Conflict-affected person. The United Nations provides very distinct definitions for terms such as migrant, refugee and internally displaced individuals with legal implications for each term. According to the office of the UN High Commissioner for Refugees (UNHCR), ${ }^{2}$ "Refugees are persons fleeing armed conflict or persecution." This is in contrast to migrants who "choose to move not because of a direct threat of persecution or death, but mainly to improve their lives by finding work, or in some cases for education, family reunion, or other reasons" (UNHCR, 2016c). The term forcibly displaced is often used to refer to refugees, asylum seekers, and internally displaced persons as a group. However, as noted above, there are many stuck in a conflict-affected or fragile situation who may considered to be "conflict-affected."

The 10 women who are the focus of this study self-reported that their educational journeys had been interrupted due to violent conflict. Some explicitly shared that they had official "refugee" status, while others did not. Those who did not explicitly designate themselves as such alluded to forced displacement or discussed how violent conflict had affected their access to education, even if they had not left home. Therefore, within this study these 10 women are all considered to be "conflict-affected."

\section{Nontraditional Students}

Nontraditional students are often identified by what they are not. "Traditional" students (at least in the Global North) are generally considered to be from middle-class households and financially secure, unmarried, without dependents, and younger as they have had uninterrupted access to education from K-12 into higher education (Collis \& Reed, 2016, p. 4). Traditional students also share a primary language and culture with their institution.

\footnotetext{
${ }^{2}$ For readability, sources by the UN High Commissioner for Refugees will be cited in text as "UNHCR"
} 
Within this research, nontraditional students will be identified as those who are from lower income parts of the world, have financial and familial responsibilities, are aged 24 or older, and/or have different primary languages or cultures from their institution. The unifying "nontraditional" characteristic of the population of study is that they have all had their educational journeys interrupted by conflict.

\section{Global}

Global vs. international. The terms "global" and "international" are often used interchangeably. However, there are distinctions between these terms. In short, "international" signifies "between nations", or inter-national - the relationships between and among nation-states. The term "global" is more holistic as it encompasses relationships between and among entities beyond the parameters of the "nation state" level. When discussing policies involving organizations and actors beyond simply national governments (e.g. private sector, NGOs, etc.), the term global is more appropriate.

Global (Developed) North / Global (Developing) South. Researchers, economists and policymakers often use the terms Global North or Global South, Developed or Developing when referring to different economies ("Western" is sometimes used in place of "Global North"). These terms are generally relational (e.g. economies in the Global South are defined in contrast to those in the Global North, which are often seen as "more developed"). Much of the criticism of development agendas revolves around the perceived superiority of the Global North (e.g. Developed) and thus inferiority of those economies, communities, countries in the Global South which are seen as "Developing" and thus somehow "less than." As will be outlined below, much of the criticism is due to the power imbalances that these designations maintain in terms of knowledge creation (the knowledge from the Global North 
is seen as superior) and funding (the Global North provides funding via the World Bank, IMF, etc. to the Global South to help the Global South develop in terms of education, healthcare, and other systems). This funding has historically been tied to Global North notions of what appropriate education systems and policies are. These "appropriate" systems and policies are often based on those in the Global North and have not always been successful when implemented in the Global South. As will be illustrated below, the development of these "Developed" systems and policies of education have often had the effect of delaying and even reversing actual development of economies in the Global South. Many have argued that the Global North is also missing out as it has not appreciated the experiences and wisdom of those in the Global South.

In response to this criticism, the UN's Sustainable Development Agenda was developed to provide more opportunities for dialogue between those in the Global North and in the Global South. The World Bank stopped using the terms "Developed" and "Developing" in its 2016 edition of World Development Indicators (Fantom, Khokhar, \& Purdie, 2016). This study seeks to incorporate knowledge from those in the Global South through a close examination of the discourses used by women in these communities. 
WOMEN'S DISCOURSES

\section{Chapter}

\section{LITERATURE REVIEW}

- Lawan was 27 and from a low-income country enveloped in ongoing conflict in SubSaharan Africa. Her goal was to obtain a degree in a different country that would enable her "to advocate for the voiceless [e]specially women and children who are the most vulnerable people in our community."

- Nifa had begun pursuing an undergraduate degree in a high-income country but was forced to drop out when her father died, and her source of funding was no longer available. As her lower income home country was in the midst of ongoing violent conflict, she fled to a neighboring country with her children. Despite having to provide for her dependents, she was able to learn the local language and was finally able to enroll in a completely new academic program in that country at the age of 27.

- Laleh was 27 and also a refugee from a low-income country in the midst of ongoing conflict. She was the first in her family to access higher education and wanted to use her degree to develop a community-based organization teach entrepreneurial skills to female entrepreneurs with a goal of generating income so that they could then afford school fees for themselves and for their children.

These are just a few of the stories about women around the world who are fighting for access to higher education. They represent a unique population as they fall at the intersection of several characteristics of underserved students, as well as being among the handful of women in their countries who have been able to gain access to higher education. Understanding more 
about this unique group may help organizations like the United Nations and the Asherah Foundation better support them.

There are several interconnected Discourses, or meta-narratives, about higher education that shape and reflect how and why various populations around the world (e.g. women, nontraditional students, refugees) seek to access it. Underlying these interconnected Discourses are the assumptions that education is important to these populations around the world and that research is critical to support equitable educational attainment as well as local and global sustainable development (Briant Carant, 2017; UNESCO, 2016a).

As the following empirical literature review will demonstrate, however, while International Organizations (IO) such as the United Nations (UN) have shaped these Discourses and called for more diverse voices in global conversations about higher education, rarely do they document the perspectives or experiences of the most vulnerable, including women from lower income countries impacted by conflict (Briant Carant, 2017; UNESCO, 2016a). The main question here is: how can higher education be sustainable and reach the most vulnerable to support local development, if the Discourses (and in turn social practices) are not reflective of their experiences?

This chapter will begin with an overview of how underserved student populations are described in documents from IOs and in research about access to higher education for these students around the world. The populations considered here include women (e.g. Andersson, \& Hatakka, 2017; Mollett, 2017), students from lower income countries (e.g. Mundy, \& Verger, 2015); "nontraditional students" (e.g. Collis, \& Reed, 2016), and those that are “conflict-affected” such as refugees (e.g. Berg, 2018; Dryden-Peterson, 2016a, 2016b, 2017). These descriptions will be followed by a review of empirical research about the most 
common critiques of IO (e.g. UN, World Bank) Discourses around access to higher education. In brief, this work argues that the articulated purpose of higher education lies somewhere along a spectrum of "transactional," reflecting a neoliberal economic approach of higher education, to "transformative," reflecting a value of local knowledges and sustainable, inclusive development (Brissett \& Mitter, 2017; Cummings et al., 2017). Understanding the Discourses of IOs and their critiques will provide a framework to analyze the discourses of a select group of students - women such as Lawan, Nifa, and Laleh who are from lower income countries, and who have had their educational journeys affected by conflict.

\section{Discourses about Global Access to Higher Education}

\section{Why it Matters}

Lawan, Nifa, and Laleh are not the only ones concerned about their access to higher education. Education "emerged as the top priority among the more than 7 million people who contributed to the United Nations' MY World survey of 2015" (UNESCO, 2016a, p. 172). The United Nations (UN), among other organizations like the World Bank and governmental agencies, has made it very clear that education, particularly for females, is essential to meet a global development agenda that sustainably improves lives of everyone. Broadly, the UN has argued that education is integral to improve health, employment rates, and sustainable consumption. The 2016 GEM Report, a report published annually under the auspices of the United Nations Educational, Scientific and Cultural Organization (UNESCO) since 2002, summed this up (see Table 1: How Education is Typically Linked with Other Sustainable Development Goals). Specifically, the 2016 GEM Report noted that education is needed to (1) enhance long-term economic growth (UNESCO, 2016a, p. 47), including improvements in decent work outcomes and labour markets (p. 55), and (2) develop inclusive methods for 
achieving social development goals (pp. 67, 77), particularly regarding health outcomes (pp. $66,77-80)$. Education is thus "an enabling right, i.e. it enables other human rights" (UNESCO, 2016a, p. 8) which are essential to the success of the rest of the goals.

\section{Access to Higher Education}

Access to higher education around the world continues to increase. The promise of better economic and employment opportunities has inspired individuals to pursue higher levels of education (Wong, 2018). These individual actions occur within larger, global frameworks around the increased importance of formal education in the "knowledge economy" and efforts to promote accessibility and support for those seeking higher levels of education. The global frameworks include policies and strategies such as the United Nations Sustainable Development Goals (SDGs), increased funding and technical advice from entities such as the World Bank, and a number of multi-sector partnerships and programs devoted to the promotion and success of formal education pathways, organizations, products, and talent in the Global Education Industry (GEI) (Verger, Lubienski, \& Steiner-Khamsi, 2016). Those who have been historically underserved by the formal higher education sector are beginning to gain greater access. This growth has happened for those from lower income countries, women, nontraditional students, conflict-affected, and those who identify as belonging to one, or more, of these groups.

\section{Research on Access for Underserved Populations}

There is limited data on access to higher education for women like Lawan, Nifa, and Laleh. They are a part of a subpopulation at the intersection of several categories of underserved students: those from lower income countries, women, nontraditional students, and conflict-affected students. In order to better understand the context within which these 
women access education, this section will highlight ways in which each of these populations has been described in documents from IOs and from empirical research about their access to higher education. As these women fall within each of these groups, attention will be paid to ways in which group characteristics may overlap in their experiences.

Women. International organizations such as the United Nations have made it clear that education, particularly for women, is essential to meet the rest of the sustainable development agenda. A brief overview of some of the reasons for this assertion from the 2016 GEM Report include the following:

- Increased levels of education for women are the most effective means of ensuring healthy children through improved family planning (pp. xv, 83), improved nutrition, awareness of health risks, and the ability to provide stable socio-economic environments (p. 82), including reductions in maternal mortality (p. 83).

- Increased levels of education for women provide improvements in inclusive social development such as improved levels of education for their children (p. 85), rising labor market involvement (p. 88), increases in political participation (p. 89), and the provision of more female role models which inspire more women to access education (p. 91).

A 2018 World Bank report considering SDG \#4 highlighted the potential costs to socio-economic domains when women don't attain higher education, and the potential gains if they were to achieve it (Wodon, Montenegro, Nguyen, \& Onagoruwa). Many of their calculations were based on a hypothetical universal level of tertiary education access in up to 126 countries around the world. The authors noted that these impacts may be heightened for women in fragile and conflict-affected situations (p. 3), and presumably also in lower income 
countries given the incredibly small percentage of women actually accessing higher education in these countries. The report's findings support the need for increased levels of education for women and may be even more relevant in discussion about access to higher education for those least likely to obtain it (women in lower income and/or conflict-affected countries).

The report noted that around the world, women who had tertiary education had a gain of $323.4 \%$ in earnings over those that had no education (Wodon et al., 2018, p. 12) and a $25.4 \%$ increase in global labor force participation over those with primary education (p. 16). If universal tertiary education were achieved, the gain in labor force participation would be a $34.4 \%$ increase over current rates (p. 17). Women's own perceptions of well-being would be greatly improved, with increased levels of education leading to gains in positive perceptions and decreases in negative perceptions, benefiting them psychologically (p. 34). In addition, universal tertiary education for women would be associated with their increased altruistic behavior (p. 45), as well as increased reliability of their friends (improved social support) (p. 45). Universal tertiary education was also associated with decreased satisfaction with services (e.g. public transportation system, educational system) (p. 41), and with decreased confidence in governmental institutions - including increased perceptions of corruption (p. 47). The report notes that these decreased levels of satisfaction may be a good thing as they "could lead women to exercise their agency and require [changes], which could in turn lead to some improvements" (p. 40). This is supported by the finding that increased levels of educational attainment are also associated with women's improved satisfaction with their community (p. 47). This report calls for more qualitative analysis to "illustrate interdependence between domains" (p. 9), as this research seeks to do. 
The UN Gender Supplement released in conjunction with the 2016 GEM Report noted that "gender disparity is more prevalent in tertiary education than at lower levels" (UNESCO, 2016b, p. 25); particularly at the expense of women with the greatest need as illustrated in Table 2: Completion rates by education level, income group, sex and wealth, 2008-2014 (\%). This is problematic as data shows that successes in the majority of the 17 SDGs are tied to the ability of women to access education. Women's access to education "is important for female empowerment [that leads to] positive outcomes in health, nutrition, sanitation and energy, and between generations" (UNESCO, 2016a, p. 13).

Lower income countries. Access to higher education for students from lower income countries has historically been quite low. These are students from countries designated as low- or lower-middle-income by IOs such as the UN and World Bank. Data on who completes upper secondary education (and thus able to enter higher education) in these countries has been lacking (UNESCO, 2016a, p. 184). However, through analysis of household surveys, GEM Report staff were able to note that the upper secondary completion rate was " $38 \%$ in lower middle income and $14 \%$ in low income countries" over 2008-2014 (UNESCO, 2016a, p. 178). These extremely low levels of completion at the upper secondary level result in even lower levels of access to higher education, as students who do not complete secondary education are not eligible to access higher levels of education. Those women who are able to access higher education have been able to overcome significant obstacles. These women are the focus of this study.

The low levels of access are even starker when compared to levels of access for students in higher income countries. The 2016 GEM Report noted huge disparities across countries in terms of access to tertiary education (p. 229). For example, the gross enrollment 
ratio in 2014 for low-income countries was $8 \%$ compared to $74 \%$ in high-income countries (and 34\% world average). These discrepancies are also regional. In Sub-Saharan Africa, the gross enrollment ratio in 2014 was 8\% compared to $75 \%$ in Europe and Northern America (p. 229). As access to higher education has increased around the world, those in lower income countries have been able to participate in higher education to a larger extent due to the increase of international trade in higher education (although access rates are still low). For example, the 2016 GEM Report noted that "In 2013, out of a global population of 199 million students in post-secondary institutions, 3.5 million were studying outside their country, of which 2.5 million were from developing countries" (UNESCO, 2016a, p. 322). This increase is seen in Table 3: Tertiary education participation indicators. Access to higher education for students from these countries is considered essential towards achieving global sustainable development (UNESCO, 2016a).

Conflict-affected. The focus of this research is on scholarship applicants from fragile and conflict-affected situations (see Appendix 5: Fragile and Conflict-affected Situations). There are various terms that may apply to these applicants (e.g. refugee, migrant, internallydisplaced person, asylum-seeker). These terms have specific legal definitions within the United Nations framework. These definitions have implications for policy and funding decisions. Defined under the 1951 United Nations Convention and made universal under the 1967 Protocol, a refugee: "is someone who is unable or unwilling to return to their country of origin owing to a well-founded fear of being persecuted for reasons of race, religion, nationality, membership of a particular social group, or political opinion" (UNHCR, 1967, p. 3). They "cross national borders to seek safety in nearby countries, and thus become internationally recognized as 'refugees' with access to assistance from States, UNHCR, and 
other organizations" (UNHCR, 2016c). Refugees are different from migrants as migrants choose to move for reasons other than fear of persecution (UNHCR, 2016c). Internallydisplaced persons (IDPs) are those

[W]ho have been forced or obliged to flee or to leave their homes or places of habitual residence, in particular as a result of or in order to avoid the effects of armed conflict, situations of generalized violence... and who have not crossed an internationally recognized State border. (emphasis mine, UNHCR, 2004, p. 1)

The Asherah Foundation application process did not ask for a specific designation, so it was not always clear which terms to apply to which applicant. For the purposes of this research, this particular group of applicants was referred to as "conflict-affected."

There is growing research on the experiences of conflict-affected students with higher education, including refugees (e.g. Berg, 2018; Dryden-Peterson, 2016a, 2016b, 2017; Dryden-Peterson \& Giles, 2010) and students with refugee backgrounds (Baker, Irwin, Freeman, Nance, \& Coleman, 2018; Mangan \& Winter, 2017; Naidoo, Wilkinson, Adoniou, \& Langat, 2018). Much of this research has relevance to the current Population of Study.

When this research began, the world was experiencing the largest migration in recent history. According to the UNHCR's 2016 Global Trends report, "65.6 million individuals were forcibly displaced worldwide as a result of persecution, conflict, violence, or human rights violations" (UNHCR, 2017, p. 2). That was the "equivalent of 20 people being forced to flee their homes every minute of 2016." (UNHCR, 2017, p. 2). At the end of 2016, 22.5 million people were refugees, 40.3 million people were internally displaced, and there were 2.8 million asylum-seekers (UNHCR, 2017, p. 2). Dryden-Peterson (2016c), noted that the “average length of exile was 25 years" in 33 conflicts around the world (p. 474). 
Those counted officially as refugees in a host country are often more highly educated than those who remain behind. In part, this is because those who are able to travel abroad have more resources. This has been particularly true of Syrian refugees (Streitwieser, Brueck, Moody, \& Taylor, 2017, p 235). Those without resources are often left to suffer, unable to leave the conflict-affected area, or at least not able to leave the country's borders (Perry, Mallozzi, 2017, p. 492). In a recent report, the UNHCR noted that, in 2016, only $1 \%$ of refugee youth was enrolled in some sort of higher education (vs. 36\% of the world's youth overall) (UNHCR, N.D., p. 10). This is unfortunate as research has indicated "that refugees who arrive with prior educational experience share nearly universal interest in continuing their studies" (Streitwieser et al., 2017, p. 236). These reports only consider those who meet the legal definition of "refugee." There is little data on those falling outside of this specific designation. However, given the ratio of refugees to those who have been affected by conflict (e.g. IDPs), it may be surmised that access to higher education for conflict-affected students has been low.

Nontraditional students. Nontraditional students are students who do not have the characteristics of "normal" students. They may be from lower socio-economic groups, married, have dependents, and be older - often because they have had interruptions in their schooling. These characteristics often overlap. Forcibly displaced and conflict-affected individuals generally meet these criteria as they have had their educational journeys interrupted by violent conflict. Baker, et al., highlight the importance of not collapsing different aspects of a nontraditional student population "into broad labels, such as 'NonEnglish Speaking Background students' as this can conceal the need for more responsive and sensitive pedagogies, curricula, and support" (2018, p.66). Many of the factors contributing 
to a student's nontraditional designation overlap and interact in different ways depending on the individual and the context (p.66). These factors include age, structural (often familial) conditions, and the interruption of schooling. This highlights the importance of understanding how they may interact in an individual's experience. Much of this research has focused on nontraditional students in the Global North, making it even more important to learn more about the experiences of those in the Global South with these characteristics.

Age. There is a lack of agreement on what age leads one to be classified as a nontraditional student. Bye, Pushkar, and Conway (2007, p.141) state that "Traditional students are defined as those aged 21 and younger, who are most likely to have followed an unbroken linear path through the education system, whereas nontraditional students are defined as those aged 28 and older, for whom the undergraduate experience is not necessarily age normative." Other studies focus on those 25 or older (e.g. Schatzel, Callahan, Scott, \& Davis, 2011). The Asherah Foundation had a minimum age of 24 for applicants in its first round of funding in 2016. The (United States) National Center for Education Statistics also uses 24 as a marker for nontraditional students (NCES). The 2016 GEM Report used these "traditional" ages of those included in generally-available statistics: tertiary enrollment: 1923, tertiary graduation: 25-29 (UNESCO, 2016a, p. 230). Ages 24 and above were considered nontraditional in this research.

Structural conditions. Structural factors are also used to define a "nontraditional" student. These may include status as first-generation students (those who were the first in their family to participate in higher education) (Cotton, Nash, \& Kneale, 2017, p. 63; see also Collis \& Reed, 2016). They may be mature, disabled, and/or from lower income families (Collis \& Reed, 2016; Cotton, et al., 2017). They may have family responsibilities 
(particularly single parents) (Collis \& Reed, 2016; Cotton, et al., 2017; NCES) and/or work more than 10 hours a week (Collis \& Reed, 2016) or even full time (NCES). They may be from minority ethnic groups (Cotton, et al., 2017, p. 63). They may live off campus (NCES). Finally, they do not share the same financial stability as more "traditional" students and are often financially independent of their parents (NCES). Many of these characteristics also apply to English-language learners (Baker, Irwin, Freeman, Nance, \& Coleman, 2018), and others with culturally and/or linguistically diverse backgrounds (CLD). They also include immigrants, and refugee-background, conflict-affected students (Mangan \& Winter, 2017).

Interrupted schooling. One of the underlying factors for almost all nontraditional students is that their educational journey has been interrupted in some way. Many of them finish lower levels of schooling and enter the workforce, raise families, and/or engage in pursuits other than higher education. Many nontraditional students do enter higher education immediately following their secondary education (or after many years) and then drop out. Some nontraditional students may return to their educational journey at some point in the future. Those that do return are designated as "stop-out" students (Schatzel et. al., 2011; Schulte, 2015). The NCES considers "students who delayed enrollment in postsecondary education by a year or more after high school or who attended part time" as nontraditional (NCES).

Overlapping characteristics. In addition to the individual population designations and characteristics mentioned above, researchers are beginning to look at the ways in which multiple characteristics impact the experiences of underserved students in higher education. For example, what are the unique experiences of female nontraditional students? How do the experiences of conflict-affected women compare to those whose educational journeys have 
not been affected by conflict? This section will look at three often-interrelated characteristics: women, those who have been affected by conflict, and students from lower income countries. These three characteristics are important aspects of the 10 applicants featured in this study.

Women from lower income countries. As noted above, in low-income countries, just $1 \%$ of the poorest girls completed upper secondary school and were thus eligible for higher education (UNESCO, 2016a, p. 185). This rises to 17\% in lower-middle-income countries (p. 185). Gender parity in higher education is particularly problematic for women in lower income countries. The 2018 Gender Review noted that only $6 \%$ of countries in lower-middleincome countries have achieved gender parity in higher education. Only $5 \%$ have done so in low-income countries (UNESCO, 2018, p. 11). The handful of women from these countries who have managed to access higher education are the minority and have much to share about how they were able to do so. The 10 women at the center of this study are a part of this unique group.

Conflict-affected women. The UN Refugee Agency notes that women make up 50\% of forcibly displaced populations (UNHCR, 2017, p. 54). Girls and women make up 70\% of the world's internally displaced population and are left the furthest behind in education (UNESCO, 2016a). This represents what Freedman (2017) terms the "'feminisation' of refugee flows" (p. 126).

Historically, many of the UN's responses to forcibly displaced individuals have "mainstreamed" gender and neglected to take into account the unique needs of women when designing programs (Brookings Institution, 2014, p. 6). Akyüz and Coşkun (2014) and Freedman (2017) provide insights into the situations of female refugees in southeastern Turkey (Akyüz \& Coşkun, 2014) and various points of transit across Europe. Akyüz \& 
Coşkun (2014) noted that "the refugee [has been] imagined as a depoliticized victim emblematized by a third world woman and child" (p. 9). They note that this depoliticization replicates patriarchal power structures and denies female migrants agency. Akyüz and Coşkun (2014) noted that "in practice, refugee policies...emphasize the victimhood of women" (p. 14). As they and Freedman point out, this has the effect of dis-empowering these women which exacerbates many of the unique risks they face (e.g. gender-based discrimination and violence) and prohibits them from exercising agency to improve their situations (e.g. seeking out culturally-appropriate educational opportunities).

Lower income countries and conflict-affected. The 2016 GEM Report was produced in the midst of significant demographic changes around the world. Many lower income states were experiencing a "youth bulge" where significant members of their populations were very young and often unemployed (UNESCO, 2016a). As with the Arab Spring in 2011, this particular population dynamic may lead to civil unrest (Talbot, 2013; UNESCO, 2016a). A further consideration is that the majority of those who have fled violence end up in those countries with the fewest resources. The UNHCR (N.D.) reported that these lower income countries:

bear the brunt of the global refugee crisis: more than 84 per cent of the world's refugees are hosted in developing regions, and 28 per cent are in the least developed countries - that is 4.9 million people. As a result, refugees often find themselves in places where resources are already stretched. Even where the national policy is to include refugees in education systems, funding and support from the international community is falling short. (p. 23) 
The UNHCR presented a call to action for governments in its Left Behind report for both host countries and donor governments. For host countries, the UNHCR asks that they work to "[e]ffectively include refugees in national systems and multi-year education sector plans" (N.D., p. 53). For donor governments, UNHCR asks that they "[c]ommit to multi-year predictable funding levels from the emergency phase onwards so no refugee is excluded from schooling due to lack of funds" (p. 53). The UNHCR also asks them to "[e]stablish clear links between humanitarian and development funding and programming” (p. 53). These statements illustrate the imperative to support "refugees." The focus on "refugees" (for whom support is already low) indicates the even tougher situations of those who have been affected by conflict, but not officially counted as refugees.

Population of Study. Students such as Lawan, Nifa, and Laleh who identify as nontraditional women from lower income countries, and who have been affected by conflict are a tiny fraction of the sub-populations mentioned above. There is limited data on how they access (or do not access) higher education. Those nontraditional women from lower income countries, whose lives have been affected by conflict, yet still have managed to access higher education, are central to current and future development efforts. They represent an elite minority who can tell us a great deal about how they achieved success in this area where so many others have not. This population is the focus of this research.

\section{Common Critiques of IO-related Global Discourses (e.g. UN, World Bank)}

International organizations (IOs) such as the United Nations and World Bank have had tremendous influence over global goals for education through the development, implementation, and funding of agendas such as the Sustainable Development Goals (SDGs). Such goals seek to support women like Lawan, Nifa, and Laleh in their quest for education. 
The dominance of these IOs in efforts to improve educational access means that they affect the experiences of Lawan and her colleagues, as their educational experiences occur within the world that these IOs have created. This section will begin by looking at ways in which they exercise this power via the Discourses they create and use. Common critiques of these IOs will then be highlighted with a focus on how the efforts of these IOs might actually be limiting progress towards the SDGs. This overview will illustrate how these Discourses may affect the experiences of Lawan and her peers accessing higher education.

\section{Power of International Organization (IO) Discourses}

An important part of the theoretical framework for this research is that documents such as the GEM Reports and the Asherah Foundation scholarship application essays are inherently persuasive and are based on certain structures of power. In addition to coconstructing social realities, these documents also have a more straightforward, persuasive component. In the case of the GEM Reports, the documents are trying to persuade those that engage with it of 1) its relevance and 2) the need for additional conversations around SDG \#4. In the case of the Asherah Foundation scholarship application essays, the applicants are trying to persuade a review committee to provide scholarships to support their desired access to education. Saarinen (2008) wrote "Persuasion is the property of texts to represent and construe competing views of the world as common sense and self-evident” (p. 344).

These persuasive presuppositions, especially in the ways in which they (re)create certain power dynamics, are of interest to this research. The discourses of international organizations (IOs) such as the UN have tremendous power to shape policy and direct funding around the world. The transition from the Millennium Development Goals to the Sustainable Development Goals involved global dialogue about what should be included and 
how progress should be measured. The many discourses in the conversations around this transition of global goals are notable, in part, as they were in response to the invitation of the UN to provide input into its new global development agenda.

Critiques of IO efforts, such as the development of the UN's Sustainable Development Goals, have revolved around the enormous power of IOs. They set the agenda, delineate who gets to respond, and how it should all be done. Through their political, financial, and global influence, IOs often control the Discourses (meta-narratives) around what types of knowledge are considered appropriate, who should have access to this knowledge, and who should be in charge of developing it. International organizations such as the UN can have enormous impact on the forms of education that are available to people around the world and how they access it.

The influence of IOs takes many forms (Bassett \& Maldonado-Maldonado, 2009; Shahjahan, 2012; Shahjahan \& Madden, 2015). Funding from institutions such as the World Bank is an obvious example as the funding is tied to implementation of specific policies. The more ideological impacts come from international engagement with various ideas (Shahjahan, 2012; Spring, 2009), cross-national networks that are created (Rizvi \& Lingard, 2010), and the Discourses that are created (King, Marginson, \& Naidoo, 2011). Shahjahan and Madden, referencing Robertson (2009), noted that IOs have evoked a global [D]iscourse around what could be considered "a neoliberal social imaginary of [higher education (HE)], by which a convergent effect is produced in HE policy. IOs achieve this through the mobilization of 'crisis talk' and 'opinion formation'” (2015, p. 707). Rizvi and Lingard (2010) and Teferra (2009) discussed ways that IOs have used such talk surrounding the idea of the knowledge economy to their advantage, in ways that are resonant with the SDGs. 
Shahjahan and Madden noted that IOs have developed specific Discourses around innovation in higher education through specific contributions to the working vocabulary and through "sharing best practices, highlighting innovative policy developments, establishing common definitions, and setting the frameworks through which state actors operate" (2015, p. 708) (see also Antunes, 2006; King, R. 2009; Lebeau \& Sall, 2011; and Wende, 2011). Saarinen's (2008) research on the "persuasive presuppositions" of IO discourse around higher education is particularly instructive. She noted that "[p]resuppositions set the assumed common ground, which in turn sets the frame of interpretation of texts" (p. 341). Technical reports (such as the 2016 GEM Report) have often been "presented as influential forms of expertise that are not at the disposal of certain nation-states. State actors rely on IOs to provide them with the latest data on trends, current issues/dilemmas, and, more importantly, how to respond to [higher education] crises" (Shahjahan \& Madden, 2015; see also Lebeau \& Sall, 2011; Samoff \& Carrol, 2003).

Shahjahan and Madden (2015) also pointed out that powerful actors often have a hand in shaping the discourses from behind the scenes (see for example, Moutsios, 2009; Robertson, 2009). Common critiques of previous development agendas (such as the MDGs) point out the disproportionate influence developed states had on the creation of the agendas, and ideas of what constituted "good" education. This influence has often been at the expense of the "undeveloped" states they were seeking to aid; particularly in the realm of higher education (Collins \& Rhoads, 2010; Hartmann, 2010; Naidoo, 2008; Salmi, Hopper, \& Bassett, 2009). 


\section{Critiques of IO Discourse Formation and Use}

Given the power of IOs to share policy, direct funding, and designate what counts as progress towards "quality" education, there have been many critiques of their practices and of the Discourses they create and perpetuate. Many of the critiques relate to the neoliberal focus of their agendas, and of the neo-colonialist structures of power they perpetuate. Underscoring these two areas of critique were broader critiques about the lack of diversity in voices from those these goals sought most to help - including women, and those in lower income countries. Highlighting the voices of the women at the heart of this study via this research is one example of how these critiques might be addressed.

The transition from the UN's Millennium Development Goals to its Sustainable Development Goals in 2015 explicitly encouraged critical research on the progress made towards these goals, and invited critiques regarding areas were progress was not made. Education was identified as a central pillar of global development efforts (UNESCO, 2016a) and thus became a topic of critical research. The following section will review some of the critiques of these global development efforts, with a focus on the UN's SDGs. Although the focus here is on these SDGs, other international organizations (e.g. World Bank, OECD, European Union) have been deeply involved with these conversations, and thus implicated in these critiques (Cummings et al., 2018; Verger, Lubienski, \& Steiner-Khamsi, 2016).

Critical discourse analysis of the SDG documents emphasized the power of these global Discourses to influence funding, implementation strategies, and policy decisions, thus impacting the communities they were meant to serve. These critical analyses focused on the perceived dominance of colonialist (Briant Carant, 2017; Wilson, 2017) and neoliberal agendas, (Mundy \& Menashy, 2014; Robertson, \& Komljenovic, 2016), and the hegemony 
of knowledge production as dictated by the Global North and its capitalist and colonialist power structures (Cummings, Regeer, de Haan, Zweekhorst, \& Bunders, 2017; McCormick, 2014; Mundy, \& Verger, 2015; Shahjahan, \& Madden, 2015; Stein, 2017b; Zapp, 2017).

As will be highlighted below, global efforts to improve education access post-2015 attempted to address neoliberal and neo-colonial critiques that had been raised about the MDGs. These global agendas (e.g. the SDGs) were created through complex negotiations among various actors. These development agendas were produced in a global context composed of multiple characteristics that were "outside" of, but integrated with, the core of the IO system (e.g. the United Nations). The neoliberal perspective of education supported by the global education industry is one major aspect (e.g. Verger, et al., 2016). Demographic changes and protracted conflicts exacerbated by climate change and global inequities also influenced the developments of these policies (e.g. Talbot, 2013). Increased (often forced) migration and a history of colonialism negatively impacted many of the issues that these global education agendas sought to overcome (Hirsch \& Malylea, 2016; McCormick, 2014; Tecle, Thi Ha, \& Hunter, 2017; UNHCR, 2016a, 2016b).

Neoliberal critiques. Global Discourses about the purpose of education have often framed discussions in utilitarian and transactional terms; education as a means to a (usually economic) end. This is often the case when reports discuss the "return on investment" to funding education. This Discourse has been invoked in discussions about education leading to economic development and increased participation in formal labor forces. Critiques of this Discourse are often tied to critiques about the neoliberal nature of educational policies. Briant Carant noted that "Economic theories, such as...neoliberalism, utilise specific language to establish 'facts' and give meaning to the workings of the economy...[they] 
predispose various modes of theoretical thought and methodological inquiry that shape what truths can be known about the economy" (2017, p. 18). Signifiers of neoliberal discourses include: "economic deregulation, complete privatization, free trade and a reduction in government size and spending for the creation of a strong private sector" as well as "the valorising of individual agency" (p. 19). The transactional view of education is intimately related with the neoliberal view which sees education as integral to a capitalist society with the main purpose of training future workers for gainful employment (Brissett \& Mitter, 2017).

What happened? The Millennium Development Goals were designed to "meet the needs of the world's poorest" by focusing on the elimination of extreme poverty. This agenda largely focused on education as a tool of economic development. The shift to the Sustainable Development Goals likewise focused heavily on education as a tool for economic development. This focus encouraged involvement by the private sector. In his 2012 editorial, Jeffrey Sachs, Special Advisor for the MDGs opined that the private sector should be crucially engaged with the Sustainable Development Goals from the very start (Sachs, 2012). He suggested that "[n]either the MDGs nor the SDGs could be achieved without the leadership of private companies, large and small. Multinational companies bring unique strengths: a worldwide reach, cutting-edge technologies, and massive capacity to reach largescale solutions, which are all essential to success" (Sachs, 2012, p. 2211). The private sector has been especially active in providing funding for scholarship programs. Those in the private education and development space see international education-for-development needs as potentially lucrative and have taken advantage of this (Verger et al., 2016). It has simply been good business for corporate partners to provide substantial donations to organizations 
such as UNESCO (especially if they are then appointed to positions of influence) (Verger et al., 2016b, p. 22).

The Global Education Industry (GEI) has been intimately connected with many efforts to drive progress towards the SDGs (Verger et al., 2016). The GEI consists of forprofit and related entities such as Pearson Education, Laureate Education, and the International Finance Corporation. They have provided substantial support to both the MDG and SDG development agendas. These entities have often partnered with organizations such as UNESCO to obtain legitimacy and access to markets. Such partnerships have provided UNESCO and member states with important global sources of funding and technical advice. In return, these organizations obtain access to global markets and an important veneer of charitability (Verger et al., 2016; see also McCormick, 2014; Mundy, \& Menashy, 2014; Mundy \& Verger, 2015).

What is the critique? What went wrong? Critics argued that the ways in which both the MDGs and SDGs were designed would continue to impoverish the very people that they sought to help; widening income gaps and supporting corporate interests at the expense of public infrastructure and services. Despite the funding and technical support from the GEI, these partnerships have been problematic. Although advocating for increased private-sector partnerships for the SDGs, Jeffrey Sachs noted the problematic nature of engaging more with the private sector. He acknowledged that "many large companies are also lobbyists for policies antagonistic to sustainable development, so engagement with business has to be done cautiously, but it should also be active, forward-looking, and intensive" (Sachs, 2012, p. 2211). 
King (K.) (2016) pointed out that there were many who had financial incentives to participate in the design of the SDGs: "once the notion of a new development agenda had surfaced, many different constituencies began to recognize that it could be crucial to the future status and even funding of their particular thematic area for it to be represented in the world's next step of development priorities" (p. 964). Briant Carant argued that the agenda remained representative of donor and corporate stakeholder interests - and not the marginalized and underserved populations that the agenda was purportedly created for (2017, p. 27). In her view, even NGOs were not exempt from financial considerations as they are often "burdened and propagandised by their corporate stakeholders' desire for financial success, resulting in a shift from their intended mission towards profitability" (p. 27). The 2016 GEM Report acknowledged this, stating:

While some hail the growth of private involvement as bringing financing, flexibility, innovation and improved learning outcomes...sceptics, who view the private sector's growing role as a result of the public sector retreating from its responsibility to provide education, see a potential for undue market influences in schooling and widening inequality. (UNESCO, 2016a, p. 145)

Verger et al. (2016b) note that private sector actors have encouraged either loose regulations, or the promotion and dissemination of their own accountability systems. A major criticism of earlier UN-related development goals (e.g. the MDGs) was that the global development agenda was designed by elites in developed countries to "help" undeveloped countries, often through providing expensive policy advice and provision of services, or through gaining positions of influence through providing major sources of funding (McCormick, 2014; Verger, et al., 2016). McCormick (2014) noted that "the majority of the 
30 per cent of [funding] allocations from development partners are in the areas of high quality policy advice" (p. 178). Verger et al. explained that the GEI was

a structured social space with its specific institutions, forms of agency and power practices; in this space, different actors struggle for the expansion, transformation and/or reproduction of the field, as well as for having an advantageous or dominant position in it. Despite being open to the participation and involvement of a broad range of actors, a field is far from a flat terrain but a three-dimensional space. Not all the actors have the same power and capacity to mobilize the different types of capital (social, economic, symbolic, etc.) that are necessary to achieve their objectives within the field in question. (p. 11)

Neo-colonial critiques. Critiques about the neoliberal focus of the SDGs were tied to the structural inequities that this focus helped to maintain. These structural inequities replicated power imbalances originally created by the colonization of the "developing" world by the "developed" world. These neo-colonial critiques of the SDGs argued that focus on economic growth seemed to be at the expense of addressing structural inequities contributing to poverty. These structural inequities included the production and utilization of knowledge. Critics argued that the hegemony of knowledge production by the economic interests of the Global North prevented the development and recognition of knowledge produced by those the SDGs were designed to help. This dominance of knowledge production resulted in Discourses about the role of education and its relationship to underserved students that may not have been contextually appropriate, nor addressed the complexity of these students' experiences of education. 
Critiques of IO development agendas pre-date the SDGs. For example, Saith (2006) warned about the lack of mechanisms to address rising levels of inequality (which exacerbated poverty) as being particularly problematic and detrimental to the achievement of many IO goals. Meanwhile, many of the structural issues (such as a lack of public services and infrastructure) that had led to the entrenched levels of poverty were not incorporated into the UN's Millennium Development agenda set in 2000 (Barton, 2005; Briant Carant, 2017). Related to these structural inequities was the absence of Discourse around human rights. Critics asserted "that the MDGs define[d] development as increasing GDP rates, thereby neglecting human-centered development issues" and "highlight [for example] how many African countries' strong GDP growth has not translated into better human rights, arguing that economic growth is unevenly distributed, thus increasing income inequality" (Briant Carant, 2017, p. 24; see also Doyle \& Stiglitz, 2014). This was problematic as it denied "the fundamental human rights necessary to 'allow individuals the capability of what they can do or be"” (Briant Carant, 2017, p. 24).

Deciding what knowledge "counts" is a key issue at the heart of addressing global inequities. Education is a means of producing and reproducing knowledge. Knowledge that is considered important is passed on through education. Research agendas prescribe how to advance this knowledge. This section will look more closely at who gets to decide what knowledge is important (and conversely, what knowledge is not important). Political (and financial) agendas and cultural perspectives influence the ways in which "appropriate" knowledge is produced and reproduced. This has implications for how global education agendas such as the SDGs were developed, and how efforts to achieve educational outcomes 
are implemented. The central question surrounding this discussion is "who decides what knowledge 'counts.",

The Global South has a rich history of higher education (e.g. India, China, and Pakistan) that began well before the system in the Global North was developed (Robertson \& Komljenovic, 2016). Unfortunately, as the colonial ambitions of the Global North intensified, particular sets of ideas about what constituted a "university" and a proper mode of knowledge production expanded in kind. Colonial powers also transplanted "western disciplinary-based knowledges and created new dependencies through alignments with universities in the $[\mathrm{G}]$ lobal $[\mathrm{N}]$ orth. This included educating the university's faculty in the north, funded as part of a university's international mission, or by national and regional aid programmes" (p. 596).

Many of those countries deemed "developing" and "lower income" were once colonies under the control of those countries classified as "developed" and which are now classified as "higher income." Critics have noted that the development agendas created by organizations such as the UN are replicating the power dynamics of the colonial system, particularly as the former colonial powers are the ones creating the agendas to "help" the lower income developing countries (Briant Carant, 2017; Brissett \& Mitter, 2017). In addition to maintaining inequities in economic development and access to education, these agendas maintain the colonial power dynamics through their articulation of what knowledge "counts" and what methods of gaining this knowledge are appropriate. This articulation is created through the various discourses that the development agendas create and perpetuate through the cycles of agenda development, implementation, and evaluation. 
Many saw the MDGs as a neo-colonial attempt to retain the previous colonial power relationships among and between countries (Esser \& Ha, 2015; McCormick, 2014). For example, MDG critic Samir Amin saw 'the MDGs as a facade for pushing the superpowers' [USA, Japan, and Europe] economic agenda with minimal concern for gathering developing countries' opinions” (Briant Carant, 2017, p. 25). Others argued:

that the MDGs' technocratic and top-down approach...produced inadequate vocal inclusion of developing countries, since economically dominant countries assume that development only proceeds through their methods. As such, developing countries' traditional norms and values are considered to hinder the adoption of technological advances facilitating consumer economies. More specifically the MDGs' targets fail to consider each country's 'historical, cultural and political circumstance', thereby prescribing inappropriate preconceived models for development. (p. 25)

The MDGs were based on "[r]ealities and regimes of truth based on Northern knowledge [which determined] how countries and people [were] represented and [shaped] development interventions" (McEwan, 2009, p. 181) which often were either ineffective, or worsened the economic situation. This led countries, policy-makers and funding entities to conceive of "solutions" in ways which favored Northern concepts of what a "developed" economy should look like (p. 181), often based on neoliberal perspectives as described above. The lack of participation in the development of the MDGs exacerbated this (Baaz, 2005; Escobar, 2012; Holden et. al, 2016; McEwan, 2001; McGrath \& Powell, 2016; Sayed \& Ahmed, 2015).

Critics such as King (K.) (2016) appreciated the more inclusive approach to developing the UN's post-2015 development agenda but noted that much of the discourse was still "associated with agencies, foundations, think-tanks and academic centers, based in 
the North" (p. 970). This is important as those who decide the development agenda decide what is important. They decide what "counts" as "development" (including what counts as education-for-development) and can channel funds and other resources towards that.

Robertson and Komljenovic noted that:

the turn to trade in services—-including in higher education — for the global north, the growing dominance of English as a global lingua franca, together with pressures to acquire symbolic capital in the form of an education in a 'western' institution to power social mobility, all injected new momentum into the already existing uneven relationship between and within the global north and global south. (2016, p. 597) Dryden-Peterson described 'the 'ceding of some of individual states' powers to supranational bodies,' bodies that became critical determinants of national education policy" (2016, p. 475). She noted 'the 'imposition' of policy in nation-states [which] occurs through explicit and compulsory relationships with organizations that hold power, such as World Bank education loans tied to structural adjustment” (p. 475; see also Altbach, 2016, pp. 151, 166; Bassett \& Maldonado-Maldonado, 2009; Moutsios, 2009; Robertson, 2009; Shahjahan, 2012; Shahjahan \& Madden, 2015). This was evident during the development of the SDGs as noted above.

In his 2012 editorial on the future of the UN's development agenda, Jeffrey Sachs (2012), Special Advisor for the MDGs and subsequent SDGs, advocated for the distribution of goods and knowledge from higher income (Global North) to low-income (Global South) countries: "When it comes to elimination of extreme poverty, the main strategy is to expand the reach of crucial technologies (including medicines, diagnostics, electrification, high-yield seeds, and internet) from high-income and middle-income economies to low-income 
economies" (p. 2211). However, he finished by arguing against a "top-down approach" and for "a highly energised era of networked problem solving that engages the world's universities, businesses, nongovernmental organisations, governments, and especially young people, who should become the experts and leaders of a new and profoundly challenging era" (Sachs, 2012, p. 2211).

The 2016 GEM Report addressed these critiques by frequently mentioning that previous development agendas were criticized as being created for the benefit of "developed" states at the expense of the undeveloped states that the agendas sought to aid. Much of the 2016 GEM Report's encouragement of dialogue is in reference to this. Likewise, Shahjahan and Madden (2015) encouraged researchers to consider Non-Western (non "Global North") perspectives on international organizations, and the various voices and discourses that have been left out of the dominant development agenda. This research considers these perspectives as it is focused on women who are both from the Global South and attending universities in the Global South.

Diversity critiques. Related to both the neo-colonial and neoliberal critiques above is the overarching critique of the lack of diverse perspectives. Those for whom these development agendas are purported to serve were mostly absent in the development of these agendas (Briant Carant, 2017). Their discourses were not initially sought, nor well-included or integrated into these agendas. This was particularly harmful to women in terms of the MDGs. While the SDGs included women in much greater depth, the lack of diverse Discourses in their development remains problematic as has been outlined above. This section will provide an overview of the ways in which the lack of diverse voices was 
recognized as problematic and partially addressed. However, significant limitations remain which will be highlighted briefly below.

Gender critique: MDGs. Of particular interest to this research are critiques about the lack of input from women. In addition to the absence of input from the Global South, input from those which the MDGs sought to "help" was also lacking. The lack of input from underserved women in particular was noticeably absent. Briant Carant (2017) pointed out that the MDGs attempted to address the importance of gender in working towards meeting the goals. For example, she wrote:

Goal 2 [achieve universal primary education] centres on ensuring equal access to education and suggests that exclusion of girls is 'not only a matter of gender discrimination but is bad economics'. Beyond the proximal effects of education, goal 2 acknowledges that an educated female populace can lead to reduced fertility rates and potentiates increased family incomes and decreases in poverty, as women attain new roles in the workforce. (p. 21)

Furthermore, she argued that "Goal 3 aspires to eliminate gender disparity in all levels of education." However, many have noted that the "attainment of MDGs 2 and 3 [would leave] women subjugated because of the narrow definition of gender equality" (p. 23). The MDGs were also criticized for ignoring key aspects of the 1996 Beijing Declaration and Platform for Action, including sexual and reproductive rights as well as human trafficking (p. 24). Briant Carant also pointed out that "the MDGs' focus on increasing women's access to health and education does little to increase equality if reproductive, social, political and economic rights remain unaddressed" (p. 24). These critiques are illustrated by the experiences of the 10 women who are the focus of this study. 
SDG Response-attempts to include more voices. In the development of the post2015 agenda, the UN worked to dramatically increase the participation of diverse and marginalized groups. The UN spent several years gathering feedback from diverse constituencies around the world. In addition to developing a global agenda for both developed and developing countries (as opposed to just developing countries), those involved with designing the SDGs went around the world to talk with those who might be impacted by the new agenda with mixed results (Faul, 2014; Holden, Linnerud, \& Banister, 2016; Rugg, 2016; Sachs, 2012). This was done through international conferences, a 30-member Open Working Group (OWG), a High-Level Panel (to oversee the OWG), and global outreach through online discussion boards, surveys, and polls. Unfortunately, these attempts were not as successful at increasing the participation of these groups as hoped (Briant Carant, 2017).

Although the process for developing the 2030 Sustainable Development framework was more open than that of the Millennium Development Agenda, many felt that the process was not open enough (e.g. Benavot, 2016; Briant Carant, 2017). In particular, Ahmed (2015) noted that women (as a marginalized group) were "deeply concerned by the general direction of the SDG process - whereas corporate interests from the rich, industrialized world have viewed the process favorably" (p. 191). This lack of representation was problematic for several reasons. In addition to the critiques discussed above, demographic shifts and dramatic increases in forced migration have complicated efforts to make progress towards these goals.

Fortunately, awareness of the lack of data on underserved populations is frequently acknowledged by the UN, including in the 2016 GEM Report. It is noted that the ways in which these populations interact with educational systems vary by age, gender, race, language, and ethnicity. As noted with critiques of the MDGs, this lack of input may lead to 
policies that are inappropriate, ineffective, and even counterproductive to development goals. For example, adult women who have been affected by conflict are remarkably absent from official discourses pertaining to the GEM Report. Inputs from women in lower income countries are also noticeably absent. As noted throughout, these underserved populations have both unique struggles in accessing education, and unique opportunities to provide leadership for their communities once they do access it.

Throughout the 2016 GEM Report, gaps in the overall development agenda are highlighted. The report frequently exhorts readers to engage in dialogue regarding ways to fill these gaps with additional research. For example, the report acknowledged that "[m]any important concepts in the 10 SDG 4 targets are not yet covered by any proposed indicator. Among those that are covered...details remain to be fixed in the indicators" (UNESCO, 2016a, p. 170). The report further noted that "many, if not most, major issues in education are context-specific and difficult to generalize or compare" (pp. 175-176) and that "both national and international reporting need to adjust to enable monitoring of the growing diversity in student attendance, programme delivery and private provision patterns, which have implications on inequality in access" (p. 231). This argument has been repeated in subsequent GEM Reports (UNESCO, 2017b, 2018). This research provides insight into such diversity, as the focus of this research is the 10 applicants representing multiple subpopulations (lower income, conflict-affected, and nontraditional).

Limitations of SDG approach to diversity. Despite impressive attempts to gather input from diverse and marginalized populations, the efforts of the UN were not without limits. The UN emphasized that its first survey reached "1 in every 1000 people." However, Briant Carant (2017) noted that the report "A Million Voices" failed "to indicate how 
communities were selected and the number of voices obtained from each country in its sample" (p. .26). This "failure to explicitly state a procedure limit[ed] the ecological validity of the sample, as it remain[ed] unclear whether these voices [were] representative of a global seven billion" (p. 26). In addition, the "1 in every 1000 people" comment may have been misleading. She noted that "voting patterns reveal[ed] trends unrepresentative of the general populace" as $43 \%$ of voters possessed education beyond high school, whereas only $11 \%$ had not completed primary education (p. 26-27). Briant Carant also noted a lack of equitable or geographical reach and claimed that outreach efforts were more representative of corporate (donor) stakeholder interests than those with the greatest need. The lack of representation among those without internet access was also noted by critics (e.g. Benavot, 2016).

This research attempts to address the larger diversity critique through looking at what the women such as Lawan, Nifa, and Laleh actually say. Through critical discourse analysis, the actual words of these women were looked at through the lenses of the critiques outlined above. This analysis asks "what is the role of education in their lives - does it fill a more utilitarian or transformative role?" "How do they view themselves in reference to education as victims who have been prevented from accessing it, or as victors who have triumphed over adversity?" The following section will outline four major Discourses around the purpose of education, and the ways in which women such as Lawan, Nifa, and Laleh might relate to them.

\section{Discourses: Role of Education and Identities of Students}

Conversations about access to education take place within larger Discourses, or metanarratives about the purposes of education, and the roles of individuals and institutions within their communities. Education is viewed and discussed in different ways. The roles that 
education can play in society and in the lives of individuals can be quite different. These different roles are emphasized by various groups in accordance with their agendas. In practice, they often overlap as noted in the 2016 GEM Report and in many of the critiques of the SDGs. This section will outline some of the Discourses that have been applied to and used by women seeking to access education. Building on the research and critiques reviewed earlier, these meta-narratives will provide an initial starting point for analysis.

There were several prominent Discourses used in the transition from the MDGs to the SDGs. These include Discourses about the purpose of education and the roles of those seeking to access it. Discourses about the purpose of education tended to highlight either the transactional purpose of education, or its transformative potential. Neoliberal critiques tended to focus on the limitations of the transactional purpose. Neo-colonial critiques tended to focus on the limits or failures of education's transformational potential. Discourses about the roles of those seeking to access it were more complex but tended to either view students as victims or survivors (or even victors). Victimhood was often used in the context of highlighting ways in which education reproduced inequities. The victorious student identities were often used in Discourses around the ways in which education reduced inequities. Awareness of these Discourses, and the contexts within which they were used, is important to understand both barriers and opportunities for increased access to education for underserved populations.

\section{Discourses about the Role of Education}

Critics such as Brissett and Mitter (2017) identified two primary Discourses, or metanarratives about the role of education throughout Sustainable Development Goal \#4 in their critical discourse analysis of the text. Specifically, education was presented as playing either 
a utilitarian (transactional) or a transformative role in the development of communities. These perspectives were tied closely to narratives around neoliberalism and human rights, respectively. They argued that the neoliberal perspective viewed education as a means to an economic end, in a utilitarian way. In contrast, the human rights discourse viewed education as transformative. In a similar vein, Cummings and colleagues identified two Discourses about the role of knowledge and the knowledge society within the sustainable development agenda (2017, p. 1). The first Discourse they termed the "techno-scientific-economic discourse" which was aligned with utilitarian, neoliberal discourses emphasizing the "[p]rimacy of monetary value of knowledge" (p. 5). One aspect of this Discourse was the "[f]ailure to recognize the value of local knowledge" (p. 5). The second discourse they termed the "pluralist-participatory discourse" which highlighted the "[a]wareness of the existence of complex problems" and the need for multiple knowledges to solve these complex problems (p. 5). This second Discourse also focused on the "[t]ransformational value of knowledge" (p. 5) and aligned with Brissett and Mitter's Discourse of education as transformational. The role of education seemed to be placed at different points of a spectrum from transactional to transformative, with simple econometric implications on the transactional side, and the complex, society-changing transformative potential on the other side.

Education is Transactional. Global Discourses about the purpose of education have often framed discussions in utilitarian, transactional terms. For this study, the transactional side of the spectrum is based on Brissett and Mitter's (2017) categorization of education as utilitarian. It aligns with the "techno-scientific-economic" Discourse articulated by Cumming, Regeer, de Haan, Zweekhorst and Bunders (2017). Discourses at this end of the 
spectrum often focus on the economic aspects of education (e.g. job creation, returns on investment, human capital development) and are present in neoliberal critiques of the global higher education system (Briant Carant, 2017). This Discourse is invoked in discussions about education leading to economic development, increased labor force participation, and other developmental goals (e.g. improvement of health outcomes linked to labor market impact).

Education is Transformative. The other side of this spectrum is based on Brissett and Mitter's categorization of education as also transformative. This transformative end of the spectrum includes Cumming et al.'s "pluralist-participatory" categorization, is often related to the production of knowledge, and is present in many of the neo-colonial and neoliberal critiques (e.g. Briant Carant, 2017). Brissett and Mitter argued that the transformative view of education approach "values education for its liberatory and critical capacities that can drive fundamental social change" (2017, p. 185). It is intimately connected with human rights discourses as it can reduce inequities and secure social justice by "deliberately challeng[ing] social and economic structures that define our contemporary world" (p. 182). The goal of education is seen to be "addressing societal inequalities and injustices" (p. 195). Brissett and Mitter explained that "[a] transformative approach to education can have cross-cutting impacts, contributing to gender equality, peace, human rights, environmental sustainability and a myriad of other objectives that a utilitarian approach will not achieve" (2017, p. 201). However, in order for this to happen, "[e]ducation must be valued and used as a tool to recognize and act upon societal inequities, placing issues of social and ecological justice at the heart of its objectives" (p. 201). Discourses around the transformative impact of education on underserved students are common. 
The GEM Reports and Gender Supplements explicitly acknowledged that education is intimately tied to many other aspects needed for sustainable development (see Table 1). The 2018 Gender Review further discusses domains that should be included in conversations about gender equality in education. These include "gender norms, values and attitudes (many of which can be influenced through education); institutions outside the education system; laws and policies in education systems; resource distribution; and teaching and learning practices" (UNESCO, 2018, p. 10). In analyzing experiences of women from lower income countries where they suffer from educational inequality, acknowledging the ways in which their educational experience is tied to these "transformative" domains will be instructive.

\section{Sustainable Development - Education as Transactional, Transformative, or}

both? Those involved with the development of the Sustainable Development Goals were aware of the neoliberal critiques of the MDGs and sought to address them. In his 2012 editorial announcing the replacement of the MDGs, Jeffrey Sachs, special advisor to the UN's Secretaries-General, described "sustainable development" thusly: "sustainable development embraces the so-called triple bottom line approach to human wellbeing. Almost all the world's societies acknowledge that they aim for a combination of economic development, environmental sustainability, and social inclusion” (Sachs, 2012, p. 2206). His proposed "goal" for social inclusion was that:

every country will promote the wellbeing and capabilities of all their citizens, enabling all citizens to reach their potential, irrespective of class, gender, ethnic origin, religion, or race. Every country will monitor the wellbeing of its citizenry with improved measurements and reporting of life satisfaction. Special attention will be 
given to early childhood, youth, and elderly people, addressing the vulnerabilities and needs of each age cohort. (Sachs, 2012, p. 2209)

After several years of deliberation and consultation with millions of scholars, researchers, policymakers, and others, the UN adopted its Sustainable Development Agenda in 2015. This development agenda included 17 aspirational SDGs and 169 targets to track progress towards the goals. Efforts to incorporate the "triple-bottom line" can be seen throughout the final goals and related documents as has been discussed throughout this chapter.

Sustainable Development Goal (SDG) \#4: Education. Education remained a key component of the new UN development agenda. Sustainable Development Goal (SDG) \#4 was to "Ensure inclusive and equitable quality education and promote lifelong learning opportunities for all” (UNESCO, 2016a, p. 6). It included 10 primary targets (see Appendix 2: SDG \#4 Targets). These targets form the basis for the 2016 GEM Report which is a focus of this research. Related to this is the Education 2030 Framework for Action which was adopted in November 2015 by an "Inter-agency and Expert Group on SDG Indicators and agreed by the UN Statistical Commission" (UNESCO, 2016a, p. 2).

The 2016 GEM Report explicitly noted the transformative goals of SDG \#4 and devoted a chapter entitled "People" to "the transformative social development needed to change social structures, institutions and relationships" (p. 13). This particular chapter in the report looked at the need to achieve gender equality and to increase quality educational opportunities for the marginalized and for women to improve social development goals (e.g. improved health) which were central to the achievement of the rest of the sustainable development agenda. Target 4.7 was identified as a "transformative" goal by Brissett and Mitter (2017): 
4.7: By 2030, ensure that all learners acquire the knowledge and skills needed to promote sustainable development, including, among others, through education for sustainable development and sustainable lifestyles, human rights, gender equality, promotion of a culture of peace and non-violence, global citizenship and appreciation of cultural diversity and of culture's contribution to sustainable development. (UNESCO, 2016a, p. 287)

Throughout the SDG documents, there is a strain of dialogue discussing the ways in which education can provide more than just economic benefits (e.g. Guinée, 2014;

Stromquist, 2015; UNESCO, 2016a; UNHCR, 2016b) The 2016 GEM Report claimed that it "demonstrates the importance of education as both a human right and as tool for the advancement of all Sustainable Development Goals (SDGs)” (UNESCO, 2016a, p. 368).

Researchers have discussed the many ways in which education can support sustainable development. Education can provide economic opportunities which are often interconnected with health, political participation, and better integration into communities. Education for women leads to their improved health (UNESCO, 2016a, p. 83), "inclusive social development such as increases in political participation" (p. 89), and the provision of more female role models which inspire more women to access education (p. 91). Education for refugees, or for students with refugee backgrounds may provide better integration with new communities for refugees through increased economic opportunities (Baker, et al., 2018; Mangan \& Winter, 2017), “enhance[d] engagement with new communities" and the facilitation of "a sense of connection and belonging" (Baker, et al., 2018, p. 65). Streitwieser et al. (2017) argue that education "helps to reduce the stress of displacement, builds critical social capital, and can stave off a pull toward radicalization (p. 236) as it "has transformative 
and egalitarian potential for students from refugee backgrounds" (Mangan, \& Winter, 2017, p. 500). The impact of education on all communities may be seen in improved health and educational outcomes for children of educated women (UNESCO, 2016a) as well as with the contribution of knowledge, advanced skills, and research (The World Bank, 2018b). On a global level, education may be important to nation-states hosting conflict-affected individuals, to future reconstruction efforts (Dryden-Peterson, 2016b; UNHCR, 2015b).

Limitations of "sustainable" development approach. Although care was taken to provide alternative discourses, the neoliberal approach was a part of the "sustainable" development conversation from the beginning. In recognition of neoliberal critiques, there is a strain of dialogue throughout the SDG documents arguing that having a narrow focus on economic development is counterproductive (Holden et al., 2016; McGrath \& Powell, 2016; Sayed \& Ahmed, 2015). Despite efforts to lessen the neoliberal focus, education throughout the SDGs is often portrayed as a means to an economic end. For example, in his 2012 editorial outlining goals for a new sustainable development agenda, Jeffrey Sachs encouraged progress in equitable access to education so "that all young people can complete secondary education and make an effective transition from school to skills to the labour market" ( $p$. 2209). Verger et al. pointed out that "the rhetoric surrounding global education reform often conflates individual and collective economic benefits of schooling" (2016, p. 7; see also Brissett \& Mitter, 2017). In addition, the continued inclusion of a neoliberal discourse may be closely related with the increased focus on engagement with the private sector. As Sachs (2012) himself noted, "the private sector should be crucially engaged from the very start" (p. 2211). Despite the inclusion of significant rhetoric around the transformational nature of education in the SDGs, implementation efforts seem to prioritize its transactional nature 
(Briant Carant, 2017; Cummings et al, 2017). Discussions about whether education is transactional or transformative often revolve around the individual student. Why, for example should they seek higher education? Is it to learn skills and build a career, or is it to develop capacity to uplift their community?

\section{Student Identities}

Discourses about the roles of the students, about why (and how) they should, or should not access higher education, highlight the many ways in which education can be transactional, transformational, or both. These Discourses about the identities of students can highlight or hide barriers and inform opportunities. These Discourses are often used in discussions about access to higher education for underserved students - whether it is a mother seeking to provide for her family, a refugee trying to integrate into a community, or an impoverished student trying to get a better job.

Individuals choose to access higher education for a variety of reasons. Bye, et al., noted that increased "complexities in students' lifestyles and the subsequent blurring of transitions between stages in life" have been important factors behind the increase of nontraditional students (2007, p. 142). This takes the form of delayed entry as well as reentry at later points in life. The ways in which an individual engages with the various discourses around access to education may influence actions (or non-actions). In research highlighting issues of access for underserved students, the identities of students are either viewed from a deficit perspective - as a victim, or from a strengths-based perspective which sees the individual as someone victorious over challenges to educational access. The victimization or valorization of students is often tied to the perception of increased or decreased inequities. These Discourses around student identities will be discussed in this 
section. In their research on the educational experiences of students with refugee backgrounds, Mangan and Winter note that "[e]ducation certainly has the potential to be a validating environment... and perhaps to contribute to a wider egalitarian agenda, [unfortunately] the current experience of [underserved students] is skewed towards invalidation and misrecognition" (2017, p. 499). One of the goals of this research is to listen to these underserved students in the hopes of validating and recognizing their experiences, whether they see themselves accessing education for transactional or transformational goals, and whether they identify as victimized or victorious.

Transactional identities. The utilitarian perspective of education views students in utilitarian ways. It presumes that people will engage with education for very pragmatic reasons. Education can provide people with training so that they can get better jobs and support economic development (Brissett and Mitter, 2017). People are seen as resources (human capital) that need to be cultivated, particularly in neoliberal discussions which assume that the role of education is to develop these resources through providing training (Cummings et al., 2017). Much of the literature about access to higher education for nontraditional students and for refugee populations sees their access to education as essential for their economic success (Dryden-Peterson, 2016b; 2017). Andersson and Hatakka's (2017) critical discourse analysis of ICT policy documents pertaining to women found that women were viewed as "untapped resources" and seen in terms of potential members of the workforce. The focus of these particular policy Discourses was on the economic loss from women's lack of participation in the formal economy (Wodon et al., 2018). Highlighting opportunities for job growth and changing perceptions of what counted as a viable career for women were policy objectives. 
Transformational identities. Underserved students are often discussed in terms of the ability of their education to transform themselves and their communities. As noted above, this may be through multiple avenues. Education for women may provide their families, their communities, and themselves with both improved health outcomes and improved political participation (UNESCO, 2016a). Conflict-affected students may develop social capital, help their families integrate better into new societies, and increase the capacity to rebuild postconflict (Dryden-Peterson, 2016b). Education may also provide such students important legal "rights, a respected status, and a way to participate in the economy and well-being of their adopted society" (Streitwieser, et al., 2017). Finally, education for underserved students holds the promise of the development of new knowledges, research, and skills. As discussed throughout, it has been argued that this new knowledge is essential for sustainable development to be successful in the most underserved parts of the world (Crea, 2016; Cummings et al., 2017).

Victimization identities. Despite claims in countless documents, including the UN documents cited thus far, access to higher education is not a panacea for inequities. In many cases, it can exacerbate them. As more students access higher levels of education, one result is the widening gap between those who have access and those who do not. As noted above, much of the feedback related to the development of the SDGs relied on those who had access to the internet; who were aware that feedback was being collected via surveys, websites, and conferences; and who were able to constructively participate in complex discussions about global development issues through these vehicles (Briant Carant, 2017). The structural inequities their participation perpetuated is one of many ways in which access to education 
can make inequities and inequalities worse. Understanding of how inequities are perpetuated is essential for those seeking to mitigate this problem (e.g. the Asherah Foundation).

Despite decades of concerted effort, inequities among both students and their communities remain. The structures that led to these inequities may be reproduced through the global higher education sector. Capital is mis-directed, knowledges are discarded, and barriers are reinforced and remain. Some argue that the very structure of the global higher education sector "systematically reproduce[s] inequalities of both experience and outcome" (Clegg, 2011, p. 93). Global goals for higher education have been criticized for contributing to "brain drain" and to the de-funding of education in lower income countries while providing additional resources to education in more developed areas via increased focus on scholarships (UNESCO, 2016a).

Students are portrayed as victims in literature highlighting the negating of their “cultural knowledges, experiences, histories, and practices" and through the positioning of their knowledge as inferior (Baker, et al., 2018, p. 66). Researchers such as Tecle et al. discuss the ways in which stereotypes send the message that these underserved students are "'lacking,' backward, and traditional" and need to "'catch up' with the modern world" (p. 172).

Transactional victims. This lack of appreciation for the unique backgrounds of underserved students has many costs in terms of the transactional nature of education. For nontraditional students this may result in "limited social support systems, lack of peer group classmates, and [acknowledgement and accommodations for] other life obligations" (Schatzel, et al., 2011, p. 49; see also Suarez-Orozco, Teranishi, Suarez-Orozco, 2015). Support systems may not adequately address some of "[t]he most frequently described 
barriers to enrollment include[ing] time constraints, costs, family responsibilities, inconvenient class schedules, transportation, and employment problems" particularly as "[m]any of these problems are interrelated and it is often impossible to separate the effects [of] factors such as family responsibilities, time constraints, and costs" (p. 50).

In addition to inequities among regions and country income-levels are the disparities within countries in educational attainment by wealth and gender (UNESCO, 2016a, p. 74). One example of the ways in which this is being exacerbated is by the increase in student loan debt. Verger, et al., noted that "the rhetoric surrounding global education reform often conflates individual and collective economic benefits of schooling" (2016, p. 7). This leads to a disproportionate cost (financial burden) being borne by individuals and their families. As public expenditure has declined, the student loan industry has increased. Robertson and Komljenovic pointed out "the tendency in frontier market-making to exploit the aspirations of the marginalized populations by offering them often inferior higher education experiences at significantly higher costs and levels of indebtedness" (2016, p. 596). Furthermore, much of the capitalist discourse around education actually provides "the rationale for indebtedness, with the expectation (fictional as one cannot know what the future will actually hold) this will be a good investment for the future" (p. 598). This "fantasy" is often encouraged by marketing and recruitment campaigns which speak to aspirations to 'do well', to 'be western', to acquire the status of 'a good English speaker', and so on, which in turn reproduce and strengthen 'global north' and 'global south' relations now shaped through market imaginaries and relations" (p. 598). They also noted that this exacerbates class bias and reproduces inequities (p. 607). This is the unfortunate outcome of the "gap between the 
rhetoric of promised social mobility and personal advantage, and the realities of the consolidation of social place and status" (Clegg, 2011, p. 93).

Clegg argued that "[t]he neo-liberal language of students wisely investing in their future employability, making calculations of the returns on their investment is subverted by systems that can continue [to] increase price secure in the knowledge that the social value of what is on offer is read through the lens of class distinction not pure economic rationality" (2011, p. 95). "So while participation is officially constructed in meritocratic and individual terms, the actual costs and benefits of participation are unevenly socially structured" (p. 95).

Transformational victims. The identification of students as "transformational victims" is a complicated mixture of both respect for student agency and pity for their naivete. Discourses around students that are identified as "transformational victims" often highlight the sacrifices an individual has made and the resilience she, or he, has demonstrated (Mangan \& Winter, 2017). Unfortunately, these strengths become seen as, or subsumed by, weakness. Such students are depicted as, perhaps naively, chasing a dream that is likely unattainable - often incurring further harm to themselves in the process (and even enriching others) (Clegg, 2011; Mangan \& Winter, 2017).

For example, Andersson and Hatakka found that "The Victimized Woman" was a common theme in the policy documents they analyzed. They noted that women were described as marginalized, underprivileged, and "as a group that needs extra care [special treatment] on the same terms as people who are disabled or who live in extreme poverty" (2017, p. 78). Policies highlighted ways in which women were disadvantaged and vulnerable, different from those who were advantaged (e.g. high-income, ethnic majorities, men). Women were "reduced to victims of injustices and inequalities" (p. 78). The authors pointed 
out that the victimization of women removed the focus from the "social structures, cultures, and societal norms" that were problematic - and often root causes - of the policy problem, thereby reducing the possibilities for appropriate policy action to remedy the issue. Andersson and Hatakka noted that "[p]ositioning women as victims in need of help also means that women are seen as 'inherently deficient and insatiable, as always needing more and more"” (p. 81).

Victorious identities. Counter narratives are an important component of Critical Discourse Analysis (CDA) (Gee, 2014a; Saarinen, 2007). In contrast to Discourses highlighting the disadvantages and victimization of underserved students are those Discourses which highlight their agency, success, and strengths. These Discourses value the unique knowledge and experiences of these students (Baker, et al., 2018; Tecle et al., 2017) and highlight their resilience and strength in the place of tremendous obstacles (Mangan \& Winter, 2017). In one example, Suarez-Orozco, et al., noted that undocumented students "possess an array of strengths including hope, optimism, and motivation, which can serve them well in their educational pursuits" $(2015$, p. 2). Collis and Reed noted that "[r]egardless of how one might come to higher education, being prepared in higher education involves resourcefulness and resilience" (2016, p. 2).

Transactional victors. Discourses around underserved students often focus on the ways in which education can help them develop essential skills and productively join the formal labor force (Andersson and Hatakka, 2017). They may become skilled professionals in vital healthcare and STEM fields (UNESCO, 2016a) helping their local workforce become healthier and their economies become stronger. Discourses featuring underserved students as these "transactional victors" highlight the ways in which they can contribute to a knowledge- 
based economy through learning valuable skills and developing new knowledges. This is highlighted in Cumming et al.'s (2017) discussion on the "techno-scientific-economic" Discourse about the knowledge society within UN SDG documents. These Discourses include assumptions about "the monetary value of knowledge...the primacy of scientific knowledge [and] linear and instrumental conceptions of how knowledge generates economic growth" (p. 3). Transactional victors are those who succeed in this vision of a knowledge society. These victorious students help their families and communities to grow in these areas, ostensibly reducing inequalities of economic development.

Transformational victors. As noted in the sections above, students who access education have the ability to overcome obstacles, secure their education, and are able to transform their communities. The health and educational outcomes for their children often improve, they may have increased political power, seek ways to advocate for and inspire others, and, in the case of forcibly displaced individuals, help integrate their new communities. These outcomes are essential to the goals of global higher education agendas to reduce many of the inequalities that global agendas for higher education seek, fulfilling the third mission of the "triple bottom line approach to human wellbeing" - including a focus on “social inclusion" (Sachs, 2012, p. 2206). This "triple bottom line" undergirds many of the documents surrounding the SDGs, including the main policy document Transforming our World (United Nations, 2015).

All of this can have the added benefit of increased recognition of different "knowledges" (see Clegg, 2011, p. 100). Tecle et al. note that "[n] ewly arriving communities come from diverse backgrounds, yet their heterogeneity frequently has been considered a barrier to moving forward rather than a cultural wealth to harness" (2017, p. 180). This 
"cultural wealth" is an important aspect of the "pluralist-participatory" Discourse identified by Cummings et al. (2017). The "pluralist-participatory" Discourse highlights "respect for linguistic and cultural diversity" and replaces the traditional vertical hierarchies with "horizontal relationships that are able to transcend social and national borders" (p. 4). It is aligned with Discourses about the transformative potential of education. Students within this Discourse work collectively to harness multiple knowledges to solve complex problems, highlighting the importance of local knowledges (p. 5).

As seen in the stories of the Asherah Foundation scholarship applicants, students can experience education as both transactional and transformative as it gives them, for example, the ability to procure better employment (transactional) which may then enable them to inspire others in their communities (transformative). They can also identify as both victims and victors; victimized by an education interrupted by conflict, but victorious as they persist and attain higher levels of education despite the interruption.

\section{Theoretical Framework: Critical Discourse Analysis (CDA)}

This next section will now outline the theoretical framework underpinning this research. CDA as articulated by Norman Fairclough, provides a theoretical lens with which to look more closely at the problems identified earlier, as well as a framework for research methodologies proposed by James Paul Gee that are presented in Chapter Three.

Given the critiques of the ways in which the sustainable development agendas pertaining to education were created and have been implemented, a critical approach to this research is appropriate. The 2016 GEM Report's acknowledgement of the deficiencies in data collection provides a starting point for examining possible foundations for these critiques. A better understanding of the ways in which underserved populations access 
education (or are prevented from accessing it) may shed light on possible policy interventions to address these critiques. Understanding which barriers prevent access to education, and what supports are helpful, may help countries and organizations design policies to encourage more equitable access to education for underserved populations. As many of the critiques pointed out, policies designed to provide access to education often benefitted those making the policies at the expense of those the policies were trying to serve. The existing structures of power maintained themselves through the creation of the SDGs, in part by deciding which data was important to collect to inform policy decisions.

Fairclough's theories underlying CDA provide a framework to critique power structures and investigate various discourses. A central issue that will be examined are the relationships among conflict-affected women from lower income countries who applied to the Asherah Foundation's scholarship program, their access to higher education, and the ways in which scholarships may or may not assist them.

Moreover, CDA is well-aligned with the principles of voice and empowerment underpinning the Asherah Foundation. It is also well-suited to gleaning information about the unique and context-specific experiences of this population not captured in the 2016 GEM Report. CDA is useful for amplifying the voices of those who are not usually heard (and often contrasting it with those that seek to [either explicitly or implicitly] control them). In this case, this paper seeks to highlight the voices of this group of scholarship applicants and compare their personal discourses around the role of education with common Discourses of the UN Sustainable Development Goal \#4. 


\section{Epistemological Perspective}

This way of viewing data - particularly when in relation to the larger global educational agenda - is based on the theory of social constructivism. Saarinen used the term "discourse" to refer "to dialectical relationship of language as constructed by society and as construing it" (2007, p. 16). Her application of CDA framework to her analysis of policy documents provides a starting-point for the research here (Saarinen, 2007, 2008). The concept of discourse as constructing (and re-constructing) a social reality will be examined throughout, particularly in the discussion of the research methodologies in Chapter Three.

\section{Construction through Discourses}

The social constructivist perspective argues that realities are constructed through the engagement of different discourses with one another. The process of creating discourses is inherently a social practice. This perspective necessitates the consideration of context: what is the context (time, place, socio-cultural, political, environment) the discourses are produced in? There are several interrelated frameworks about the ways in which discourse constructs (and is constructed by) society. These frameworks overlap substantially and will be considered in tandem. The chart below lays out the key concepts around what constitutes "discourse" and ways in which it may be critically analyzed. The section below will examine the three key concepts around the production and critical analysis of "discourse." Considerations for analysis of the scholarship applications will be briefly introduced to illustrate key points. 


\section{Table 4}

\begin{tabular}{|c|c|c|c|c|c|}
\hline \multicolumn{6}{|c|}{ Definitions and Components of D/discourse and Critical Discourse Analysis (CDA) } \\
\hline Component & Fairclough & Gee & Gee CDA & Fairclough CDA & $\begin{array}{l}\text { Contextual } \\
\text { Considerations }\end{array}$ \\
\hline Data & $\begin{array}{l}\text { Text (spoken or } \\
\text { written language) }\end{array}$ & Text (discourse) & Piece of data & $\begin{array}{l}\text { Analysis of } \\
\text { language texts }\end{array}$ & $\begin{array}{l}\text { Context of } \\
\text { Situation }\end{array}$ \\
\hline Action & $\begin{array}{l}\text { An instance } \\
\text { of discourse } \\
\text { practice involving } \\
\text { the production and } \\
\text { interpretation of } \\
\text { text }\end{array}$ & $\begin{array}{l}\text { Communicative } \\
\text { Event (uses text } \\
\text { to communicate) }\end{array}$ & $\begin{array}{l}\text { Six Theoretical } \\
\text { (Building) Tools }+ \\
\text { Seven Building } \\
\text { Tasks }\end{array}$ & $\begin{array}{l}\text { Analysis of the } \\
\text { processes of text } \\
\text { production }\end{array}$ & $\begin{array}{l}\text { Institutional } \\
\text { Context }\end{array}$ \\
\hline Context & $\begin{array}{l}\text { A piece of social } \\
\text { practice }\end{array}$ & $\begin{array}{l}\text { Meta-narratives } \\
\text { (Discourse) }\end{array}$ & $\begin{array}{l}\text { Reflection on } \\
\text { Context }\end{array}$ & $\begin{array}{l}\text { Analysis of the } \\
\text { events of } \\
\text { discourse as a } \\
\text { form of } \\
\text { sociocultural } \\
\text { practice }\end{array}$ & $\begin{array}{l}\text { Wider Societal } \\
\text { Context }\end{array}$ \\
\hline
\end{tabular}

Sources: Fairclough, 1992, 1995, 2001, 2013; Gee, 2014a, 2014b 
Concepts around the term "discourse" begin with the actual piece of discourse ("text"). This piece of discourse (text) is seen as a vehicle for communication ("communicative event") within a specific environment (institutional context). This "communicative event" is seen as taking place within a "wider societal context." Meta-narratives, or Discourses, provide the sociocultural structure for these communicative events. Analysis of discourse begins with the actual text (piece of data). Investigation of the process of creating the discourse (the action) and consideration of the wider context provide a more critical lens with which to analyze the piece of data.

\section{Why "Critical"?}

In more recent "Foucaultian" traditions, the idea of "discourse" refers to "meaning systems, which have historical, social and institutional implications" (Saarinen, 2007, p. 15). This perspective views "discourse as a system of organizing truth and knowledge, and consequently on how power is exercised by some and not others...a field of competition for world views, rather than on the linguistic forms of discourse analysis" (p. 18). Discourse analysis, in Gee's view, "needs to be critical...because language itself is...political” (Gee, 2014a, p. 9). For Gee, analysis consists of "looking closely at the structure of language as it is being used...[to] uncover different ways of saying things, doing things, and being things in the world" (p. 9). CDA is particularly concerned with unpacking the power structures underlying cultural meta-narratives/Discourses.

As an example, Saarinen's analysis of policy texts sought to explain and understand how higher education policies were implemented, including "the (political) views which are embedded in the debates and in understanding how policies are produced (discourse as social practice)" (2007, p. 18). She noted that the creation and implementation of policies 
simultaneously describe the world, create and recreate the world, foreground problems (which narrows "the space for alternative views") and thus "perpetuate some political views of social reality" (p. 18). She also stated that this ability to perpetuate a politicized view of reality has effects beyond simply ideological - funding allocation being one example.

Both the act of developing discourse (e.g. publishing the GEM Reports, writing the scholarship applications essays) and the act of interpreting discourse (i.e. developing educational policies, reviewing applications essays) can have significant ramifications. As Rogers and Wetzel explain: "Discourses play many roles...[t]hey sustain, build, resist, or transform existing narratives and ideologies" (2013, p. 9).

\section{Three-dimensional Analytic Framework}

Fairclough's three-dimensional framework will set the stage for undertaking a critical discourse analysis of the applications to the Second Chance Scholarship program as it will help situate them in relation to the meta-narratives identified above, and in relation to the critiques of SDG \#4. Fairclough's framework involves incorporating three distinct (but interrelated) forms of analysis into a comprehensive picture. As noted above, these include the analysis of language texts, analysis of the processes of text production, and the analysis of the events of discourse as a form of sociocultural practice (Fairclough, 1995, 2001). The use of this framework will help develop a more holistic picture of the scholarship application process to set the stage for analysis. James Paul Gee's methodology is based on these concepts and will be explored in greater detail in Chapter Three.

Data (Texts) ("d"iscourse). The terms "text" and "discourse" are often used interchangeably, although they have slightly different meanings in the context of CDA as will be explored here. Saarinen (2007) provided a historical overview of the relationships 
between the terms "text" and "discourse," particularly as understood in the field of linguistics. She noted that a "text" was originally conceived of as a static product in contrast to the dynamic product that is discourse (see also Titscher, Meyer; Wodak \& Vetter, 2000). Gee (2014b) uses the term "discourse" (with a small "d") to mean "language in use" (p. 183). This "language-in-use" is "language actually used in specific contexts" (p. 19). It is more than just "an abstract system" - it is that system in specific contexts being used towards specific objectives. As Gee notes "We use language to build things in the world, to engage in world building, and to keep the social world going" (p. 31).

Fairclough (2013) sees text as composed of three interdependent aspects: “'ideational', 'interpersonal' and 'textual"' (p. 94). These three aspects all take place in a specific context. As scholarship applicants write application essays, they are simultaneously constructing (and reconstructing) a specific view (or idea) of the world. They are negotiating and (re)creating their identity in collaboration with the imagined reader of the essay. The form of the text highlights certain aspects of their worldview and presents certain aspects of their selves (various identities) while backgrounding certain other aspects. Looking at what is highlighted through initial content analysis may give insight into the persuasive presuppositions they are engaging with. These presuppositions include "the assumed common ground, which in turn sets the frame of interpretation of texts" (Saarinen, 2008, p. 341). For example, common assumptions in the scholarship applications may include that education is a social good, women should have access to education, and even that the applicants are deserving of financial support. 
Action. The term "action" is used here to refer to both "communicative events" and “discourse practice.” These are the actions of practicing discourse, of using (writing, speaking) words to communicate.

Communicative event. The creation of a discourse (text, piece of data) is an action meant to communicate. Rogers and Wetzel (2013) pointed out that "'discourses' [small 'd'] are the language bits that comprise communicative events. This includes the hard and soft structures of language - grammar, morphology, intonation, and so on" (p. 9). These aspects of discourse are often learned through years of both formal and informal instruction. This type of discourse is often very consciously applied (as when an applicant reviews her essay for grammatical errors). Texts are vehicles for these events. These events are part of a larger practice of communication or "discourse practice."

Discourse practice. Fairclough (2013) wrote that analysis of this part of a text consists of the "moment-by-moment explication of how participants produce and interpret texts" and "analysis which focuses upon the relationship of the discursive event to the order of discourse, and upon the question of which discursive practices are being drawn upon and in what combinations" (p. 95). One key to this analysis is the ways in which the particular discourse practice "transforms the past - existing conventions, or prior texts - into the present" (p. 95). The narratives provided in the writing and submitting of the application essays are clear examples of this transformation of the applicant's past into the present, particularly in the ways in which the applicants discussed why they needed a "second chance." Thus, in looking for discourse practice in the scholarship essays, I looked at how applicants present their identities. For example, how have they transformed themselves from 
victims of violence or poverty into agents of change? Analysis of the processes of discourse (text) production is key to this aspect of CDA.

As will be outlined in Chapter Three, Gee has developed a series of Six Theoretical (Building) Tools and Seven Building Tasks to examine each piece of discourse. The combination of these provides a series of 42 questions to ask of each piece of data (text). The questions examine the ways in which those producing the discourse have constructed (built) a specific social reality through their act of communication. Fairclough (2013) noted that “people's self-identity...is reflexively built up through a process of negotiation” (p. 98). Furthermore, one of the consequences "of the increasingly negotiated nature of relationships is that contemporary social life demands highly developed dialogical capacities" (p. 98). The constant negotiation requiring a high degree of dialogical skill is something to be mindful of when analyzing the discourse of the Asherah Foundation applicant essays. While attracting applicants from all over the world, those that applied had to be familiar with the discourse practices around scholarship applications for higher education. Fairclough also noted that "[t]he seemingly limitless possibilities of creativity in discursive practices suggested by the concept of interdiscursivity - an endless combination and recombination of genres and discourses - are in practice limited and constrained by the state of hegemonic relations and hegemonic struggle" (p. 95). The relationships of scholarship applicant to the organization, and to scholarship review committee members and funders, are very specific relationships demanding very specific ways of speaking and representing oneself - of very particular discourses within the larger Discourses (meta-narratives) of scholarship application processes and larger Conversations around the access of women to higher education within these Discourses. 
Context. The contexts within the action of practicing discourse, or the communication via words or speech, are essential components of the discourse. These actions take place within layers of social expectations about what words are appropriate, what they mean, and how they should be used. The concept of "meta-narratives" is helpful to identify the contexts within which these communicative events take place.

Social practice. The creation of a piece of discourse (text) to communicate is based on social conventions of what is appropriate to say, when it is appropriate to say it, and how it should be said. For example, the social practice of applying for a scholarship requires communication about educational goals and scholastic ability - often within very limited timeframes. The social practice is for those who are students to apply for funding to support their near-term educational goals. It is not generally a social practice for three-year-old children to apply for scholarships to university programs that they may be interested in 15 years later.

Social practice at the center of the discursive practice of writing and submitting essays involves many levels. Fairclough (2013) noted that these include "the context of situation, the institutional context, and the wider societal context" (p. 95). Within each of these levels "[q]uestions of power and ideology" should be asked" (p. 95). As identified in this chapter, there are a number of critiques pertaining to the SDGs; including the use of scholarships to promote higher education access. These will be integrated throughout the analysis. Exploration of the ways in which "the context of situation, the institutional context, and the wider societal context" (p. 95) impact this research will be explored in Chapter Three. 
Meta-narratives. In contrast to the conscious nature of constructing discourses, “Discourses” (upper case 'D') are often much more automatic and unconscious. These Discourses include "ways of using, being, and representing language. [These] Discourses refer to the systems of meaning that are attached to what we say, or the Tools that we use. Discourses draw on and construct larger meta-narratives — narratives about gender, race, and class" for example (Rogers \& Wetzel, 2013, p. 9). These meta-narratives contain shared "conventions about how to use and interpret language" (Gee, 2014b, p. 182). They also share “distinctive ways [of] writing/reading" (p. 183) which "are coupled with distinctive ways of acting, interacting, valuing, feeling, dressing, thinking, and believing...[which are in turn] coupled with ways of coordinating oneself with...other people" (p. 183). "All this is in the services of enacting specific socially recognizable identities" (p. 183). Discourses "are ways of recognizing and getting recognized as certain sorts of whos doing certain sorts of whats" (p. 184). The context within which the discourse is created influences the discourse that is created, which in turn, creates a new context as it is read (and critically analyzed). Gee's methodology highlights this "'reflexive' property of context (p. 91). An ongoing engagement with reflecting on the context of the discourse production and the context of the analysis of the discourse is essential for identifying the politics and power dynamics underlying the social world built by the discourse.

In the applications for the Asherah Foundation scholarships, the women are drawing on and constructing larger Discourses through their conversations about the purpose of education for women, and responsibilities for funding this education. For example, many of the women positioned themselves as mothers and caretakers for their families and 
communities. This plays into larger Discourses about the appropriate role of women in society, particularly in regard to education and financial status.

\section{Conclusion}

This chapter has provided an overview of trends, narratives, and discussions around the access of underserved populations to higher education around the world. Decades of global educational goals have resulted in progress towards increased access to education. However, structural inequities exist. These inequities maintain power structures that prevent progress being made in accessing higher levels of education in ways that provide meaningful sustainable development. Critiques abound, including lack of diverse perspectives, problematic gender dynamics, shifts in financing from the public sector to individuals, and the pattern of "brain drain" which results.

These global trends constitute the social context within which this analysis will take place. The population of study represents a unique group of women. Those who are from lower income countries, who have had their education interrupted due to violence yet have been able to access higher education, present a population from which important insights may be gained. Their success in the face of global forces against them provide a window into that which is possible. Lessons may be learned which may shed light on ways to counteract the global trends preventing others from accessing higher education.

The next chapter will expand upon the CDA framework introduced in this chapter. Chapter Three will examine how this framework is applied in methods of inquiry proposed by James Paul Gee. It will begin with an overview of the pieces of data to be examined, including applicants, research questions, and an in-depth look at Gee's proposed CDA methodology. It will conclude with descriptions of how this methodology was applied to 
analyze the data provided by applicants to the Asherah Foundation's Second Chance Scholarship program. 


\section{Chapter}

\section{METHODOLOGY}

This study set out to examine the experiences of a select group of women seeking to access higher education. Between 2016 and 2018, out of over 100 applicants to an international scholarship program, only 34 women identified violence from civil conflict as impacting their educational journeys. A sub-group of applicants also identified themselves as coming from low- and lower-middle-income countries classified as fragile or conflictaffected. This sub-group succeeded in accessing higher education programs despite the odds against them. To examine how they did so, the overarching question for this research was: How do nontraditional women from lower income countries and conflict-affected regions describe their journeys to higher education despite tremendous obstacles including violence and poverty? In this study, the question was addressed by identifying how a specific subset of applicants to the Asherah Foundation Second Chance Scholarship talked about their educational experiences by asking more specifically: "How do they talk about themselves, and how do they describe the role of education in their lives"?

This chapter will provide an overview of the methods of inquiry that were used to answer this question. It will begin with an elaboration of the research question, overall research context, and then explain the process of data collection and descriptions of the populations of study. Next, it will describe James Paul Gee's proposed methodology for Critical Discourse Analysis (CDA), including descriptions of six Theoretical (Building) Tools of analysis and seven Building Tasks to identify (Gee, 2014a, 2014b), and the methods of analysis used in this study. Awareness and reflection on the context of the data production, the analysis, and the ways in which this context constantly (re)creates itself is a key 
component of Gee's framework and methodology. As such, this chapter will also provide a brief discussion of context and the ways in which this research is simultaneously discourse (production of "text") within Discourses (meta-narratives). Additional reflections on the context of this research will be incorporated into Chapter Four (Findings) and Chapter Five (Discussion and Conclusion).

\section{Research Context: The Asherah Foundation}

The Asherah Foundation was founded in 2016 to support women around the world through "Second Chance Scholarships." As noted in Chapter Two, organizations such as this are viewed as important partners in the pursuit of sustainable development goals for higher education. Through its scholarship program, the Asherah Foundation seeks to assist women in accessing higher education around the world. The context within which this data was collected and analyzed was influenced by many factors. These include the positionality of the researcher, the composition of the Asherah Foundation Executive Board, potential barriers to possible applicants, and the pool of those who did apply (participants in this research).

\section{Positionality of Researcher}

As the founder, Executive Director, and current President of the Executive Board of the Asherah Foundation, the positionality of this researcher was an important component of this study. I am an adult White, U.S.-born woman with a graduate degree working professionally in the field of international higher education. My access to higher education was not interrupted due to conflict. However, like these applicants, I did identify higher education as an important goal, and worked through (far less difficult) obstacles to obtain it. My position allows me to physically and intellectually interact with international organizations representatives (e.g. World Bank, UN) and others concerned with access of 
women, refugees, and other underserved students to higher education - often in the context of development in lower income countries. This positionality enabled me to create and sustain this global organization, and to bring on women and men with more direct experience of these obstacles to provide guidance.

It was hoped that this critical analysis would help to highlight my own assumptions about the applicants to the scholarship program, as well as about the role of the Asherah Foundation in promoting educational opportunities for women around the world. An important part of the analysis included efforts to explicitly identify power structures that influence the operations of the organization.

\section{The Asherah Foundation}

The Asherah Foundation was founded in 2016 by professional women with graduate degrees from higher income countries. The organization was developed to provide "Second Chance Scholarships to Women around the World" (www.asherahfoundation.org), with the term "second chance" being left up to applicants to define.

Leadership (Executive Board). As the chart below demonstrates, the inaugural Executive Board was a highly-educated and internationally-connected group of professional women. The three original founders quickly brought on two additional colleagues for assistance and advice in managing the organization. The majority of the Executive Board members have been adult women with graduate degrees (three of the inaugural members had earned doctorates) who were working full-time and had the resources (financial, temporal), connections (international, educational), and freedom to develop this organization during the time of this study. As noted in Chapter Two, these highly-educated individuals represented a very tiny minority of women around the world. 
Table 5

Characteristics of Inaugural Executive Board: 2016

\begin{tabular}{llcccc}
\hline Board Member & $\begin{array}{l}\text { Professional }- \\
\text { International } \\
\text { Higher } \\
\text { Education Field }\end{array}$ & $\begin{array}{l}\text { University } \\
\text { Professor } \\
\text { (part time) }\end{array}$ & $\begin{array}{l}\text { Earned } \\
\text { Doctorate }\end{array}$ & $\begin{array}{l}\text { Significant } \\
\text { International }\end{array}$ & $\begin{array}{l}\text { Multiple } \\
\text { Languages } \\
\text { Travel / Personal } \\
\text { (Fluent) } \\
\text { Connections } \\
\text { Abroad }\end{array}$ \\
\hline President & $\mathrm{x}$ & $\mathrm{x}$ & $\mathrm{x}$ & $\mathrm{x}$ \\
\hline President Elect & $\mathrm{x}$ & $\mathrm{x}$ & $\mathrm{x}$ & $\mathrm{x}$ \\
\hline Treasurer / & $\mathrm{x}$ & $\mathrm{x}$ & $\mathrm{x}$ & $\mathrm{x}$ \\
Secretary & & $\mathrm{x}$ & $\mathrm{x}$ & $\mathrm{x}$ \\
\hline At-large & & & $\mathrm{x}$ & $\mathrm{x}$ \\
\hline At-large & & & $\mathrm{x}$ & $\mathrm{x}$ \\
\hline
\end{tabular}


Location. The Asherah Foundation is based in the Washington, DC metro area. It is in close proximity to international organizations such as the World Bank. Aspects of this research were presented at conferences held in conjunction with the United Nations' Annual Meetings (in New York City, NY) to fellow researchers in the field of sustainable international development.

Theoretical Orientation. The organization was incorporated as a non-profit. Given the social and financial capital of the founding Executive Board, the organization could have chosen to become part of the global education industry, finding ways to monetize and profit from the large number of women who need a "second chance." However, the idea of this organization being incorporated as a for-profit entity was never raised in discussions about its legal formation.

\section{“Second Chance Scholarship" Application Processes}

Outreach efforts. As a new organization, the Asherah Foundation had a very limited ability to let women around the world know about its scholarship program in its first year (2016). This increased substantially as the organization grew. Members of the Executive Board and their colleagues formed the Scholarship Review Committees in 2016, 2017, and 2018. In addition, board members used personal connections abroad to share information about this scholarship. They provided translations in Arabic, Chinese, French, Spanish, and Turkish. Subsequent communication with and outreach to potential applicants were in these languages. The composition of the organization's leadership impacted the Discourses (metanarratives) that were involved, which, in turn, impacted the discourses that were produced via the scholarship applications and were examined as part of this study. 
The 2016 pool of applicants consisted of 19 women. Outreach to potential applicants was carried out through personal posts on Facebook and Twitter by members of the Executive Board, particularly through contact with EducationUSA officers around the world. Through a personal connection of the Executive Director in 2016 (this author), the scholarship announcement was posted on the Al-Fanar Media website in both Arabic and English.

Outreach in 2017 was carried out through similar means as in 2016, but with a more centralized message from official Asherah Foundation social media accounts (Facebook and Twitter). EducationUSA officers, embassies, Ministries of Higher Education, and prominent universities in various countries were directly contacted in appropriate languages (Arabic, English, Chinese, French, Spanish, and Turkish) through social media. This resulted in almost 100 applications.

Outreach in $\mathbf{2 0 1 8}$ was similar to that of 2017. Past applicants who had not been successful were invited to re-apply. One major change was that the application in English, Spanish, and French was available primarily as an online form (as opposed to an MS Word document).

Application criteria. The women who applied for the scholarship program represented a relatively elite group in terms of global access to higher education - for example, in low-income countries, just $1 \%$ of the poorest girls completed upper secondary school and were thus eligible for higher education (UNESCO, 2016a, p. 185). In order to be eligible for the scholarship, these women had to have been accepted and enrolled in a higher education program at an accredited institution. This meant that they had to have completed upper secondary school, gone through the complex process of applying to institutions of 
higher education, and been competitive enough to be accepted. In addition, they needed fluency in one of the application languages, access to the internet and a level of digital literacy to enable them to send the application to the organization, either by themselves or through others. They also needed to have access to the global higher education community to even learn about this scholarship opportunity.

The application process consisted of filling out an eight-page application (migrated to an online form in 2018) and submitting appropriate documentation. (See Appendix 6: Scholarship Policy \& Application Form). Specifically, the application form asked applicants to provide the following information:

- Demographics

○ Name

- Address

- Date of Birth

○ Social Security Number (2016 only)

- Contact information

- Dependents (names and ages)

- Educational Goals

- Institution

- Academic program

- Degree level

○ Date admitted

- Anticipated date of graduation

- Recent work experience 
- Contact information for two personal references

- Previous educational experience

- Educational expenses and income

- Certification of accuracy and use of application materials

In addition to the application, applicants were asked to send in supporting documents, including:

- Two letters of recommendation

- Official copy of latest transcript

- Documentation of current financial need

- Essay

- Photo (optional)

Finally, the applicants were asked to follow this prompt in writing their essays: "Please attach an essay illustrating how this scholarship will give you a second chance and how it will benefit your community. Essay shall be no less than 500 words and no more than 1000 words."

It should be noted that in applying for this scholarship, the applicants were informed of the policies regarding the use of their application materials:

I understand that the attached essay and a photo of myself may be used for promotional and research purposes. I also understand that I may request that my name and other identifying details be changed for all outreach, research, and promotional purposes to protect my identity. However, I understand that the scholarship will be given in my legal name and that all identifying information will be available to those involved in the scholarship selection and awarding process, including the institution 
to which the scholarship funds will be paid. I waive any right to damages that may result as a consequence of applying for this scholarship.

Potential barriers to application. The scholarship application process provided a number of barriers that potential applicants had to overcome once they learned about the scholarship. In addition to having digital literacy, access to the internet, and to the global higher education community, these women also filled out a complex application. Although applicants could mail hard copies to the foundation's office in the Washington, DC area (and a few did), that required additional funds for postage, and the ability to obtain and send official documents (such as transcripts) across the world in a brief window of time. This complexity resulted in a very small percentage of potential applicants actually applying. This was demonstrated by the $10,000+$ hits on the Asherah Foundation website and hundreds of inquiries - all of which resulted in only around 100 completed applications for the 2017 cycle.

\section{Data Collection}

The data for this study were the applications to the Asherah Foundation's Second Chance Scholarship programs in 2016 - 2018. There was a total of 175 applications over these three years. The characteristics of these applicants will be described here before turning to the selection criteria/sample of applications chosen for this study's critical discourse analysis. Tables below list the origins of the applicants using both World Bank and UIS classifications for geographical region, income level, and development level. 


\section{Applicants}

Age range. The ages of applicants ranged from 17-52, with an average age of 29 and a median age of 28.87 . In 2016, only applicants 24 and older were eligible to apply. The age restriction was removed for 2017 and 2018.

Geographical regions. Applicants came from 46 countries/territories and were attending school in 31. The most common area applicants were from was Palestine. (The Asherah Foundation does not have a formal position regarding recognition of the State of Palestine. These numbers reflect self-reporting by applicants.) Seventeen came from countries/ territories not counted by the World Bank (East Jerusalem, Gaza, Jerusalem [West Bank], and Palestine [n=13]). The UIS includes Palestine. Please see Appendix 4: Comparison of World Bank and UIS Country Classifications for details. The most common regions were the Middle East and North Africa (MENA) (or West Asia), and Sub-Saharan Africa. It should be noted that one of the winners in 2016 was from Palestine which may have influenced the dissemination of information and encouraged women there to apply at higher rates than elsewhere. Classifications of countries by region differed slightly between the World Bank and UIS. This table includes East Jerusalem, Gaza, Jerusalem (West Bank), and Palestine in the MENA Region, although they are not recognized in the World Bank's country categorizations. The UIS included Palestine in the West Asian region which otherwise overlapped considerably with the World Bank's MENA region. 


\section{Table 6}

Applicants by Region

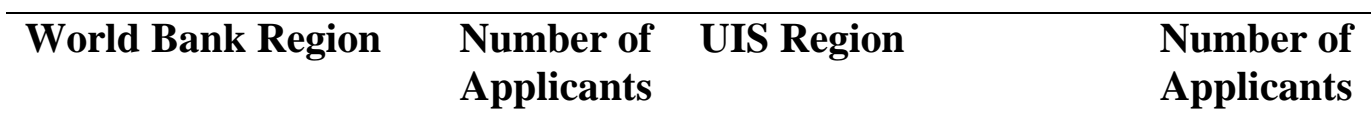

\begin{tabular}{llll}
\hline East Asia and Pacific & 3 & Caribbean & 5
\end{tabular}

\begin{tabular}{lll}
\hline Europe \& Central Asia & 11 & $\begin{array}{l}\text { Caucasus \& Central } \\
\text { Asia }\end{array}$
\end{tabular}

\begin{tabular}{llll}
\hline Latin America \& the & 7 & Europe & 5
\end{tabular}

Caribbean

\begin{tabular}{lclc}
\hline $\begin{array}{l}\text { Middle East \& North } \\
\text { Africa }\end{array}$ & 75 & Latin America & 2 \\
& & \\
\hline North America & 6 & North Africa & 28
\end{tabular}

\begin{tabular}{llll}
\hline South Asia & 7 & North America & 6
\end{tabular}

\begin{tabular}{llll}
\hline Sub-Saharan Africa & 44 & Southern Asia & 8
\end{tabular}

Southeast Asia 3

\begin{tabular}{lll}
\hline NA & Sub-Saharan Africa & 39 \\
& & \\
\hline & West Asia & 76
\end{tabular}


Economic development level. The majority of applicants were from lower income countries/territories, and from what the UIS considers to be "developing" countries/territories. Palestine was not included in the World Bank data but was in the UIS data. As noted in Chapter One, the World Bank has specific criteria which explains why some countries (e.g. Jordan) are classified differently by the World Bank and UIS. The UIS does not provide definitions for either the income or development level classifications (personal communication, UN Statistics Division, 2017).

Table 7

Applicants by Income Classification Level

\begin{tabular}{lclc}
\hline World Bank Income & Number of & UIS Income & Number of \\
Classification & Applicants & Classification & Applicants \\
\hline High-income & 21 & High-income & 21 \\
\hline Upper-middle-income & 25 & Upper-middle-income & 34 \\
\hline Lower-middle-income & 85 & Lower-middle-income & 98 \\
\hline Low-income & 22 & Low-income & 22 \\
\hline
\end{tabular}




\section{Table 8}

Applicants by UIS Level of Development

\section{UIS Development Level Number of Applicants}

Developed 12

Transitioning 4

Developing 159

Conflict-affected. Almost two-thirds of the applicants (101/175) came from countries identified as "affected by conflict" in the 2016 GEM Report (UNESCO, 2016a, p. 399) or from a fragile and conflict-affected situation (Appendix 5: Fragile and conflict-affected situations). In addition, the following were identified as homes of the applicants (although not identified as a country in the 2016 GEM Report): East Jerusalem, Jerusalem (West Bank), and Gaza - areas which conceivably are also "affected by conflict" as well.

\section{Selected Research Sample}

As noted in Chapter Two, there is a dearth of information on the access of conflictaffected adult women to higher education. This study focused on those women who were from conflict-affected states, who had explicitly noted that their educational journeys had been interrupted by conflict, had characteristics of "nontraditional" students (as identified in Chapter Two), and who were from lower income countries as identified above. The common "nontraditional" aspect of each applicant's identity was that her educational journey had been interrupted. In addition, they each had at least one additional characteristic of nontraditional students, including age (24+), being the first in their family to attend higher education, culturally and/or linguistically diverse (CLD) - going to school in a different country or culture and/or with a different language than their native tongue, having a refugee 
background (explicitly identified themselves as a "refugee"), and familial and/or financial responsibilities.

The demographics of all applicants were used to narrow the field of potential applicants for this research. Initially, all those who had explicitly mentioned conflict or violence were considered. However, throughout the process of reviewing relevant research, the criteria for selection were narrowed. The decision was made to focus on those applicants affected by civil conflict. While there was significant overlap between civil conflict and domestic/interpersonal conflict, the decision was made to focus on those affected by civil conflict, excluding those who were "only" affected by domestic/interpersonal conflict. Due to the need for more research on education within lower income countries, the decision was made to also focus on those who were originally from these countries. This dual focus of civil conflict + lower income countries resulted in a pool of 32 applicants. This group of 32 was looked at as a whole in the beginning stages of this analysis. The basic content analysis of the essays from these women highlighted potential themes and issues that informed the rest of the study.

After this initial analysis, a primary sample of 10 women was identified, with the remaining 22 composing two "alternate" groups for consideration. Out of the 32 women, only 19 explicitly identified conflict as affecting and interrupting their educational journeys.

The 13 who did not were considered as the first alternate group for analysis. As noted in Chapter Two, much of the literature on nontraditional students (especially in the Global North) focuses on those students who have not yet attained their undergraduate degree (usually at the baccalaureate level). As nine of the remaining 19 women were pursuing 
graduate degrees, they were set aside as the second alternate group. The 10 women who remained became the primary population of study. 
Table 9

Primary and Alternative Samples

\begin{tabular}{llllll}
\hline Group & Size & $\begin{array}{l}\text { Lower } \\
\text { Income }\end{array}$ & $\begin{array}{l}\text { Conflict- } \\
\text { affected / }\end{array}$ & $\begin{array}{l}\text { Interrupted } \\
\text { Educational }\end{array}$ & $\begin{array}{l}\text { Undergradu } \\
\text { ate Degree }\end{array}$ \\
& & Country & Fragile State & Journey & \\
\hline Primary & 10 & Yes & Yes & Yes & Yes \\
Sample & & & & & \\
& & & & &
\end{tabular}

\begin{tabular}{lccccc}
\hline $\begin{array}{l}\text { Alternative } \\
\text { Sample One }\end{array}$ & 13 & Yes & Yes & No & Yes \\
\hline Alternative & 9 & Yes & Yes & Yes & No
\end{tabular}

Sample Two 
Primary Sample. As a result of this winnowing process, the 10 women composing the main population of the study were from lower income countries, working on an undergraduate credential, and explicitly noted in their application that their educational journeys had been interrupted by conflict. Five were from Sub-Saharan Africa (SS Africa), four were from West Asia, and one was from South Asia. They ranged in age from 18-28 and were studying in a variety of fields. They also submitted their applications in English. The majority of them originated from countries that were low-income and/or that had recently been re-categorized from a lower-middle- to a low-income country. These re-categorizations were likely due to the same deteriorating conditions that forced several of these women to leave their homes.

Ethical considerations. Given the sensitive nature of the content within the scholarship applications, a great deal of care was taken to handle it appropriately. The original documents remained under the control of the Asherah Foundation Executive Board (on which this author currently serves as its president). The author went through the formal University of Missouri Institutional Review Board (IRB) evaluation process and maintained compliance with its parameters. All research was conducted on documents that already existed; no additional data was collected for this research. All information was recorded in such a manner that subjects could not be identified, directly or through identifiers linked to them. The subjects were not contacted, and care has been taken to not re-identify them.

When these women submitted their scholarship applications to the Asherah Foundation, they signed a waiver acknowledging that their information could be used in research. Although it would have been ideal to have these women more closely involved with this study, it was not ethically appropriate to reach out to them about this particular project. 
Given the author's role with the Asherah Foundation, any request made of applicants would have been problematic. Any requests for additional information or more detailed and informed consent would have involved the power dynamics between the author (as representative and funder of future scholarships) and the applicant as a future seeker of scholarships, making any consent, in effect, coerced. In addition, given the many demands on the applicants' time, asking them to become involved with a research project that was not going to directly impact their educational success would be an unnecessary burden.

Throughout this dissertation, efforts were made to balance the ways in which aspects of the applicants' lives were presented. The privacy of the applicants and need to protect personally identifiable information was the foremost consideration. In addition, effort was made to provide sufficient context for discussions while being mindful of the need to avoid exploiting their experiences (de Jong, 2017).

In order to achieve this balance, a number of choices were made about how and where to provide information about the applicants. The use of graphs to highlight findings in Chapter Four was decided upon in efforts to present patterns within the applicants' discourses without signaling any of them out. When providing descriptive details, compromises were made. For example, they are identified below as being one of two "ages." The first age, 19, represents those who were below the age of 24 when they submitted their applications. The average age of those applicants was 19.5. The decision to use 19 was made to contrast them more with the older women in the study. The average age of those 24 and older was 26.5 , therefore their age was noted as 27 in order to provide contrast with the younger women. When discussing the various aspects of their "nontraditional" student 
characteristics, they were noted in general terms (i.e. "familial responsibilities" instead of "three children" or "married").

In order to understand how they discussed the four Discourses, three sets of applicants were grouped together into mini "cohorts." Each of these three sets consisted of women with substantial overlap of characteristics and experiences. By talking about them more as a "cohort," it is hoped that relevant context will be able to be shared without providing personally-identifiable information and by highlighting the commonalities within their discussions. 
Table 10

Characteristics of Population of Study

\begin{tabular}{|c|c|c|c|c|c|c|}
\hline $\begin{array}{l}\text { Applicant } \\
\text { (Pseudonym) }\end{array}$ & Age & UIS Region & $\begin{array}{l}\text { Origin: } \\
\text { World Bank } \\
\text { Income } \\
\text { Level }^{3}\end{array}$ & $\begin{array}{l}\text { School } \\
\text { Location: } \\
\text { World Bank } \\
\text { Income Level }\end{array}$ & Degree Field & $\begin{array}{l}\text { Non-Traditional Student } \\
\text { Characteristics }\end{array}$ \\
\hline Amara & 19 & S. Asia & Lower-middle & Lower-middle & Medicine & First-in-family \\
\hline \multirow[t]{2}{*}{ Gaeti } & 19 & W. Asia & Low* & Upper-middle & $\begin{array}{l}\text { Architecture \& } \\
\text { Design }\end{array}$ & $\begin{array}{l}\text { Culturally \& Linguistically Diverse } \\
\text { (CLD) }\end{array}$ \\
\hline & & & & & & Refugee-background \\
\hline \multirow[t]{2}{*}{ Layan } & 19 & W. Asia & Lower-middle & Upper-middle & Health & $\begin{array}{l}\text { Culturally \& Linguistically Diverse } \\
\text { (CLD) }\end{array}$ \\
\hline & & & & & & Refugee-background \\
\hline \multirow[t]{5}{*}{ Laleh } & 27 & SS Africa & Low* & Low & Business & First-in-family \\
\hline & & & & & & Age: $24+$ \\
\hline & & & & & & Familial responsibilities \\
\hline & & & & & & Financial responsibilities \\
\hline & & & & & & $\begin{array}{l}\text { Culturally \& Linguistically Diverse } \\
\text { (CLD) }\end{array}$ \\
\hline \multirow[t]{2}{*}{ Lawan } & 27 & SS Africa & Low* & Lower-middle & Law & Age: $24+$ \\
\hline & & & & & & $\begin{array}{l}\text { Culturally \& Linguistically Diverse } \\
\text { (CLD) }\end{array}$ \\
\hline
\end{tabular}

${ }^{3}$ Note: Income level per World Bank FY2020 classification. World Bank data used here as UIS does not have detailed classification parameters. 


\begin{tabular}{|c|c|c|c|c|c|c|}
\hline Mahin & 27 & SS Africa & Low & Low & STEM & $\begin{array}{l}\text { Age: } 24+ \\
\text { First-in-family } \\
\text { Familial responsibilities } \\
\text { Financial responsibilities }\end{array}$ \\
\hline Moza & 19 & W. Asia & Low* & Upper-middle* & $\begin{array}{l}\text { Architecture \& } \\
\text { Design }\end{array}$ & $\begin{array}{l}\text { Culturally \& Linguistically Diverse } \\
\text { (CLD) }\end{array}$ \\
\hline Nifa & 27 & W. Asia & Low* & Upper-middle* & Finance & $\begin{array}{l}\text { Age: } 24+ \\
\text { Culturally \& Linguistically Diverse } \\
\text { (CLD) } \\
\text { Familial responsibilities } \\
\text { Financial responsibilities }\end{array}$ \\
\hline Rada & 27 & SS Africa & Low* & Low & Public Health & $\begin{array}{l}\text { Refugee-background } \\
\text { Familial responsibilities } \\
\text { Financial responsibilities }\end{array}$ \\
\hline Rayna & 27 & SS Africa & Low & Low & Economics & $\begin{array}{l}\text { Age: } 24+ \\
\text { Financial responsibilities }\end{array}$ \\
\hline
\end{tabular}

Note: * Income level of country was downgraded within the time period of this research (2016-2019) 
- Amara was the first in her family to access higher education. She lived in a lowermiddle-income country in South Asia. Her state was in the midst of ongoing violent conflict which had caused educational institutions to close. She was 19 and enrolled in a program in the medical/healthcare field as she wanted to be able to treat the injuries of her fellow citizens.

- Gaeti was 19 and had fled her home country as civil war had worsened. In addition to the ongoing conflict, her country's income level deteriorated to the point that it was downgraded from lower-middle- to low-income. She was a refugee in another country (also in West Asia), and had not been able to enroll in a higher education program due to the difficult financial situation her family was in. Her goal was to obtain a degree in the field of architecture/design that would enable her to help rebuild her country of origin once the violence ended. The program she wanted to enroll in was in a third country and in English (not her native language). This third country was an upper-middle-income country in East Asia.

- Layan was 19 and also a refugee in West Asia. Like Gaeti, she had fled from an ongoing conflict-affected situation. Like Amara, she wanted to obtain a degree in a healthcarerelated field to help her community. She was currently a refugee in an upper-middleincome country in West Asia.

- Laleh was 27 and also a refugee from a country in the midst of ongoing conflict. Her country in Sub-Saharan Africa had deteriorated to the point that its income level had been recategorized from lower-middle- to low-income. She was the first in her family to access higher education and wanted to use her degree to develop a community-based organization to help develop entrepreneurs by teaching entrepreneurial skills and 
assisting women to generate income so that they could then afford school dues for themselves and for their children. She had both familial and financial responsibilities.

- Lawan was 27 and from a low-income country enveloped in ongoing conflict in SubSaharan Africa. As with Laleh, her home country had also deteriorated economically. Her goal was to obtain a degree in a different country that would enable her "to advocate for the voiceless [e]specially women and children who are the most vulnerable people in our community."

- Mahin had lost her father at an early age as he was killed in her low-income country's civil war. She was 27 and had endured year of abuse by a guardian, battled an infection due to female genital mutilation (FGM), and marriage to another abusive older man (she was married when she was 17 and he was 60 ). When the patriarch of her family died, she was able to escape and begin to improve her life. She was the first in her family to get a secondary education due to the support of her community. She hoped to use her postsecondary education in STEM to provide development opportunities for this community. While enrolled in her program, she maintained both familial and financial responsibilities.

- Moza was a 19-year-old refugee from a low-income country in West Asia, wanting to obtain a post-secondary credential in order to help rebuild her country once the war was over. Like Gaeti, her home country had deteriorated economically to the point where it had been recategorized as low-income. Also, like Gaeti, she wanted to study Architecture \& Design in a third country in East Asia where higher-quality programs were offered in English (not her native tongue). 
- Nifa began pursuing an undergraduate degree in a high-income country but was forced to drop out when her father died, and her source of funding was no longer available. As her home country in West Asia was in the midst of ongoing violent conflict, she fled to a neighboring country. She learned the local language and was finally able to enroll in a completely new academic program in that country at the age of 27 . In addition to ongoing conflict, her home country had also deteriorated economically, being recategorized from a lower-middle-income country to a low-income country.

- Rada was from a low-income country in Sub-Saharan Africa and had spent her entire life in a refugee camp. She was pursuing a degree in public health. Her goal was to become a healthcare professional, and then begin training others in order to help address the shortage of qualified healthcare professionals in her country. She was 27 when she submitted her scholarship application. She maintained both financial and familial responsibilities.

- Rayna was 27 and had survived a number of ordeals in her country in Sub-Saharan Africa. She was kidnapped by rebels when she was six and held captive (enslaved) for years, losing her family and interrupting her schooling at the secondary level. She was fortunate to find a surrogate mother who took her in. Unfortunately, this woman was impoverished and then died in an Ebola outbreak. Rayna was pursuing her degree in economics with the goal of eventually helping children who had become homeless and family-less as a result of the war in her low-income country.

The experiences of the Asherah scholarship applicants were generally not reflected in the 2016 GEM Report. These 10 women had explicitly shared that their educational journeys had been interrupted by conflict. This decreases the likelihood that their experiences were 
captured in the 2016 GEM Report or in other forms of reporting due to the limitations of data gathering from conflict zones. As argued in Chapters One and Two, considering global efforts to support the development and increase the education of disenfranchised groups such as these women, it is important to understand ways in which women in these non-traditional settings (particularly those from lower income countries and areas of conflict) perceive their pursuit of higher education. 


\section{Methodological Considerations (Gee's Theoretical (Building) Tools and Building Tasks)}

Methods of analysis were shaped by both Norman Fairclough (2013) as discussed in Chapter Two and James Paul Gee (2014a, 2014b). The analysis was designed to look at how discourses were used in the various experiences of individual women in order to gain a better understanding of the ways in which these women discussed their access (or lack thereof) to higher education. The unique perspectives of those individuals who successfully accessed higher education, despite conflict, and despite other obstacles such as poverty, familial responsibilities, etc. are particularly important. This approach views the discourses of international organizations (IOs) such as the United Nations, academic researchers, and of the applicants to the Asherah scholarship program as forms of social practice that develop and reinforce social constructs that should be critically viewed.

As noted in Chapter Two, Fairclough's three-dimensional analytical framework provided the background for the methodological recommendations of Gee. Fairclough (2013) explains that each discursive event has "three dimensions or facets: it is a spoken or written language text, it is an instance of discourse practice involving the production and interpretation of text, and it is a piece of social practice" (p. 94). The discourse practice is what mediates the text with the social practice (p. 94).

This section will provide a brief overview of the methods for Critical Discourse Analysis (CDA) recommended by James Paul Gee (2014a, 2014b). These methods begin with ideas about what constitutes an "ideal" discourse analysis, including considerations about the validity of analysis. This section will then provide an overview of six specific tools for analysis that were used to investigate seven Building Tasks. Following this overview, the section will outline the specific ways in which Gee's suggested methodological approaches 
were used in this particular analysis. This included analysis of the context within which the data were created, as well as close reading of the data.

Ideal discourse analysis. Discourse analysis, in Gee's view, "needs to be critical... because language itself is...political” (Gee, 2014a, p. 9). For Gee, analysis consists of "looking closely at the structure of language as it is being used...[to] uncover different ways of saying things, doing things, and being things in the world" (p. 9). Such analysis should seek to explain the "rules" by which the author is writing. This involves ongoing reflection about the context within which the discourse is created, the context the discourse is itself (re)creating, and the context within which the act of analysis itself is being undertaken. Gee writes:

all discourse is critical discourse analysis, since all language is political and all language is part of the way we build and sustain our world, cultures, and institutions. So, then, too, all discourse analysis is "practical" or "applied," since it uncovers the workings - for good or ill - of this world building. (Gee, 2014a, p. 16)

A discourse analysis investigates the ways in which language is being used in a particular context (time, place, social environment) to shape the context, to (re)build identities, to build relationships, and to view the distribution of social goods. Gee (2014a) notes that an "ideal discourse analysis uses each of the [six] Tools of inquiry to ask questions about each [of] the [seven] Building Task[s]" for each piece of data (p. 140). This means a total of 42 questions per piece of data. He notes, however that "real discourse analysis only deals with some of the questions," as not all questions apply to all pieces of data (p. 141). Gee's (2014a) proposed method 'is not intended as a set of 'rules' to be followed 'step-by-step'” (p. 144). However, he outlines a general order of steps that may be 
considered. In considering these potential steps, it is worth bearing in mind his view that method and theory are intimately linked. The theory undergirding his recommendations for methods of CDA is that "language in use is about saying-doing-being and gains its meaning from the 'game' or practice it is a part of and enacts" (p. 11).

Gee recommends that analysis should begin with the selection of a piece of data. The analyst might then consider the ways in which the words in this piece of data are being used to build a certain reality within a specific context. He recommends beginning with six specific Theoretical (Building) Tools to understand this and seven Building Tasks, as follows.

Six Theoretical (Building) Tools. As noted above, Gee developed six tools with which to interrogate discourses. These tools "are centered in different theories (core ideas) about how language ties to the world and to culture" (Gee, 2014b, p. 156). As language is used to build realities, these tools help highlight the ways in which this is being done. As such, they are also considered "Building Tools" that are combined with identification of Building Tasks when analyzing discourses.

Situated Meaning. This Theoretical (Building) Tool helps to elucidate the particular meaning of words given the context of the discourse. Every word has "a range of typical meanings" (Gee, 2014b, p. 158). For example, the word "scholarship" has multiple possible meanings to people (as will be illustrated in the discussion of Building Tasks below). The specific meaning of a word is context-dependent. For example, the term scholarship, while essentially defined as "funding given for education" can mean different things to different people. The ways in which the Asherah Foundation uses the term scholarship differs from the ways in which the 2016 GEM Report discussed it. The applicants to the Asherah Foundation 
Second Chance Scholarship likewise give meaning to the term in their own way, based on their own context (e.g. financial, familial, political). The meaning of a word is thus dependent on the context of the situation within which the word is used. This means that analysts must consider both the context within which the writer used the word, and the context of the analysis (e.g. what prior experiences/assumptions does the analyst have which might influence the interpretation?). Analysts must also consider what assumptions the writer had about the audience they were writing for. For example, when writing about their desire for a scholarship, what assumptions did the applicants have about the meanings that the scholarship review committee gave to the word "scholarship"?

Social Languages. When writers create a discourse, they are not using a generic language, they are using very specific types of language. They use both regional variations (i.e. dialects) and social variations. Gee (2014b) defines "social languages as styles or varieties of a language (or a mixture of languages) that enact and are associated with a particular social identity" (p. 162). For example, a scholarship applicant uses a particular version of a language (e.g. English) that she was taught, but also uses a specific version of this language based upon the social role she is playing. Her word choices and grammatical structures in her application essays may be quite different from the ways in which she uses language when interacting with her parents, a spouse, or her children. If she is a physician or teacher, she likewise uses a different version of the language when interacting with her patients or students. Language is used "to enact specific socially-situated identities" (Gee, 2014b, p. 162) such as "scholarship applicant," "daughter," "wife," "mother," "doctor," or "teacher." 
Figured Worlds. Words are used in context. This context includes assumptions based "on stories, theories, or models in our minds about what is 'normal' or 'typical' (Gee, 2014b, p. 174). This, of course, varies by context. In some cases, this can be harmful as assumptions about what is "typical" may marginalize or otherwise harm people. For example, when talking about scholarships, many of the people in this author's orbit consider it "typical" to give them to young, promising people. In contract, giving 42-year-old mothers scholarships to go back to school is likely an alien world to many people. For many of the applicants, the world where a woman gets a college degree is also not familiar to them, thus discourses around access to higher education in their society may unintentionally exclude them.

Intertextuality. Quite simply, the theoretical tool of "intertextuality" involves looking at the ways in which one text "refers to, or alludes to another text" (Gee, 2014b, p. 171). This can be obvious if the writer is quoting another text or alludes to it (e.g. "my teacher said..."). Intertextuality is also useful to consider the context "when a text written in one style (in one social language associated with one identity) incorporates a style of language (a social language) associated with a different identity" (Gee, 2014b, p. 171). This might also occur when a writer mimics "the grammar or phrasing... of another text or style of language" (Gee, 2014b, p. 171).

Big “D” Discourse. As noted in Chapter Two, the term "Discourse" with a capital "D" may be thought of as a meta-narrative. As Gee (2014b) notes, acts or "communicative events" (Rogers \& Wetzel, 2013) of discourse (small “d”) take place in a larger societal context, which is driven by meta-narratives or Big D Discourses. People write with certain identities within certain social environments. These meta-narratives contain shared "conventions about how to use and interpret language" (Gee, 2014b, p. 182). They also share 
"distinctive ways [of] writing/reading" (Gee, 2014b, p. 183) which "are coupled with distinctive ways of acting, interacting, valuing, feeling, dressing, thinking, and believing...[which are in turn] coupled with ways of coordinating oneself with...other people" (Gee, 2014b, p. 183). "All this is in the services of enacting specific socially recognizable identities" (Gee, 2014b, p. 183). Discourses "are ways of recognizing and getting recognized as certain sorts of whos doing certain sorts of whats" (Gee, 2014b, p. 184). (Big "D" Discourse is not to be confused with "discourse" [with a small "d"] as "language in use" [Gee, 2014b, p. 183]).

Big "C" Conversation. Within the Discourses are ongoing thematic debates or issues (e.g. what is the purpose of education?). Gee uses the term Conversation (with a capital "C") to describe these debates. In the case of this particular analysis, Conversations might include debates about the value of education to individuals and/or to society, the appropriate levels of education for women, who bears the responsibility for financing education (Public sector? Private sector? Individuals?). In analyzing these applications, it will be instructive to consider in which Conversations the applicants are engaging and what side(s) they take. This is an integral part of defining one's identity and noting one's role in a society.

Seven Building Tasks. Gee (2014a) writes that "language-in-use" is "language actually used in specific contexts" (p. 19). It is more than just "an abstract system" - it is that system in specific contexts being used towards specific objectives. As Gee (2014a) notes, "We use language to build things in the world, to engage in world building, and to keep the social world going" (p. 31). This building is accomplished through various context-specific "building tasks." 
Building Tasks Sample Analysis. To help illustrate the ways in which these Tasks are used, this section will provide an overview of the ways in which Gee recommends using these tasks by using three related statements around the word scholarship.

- "I won a scholarship, now I can leave my abusive husband and go to school."

- "Let's offer a scholarship to a woman in need."

- "The playwright considered how to end the story and thought about having the character exclaim, 'I won a scholarship, now I can leave my abusive husband and go to school' but then changed his mind."

This overview will hopefully shed light on the ways in which these seven different ways of building discourses (socially-constructing realities) may be used in this analysis by briefly explaining the Building Task, noting the associated question(s) to ask of the text, and applying it to topics related to this analysis. These three statements (discourses) are about "scholarships," but may present very different realities.

Significance. The significance of a word in one context (e.g. "scholarship") may have a very different meaning in a different context. For example, let's consider: "I won a scholarship, now I can leave my abusive husband and go to school" versus "Let's offer a scholarship to a woman in need." The significance of the term "scholarship" in the first instance might mean freedom, a second chance, salvation, etc. In the second instance, it might mean a technical vehicle for providing a service, perhaps to get a tax deduction, or to increase the public image of a corporation. In order to analyze the significance of the term "scholarship" Gee (2014a) recommends that one ask how the language surrounding the term is "being used to make certain things significant or not" as well as in what ways the language is making (or not making) the term significant (p. 32). For example, the language 
surrounding the first instance would make the term "scholarship" very significant if this sentence were spoken by an actual abused woman who truly needed (and received!) a scholarship to escape her situation. It would not be nearly as significant if the language proceeding that sentence included "The playwright considered how to end the story and thought about having the character exclaim, 'I won a scholarship, now I can leave my abusive husband and go to school' but then changed his mind."

Practices (Activities). Gee (2014a) considers this Building Task to "mean a socially recognized and institutionally or culturally supported endeavor that usually involves sequencing or combining actions in certain specified ways" (p. 32). In the instance of a scholarship, the socially recognized endeavor is that financial contributions are being made on behalf of one entity to another entity to engage in an activity. Gee (2014a) writes that “language and practices 'boot strap' each other into existence in a reciprocal process through time" (p. 33). In order to discern the relationship between the language and practice, he recommends that the analyzer asks, "What practice (activity) or practices (activities) is this piece of language being used to enact (i.e., get others to recognize as going on)?" (Gee, 2014a, p. 33). In the three examples given above, the practice of giving/getting scholarships is illustrated in three very different ways. In the first, the activity of receiving a scholarship provides a welcome relief. In the second, the activity of giving a scholarship provides a good public relations solution. In the third, the practice of scholarships is being considered as a plot device.

Identities. Gee (2014a) asserts that language can be used to build identities (p. 33). The use of language can build up idealized identities, reconfigure identities, switch identities, etc. Language can be used to build up the identities of oneself and of others. In the 
act of communication, the context of the language provides the vehicle through which these identities are constantly being (re)created. In the first example above, the language builds up the identity of the speaker as a scholarship recipient who believe s/he has been abused. For the purposes of this exercise, it will be assumed that the speaker is female, although without additional context, we cannot know this. The context around the practice of "scholarships" implies that this person is also someone who is 1) interested in education, 2) academically proficient, and 3) proactive in seeking out resources. The second example implies that the speakers are 1) capable of providing a scholarship (financially, administratively), 2) care about women, and 3) consider "need" to be of greater importance at this moment than academic or athletic achievements. The focus on "need" may indicate a focus on economic development and/or human rights. It may be driven by sincere feelings of pity, guilt, or a desire for better public relations. The third example indicates that the playwright is a male, is aware of certain dynamics around education and marriage, and considers these dynamics to be of importance to a plot.

Relationships. Relationships are often built/changed/destroyed through language. The language we use signals the type of relationship we believe we have as well as the type of relationship we want and are closely tied to our identity/ies. As Gee points out, the "other(s)" in the communication may or may not be present. In the first example, the relationship(s) of the scholarship recipient may change based on the context. If the woman is making this statement to her mother, the relationship with the mother may, or may not, change depending on other contextual factors. For example, if the mother thought the marriage was a happy one, she may be surprised to learn that the marriage was, in fact, abusive. However, if the mother has been aware of this, the change in relationship might be 
a slight one with the mother's pride in her daughter being increased and her overall actions becoming more supportive. If the mother does not believe that the daughter should leave her marriage (e.g. due to religious or social mores) then the relationship might change into one of disapproval.

Politics. For Gee (2014a), politics involves "the nature of the distribution of social goods" (p. 34). The question he recommends is "What perspective on social goods is this piece of language communicating" (Gee, 2014a, p. 34). In the case of the scholarship recipient, she is communicating that her receipt of the scholarship is a good thing. She is communicating that her current situation is not good and may not in fact even be normal. The fact that she has 1) applied for a scholarship with the (presumed) intent of using it to leave her marriage, 2) received the scholarship, and 3) states that she can now leave her abusive marriage are all indicators of what she values. She is wanting the social good of education which she can presumably only obtain via the scholarship. She wants to trade the (in her mind) lesser good of her marriage for the greater good of going to school.

Connections. The question Gee (2014a) recommends asking about the way connections are "built" through discourse is: "How does this piece of language connect or disconnect things; how does it make one thing relevant or irrelevant to another" (p. 35). In the first example, the woman makes the scholarship tied to her freedom from a bad marriage. It is not clear whether or not the bad marriage is tied to the scholarship (e.g. the husband was jealous of his wife's interest in education and started abusing her). In the second example, the scholarship is tied to the speaker, the speaker's companion(s) [the use of the contraction "let us"] and their desire to give it to a woman in need. In the third example, the scholarship is connected to a character in a play and is used as a possible plot device. This 
scholarship is tied to the playwright's understanding of the role that a scholarship may (or may not) play in certain situations.

Sign Systems and Knowledge. Gee points out that languages (e.g. English), varieties of languages (e.g. scholarship applicants, scholarship donors, playwrights) and other communicative systems (e.g. the code used to create the software used to type this paper) are all different systems of signs. The way these systems are privileged (or not) in discourse says a lot about those engaging in the discourse as well as the context of the discourse. The three examples of discourse around a scholarship all privilege the English language. They all privilege ways of knowing about the world that have a certain level of resourcefulness and awareness. Not every woman who is abused will identify her husband as abusive. Not every woman who needs to escape a marriage will have the resourcefulness to seek out (much less obtain) a scholarship with the goal of using education to leave a bad situation. Not many people have the resources or awareness to 1) offer a scholarship or 2) think about giving it to a woman in need (and not a young academic superstar or talented athlete). Not many people are privy to the inner workings of a playwright. The relationships among the terms "woman" + "need" + "scholarships" are complex and are highly privileged in these three statements. There are many sign systems that are not privileged in any of these discourses. For example, Spanish is not privileged, and neither is the idea that a woman should stay in an abusive marriage. Explicit political, religious and economic ways of speaking about these situations are not privileged. Although the software used to write this paragraph is extremely important, it is not privileged in any of the statements. It is only acknowledged at all due to the nature of this discussion. 


\section{Research Questions}

This research begins with the basic question: $\underline{\text { How do nontraditional women from }}$ lower income countries and conflict-affected regions describe their journeys to higher education despite tremendous obstacles including violence and poverty? In this study, the question will be addressed by identifying how a specific subset of applicants to the Asherah Foundation Second Chance Scholarship talked about their educational experiences. For this analysis, the specific questions were focused on:

- What is: How do the women identify themselves and the role of education in their experiences?

- What might be: How do these discourses compare to women in similar situations?

- What else is possible: How might critiques regarding inequities be addressed?

\section{Analysis Process: Four Parts}

Analysis is inherently a political act "because language itself is...political" (Gee, 2014a, p. 9). As discourse is a way of (re)creating reality through shared ideas of identities, it is important to think about the ways in which discourse is being used. As Gee (2014a) pointed out, analysis can "foreground saying (information), doing (action), or being (identity)" (p.20). Following the three steps outlined in Chapter Two, this analysis looked at the discourse (text), the process of creating the discourse, and finally the social context within which the discourse was created (and was being analyzed):

- Part I: Context of the Situation

- Part II: Institutional Context

- Part III: Wider Societal Context

- Part VI: Reflections on Context 
The following sections provide an overview of the process of inquiry. This process involved several steps, centered around the analysis of the scholarship application essays from the 10 women at the center of this study. Reflections on context in the beginning and end of Chapter Four will provide bookends to the analysis. Table 11: Components of Discourse, CDA, and Parts of Analysis below ties each part of analysis to the research question(s) the step is meant to address, the general methods of analysis that were used, the phases of analysis in terms of the questions asked and finally, the specific rounds of analysis that were ultimately used to answer these questions. 
Table 11

Components of Discourse, CDA, and Parts of Analysis

\begin{tabular}{|c|c|c|c|c|c|c|c|c|}
\hline $\begin{array}{l}\text { Parts of } \\
\text { Analysis }\end{array}$ & $\begin{array}{l}\text { Analytical } \\
\text { Considerations }\end{array}$ & $\begin{array}{l}\text { Research } \\
\text { Questions }\end{array}$ & $\begin{array}{l}\text { Phase of } \\
\text { Analysis }\end{array}$ & $\begin{array}{l}\text { Analytic } \\
\text { Questions }\end{array}$ & Sample & Data & Tools of Analysis & $\begin{array}{l}\text { Rounds of } \\
\text { Analysis }\end{array}$ \\
\hline $\begin{array}{l}\text { Part I: Context of } \\
\text { Situation } \\
\text { What is? - } \\
\text { Preliminary } \\
\text { Content Analysis }\end{array}$ & $\begin{array}{l}\text { Data } \\
\text { Analysis of } \\
\text { language texts }\end{array}$ & $\begin{array}{l}\text { How do the } \\
\text { women identify } \\
\text { themselves and the } \\
\text { role of education } \\
\text { in their } \\
\text { experiences? }\end{array}$ & Phase 1 & $\begin{array}{l}\text { What are the key } \\
\text { terms? } \\
\text { How do these terms } \\
\text { fit with Discourses? }\end{array}$ & $\begin{array}{l}\text { All three } \\
\text { applicant groups }\end{array}$ & $\begin{array}{l}\text { Application } \\
\text { Essays }\end{array}$ & $\begin{array}{ll}- & \begin{array}{l}\text { Content } \\
\text { analysis (word } \\
\text { and phrase } \\
\text { frequencies) }\end{array} \\
\text { - } & \begin{array}{l}\text { Demographics } \\
\text { for each group }\end{array}\end{array}$ & $\begin{array}{l}\text { Round 1- } \\
\text { Identification of } \\
\text { Content (all } 3 \\
\text { groups) }\end{array}$ \\
\hline \multirow[t]{3}{*}{$\begin{array}{l}\text { Part II: } \\
\text { Institutional } \\
\text { Context } \\
\text { What is? Examine } \\
\text { what applicants } \\
\text { are } \\
\text { communicating }\end{array}$} & \multirow[t]{3}{*}{$\begin{array}{l}\text { Action } \\
\text { Analysis of the } \\
\text { processes of text } \\
\text { production (use of } \\
\text { applications to } \\
\text { communicate) }\end{array}$} & $\begin{array}{l}\text { What is? } \\
\text { How did they } \\
\text { discuss } \\
\text { themselves? } \\
\text { How did they } \\
\text { discuss the role of } \\
\text { education in their } \\
\text { lives?" }\end{array}$ & Phase 2 & $\begin{array}{l}\text { What are the } \\
\text { applicants } \\
\text { communicating via } \\
\text { these Theoretical } \\
\text { Tools? } \\
\text { - Figured } \\
\quad \text { Worlds } \\
\text { - Conversations } \\
\text { and Building Tasks? } \\
\text { - Identities } \\
\text { - Practices } \\
\text { - Social Goods? } \\
\text { Patterns? Outliers }\end{array}$ & \multirow[t]{3}{*}{ Primary sample } & \multirow[t]{3}{*}{$\begin{array}{l}\text { Application } \\
\text { Essays }\end{array}$} & \multirow[t]{3}{*}{$\begin{array}{ll}\text { Building Tasks } \\
\text { - } & \text { What } \\
& \text { Identities? } \\
\text { - } & \text { What } \\
& \text { Relationships? } \\
\text { - } & \text { What } \\
& \text { Practices? } \\
\text { - } & \text { What Politics } \\
& \text { (Social } \\
& \text { Goods)? } \\
\text { Theoretical } \\
\text { (Building) Tools } \\
\text { - Figured } \\
\quad \text { Worlds } \\
\\
\text { (assumptions } \\
\text { - about reality) } \\
\text { Conversations } \\
\text { (role of } \\
\text { identity) }\end{array}$} & $\begin{array}{l}\text { Rounds 2-3 } \\
\mathbf{2} \text { - Development of } \\
\text { Building Task Codes } \\
\mathbf{3} \text { - Analysis of } \\
\text { Building Task Codes }\end{array}$ \\
\hline & & $\begin{array}{l}\text { What is? What } \\
\text { power dynamics } \\
\text { do they operate } \\
\text { within? }\end{array}$ & Phase 3 & $\begin{array}{l}\text { How do these essays } \\
\text { align with } \\
\text { Discourses? }\end{array}$ & & & & $\begin{array}{l}\text { Round 4-6 } \\
\mathbf{4} \text { - Development of } \\
\text { Categories 5- } \\
\text { Analysis of } \\
\text { Categories } \\
\mathbf{6} \text { - Analysis of } \\
\text { Categories - by } \\
\text { Discourses }\end{array}$ \\
\hline & & $\begin{array}{l}\text { What is? What } \\
\text { power dynamics } \\
\text { do they operate } \\
\text { within? }\end{array}$ & Phase 4 & $\begin{array}{l}\text { How do these essays } \\
\text { align with } \\
\text { Conversations about } \\
\text { the role of education } \\
\text { in their lives? }\end{array}$ & & & & $\begin{array}{l}\text { Round 7-Analysis } \\
\text { of Categories - by } \\
\text { Conversations }\end{array}$ \\
\hline
\end{tabular}




\begin{tabular}{|c|c|c|c|c|c|c|c|c|}
\hline $\begin{array}{l}\text { Part III: Wider } \\
\text { Societal Context } \\
\text { What might be? }\end{array}$ & $\begin{array}{l}\text { Context } \\
\text { Analysis of the } \\
\text { events of } \\
\text { discourse as a } \\
\text { form of } \\
\text { sociocultural } \\
\text { practice }\end{array}$ & $\begin{array}{l}\text { What might be? } \\
\text { How do these } \\
\text { discourses } \\
\text { compare to } \\
\text { women in similar } \\
\text { situations? }\end{array}$ & Phase 5 & $\begin{array}{l}\text { What are the key } \\
\text { Connections? (What } \\
\text { are missed } \\
\text { Connections?) } \\
\text { What Sign Systems } \\
\text { \& Knowledge are } \\
\text { privileged? (What } \\
\text { Sign Systems \& } \\
\text { Knowledges are not } \\
\text { privileged?) }\end{array}$ & $\begin{array}{l}\text { Primary sample } \\
\text { with supporting } \\
\text { documentation } \\
\text { from two } \\
\text { alternate groups }\end{array}$ & $\begin{array}{l}\text { Application } \\
\text { Essays }\end{array}$ & 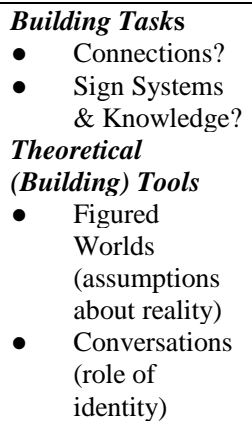 & $\begin{array}{l}\text { Round 8- } \\
\text { Reflection on } \\
\text { Context }\end{array}$ \\
\hline $\begin{array}{l}\text { Part VI: } \\
\text { Reflection o } \\
\text { Context } \\
\text { Critique of Power } \\
\text { Structures } \\
\text { (Reflections on } \\
\text { Context) }\end{array}$ & & $\begin{array}{l}\text { What else is } \\
\text { possible? How } \\
\text { might critiques } \\
\text { regarding } \\
\text { inequities be } \\
\text { addressed? }\end{array}$ & Phase 6 & $\begin{array}{l}\text { What are the key } \\
\text { Connections? (What } \\
\text { are missed } \\
\text { Connections?) } \\
\text { What Sign Systems } \\
\text { \& Knowledge are } \\
\text { privileged? (What } \\
\text { Sign Systems \& } \\
\text { Knowledges are not } \\
\text { privileged?) }\end{array}$ & Researcher & $\begin{array}{l}\text { Research } \\
\text { Journal }\end{array}$ & 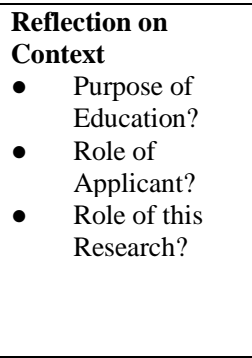 & $\begin{array}{l}\text { Round 9- } \\
\text { Reflection on } \\
\text { Context } \\
\text { (Researcher) }\end{array}$ \\
\hline
\end{tabular}




\section{Rounds of Analysis Overview}

Part I: Context of the Situation began with a simple analysis of content (e.g. word and phrase counts) of the application essays from the three groups of applicants (Table 9:

Primary and Alternate Samples). This preliminary content analysis highlighted major themes regarding both the perceived role(s) of education (e.g. transactional/transformative) and the identities presented by the applicants through their essays (e.g. victim/victor). Part II: Institutional Context used four of Gee's Building Tasks: Identities, Practices (activities), Relationships, and Politics to look more closely at the identities built by the women in their discourses. This part sought to understand how these women portray themselves and the role of education in their lives. Part III: Wider Societal Context used two other Building Tasks (Connections, and Sign Systems \& Knowledge) to identify "what might be" in order to identify possible structures of power within the broader context of these application essays. Part VI: Reflections on Context provided a critical look at identified structures of power, identified implications for future research, and to inform future operations of the Asherah Foundation Second Chance Scholarship Program.

\section{Part I: Context of the Situation}

As noted above, having a better understanding of "who applied" to this scholarship program was essential prior to beginning deeper analysis of individual discourses. In order to get a better picture of these applicants, preliminary content analysis was used to discern whether and how the Discourses identified in Chapter Two were reflected in the application essays of the three samples of applicants outlined in Table 9. This was done by looking at the frequency of words and phrases among the essays using an online tool: https://www.onlineutility.org/text/analyzer.jsp. 
Pre-Analysis. Prior to the initial round of analysis for this dissertation, I had undertaken abbreviated versions of several of these rounds on earlier groups of applicants. This involved initial coding of the identities, relationships, and practices of a previous cohort of applicants who had noted their educational journeys were impacted by violence. Through that analysis, it became more apparent that there might be significant differences between those applicants who explicitly noted that their educational journeys had been interrupted by violence, when compared to applicants from similar backgrounds who did not. It also supported the inclusion of new applicants from the 2018 Second Chance Scholarship Program. Much of that initial analysis informed the identification and focus on the various Discourses in Chapter Two, as well as the steps taken for analysis here.

Analysis: Round One. The initial round of formal analysis for this research was a content analysis of the essays from each of the applicants in the three groups. Prior to using the online tool, the data was "cleaned." This was done to standardize the essays by changing British English spelling to American English spelling. Obvious typos were also corrected. However, unusual grammar was left in the documents. The initial analysis looked at word lists generated by the online Tool. This Tool produced lists of single words in descending order of usage.

In order to get a sense of possible patterns, each of the words was then coded as follows:

- $\mathrm{E}=$ Education specific terms (e.g. university)

- $\$=$ Economic role of education $($ Discourse $=$ transactional $)$

- $\quad \mathrm{V}=$ Victimization (identity) 
- $\mathrm{X}=$ Words associated with agency (opposite of victimization) (identity) / (Discourse $=$ Transformational)

- $\mathrm{F}=$ Family (relationships)

- $\mathrm{C}=$ Community (relationships)

These codes reflected major thematic buckets aligned with discourses identified in Chapter Two about the possible identities of the applicant and the roles of education in their lives. After initial coding of word lists for each of the three cohorts, the word lists (and associated codes) were compiled into a single unified list of words with codes. This was done to ensure continuity of coding for each word across the three cohorts. Not every word received a code - notably those related to specific professions (e.g. dentistry) or words that did not seem to be associated with any of the discourses (e.g. the name of a specific bird).

The online Tool also generated lists of the most common phrases, however, it was not quite as useful as the word counts. Unusual grammar (perhaps the result of English not being a first language) distorted unity of phrasing. However, there were a handful of common phrases that stood out and will be discussed in Chapter Four.

Discussion. This content analysis confirmed that the Discourses outlined in Chapter Two were, indeed, included in these application essays. It also confirmed that identities, relationships, and "social goods" were integrated throughout. This initial content analysis provided the background for the next steps of analysis: Inquiry into Identities + Politics.

It was also used again in the final sections of the analysis: reflecting on the context of this research, power structures, and the ways in which Sign Systems and Knowledges were connected (or were not) throughout. This reflection helped frame discussion around the many implications for practice arising from this research as it shed light on ways in which these 
three interrelated (but distinct) groups of applicants may be better served in their quest to access education.

\section{Part II: Institutional Context}

Analysis Round Two: Using Building Tasks and Theoretical (Building) Tools to Create Codes. Given that these thematic buckets seemed to remain appropriate, I began analyzing the 10 application essays of the primary sample using 24 questions based on four of Gee's Building Tasks and six of his Theoretical Tools: 
Table 12

Building Tasks \& Theoretical Tools: Analysis Round Two

\begin{tabular}{ll}
\hline $\begin{array}{l}\text { Building Task (What part of "Reality" is } \\
\text { being built) }\end{array}$ & $\begin{array}{l}\text { Theoretical Tool (Investigating How } \\
\text { Language is Used to Build "Reality") }\end{array}$ \\
\hline Significance & Situated meaning \\
\hline Practices & Social languages \\
\hline Identities & Figured worlds \\
\hline Relationships & Intertextuality \\
\hline & Discourses \\
\hline & Conversations \\
\hline
\end{tabular}


I first went through each of the essays to note specific pieces of text aligned with each of the Building Tasks. (This was a continuation and refinement of earlier work done in Fall 2017). I then asked each of the 24 questions of a handful of essays. It quickly became apparent that Gee's Building Task of Significance was too broad of a term to be useful. I also found it helpful to think about the opposite of what was presented (e.g. this applicant identifies as a victim - who is the opposite of a victim [villain / victor] in this essay?). This strategy also helped highlight what else "may be possible." I also noted that identities were intimately tied to other individuals (relationships) and practices, and that many of the Tools seemed to provide similar responses for each of the Tasks.

The Theoretical Tools that most highlighted important Building Tasks (and the connections among them) were: Figured Worlds (what are the assumptions?) and Conversations. It also became apparent that the Building Task Politics was central to these essays. The "social goods" (and conversely, "social ills/bad") highlighted the roles (identities) each of the individuals played (e.g. the pursuit [or avoidance], the obtaining [or giving] of social goods) was tied to their practices and relationships with others. The Theoretical Tool Discourses overlapped considerably with the Identities Building Task. The Theoretical Tool Social Languages simply combined Identities with Practices that were already apparent via Relationships, and the Building Tool Conversations seemed to highlight the role of education in each applicant's experience, and thus the relation of their identities and practices to this role.

Discussion. This initial analysis highlighted the roles and identities discussed in Chapter Two. One notable finding was that the identity of "Savior" (and conversely, "Villain") had not been articulated, yet was frequently discussed. The frequent identification 
of the applicant as a "savior" was possibly due to the requirement that these essays address how the applicant would "help" their communities. Similarly, the focus on the need for a "second chance" may have encouraged applicants to highlight the ways in which they had been victimized by another (a "villain").

With a focus on the identities (of applicants and of others), practices, and social goods (to identify the Politics Building Task) I went back to the buckets of word lists. I segmented each of the buckets into: Identities (I am), Practices (I do), and Social Goods (I have). This segmentation highlighted additional sub-themes in each of the buckets. In order to better understand how each of these sub-themes was used (or not) across the essays, I decided to develop a series of codes. Through an iterative process, I created a chart of codes relating to the identities, practices, social goods, and relationships that built the Discourses used in the application essays. They were broken into three overlapping and interconnected themes: 1) education, 2) community (society), and 3) narratives around agency/victimhood. 
Table 13

Chart of Codes

\begin{tabular}{|c|c|c|c|}
\hline Category & $\begin{array}{l}\text { Identities } \\
\text { (Subject) } \\
\text { Person/Entity (Identities) (PID) }\end{array}$ & $\begin{array}{l}\text { Practices } \\
\text { (Verb) }\end{array}$ & $\begin{array}{l}\text { Social Goods } \\
\text { (Object) } \\
\text { Noun (social good) (NSG) }\end{array}$ \\
\hline \multirow[t]{8}{*}{ Education } & PID: [Acad. Amin.] & Practice: To do Acad. Work & NSG: [Acad. Degree/Credential] \\
\hline & PID: [Acad. Prof.] & Practice: To be Credentialed (graduated) & NSG: [Acad. Exam / Test] \\
\hline & PID: [Acad. Colleague] & Practice: To be Examined (for credentials) & NSG: [Acad. Finances] \\
\hline & PID: [Skilled Professional] & Practice: To Educate (teach others) & NSG: [Acad. Institution] \\
\hline & PID: [Acad. STUDENT] & Practice: To Have Career (pro work) & NSG: [Acad. Program (education)] \\
\hline & PID: [Acad. GRADUATE] & Practice: To Seek Education & NSG: [Acad. Work] \\
\hline & PID: Asherah Fdn. & Practice: To Seek Finances & NSG: [Career] \\
\hline & & & NSG: [Asherah Fdn. Scholarship] \\
\hline \multirow{7}{*}{$\begin{array}{l}\text { Family/ } \\
\text { Community }\end{array}$} & PID: Self & Practice: Strengthen Fam. & NSG: Trauma (social bad) \\
\hline & PID: Fam. 1 & Practice: Weaken Fam. & NSG: Burden/Adversity \\
\hline & PID: Fam 2. & Practice: Strengthen Com. & NSG: Challenge (social bad) \\
\hline & PID: Dependents & Practice: Weaken Com. & NSG: Safety (state of equanimity) \\
\hline & PID: Com. 1 & & NSG: Support \\
\hline & PID: Com. 2 & & NSG: Success! \\
\hline & & & NSG: Savior Status \\
\hline \multirow[t]{2}{*}{ Discourses } & PID: Villain 1 - Evil & Practice: Injure / be villainous 1 & NSG: Trauma (social bad) \\
\hline & PID: Villain 2 & Practice: Injure / be villainous 2 & NSG: Burden/Adversity (social bad) \\
\hline \multirow[t]{5}{*}{ No Agency } & PID: Victim & Practice: Be Victimized & NSG: Challenge \\
\hline & PID: Recipient of Being Saved & Practice: Being Saved & \\
\hline & PID: Survivor & Practice: Survive & NSG: Safety \\
\hline & PID: Fighter & Practice: Fight (demonstrates agency) & NSG: Support \\
\hline & PID: Victor & Practice: Triumph & NSG: Success! \\
\hline More Agency & PID: Savior - Victor+ & Practice: Save Others (also support others) & NSG: Savior Status \\
\hline
\end{tabular}


To confirm the appropriateness of these codes, I went through each of the words in each of the buckets and tagged it with one of the codes - consolidating/refining as I went through each of the lists. As with the earlier analysis, I often asked if there was an opposite identity/practice/social good that could be identified.

Analysis Round Three: Coding the Essays. For the next step of analysis, I broke up each essay into stanzas. I tagged each stanza with the appropriate codes. The stanzas were generally broken up by phrases with a subject (identity), object (social good) and verb (practice). Thus, each stanza received a code for the identity(ies), practice(s), and "social goods" that were featured. I also noted whether or not the applicant considered these to be "normal" or "not normal" - highlighting assumptions about what should (or should not) be, and thus how the Theoretical Tool Figured Worlds was used to build the Discourses around access to education. A stanza was considered to be discussing an applicant's normallyfigured world if it seemed aligned with an applicant's assumptions about how her world should be. For example, Rada stated that once she completed her education, she would “ further share [her] knowledge and skills gained with other personnel through teaching and supervision at training institutions in my country." This assertion of her ability to carry out her plans indicated that she assumed her world would continue to have an element of continuity and highlighted her confidence in her ability to carry out her goals. In contrast, stanzas considered to be discussing her dis-figured world were identified by comments indicating some level of a change in expectations, or a surprise. Mahan's statement is illustrative: "I thought that secondary education would have allowed me to acquire a college education through a reasonable employment but to the contrary, the fourteen year civil war has broken the economy of Liberia, my country and unemployment is very high" (bold 
mine). The use of the word "but" in combination with the contrast between two competing realities (access to reasonable employment vs. broken economy) indicates that her normallyfigured world was no longer her reality. Amara provides another example: "My parents have always tried to provide me with best education, even though money has always been an issue. With growing expenses, it has become harder for them to support me in pursuing my career in medical field [sic]." Her normally-figured world included her parents' ability to support her. This reality has been interrupted, creating a dis-figured world where her parents were not able to support her.

I also noted whether the stanza was referring to the applicant, or to someone (or something) else. This helped to highlight the relationships between the applicants and others. There were a total of 435 stanzas, resulting in 1305 Building Task Codes.

Approximately two-thirds (63\%) of the stanzas discussed what they considered to be a "normal" world as illustrated here in Table 14: Distribution of Building Task Codes. 
Table 14

Distribution of Building Task Codes

\begin{tabular}{l|ccc|ccc|ccc}
\hline & \multicolumn{3}{|c|}{ Applicant } & \multicolumn{3}{c|}{ Others } & \multicolumn{3}{c}{ Both Applicant and Others } \\
\cline { 2 - 9 } $\begin{array}{l}\text { Number of } \\
\text { Building } \\
\text { Task Codes }\end{array}$ & Normal & $\begin{array}{c}\text { Not } \\
\text { Normal }\end{array}$ & Total & Normal & $\begin{array}{c}\text { Not } \\
\text { Normal }\end{array}$ & Total & Normal & Not & Total \\
\cline { 2 - 9 } & 552 & 234 & 786 & 258 & 261 & 519 & 810 & 495 & 1306
\end{tabular}

Throughout the coding process, several additional codes were created:

Table 15

Additional Codes

Identities (Person/Entity

(Identities) (PID))

PID: [Acad. GRADUATE]

PID: Asherah Fdn.

PID: Fighter

\section{Practices}

Practice: To do Acad. Work

Practice: To Seek Education

Practice: To Seek Finances

Practice: Being Saved

Practice: Fight (demonstrates

agency)

Practice: Save Others
Social Goods (Noun (social good) (NSG))

NSG: [Asherah Fdn. Scholarship]

NSG: Safety 
These codes were not in the original list as they were not explicitly highlighted in the initial content analysis based on word counts.

The coding revealed the ways in which the applicants tended to highlight various aspects of their experiences. Given that the essays were written to elicit a positive response from the Scholarship Review Committee, it makes sense (in retrospect) that codes associated with a static experience were not used much. For example, the codes associated with achieving a state of safety and well-being were not used:

- Identity: Recipient of Being Saved

- Practice: Being Saved

- Social Good: Safety

Applicants were much more likely to highlight either the ways in which they had suffered (been victimized) or in which they were fighting for a better world - especially on behalf of others in their families and communities.

Highlighting parts of the essays where applicants were discussing others provided information on the Building Task of Relationships. The distribution of Building Task Codes among the essays is seen in Table 16: Building Task Code Distribution. 
Table 16

Building Task Code Distribution

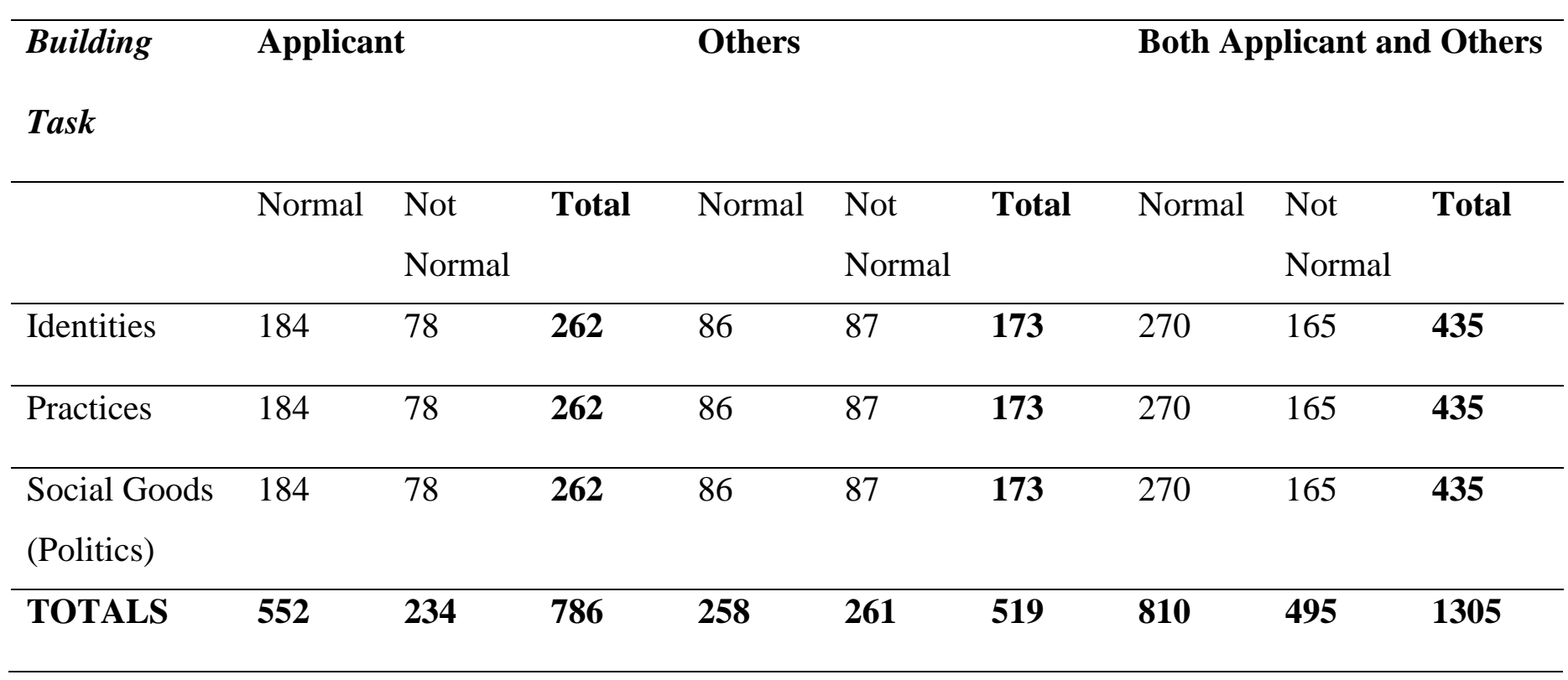


This initial observation highlights that the majority of the codes were used to describe the applicant in her normally-figured world $(n=543)$. This means that there were 184 stanzas, composed of 184 codes related to her Identity, 184 related to her Practices, and 184 related to her Politics (social goods). These numbers are significant, as they represent almost $42 \%$ of the 435 stanzas.

Analysis Rounds Four and Five: Categorizing the Codes. Given that there was a total of 1,293 codes, I decided to categorize them based on the thematic buckets, or Categories (Round Four). This categorization helped to identify patterns to note the ways in which the essays were (or were not) aligned with the Discourses identified in Chapter Two: regarding student identities, and the role of education in their lives, specifically: Transactional Victims, Transformational Victims, Transactional Victors, and Transformational Victors.

Nine different categories were identified: Financial, the Asherah Foundation, Academics, Academic-Financial, Agency (victory), Victimization, Social (generic), Villainy, and Comprehensive Education. The Financial category focused on economic aspects in the applicant's worlds. This included discussions around "getting a job" or financially providing for someone. The Academics category was focused on aspects of education connected to academics, such as a specific academic program, or development of new knowledge through research. The Academic-Financial category focused on discussion around topics pertaining to both academics and economics. This included paying for school, scholarships, and the role of education on economic development.

The category of Comprehensive Education was created to be inclusive of Financial, Academics, and Academic-Financial categories - encompassing aspects of education from 
the neoliberal (transactional) to the transformative. This code was used initially. However, when looking at the ways in which the scholarship application essays were aligned (or not) with Discourses around the roles of education (transactional/utilitarian - transformational), it became apparent that there was a need to further differentiate among the three segments of the Comprehensive Education category. As the two categories Agency and Victimization were used extensively, the Comprehensive Education category was used in some analyses to highlight the ways in which agency and victimization were in conversation with education more generally. Likewise, some analysis used the generic Social category for identities, but switched to agency or victimization based on the context of the stanza. 
Table 17

Categories

\begin{tabular}{ll}
\hline Category & Code used in Analysis \\
\hline Academic-Financial & ACAD-\$\$ \\
\hline Academics & ACAD \\
\hline Agency (victory) & S_Acy \\
\hline Asherah Foundation & A Fdn \\
\hline Education (Comprehensive) & ACAD $\$ \$$ \\
\hline Financial & \$\$ \\
\hline Social (generic) & SOCIAL \\
\hline Victimization & S Vctm \\
\hline
\end{tabular}

Each code was assigned to a category. Using the categories made it easier to identify trends within the essays overall, as well as within each stanza (Round Five). They were looked at in terms of normal or abnormal situations (Figured or Dis-figured Worlds) and whether or not the stanza referred to the applicant or to someone else. Out of 435 stanzas, 270 referred to normal scenarios while 165 referred to abnormal scenarios (dis-figured worlds). The majority $(n=262)$ referred to the applicants, while only 173 referred to others as illustrated here in Table 18: Overview of Stanza Distribution. 


\section{Table 18}

Overview of Stanza Distribution

\begin{tabular}{lrcr}
\hline Subject of Stanza & Normal & Not Normal & Total \\
\hline Self (Applicant) & 184 & 78 & $\mathbf{2 6 2}$ \\
\hline Other & 86 & 87 & $\mathbf{1 7 3}$ \\
\hline Total & $\mathbf{2 7 0}$ & $\mathbf{1 6 5}$ & $\mathbf{4 3 5}$
\end{tabular}

Identifying patterns in how categories were combined within stanzas was also useful. Amara's statement is an example: "I decided that I will attain a career as a doctor since from the very childhood." Within this stanza, she is referring to herself (not others). Given the emphasis on this statement (since from the very childhood) it seems as though this is not a normal thing in her world. Thus, the three Building Task Codes are classified as describing the applicant and describing an abnormal scenario. In this stanza, she identifies herself as wanting to get education to become a doctor, hence the code used was: PID: [Skilled Professional]. This code falls into the Comprehensive Education category (ACAD \$ \$). The practice she is referring to is attaining a career, which was coded: Practice: To Have Career (pro work). This code also is in the broad Comprehensive Education category. Finally, the social good referred to is a career, coded as NSG: [Acad. Program]/CAREER. This code also falls under the comprehensive education category (ACAD\$\$). 


\section{Example 1:}

\begin{tabular}{|l|l|l|l|l|l|}
\hline Stanza & $\begin{array}{l}\text { Normal or } \\
\text { NOT? }\end{array}$ & Analysis & $\begin{array}{l}\text { Identities }- \\
\text { Applicant }\end{array}$ & $\begin{array}{l}\text { Practices - } \\
\text { Applicant }\end{array}$ & Social Goods \\
\hline $\begin{array}{l}\text { I decided that I } \\
\text { will attain a career } \\
\text { as a doctor since } \\
\text { from the very } \\
\text { childhood. }\end{array}$ & $\begin{array}{l}\text { NOT } \\
\text { normal }\end{array}$ & $\begin{array}{l}\text { Building } \\
\text { Task Codes }\end{array}$ & $\begin{array}{l}\text { PID: [Skilled } \\
\text { Professional] }\end{array}$ & $\begin{array}{l}\text { Practice: To } \\
\text { Have Career } \\
\text { (pro work) }\end{array}$ & $\begin{array}{l}\text { NSG: [Acad. } \\
\text { Program] / } \\
\text { CAREER }\end{array}$ \\
\cline { 2 - 6 } & normal & Categories & ACAD\$\$ & ACAD\$\$ $\$$ & ACAD\$\$\$ \\
\hline
\end{tabular}

In two more examples, she talks about others, describing more scenarios that she considers to be not normal. In Example 2: "I continue to see people in [my state] facing hardships due to ongoing conflict, as daily trauma become[s] a routine" and Example 3: "it seems there is a deliberate attempt to cause eye injuries."

\section{Example 2:}

\begin{tabular}{|l|l|l|l|l|l|}
\hline Stanza & $\begin{array}{l}\text { Normal or } \\
\text { NOT? }\end{array}$ & Analysis & $\begin{array}{l}\text { Identities - } \\
\text { Others }\end{array}$ & $\begin{array}{l}\text { Practices - } \\
\text { Others }\end{array}$ & $\begin{array}{l}\text { Social Goods } \\
- \\
\text { Others }\end{array}$ \\
\hline $\begin{array}{l}\text { I continue to see } \\
\text { people in [my } \\
\text { country] facing } \\
\text { hardships due to } \\
\text { ongoing conflict, } \\
\text { as daily trauma } \\
\text { become[s] a } \\
\text { routine. }\end{array}$ & $\begin{array}{l}\text { NOT } \\
\text { normal }\end{array}$ & $\begin{array}{l}\text { Building } \\
\text { Task Codes }\end{array}$ & PID: Com. 2 & $\begin{array}{l}\text { Practice: Be } \\
\text { Victimized }\end{array}$ & $\begin{array}{l}\text { NSG: } \\
\text { Trauma } \\
\text { (social bad) }\end{array}$ \\
\cline { 2 - 5 } & & Categories & S_Vctm & S_Vctm & S_Vctm \\
\hline
\end{tabular}




\section{Example 3:}

\begin{tabular}{|l|l|l|l|l|l|}
\hline Stanza & $\begin{array}{l}\text { Normal or } \\
\text { NOT? }\end{array}$ & Analysis & $\begin{array}{l}\text { Identities - } \\
\text { Others }\end{array}$ & $\begin{array}{l}\text { Practices - } \\
\text { Others }\end{array}$ & $\begin{array}{l}\text { Social Goods } \\
- \\
\text { Others }\end{array}$ \\
\hline $\begin{array}{l}\text { it seems there is a } \\
\text { deliberate attempt } \\
\text { to cause eye } \\
\text { injuries }\end{array}$ & $\begin{array}{l}\text { NOT } \\
\text { normal }\end{array}$ & $\begin{array}{l}\text { Building } \\
\text { Task Codes }\end{array}$ & $\begin{array}{l}\text { PID: Villain } \\
1 \text { (Evil) }\end{array}$ & $\begin{array}{l}\text { Practice: } \\
\text { Injure / Be } \\
\text { Villainous 1 }\end{array}$ & $\begin{array}{l}\text { NSG: } \\
\text { Trauma } \\
\text { (social bad) }\end{array}$ \\
\cline { 2 - 6 } & $\begin{array}{l}\text { NOT } \\
\text { normal }\end{array}$ & Categories & Villain & Villain & S_Vctm \\
\hline
\end{tabular}

The categories for these three examples are:

\section{Table 19}

Categories for Each Building Task in Example Stanzas

\begin{tabular}{lll}
\hline Building Task (BT) 1 & Building Task (BT) 2 & Building Task (BT) 3 \\
\hline Identities & Practices & Social Goods \\
& & \\
\hline ACAD $\$ \$$ & ACAD\$\$ $\$$ & ACAD\$\$ $\$$ \\
\hline Social & S_Vctm & S_Vctm \\
\hline Villain & Villain & S_Vctm
\end{tabular}

They were further analyzed in terms of the three Building Tasks: Identities, Practices, and Social Goods. This round highlighted important patterns. For example, applicants overwhelmingly described themselves as having agency in normal situations. They tended to describe others as victims and focused more on others when describing abnormal situations (dis-figured worlds). 
Table 20: Category Distribution lays out the ways in which each category was used throughout the essays. For example, the most commonly used category for the Building Task of Identities was that of Agency (S_Acy). This category was used as an identity a total of 158 times, with the majority $(n=120)$ being used to describe the identity of the applicant (applicant as agent). The category Agency was also used to describe a practice 199 times (having agency), with 125 of those times referring to the practices of the applicant. As may be expected from scholarship applications, the most important "social good" was that of education (broadly defined), with Building Task Codes in this category being used 151 times. Overall, these essays portrayed the applicants as agents, practicing agency to obtain the social good of education. 
Table 20

Category Distribution

\begin{tabular}{|c|c|c|c|c|c|c|c|c|c|c|}
\hline \multirow{2}{*}{$\begin{array}{l}\text { Building } \\
\text { Task (BT) }\end{array}$} & \multirow[t]{2}{*}{ Category } & \multicolumn{3}{|c|}{ Applicant } & \multicolumn{3}{|c|}{ Others } & \multicolumn{3}{|c|}{ Both Applicant and Others } \\
\hline & & Normal & $\begin{array}{c}\text { Not } \\
\text { Normal }\end{array}$ & Total & Normal & $\begin{array}{c}\text { Not } \\
\text { Normal }\end{array}$ & Total & Normal & $\begin{array}{c}\text { Not } \\
\text { Normal }\end{array}$ & Total \\
\hline \multirow{7}{*}{ Identities } & Education* & 56 & 12 & 68 & 6 & 3 & 9 & 62 & 15 & 77 \\
\hline & Asherah Foundation & 0 & 0 & 0 & 21 & 3 & 24 & 21 & 3 & 24 \\
\hline & Agency & 100 & 20 & 120 & 24 & 14 & 38 & 124 & 34 & 158 \\
\hline & Victimization & 26 & 45 & 71 & 19 & 42 & 61 & 45 & 87 & 132 \\
\hline & Social & 2 & 1 & 3 & 14 & 8 & 22 & 16 & 9 & 25 \\
\hline & Villain & 0 & 0 & 0 & 2 & 17 & 19 & 2 & 17 & 19 \\
\hline & Totals & 184 & 78 & 262 & 86 & 87 & 173 & 270 & 165 & 435 \\
\hline \multirow[t]{7}{*}{ Practices } & Education* & 61 & 13 & 74 & 4 & 1 & 5 & 65 & 14 & 79 \\
\hline & Asherah Foundation & 0 & 0 & 0 & 0 & 0 & 0 & 0 & 0 & 0 \\
\hline & Agency & 103 & 22 & 125 & 54 & 20 & 74 & 157 & 42 & 199 \\
\hline & Victimization & 19 & 43 & 62 & 24 & 45 & 69 & 43 & 88 & 131 \\
\hline & Social & 1 & 0 & 1 & 0 & 0 & 0 & 1 & 0 & 1 \\
\hline & Villain & 0 & 0 & 0 & 4 & 21 & 25 & 4 & 21 & 25 \\
\hline & Totals & 184 & 78 & 262 & 86 & 87 & 173 & 270 & 165 & 435 \\
\hline \multirow{7}{*}{$\begin{array}{l}\text { Social } \\
\text { Goods }\end{array}$} & Education* & 79 & 36 & 115 & 16 & 20 & 36 & 95 & 56 & 151 \\
\hline & Asherah Foundation & 18 & 1 & 19 & 13 & 2 & 15 & 31 & 3 & 34 \\
\hline & Agency & 77 & 17 & 94 & 37 & 18 & 55 & 114 & 35 & 149 \\
\hline & Victimization & 9 & 24 & 33 & 18 & 35 & 53 & 27 & 59 & 86 \\
\hline & Social & 1 & 0 & 1 & 0 & 0 & 0 & 1 & 0 & 1 \\
\hline & Villain & 0 & 0 & 0 & 2 & 12 & 14 & 2 & 12 & 14 \\
\hline & Totals & 184 & 78 & 262 & 86 & 87 & 173 & 270 & 165 & 435 \\
\hline $\begin{array}{l}\text { All } \\
\text { Building } \\
\text { Tasks }\end{array}$ & TOTAL & 552 & 234 & 786 & 258 & 261 & 519 & 810 & 495 & 1305 \\
\hline
\end{tabular}

*Comprehensive Education composed of the three categories: Academics, Academic-Financial, and Financial 
Analysis Rounds Six and Seven: Categories, Discourses and Conversations. The combination of categories within each stanza was looked at next. This step was a way of looking more at how these essays were aligned with (or not) Discourses around education (Round Six), and thus the Conversations that the applicants were engaging in (Round Seven). It helped highlight the extent to which they talked about each category in terms of the other categories - for example, the proportion of times that academics was discussed in stanzas focused on agency, victimization, or finances.

These categories were looked at in terms of the Discourses and critiques noted in Chapter Two. The distribution and interaction of codes in categories relating to agency, victimization, and villainy were looked at to ascertain patterns relating to power dynamics within the essays. I also looked at the patterns of category usage in terms of the four Discourses outlined in Chapter Two. Discourses around the role of education as transactional were identified by looking at the number and distribution of codes in the three categories: Financial (\$\$), Academic (ACAD), and Academic Financial (ACAD-\$\$) together as a "Transactional Block." Categories associated with Discourses around education as transformative included almost all of the categories. The generic Social category was included in this Transformational Block as Discourses around the role of education as transformative highlight its potential to impact society, whether at the family or community level. The categories pertaining to agency, victimization, and villainy were also included. Finally, two of the three categories pertaining to education were included: Academics (ACAD) and Academic-Financial (ACAD-\$ - focused on the intersection of academics and economics (i.e. scholarships). The only category not included was Finances $(\$ \$ \$)$ pertaining only to economics. Similarly, a Victimization Block was composed of codes in the categories 
of Victimization (S_Vctm), Social (generic), and Villainy (VILLAIN). Patterns within these blocks were looked at to learn more about the tendencies of applicants to highlight either themselves or others, and normal or abnormal situations when discussing these four themes.

Finally, these blocks were re-combined into blocks aligned with the four Discourses: Transactional Victims, Transformational Victims, Transactional Victors, and Transformational Victors. Please see Table 21: Categories in each Discourse Block. 
Table 21

Categories in each Discourse Block

\begin{tabular}{|c|c|c|c|c|}
\hline \multirow[t]{2}{*}{ Category (Code) } & \multicolumn{2}{|c|}{ Transactional } & \multicolumn{2}{|c|}{ Transformational } \\
\hline & Victim & Victor & Victim & Victor \\
\hline Academic-Financial (ACAD-\$\$) & $(\mathrm{ACAD}-\$ \$)$ & $(\mathrm{ACAD}-\$ \$)$ & & \\
\hline Academics (ACAD) & & & $(\mathrm{ACAD})$ & $(\mathrm{ACAD})$ \\
\hline Agency (victory) (S_Acy) & & (S_Acy) & & (S_Acy) \\
\hline \multicolumn{5}{|c|}{ Comprehensive Education (ACAD $\$ \$ \$$ ) } \\
\hline Financial $(\$ \$ \$)$ & $(\$ \$ \$)$ & $(\$ \$ \$)$ & & \\
\hline \multicolumn{5}{|l|}{ Social (generic) (SOCIAL) } \\
\hline Victimization (S_Vctm) & $\left(\mathrm{S} \_\right.$Vctm $)$ & & $\left(\mathrm{S} \_\right.$Vctm) & \\
\hline Villainy (VILLAIN) & (VILLAIN) & & (VILLAIN) & \\
\hline
\end{tabular}


Neither the categories of the Asherah Foundation (A Fdn), or the Comprehensive Education (ACAD\$\$) were included in these Discourse Blocks. The Asherah Foundation Category was not used as it was not a part of the Discourses discussed in Chapter Two. The Comprehensive Education (ACAD\$\$) cCategory was not used in these four Discourses as it was separated into its three components for the purposes of distinguishing between the Transactional and Transformational Discourses.

\section{Beyond the 10 Application Essays}

Part III: Wider Societal Context. This part of the analysis used two other Building Tasks (Connections, and Sign Systems \& Knowledges) to identify "what might be" in order to identify and critique possible structures of power within the broader societal context of these 10 application essays. These analyses were conducted through the lens of the "wider societal context."

Analysis Round Eight: Reflection on Context. This step of the analysis looked at the key Connections made by the 10 women of the primary sample, as well as possible missed connections. Key connections were considered as the most frequent stanzas while missed connections were considered by looking at those stanzas that were rarely used - either once, or not at all. It also sought to identify which Sign Systems and Knowledges were privileged as well as those that were ignored. This was done by looking at patterns within the stanza blocks: Transformative Victor, Transformative Victim, Transactional Victor, Transactional Victim, and by asking how these varied in terms of focus on the applicants or others, and within normally-figured worlds or dis-figured worlds.

In order to reflect on the context of the essays from these 10 women, the two alternate samples of women were once again used (Table 9: Primary and Alternate Samples). The 
essays for both alternate samples were categorized in a simplified manner. The similarities and differences among the three samples provided insights into connections that were common to all or that were only seen in one of the groups. Likewise, each group highlighted slightly different Sign Systems and Knowledges as would be expected given their unique characteristics. This identification helped address the question "what else might be possible?" for the main population of study. It also highlighted aspects of the analysis that supported Gee's criteria for validity: convergence, agreement, and coverage (2014a, p. 142).

Part VI: Reflections on Context, provided a critical look at identified structures of power, identified implications for future research, and to inform future operations of the Asherah Foundation. This part also highlighted additional Discourses for IOs to engage in.

Analysis Round Nine: Reflection on Context - Research (and Researcher). The final round of analysis reflected on the wider societal context within which the applications were written and within which this research was conducted. It considered both the key connections for the researcher as well as the missed connections. As with the previous phase of analysis, it also looked at the ways in which Sign Systems and Knowledges were privileged in this research, as well as which ones were not privileged. This round looked more closely at how the researcher discussed three main topics within her research journal: the purpose of education, the role(s) of the applicant(s), and the role of research itself. The results of this analytical round informed discussion about the strengths and weaknesses of this study and highlighted potential areas for future research.

Validity. In conducting the research, an analyst should, according to Gee (2014a), look for reoccurring themes in the answers to the questions that are asked of the data, both in terms of overarching research questions, but also in terms of those of the 42 questions 
mentioned above (p. 143), as applicable. In alignment with theories of social construction, Gee (2014a) asserts that:

[v]alidity is not constituted by arguing that a discourse analysis 'reflects reality' in any simple way. All reality is socially constructed, thus any attempt to understand 'reality' is an interpretation in a specific context. This interpretation involves interrogating another's (speaker's/writer's) socially-constructed reality and their own interpretation of it. This discourse analysis is "an interpretation of an interpretation" (p. 141).

A "valid" analysis for Gee, means that the "analysis explains things that any future investigation of the same data, or related data, will have to take seriously into account" (Gee, 2014a, p. 143). He argues that four elements constitute this validity. The first, “convergence," provides a measure of "trustworthiness" as responses to the 42 questions (or to those questions that are actually useful and used) converge in support of a potential analysis. The more these responses converge, the more convincing and thus "valid" an argument is. This is related to the second element, "agreement." This agreement may be by "native speakers" of the particular social languages in the data, or by other research which supports the conclusion(s). Closely related is the element of "coverage," by which Gee (2014a) means that "the analysis is more valid the more it can be applied to related sorts of data" (e.g. that analysis of other applicant essays might provide similar insights) (p. 142). Finally, the more that the analyst can show that conclusions are tied to the fourth element, 'linguistic details'...including the grammar, structure, or other communicative functions" (p. $143)$, the more validity an analysis will have. 
Throughout analysis, researchers should look for answers to the 42 questions that are contradictory (p. 143; see also Saarinen, 2007, p. 68). Seeking out and addressing contradictory findings will add to the overall validity of analysis. However, Gee (2014a) cautions that "no piece of work can, or should, ask all possible questions, seek all sources of agreement, cover all the data conceivably related to the data under analysis, or seek to deal with every possibly relevant linguistic detail" (p. 143). Throughout the analysis, researchers should continually reflect upon the ways in which the analysis is being conducted, being mindful of the context within which the data was produced and within which the research is being conducted.

This methodology enabled an analysis that met Gee's criteria for convergence, agreement, coverage, and ties to linguistic details. The findings of this analysis, regardless of the method of analysis (looking at word frequency, creating "buckets," developing Building Task Codes, assigning those codes to categories, and then looking at the patterns of usage of these categories) supported the claim that the scholarship applicants engaged in the Discourses outlined in Chapter Two regarding the role of education, and their relationship to it. The results of these various ways of looking at the scholarship essays converged in their findings that the applicants saw education as both transactional and transformative, and that they identified themselves (and others) as both victims and victors. This convergence also indicated agreement as these Discourses have also been prominent within research about global education agendas. Given the initial findings when looking at the other two samples of scholarship applicants, it may also be argued that these findings could "be applied to related sorts of data" and thus meet the criteria of coverage. The linguistic details of these applications successfully communicated messages that were aligned with the Asherah 
Foundation essay prompt: "illustrating how this scholarship will give you a second chance and how it will benefit your community" as discussed in Chapter Four.

Contradictory issues have been sought throughout the analysis, beginning with the literature review, which sought critiques of the lauded SDGs, and identified opposing views of education as transactional vs. transformational, and of students, such that they were portrayed as either victims or victors (or saviors). The insight gained from looking at the disfigured worlds of the applicants provided additional insight into that which was considered to contradict their assumptions.

Reflections on the context of the production of these essays, and on this research, have informed the analysis. Chapter Four will address both the context of the essay texts, as well as the institutional contexts within which they were written. It will conclude with reflections on the larger situational context of the essay writing, as well as reflection on the context within which this research is being conducted.

\section{Limitations}

\section{Limitations of Sample Population}

The applicants to the Asherah Foundation Second Scholarship represented a unique and relatively elite group of women. As noted in Chapter Two, the percentage of women accessing higher education around the world is low, particularly in the countries and territories these applicants were from. In addition, due to the relative newness of the organization, the information about this program was necessarily limited to select populations connected to those affiliated with the Asherah Foundation (e.g. via EducationUSA advisors). 
The focus on applicants to a single, small organization was also limiting. However, the smallness and newness of the organization meant that only a very select group of women would have even heard of the organization, let alone gone through the effort of sending in lengthy and complex scholarship applications. The similarities in this small group of women provided a framework for analysis that was helpful as it allowed for a more concentrated look at the possible Discourses that influenced the discourses of the women who were the focus of this study.

\section{Limitations of Researcher}

As founder, Executive Director and current President of the Executive Board, the positionality of this researcher posed a limitation on the ways in which the data might have been analyzed. Having an intimate knowledge of the Asherah Foundation, I might have been be prone to seek out results which confirmed my assumptions. This was mitigated in several ways. As a member of the organization's leadership team, I had a vested interest in seeking ways to improve how the Asherah Foundation carries out its mission. In many ways, this research was being conducted to accomplish this goal. Having a deeper understanding of the women the organization seeks to serve should enable the organization to develop policies that will be more effective in serving these women. This limitation was also addressed by a detailed method of analysis as described above, and a focused reflection on the context of this research in the following discussions (Chapters Four and Five). Articulation of the steps to analyze the data as noted above provided a structured approach. The incorporation of reflections on context - including the ways in which the discourses of the applicants may have been affected by the discourses of the Asherah Foundation - were useful. A focus on 
finding discourses which contradicted the discourses that were expected to be found was also useful in addressing this limitation of perspective.

\section{Conclusion}

This study is significant as it should contribute to the development of better understanding of the struggles that underserved women face when trying to access higher education. This better understanding will provide a basis for developing improved indicators and methods of measuring (and encouraging) progress towards equitable access to higher education for underserved women (and thus the achievement of the sustainable development agenda). Both the UN and the Asherah Foundation are dedicated to improving the ability of women to access higher education.

It is hoped that this research will contribute to the production of knowledge that the 2016 GEM Report $(2016$, pp. 173, 176) encouraged. It will, at least, contribute to the discussion around contextually-appropriate responses (UNESCO, 2016a, p. 9) and provide additional ways to promote equity in educational access. It is also hoped that this research will assist the Asherah Foundation in better tailoring its scholarship program to support women around the world. The 2016 GEM Report posited that "education is both a fundamental human right and an enabling right, i.e. it enables other human rights; that it is a public good and a shared social endeavor, which implies an inclusive process of public policy formulation and implementation; and that gender equality is inextricably linked to the right to education for all" (UNESCO, 2016a, p.8). It is hoped that this research will make a significant contribution to the goal of providing this enabling human right to underserved women around the world. 


\section{Chapter}

\section{FINDINGS}

If the 10 women who were the focus of this study could talk to those involved with global education policies and the UN's Sustainable Development Goals, they would highlight the complex nature of their access to education and its roles in their lives. They would agree that they could use education to transform their communities. However, they would also highlight the need to address barriers of a more transactional nature, such as funding for education and mitigation of conflict.

This chapter will answer the central research questions guiding this study: What do nontraditional women from conflict-affected, lower income regions say about their journeys to higher education despite tremendous obstacles including violence and poverty? This chapter will illustrate how a specific subset of applicants to the Asherah Foundation Second Chance Scholarship talked about their educational experience to answer the more specific sub-question (Part I and Part II) about "What Is?: How do these women identify themselves and the role of education in their experiences? Part I delineated the Context of the Situation. Part II asked sub-questions: "How did they discuss themselves? How did they discuss the role of education in their lives? "What power dynamics do they operate within?"

The answers to the question "What Is?" informed Part III which asked "What Might Be?: "How do these discourses compare to those of women in similar situations?" This question was addressed by illustrating how these women engaged in global Conversations about themselves (as students), about the role of education in their lives, by examining how their discussions reflected relevant Conversations and prominent global Discourses, and 
finally by looking back at two other groups of applicants. Part VI sought to address the question "What else is possible?: How might critiques regarding inequities be addressed?

Part I: Context of Situation (What Is?)

Part I of this research focused on the demographics and content analyses of scholarship applicants and their essays. It resulted in the nine-step process outlined in Chapter Three. The preliminary analysis of the texts illustrated that the application essays were engaged with the four Discourses outlined in Chapter Two. This analysis also illustrated the importance of focusing on the 10 women who ended up being the primary population of study in this research.

\section{Part II: Institutional Context (What Is?)}

Part II examined what the applicants were communicating via their scholarship application essays. It sought to answer questions such as "How did they discuss themselves?" and "How did they discuss the role of education in their lives?" It also began to analyze the power dynamics they were operating within.

It was found that the 10 applicants analyzed here engaged in Conversations about the role of education in their lives that were aligned with the four Discourses identified in Chapter Two: Transactional Victim, Transformational Victim, Transactional Victor, and Transformational Victor.

These 10 women discussed themselves as agents of change in their communities, with education as a central means for them to create both transactional and transformational change - particularly for those in their communities that had been victimized. The essays suggested that the women agreed and aligned with Discourses about the transformative role of education but were also quite focused on its transactional nature. The transformative and 
transactional roles of education often overlapped as, for example, an applicant would gain important technical skills (such as in medicine) and thus be able to provide economic support through her career. These transactional, technical skills would also allow her to be able to treat those injured in her community, as well as provide inspiration through the act of completing her educational journey. Unfortunately, due to circumstances outside of their control, these women had also been victimized, preventing their access to this education. They thus sought the Asherah Foundation's help. This chapter will highlight women's assumptions about the role of education in their lives through an analysis of their "normallyfigured worlds" and how their actual experiences differed from these assumptions (what I call their abnormal, or "dis-figured" worlds).

Applicants clearly presented their ability to help their communities as normal. This makes sense as the Asherah Foundation Scholarship application explicitly asked them to write about how this scholarship would help them help their families and communities, assuming that applicants were both able and willing to help their families and communities. Applicants also discussed victimization as an unusual, but significant, occurrence. The victimization and barriers that prevented them from accessing higher education were important parts of their narratives. They needed to let the Asherah Foundation know that they were in unusual situations needing the financial assistance. Discussing victimization within the application essays involved walking a fine line between illustrating the need for the scholarship ("we were forced to flee for our lives"), but also demonstrating that they were able to actually access and be successful in school despite these unusual circumstances (“despite everything, I have been able to successfully enroll in this university"). Discussions around victimization also highlighted how others in their lives had been victimized - 
presumably with the goal of illustrating the reasons that these others needed the help of the applicants.

\section{"What Is?" What is Normal?}

Agency was a central feature in applicants' normally-figured world as was the importance of education. The most common feature of applicants' normally-figured worlds suggested that they viewed themselves as agents of change for their communities. Related to this, their Identities were often described in terms of fighting, being victorious, and saving others, while common Practices also involved fighting, saving others, and strengthening communities. The most common Social Goods included support, success, and savior status.

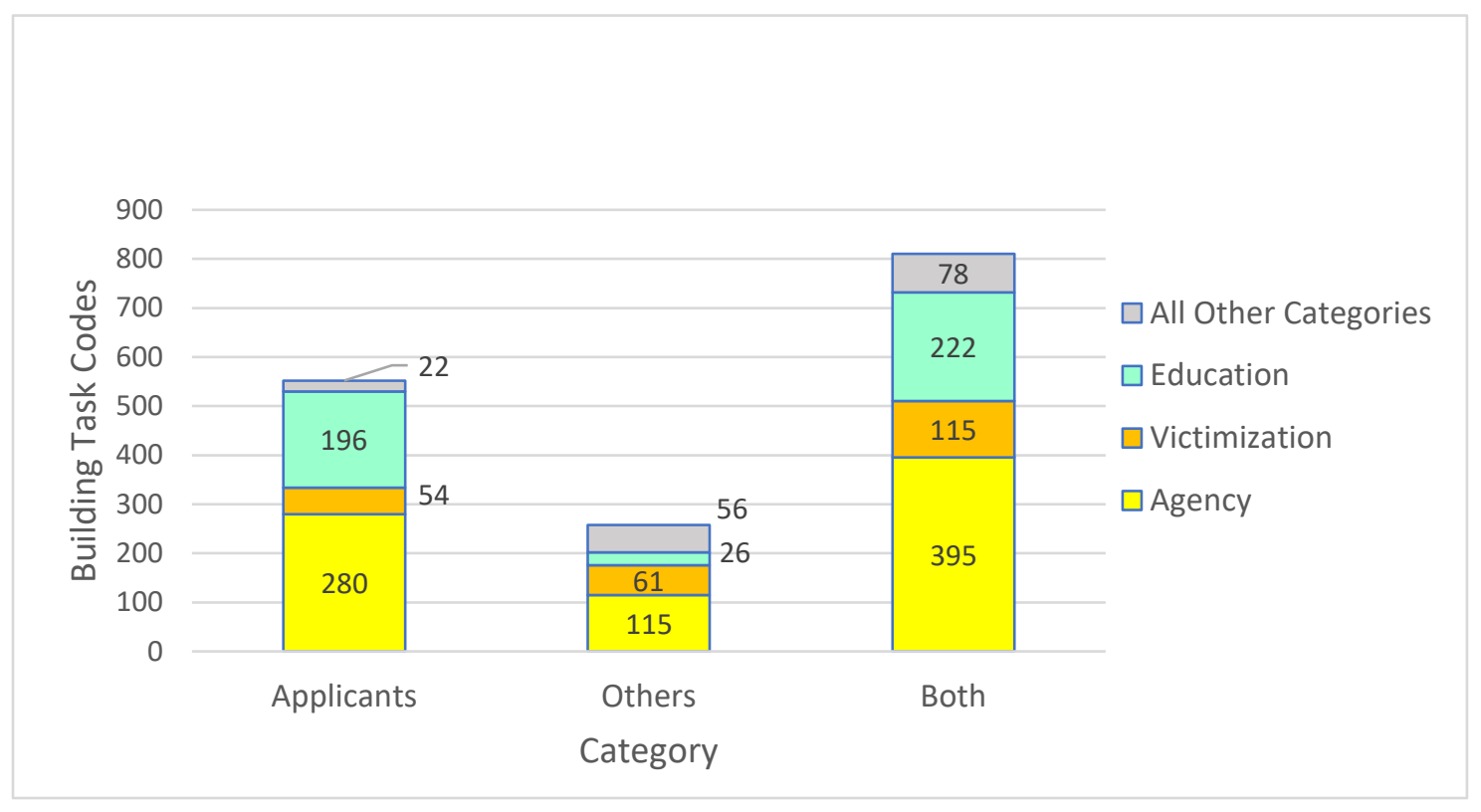

\section{Figure 2. Building Task Codes by Top Categories - Normal Scenarios}

Education figured prominently as an important pathway to becoming an agent of change. As illustrated in Figure 2, 196 Building Task Codes referring to applicants fell within the Education category in parts of the essays describing normally-figured worlds. Applicants described themselves (their Identities) as students and/or skilled professionals. Relatedly, 
common Practices also included seeking education, engaging in academic work, and having careers. The Social Goods of academic finances and education were also discussed in terms of normalcy. (Please see Appendix 7: Building Task Codes - Comparisons of Major

\section{Categories)}

\section{Applicants as Agents}

The identities described in these women's essays provide a glimpse into their assumptions about who they are, or how they should/would be had conflict not interrupted their educational journeys. Practices and "social goods" likewise highlighted what they thought they should be doing and having. Applicants primarily talked about themselves, in normally-figured worlds as agents, taking action, and having agency. As illustrated in Figure 2, 280 Building Task Codes fell within the Agency category in parts of the essays describing applicants' normally-figured worlds. This highlights their assumptions that agency was a normal part of the worlds they were discussing. This agency was directed at changing their communities as well as fighting for access to higher education. As Moza declared: "I will improve my studies and experience to be something important in the future..." 


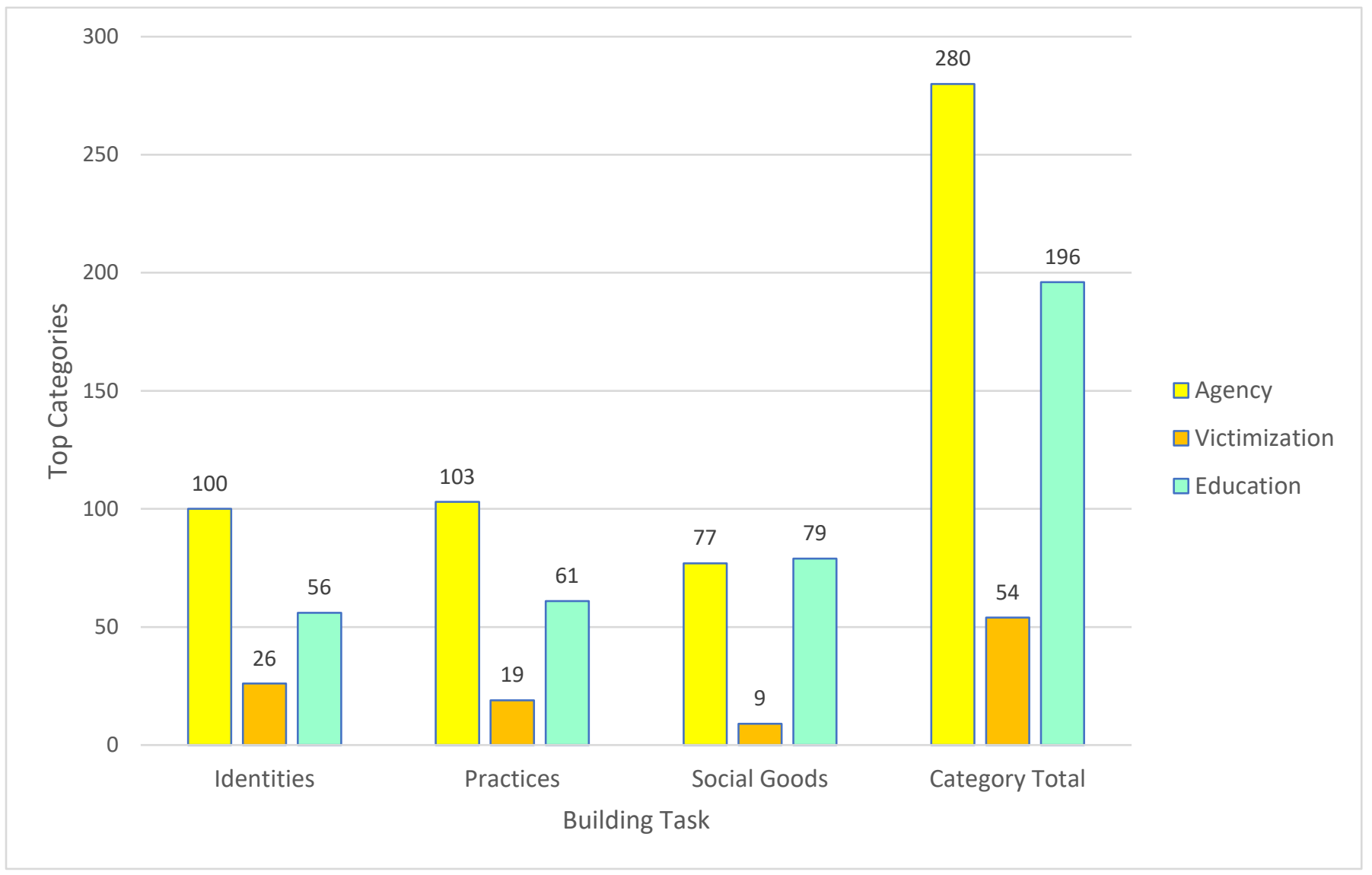

Figure 3. Top Categories by Building Task - Applicants in Normal Scenarios 
Agents of Change. When talking about themselves, applicants portrayed their identities as that of agents of change. As illustrated in Figure 3, by far, the majority of Identity codes used to describe applicants in normally-figured worlds fell under the agency category $(n=100$, or around 54\% of Identity codes [100/184]). Applicants highlighted their identities as fighters and saviors when talking about themselves and their assumptions about who they were. The most common code applicants used to describe themselves was that of "Savior" [47/184], highlighting their assumptions that they could "save" others. For example, Moza explained that she was applying for this scholarship so that she could "be the someone that I always dreamed about, who would be very welcomed to help improving the world and help people who would need me as much as I can [...], I really want to be someone that [leaves her] mark [on] this world, not only study and get a certificate."

Practices within the Agency category were also a significant part of the applicants' normal worlds. Applicants highlighted their practices around agency more than any other category. Over half (56\%) of the stanzas were coded as being within this category [101/184]. They highlighted practices around saving and strengthening their family and community $(n=33)$ as well as fighting $(n=33)$. As Rada explained, she was fighting for the opportunity "to contribute significantly to the transformation of [her] country." These agentive practices were presented as normal - as realities that were not going to change.

Applicants also highlighted social goods pertaining to agency. The Social Good Building Task Code of "savior status" ( $\mathrm{n}=27)$ was discussed along with similar social goods pertaining to agency in normal worlds [75/100]. Mahin illustrated this with her explanation for wanting the scholarship: "My interest in community development through women and children empowerment is very paramount in this time because I come from a village of about 
35 huts with a population close to 250 persons, the majority of whom are women and children under 10 years. [sic]" Her application discussed how she would use her education to actively improve and thus save her community.

Agents accessing education for careers. As applicants to an educational scholarship program, these women highlighted identities, practices, and social goods pertaining to the role of education in their lives [196/552]. They assumed that their educational identities were important and highlighted this almost one-third of the time [56/184]. As one would expect from educational scholarship applicants, the women more specifically identified themselves as students ( $\mathrm{n}=31)$ as seen in Lawan's statement that she was "a self-sponsored student." Applicants also discussed the normal practices of seeking education $(n=17)$ and performance of academic work $(\mathrm{n}=17)$. Practices within the education category were also a significant part of the applicants' normal worlds. Slightly over one-third (34\%) of the codes fell into the broader education category [61/184]. These codes included the seeking of education $(n=17)$ and performance of academic work $(\mathrm{n}=17)$. The practice "To Seek Education" is illustrated by Laleh who shared that she had "been admitted at [her] University for [her program], since May 2017 intake.” She was applying for the scholarship as she had not yet been able to attend due to financial difficulties. Despite her economic limitations, she was still seeking education. Moza exemplified the practice "To Do Academic Work" with her statement, "I am trying to put all my effort in my studies.”

Applicants also assumed that seeking a professional career was normal and important. Many highlighted their future identities as skilled professionals ( $\mathrm{n}=17)$. The pursuit of a career via education was also made apparent through the practice "To Have Career (Professional Work).” Amara was working to become a doctor. Rada included a section in 
her application: "Career plans in 5 years" involving her obtaining professional training, conducting research, and then working to address her "country's shortage of qualified personnel in the area of [the] health sector." Gaeti was seeking the scholarship so she could help in "bridging the gaps since my community suffers of the lack of professional[s]" in her field of Architecture \& Design. Moza explained that if she received the scholarship, she "would work and search a lot to have enough experience to start my own business and be a successful person that people knows [sic]." These statements highlight the applicants' assumptions that normally, women like them should be professionals in the formal workforce, and that higher education was how they would get there.

\section{Relationships with Others}

The relationships of applicants to others in their lives (e.g. family, government) were identified through analyses of the Identities, Practices, and Social Goods that they used when discussing these others. As the scholarship essay prompt encouraged discussion about how the applicant would help her community, discussion about others was a significant part of the application essays. Although applicants focused primarily on themselves, their relationships with others in their lives were significant parts of the application essays when discussing normal scenarios (as illustrated by Figure 4: Normal Scenarios: Applicants vs. Others). 


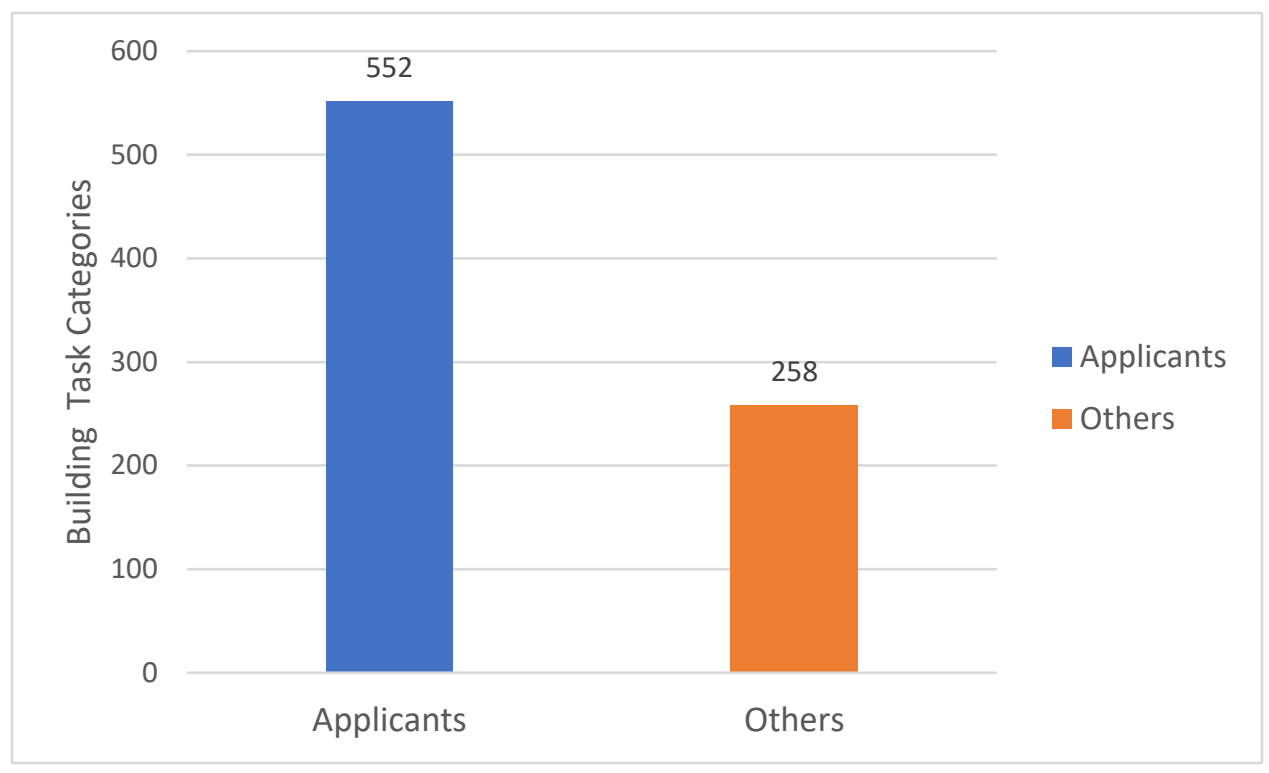

\section{Figure 4. Normal Scenarios: Applicants vs. Others}

The analysis highlighted how others in the applicants' lives were connected to their educational goals. As shown in Figure 4, when discussing their assumptions about how the world should be (their normally-figured worlds), applicants discussed others slightly less than half of the time. However, these discussions provided insight into their relationships with others, and assumptions about their relationships. The others discussed by applicants could hinder or support their educational access. Others in their lives were also discussed as victims that the applicants intended to help via education. For example, Amara's goal of becoming a doctor was directly related to her desire to help heal the victims of the ongoing civil conflict in her country. As seen in Figure 5, applicants discussed others in their lives in terms of agency, victimization, villainy, and education to varying degrees. 


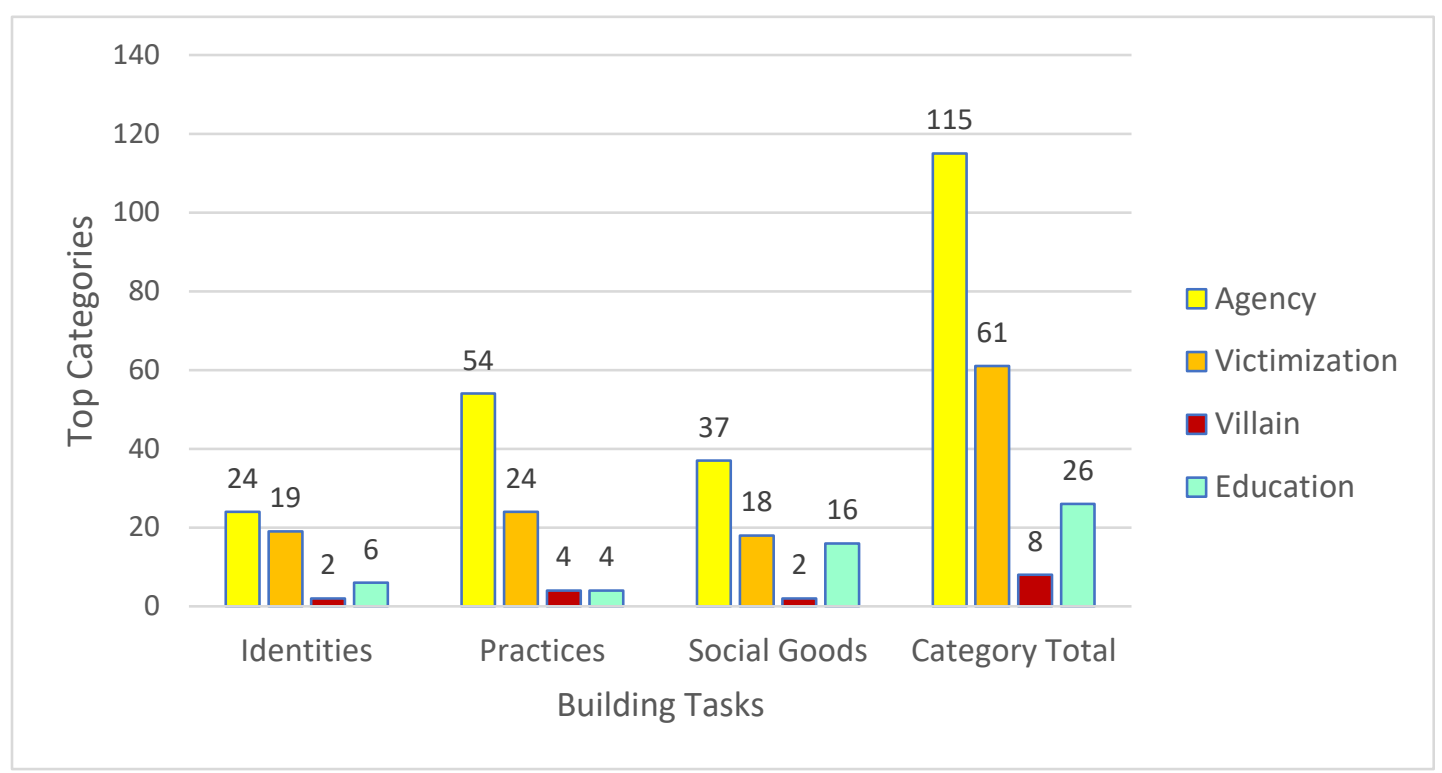

Figure 5. Top Categories of Building Task Codes for Others in Normal Scenarios Assumptions about others hindering access. As each of these women had their educational journeys affected by conflict, those causing the conflict were a key part of their essays. In several cases, violence in their communities had been going on for quite some time, and so had become normalized. For example, Mahin noted that she had been "born just few months to the outbreak of the Liberian civil war" meaning that she had grown up in a country that had been at war for most of her life. Rada had lived her entire life in a refugee camp and explained that "South Sudan, like any other developing country, faces a myriad of challenges in all sectors of its development agenda. More so when it is the youngest nation in the world to have gotten Independence after its 21 years of civil war [and then] plagued again by a civil war two years after its independence in 2011, leaving thousands dead and million displaced."

Assumptions about others supporting access. As illustrated in Figure 5, agency was an important part of the applicants' normally-figured world as pertaining to others in 
their lives, representing $41 \%$ of the Building Task Codes [115/270]. Identities within this category were noted 21 times [24/86], while Practices [54/86] and Social Goods [37/86] were also well-represented. These represent almost $42 \%$ of all the Building Task Codes referring to others' normal worlds - reflecting applicants' assumptions about how the world should be [115/258]. The most common identities were those of the family and/or community [67/258, or $25 \%]$. The most common practices referred to saving others $(n=29)$ as well as strengthening the family and/or community $(n=17)$. The social good of "support" was noted 21 times.

The agency involved in discussions about others focused on social support through families. Parents in particular were portrayed as sources of both practical and emotional support. Amara noted that her "family has made many sacrifices" and that her "parents have always tried to provide me with best [sic] education even though money has always been an issue." Layla shared that graduating from her program "has been a long-term goal for me and a dream for my parents." Moza explained that she was fighting for her education so that she could become successful and someone her "parents would be proud of after graduating."

The Asherah Foundation was also discussed in terms of agency in supporting the applicants. This makes sense as applicants presumably assumed that the organization would be able to help them (otherwise they may not have applied). For example, Rada stated that the scholarship would provide her "with an opportunity" while Layan noted that the scholarship would "help me pay the tuition fees." The applicants discussed ways in which the organization would support them beyond finances. Gaeti expressed her gratitude for "the committee's time in evaluating my application and giving me the opportunity to tell my story." Layan also expressed that beyond the tuition fees, the scholarship would "assist to 
present me with dignity and pride to reach my utmost academic potential" and help "flourish the way towards the success I have always desired to embrace."

Assumptions about others needing support. Applicants were much more likely to describe themselves as agents of change than when describing others. Seventy-eight percent (78\%) of the Building Task Codes relating to the identity of someone with agency referred to the applicant, whereas only $22 \%$ of the codes used for others referred to this identity. The dynamic between applicants and the others the discuss was that of applicants "saving" their communities. By far, the most common identity for others in normally-figured worlds was that of "community" or "family" $(\mathrm{n}=50)$. The most common practice was "Saving Others" $(n=29)$, and the most common social good was that of support $(n=21)$. As Mahin explained, her dream was "to see [her] country...to be a country that is known for progress, freedom, peace and the promotion of human dignity." Education was essential for her to be able to help achieve this dream.

Given the essay prompt to describe how they would help their communities, applicants tried to illustrate how their education would help them help others - for example, through rebuilding war-ravaged countries (Moza), treating the wounded (Amara), and providing access to educational opportunities for the less fortunate (Mahin).

Moza: one of my biggest dreams to go back to my country... with my degrees and experience to help rebuild it again, helping to improve it, and making it look like before and better especially after the big damages that were caused by the war there which demolished most of the buildings in my country [sic].

Amara: I decided that I will attain a career as a doctor since from the very childhood. I continue to see people in [my community] facing hardships due to ongoing conflict, 
as daily trauma become[s] a routine. Medical assistance is very limited due to lack of resources and shortage of dedicated [healthcare providers]. It has taken a heavy toll on our people, especially little children, costing many their lives, their limbs and a normal life. Pellets are maiming little children forever...Unfortunately, with the number of eye injuries we are witnessing...it seems there is a deliberate attempt to cause eye injuries most among them are teenagers with limited resources to access healthcare... Being able to achieve my goal of becoming a doctor will be an invaluable experience through which I will be able to help many [of these] victims. Mahin: My dream is to develop capacity... which will give me the prospect to give to the development of my community, focusing on women and children who are disadvantaged in life like I am... there are no basic social services such as school, clinic and safe drinking water. All these conditions I hope to fight against through community-based initiatives and advocacy.

\section{Dis-figured Worlds - What was Not Normal?}

Almost $40 \%$ of the essays described dis-figured worlds - scenarios where the applicants' assumptions about what should be no longer seemed valid [165/435]. These stanzas almost equally referred to applicants $(n=78)$ and others $(n=87)$. As illustrated in Figure 6, the top categories for each of the three Building Tasks were agency, victimization, villainy, and education. 


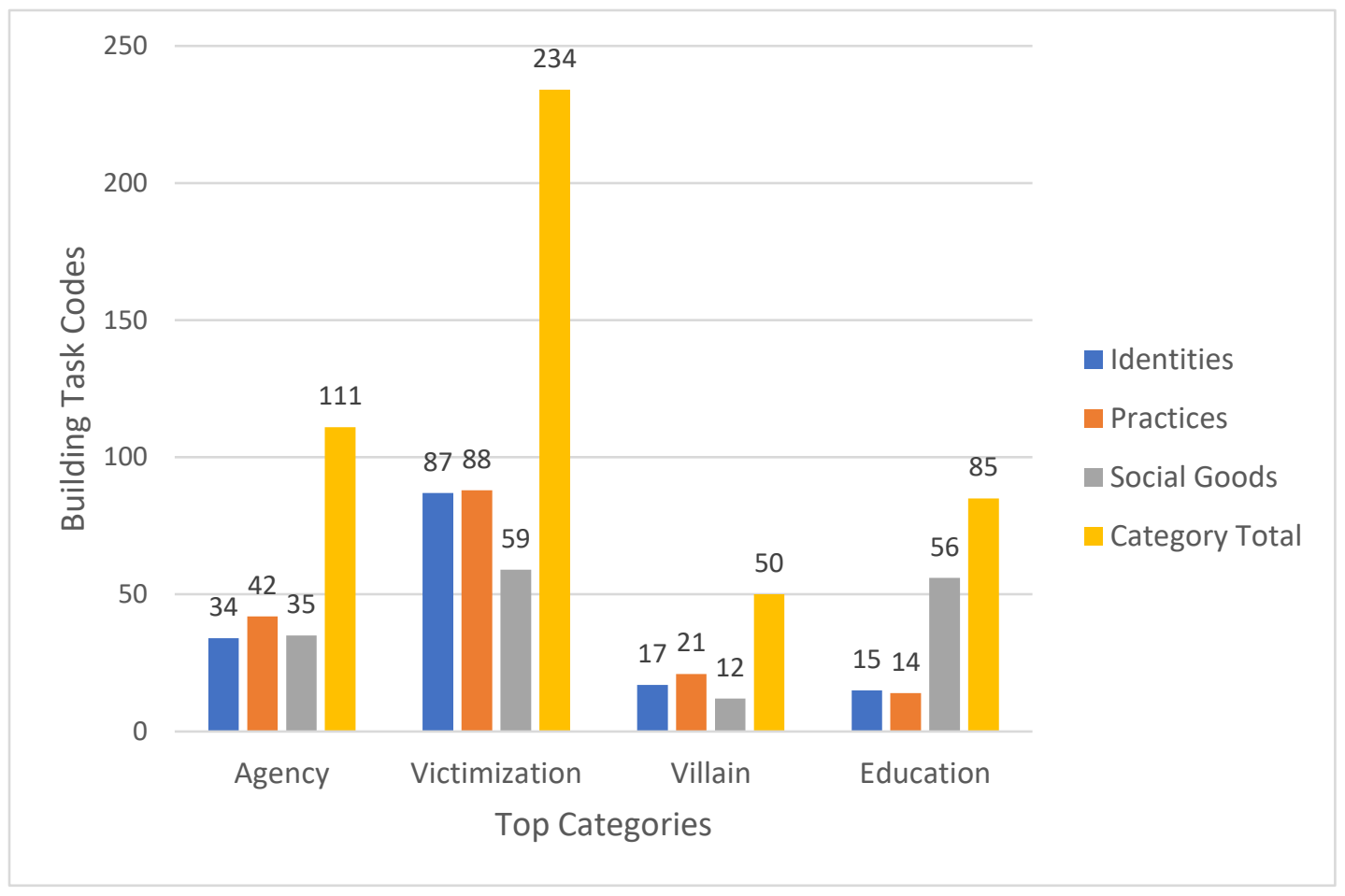

Figure 6. Top Categories for Building Tasks in Dis-figured Worlds - Both Applicants and Others

Victimization was clearly important to applicants, as almost $60 \%$ of the Building Task Codes were in either the Victimization or the Villain categories [284/495]. This focus on victimization was so prevalent that almost a third of all stanzas depicting abnormal worlds were completely focused on this category - meaning that the focus of the stanzas was on victims, being victimized, and having victimization. This pattern represented almost onethird $(31 \%)$ of all the stanzas in dis-figured worlds [50/161]. For the purposes of this research, the Social Good Building Task was coded as "having victimization" when it was the object of a stanza - for example, when Mahin explained that she had "grow[n] up under a very challenging condition.” In this stanza, Mahin was noted as the subject - a victim in this case. The act of growing up in a challenging environment was identified as the practice, and 
the "challenging condition" impacting this practice was considered to be the object, or "social good" of the stanza.

Another 64 of the stanzas had at least one of the Building Task Codes fall within this category, meaning that $69 \%$ of the stanzas describing dis-figured worlds referenced victimization [64/165]. In terms of the actual Building Task Codes (within the categories), the most common identities were related to victimization [46/270]. The most common practice by a significant amount was explicitly "Being Victimized" ( $\mathrm{n}=77)$. Over half (52\%) of the Building Tasks related to practices were within this victimization category [85/165]. Over one-third of the Social Good Building Task Codes fell under the victimization category as well [58/165], with the most common code being "Trauma" $(\mathrm{n}=50)$. As Amara described her experience: "I continue to see people in [my country] facing hardships due to ongoing conflict, as daily trauma become[s] a routine." The targeted shooting of children in Amara's community, the kidnapping and abuse of Rayna and her family, and the killing of members within each of the applicants' communities were a constant.

\section{Applicants' Dis-Figured Worlds}

Victimization was a significant part of the applicants' discussion about their own disfigured experiences. This was highlighted through the 20 stanzas where they completely focused on victimization, and another 16 focused on victimization in relation to education representing almost half of the 78 stanzas discussing applicants in dis-figured worlds [36/78] - worlds where their assumptions about reality had been challenged. As shown in Figure 7, applicants discussed themselves (their identities) as victims in almost half of the stanzas describing their own dis-figured worlds [45/78]. Out of the 78 stanzas pertaining to their dis- 
figured worlds, applicants discussed their practices in terms of victimization 43 times [43/78].

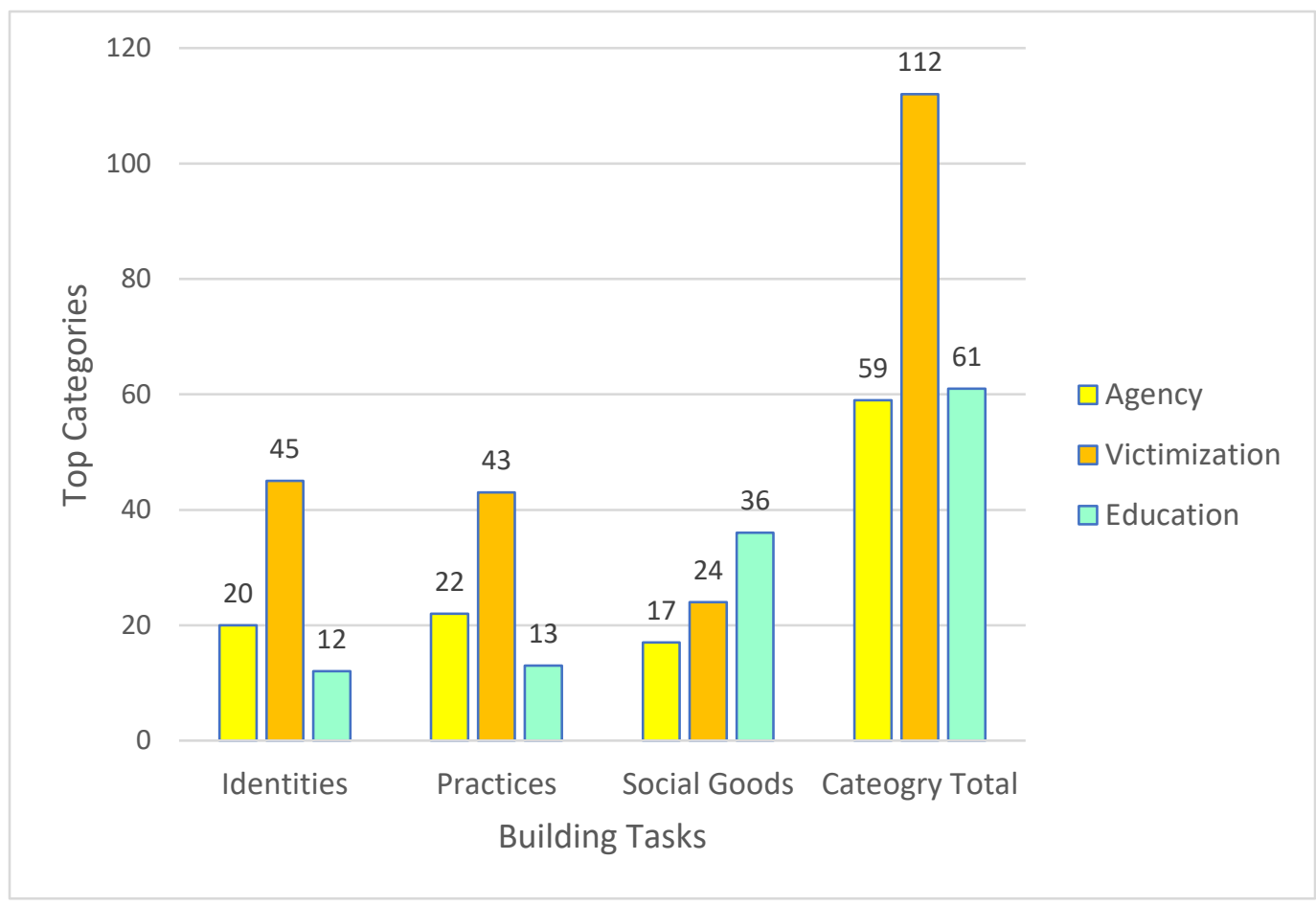

Figure 7. Top Categories for Three Building Tasks - Applicants' Dis-figured Worlds Applicants highlighted the importance of victimization in relation to education in their dis-figured worlds. Social goods in these two categories were frequently discussed, with codes in the categories of victimization occurring 24 times [24/78], and education 36 times [36/78]. The most common Building Task Codes were "Trauma" $(n=16)$ followed by codes pertaining to academic finances $(n=8)$, and academic programs related to careers $(n=8)$. As an example, Amara noted her dis-figured world left her "with no other alternative for continuing my education." Years before she became forcibly displaced, Nifa had to drop out of her first university program as “there wasn't any support available for expats...such as any form of scholarships." Laleh was unable to pay for her education as she "had to abandon my job and flee the Country [sic]. 


\section{Others in Dis-Figured Worlds}

Victimization was a significant part of the applicants' discussion about others in disfigured worlds as well. Slightly over half (52\%) of the stanzas in dis-figured worlds referred to others, including applicants' families, their communities, and hostile forces [86/165]. These others were either suffering due to the violence perpetrated by others or were the cause of this violence themselves. The most common codes were those pertaining to society (community and family) $(n=56)$, with the majority being tied to some form of victimization through the other parts of the stanza.

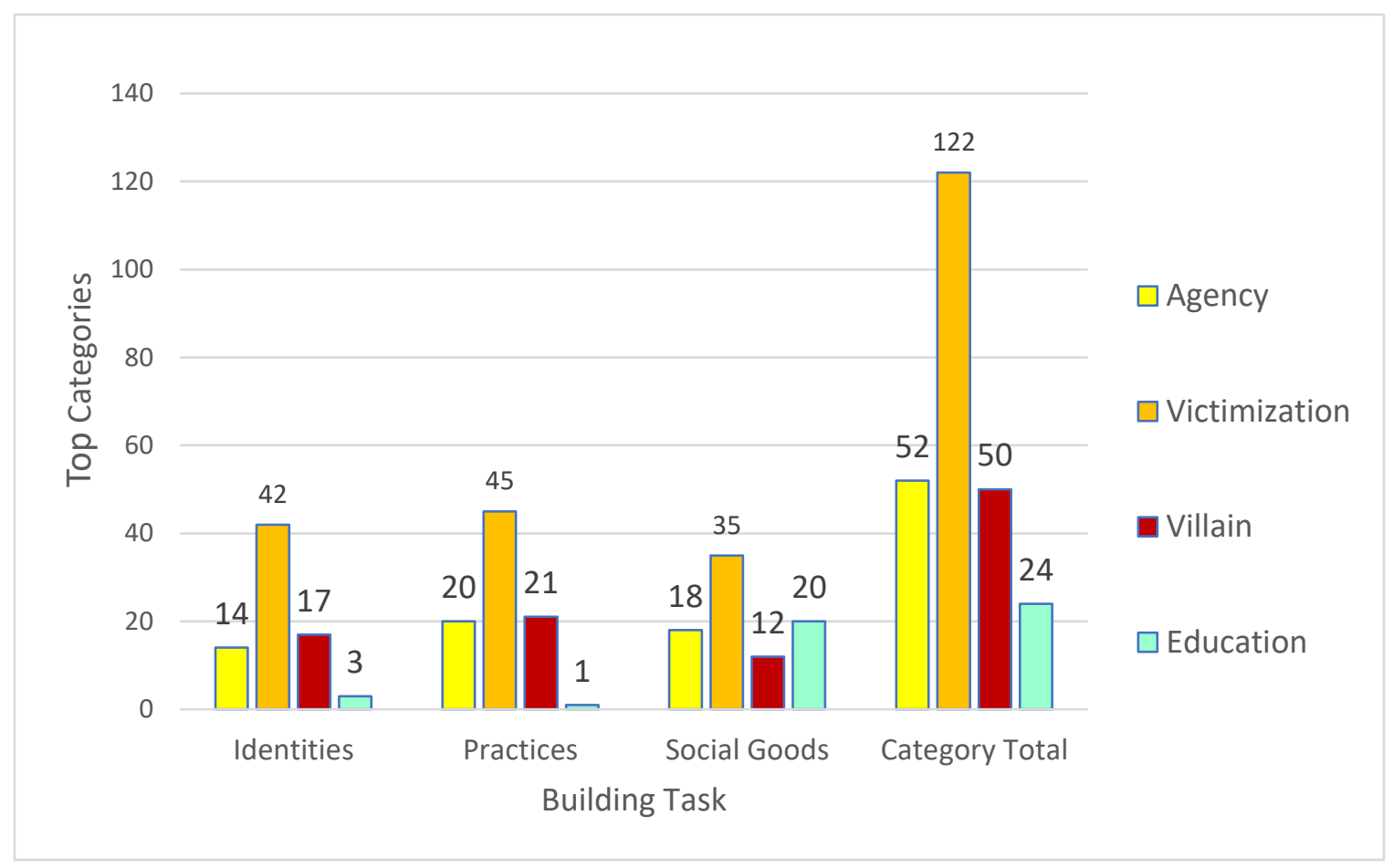

Figure 8. Top Categories for Others in Dis-figured Worlds

Out of the 87 stanzas pertaining to others in abnormal scenarios, two-thirds [57/87] were related to victimization, with almost half [30/87] focused completely on victimization. As illustrated in Figure 8, applicants discussed the identities of others as victims frequently. For example, Amara discussed how the ongoing conflict in her country had "taken a heavy 
toll on our people, especially little children, costing many their lives, their limbs and a normal life." Gaeti, Layan, Laleh, Moza, and Nifa all discussed the violence that had enveloped their home countries of Yemen, South Sudan, and Syria.

The most common codes were those pertaining to society (community and family) $(n=56)$, with the majority being tied to some form of victimization through the other parts of the stanza. Applicants discussed the practices of others in terms of victimization 45 times [45/87]. Victimization was the most common Social Good used in discussing others in disfigured worlds, with 36 Building Task Codes falling into this category [36/87], generally referring explicitly to the code "Trauma." As Amara shared: "Pellets are maiming little children forever."

Those shooting these children, continuing the conflicts, and otherwise victimizing the families and communities of applicants were noted as "villains" within this analysis, and coded as such when they were the focus of a stanza. As an identity, "Villain" was used 17 times to describe others in dis-figured worlds. This code frequently referred to military action, such as: "when rebels of the National Patriotic Front loyal to former rebel leader Charles Taylor lunched a [surprise attack] on my home town" (Rayna). The Practice "Injure / be villainous" was noted 22 times, such as when Rada discussed how the ongoing "Violent ethnic and tribal conflicts" in her country were "inflict[ing] a lot of suffering on the people and the entire country." The most common social good affiliated with the Villain category was "Trauma" which was used 12 times and illustrated by Rayna noting "the suffering and different forms of humiliations I experienced" and Mahin's description of the "period in which [she] faced...slavery." Those causing the conflicts in applicants' countries were 
referred to as "villains," "being villainous" (causing injury), and were associated with the social goods of trauma and burdens.

\section{Conversations: Alignment with Discourses?}

This section will look at the ways in which the Conversations in the 10 application essays aligned with the Discourses articulated in Chapter Two regarding student identities, and the role of education in their lives, specifically: Transactional Victims, Transformational Victims, Transactional Victors, and Transformational Victors. It will begin by looking at the Conversations around the role of education as transactional or transformative, and the identities of these women in relation to education - as victims or "victors" - triumphant despite the obstacles they face. The ways in which the women engage in these Conversations provide insight into how their essays aligned with the four Discourses found in other research.

The first part of this chapter highlighted how applicants had used each of the three Building Tasks: Identities, Practices, and Social Goods to build a world for the application reviewer. In order to understand more about the ways in which these three Building Tasks engaged in Discourses, they were looked at in more contextual detail. For example, the Identity of "victim" could be used in various ways to engage with different Discourses, and to argue about someone's appropriate role in terms of education. For example, is the "victim" the applicant or someone else in her life? Is the "victim" someone she is trying to help via her education, or is it part of a larger narrative about the general state of her community? Likewise, is education considered in a transactional way (e.g. it will help her get a job, she needs money to attend), or in a more transformative way (e.g. it will help her gain knowledge, or inspire her family)? 
In order to understand the ways in which the applicants align with the four Discourses outlined above, this section will highlight the Conversations that the applicants are engaged in. The Conversations were identified through looking at patterns in the stanzas of each application - how were the Identities, Practices, and Social Goods used - what patterns were seen in how these three Building Tasks were used together in stanzas? Appreciating the patterns of category distribution in the stanzas helps illuminate the ways in which applicants discussed the role of education (transactional or transformative) and the role of themselves as students (victims or victors).

\section{"Education is Transactional" Discourse}

The "transactional" aspects of education were captured using the educational subcategories of economics and academic-financial. The stanzas including any code within either of these two categories represented only $20 \%$ of all stanzas [85/435]. Applicants were most likely to discuss these two aspects (economics and academic - financial) of education in normal situations as evidenced by the majority (61\%) of all codes falling within this Transactional Block [52/435].

Among these 85 stanzas, the most common Identities $(\mathrm{n}=25)$ and Practices $(\mathrm{n}=13)$ were those associated with purely economic Discourses around education, such as Layan's note about pursuing a career and "achieving the skills of leadership in professional settings" or Amara's wish to achieve her "ultimate dream of becoming a doctor." The most common Social Goods were associated with the intersection of education and finance $(n=49)$. This is likely due to the applicants' focus on obtaining the Social Good of a scholarship. Layan explained that "If this scholarship is granted to me it helps me pay my schools fees in time $[$ sic]." 
The most common combination of categories within stanzas involved the relationship between agency and economics. Laleh shared that she "was promoted after six months to [management] effective from [date] 2015 to [date] 2016." Moza explained that her "first aim [was] to be one of the top [interior architects] in the world." Laleh's ultimate goal after receiving the scholarship was to create a community-based organization "to impart entrepreneurial skills into young ladies and women such as fashion design, farming and micro financing."

Given that these were applications to seek financial support for education, there were also many stanzas describing economic victimization. For example:

- Layan: "the only one thing getting in the way of achieving my dream is being able to pay for my university as the cost is very difficult to afford."

- Laleh: "Due to my financial inability, I have found it very difficult to further my education" and "I could not start due to lack of financial support."

- Lawan: "I am not able to [pay] my tuition on time and sometime am being chased from class because of the tuition fee."

- Amara: "I'm in dire need of financial assistance."

\section{"Education is Transformational" Discourse}

Transformational Conversations about education were noted through the Academics category. This category referred to education within the larger context, and in terms of the more transformational development of knowledge (as opposed to the development of professional and technical skills). This category also encompassed the power of education to transform both individuals and communities through inspiration (i.e. creating hope, achieving dreams). 
This education sub-code was more common than those considered Transactional (194:112). Over half of these codes referred to applicants in normal situations [69/194], often describing very basic education-related topics. For example, Amara noted that she had "recently finished my higher secondary studies in 2017." Layan shared that "Education has always been my biggest priority in life." Statements like these highlighted applicants' assumptions that educational progress was normal.

These Transformational codes tended to be within stanzas focused only on academics ( $\mathrm{n}=18)$ such as Rada's declaration "I will be very excited to pursue my undergraduate studies" or focused on agency ( $n=23)$ : "I am confident that I will acquire knowledge that will enable me to contribute towards the transformation of my community and it is my wish to make it come true" (Rada), or "It has always been my desire and dream to achieve a university degree" (Laleh).

As with the Transactional codes, there were stanzas linking these Transformational codes with victimization. For example, Amara shared that "My parents didn't have an opportunity to get education and are facing struggles because of this." Laleh explained the difficulties accessing education in her community saying that "girls hardly make it to the University." Applicants mostly linked education with victimization when referring to others in dis-figured worlds $(\mathrm{n}=8)$.

\section{"Students are Victims" Discourse}

As has been discussed throughout, victimization was a key part of these application essays. At the beginning of this chapter, the category of "victimization" was explored in terms of the three individual Building Tasks: Identities, Practices, and Social Goods. In order to identify the ways in which these Building Tasks were incorporated into Discourses, 
stanzas with Building Task Codes within either the Victimization or Villain categories were included in a Victim Block. Looking at how these three Tasks were combined with each other within a stanza helped identify patterns in the applications that might align with the Discourses around Students as Victims.

There were 179 stanzas (representing $41 \%$ of all stanzas) that were included in this block. The ways in which the Identities, Practices, and Social Goods were discussed relative to one another followed patterns seen throughout. Forty percent of the stanzas were composed completely of Building Task Codes within the Victimization category [55/179]. This was seen in statements like Mahin's "I [grew] up under a very challenging condition" and Rayna's lament that "my present state of affairs cannot permit me to translate this vision into reality."

Out of these 179 stanzas, $104(58 \%)$ referred to others, continuing the broader theme of applicants associating victimization with others in their lives. For example, Rayna also shared that "Of course, the issue of street children and drugs abuse among young people has not been addressed in Liberia's post war program [sic]" - something that she hoped to address once she had finished her program. Discussions about the victimization of others in dis-figured worlds were common, representing $40 \%$ of the stanzas in the Victim Block [72/179]. This included comments such as Mahin's that due to extreme poverty in her community, "Children as early as 6-7 years are compelled to leave their parents."

Victimization relating to education was a prominent theme, with over a quarter of the stanzas focused on this. Rada's statement: "I find myself unable to pay for my higher studies" illustrates this. However, the majority of these stanzas were focused on others in disfigured worlds. Moza shared that "The financial condition for my family is not stable these 
days as my father lost his job recently." Laleh pointed out that she came from a rural community in South Sudan "where access to higher education is hard."

Villainy, or victimizing others, was a re-occurring theme as illustrated by Rada's discussion about the destruction wrought by "[t]he Violent [sic] ethnic and tribal conflicts" which had "inflict[ed] a lot of suffering on the people and the entire country" or Mahin's description of the "fourteen year civil war [that] has broken the economy of [her country]." The Identity of Villain was used in 19 stanzas. The Practice of Villainy (causing harm to others) occurred in 25 stanzas. The Social Good of Villainy occurred in 14 stanzas. This Social Good was only categorized as such when both the Identity and Practice were also in this category.

\section{"Students are Victors" Discourse}

The theme of victory was a constant throughout the scholarship application essays. In order to understand more about the ways in which applicants discussed victory, a Victory Block was created by looking simply at the Agency Category. Over half (57\%) of all the stanzas fell into this Victory Block [249/435]. Out of these 249 stanzas, over half (51\%) referred to applicants in normally-figured worlds [127/249]. Out of these 127 stanzas, almost half were focused completely on agency, meaning that almost one-quarter of all stanzas in the Victory Block illustrated applicants' assumptions that their identities, practices, and social goods were all reflective of agency [60/127]. As Laleh shared "Additionally, I have been active in my early school years and also in my community."

Agency was also closely tied to education within the stanzas in the Victory Block as illustrated by Laleh's statement: "I now have an opportunity to become the first person in my family to attend college.” This makes sense for a scholarship application, as applicants 
shared how they had already achieved some level of victory by persisting in their pursuit of education. Nifa noted that "[a]fter two years of applying to different universities I was finally accepted and enrolled in [her new] University" in the program she had been fighting for.

Although not nearly as common, applicants also discussed the agency of others in terms of education. As noted above, applicants shared how others in their world had demonstrated agency and achieved a level of victory by supporting their quest for education. Mahin noted that she was only able to continue her schooling through "community members' interventions." Amara shared that her family had "made many sacrifices to support [her] education throughout [her] primary and secondary school." Another frequent pattern was noted in the 33 stanzas focused on agency in conversation with the Asherah Foundation. As noted earlier, with 22 of these stanzas referring to others in normal situations, applicants provided further evidence that they considered agency in relation to the Asherah Foundation as normal and expected.

\section{Alignment with Discourses}

In order to learn more about the extent to which applicants' essays aligned with the Discourses in Chapter Two, the categories were analyzed in terms of four Discourse Blocks. These four blocks were: Transactional Victims, Transactional Victors, Transformational Victims, and Transformational Victors. This section of the research will provide an overview of some patterns through which the applicants engaged in each of the Discourses. The following section will look at how these four Discourses were discussed in the applications of three groups of women.

Overview. A key finding is that the Discourses involving victimization were even more likely to be associated with dis-figured worlds than would be expected given the overall 
distribution of stanzas. Figure 10: Discourse Ratios presents the percentage of each Discourse that pertained to normally-figured worlds (where assumptions about reality held) versus the percentage of Discourses pertaining to dis-figured worlds (where assumptions about reality had been challenged). As Figure 10 illustrates, the ratio of stanzas in normallyfigured ("Normal") worlds to those in dis-figured ("Not Normal") worlds was approximately 2:1 (62\%:38\%). This means that the majority of Discourses were in reference to normal scenarios. In comparison, this ratio of Normal : Not Normal stanzas representing the "Victimization" Discourses were much closer to 1:1 - meaning that there were more stanzas referring to Victimization Discourses in dis-figured worlds than expected based on the 2:1 distribution across all Discourses. Relatedly, those Discourses associated with Victory were more likely to be associated with normally-figured worlds than expected - with a ratio approaching 3:1. These highlight the extents to which victimization was tied to dis-figured worlds, and victory was linked to normally-figured worlds. 


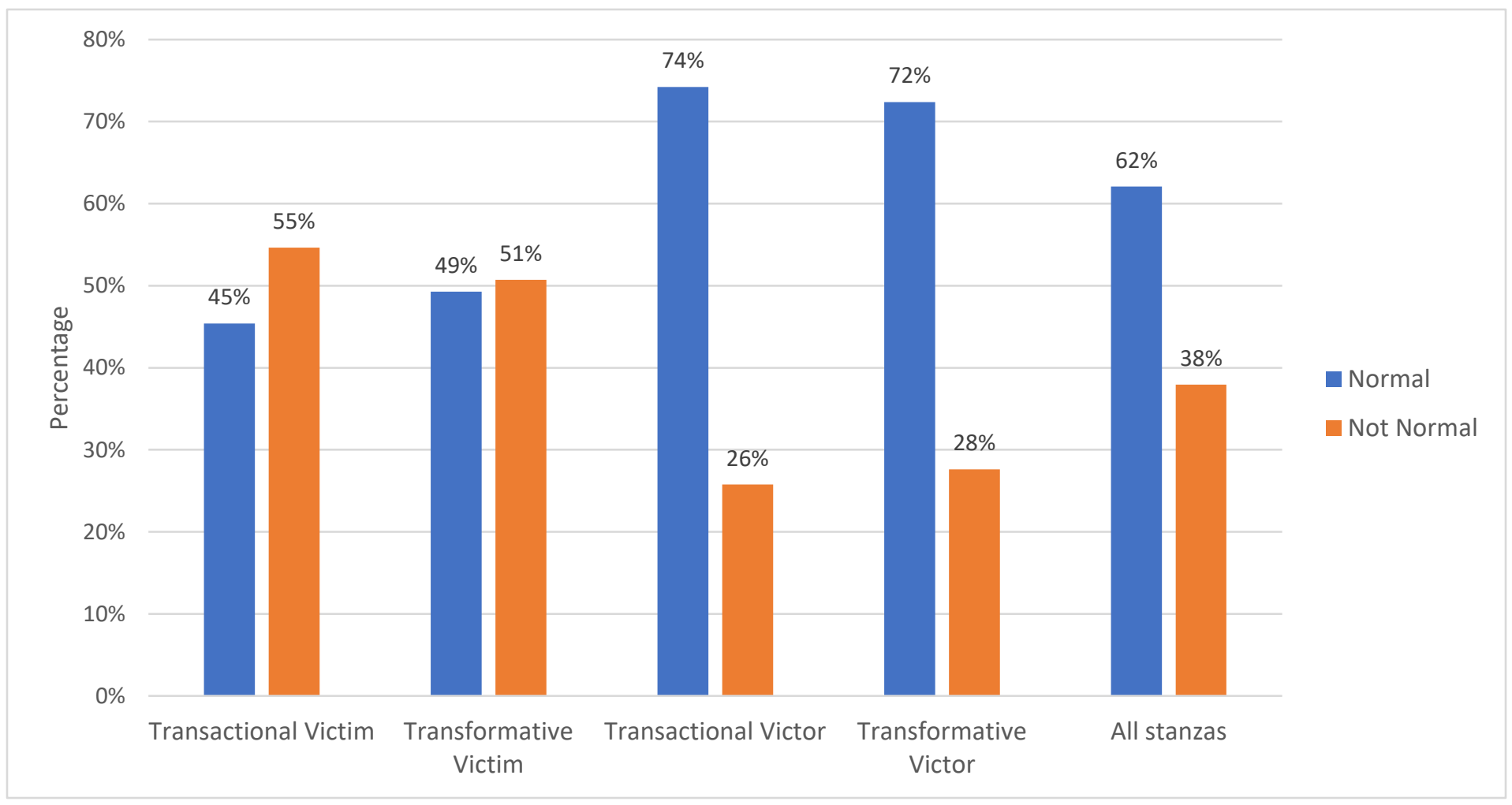

Figure 10. Discourse Ratios: Percentage of Normal: Not Normal 


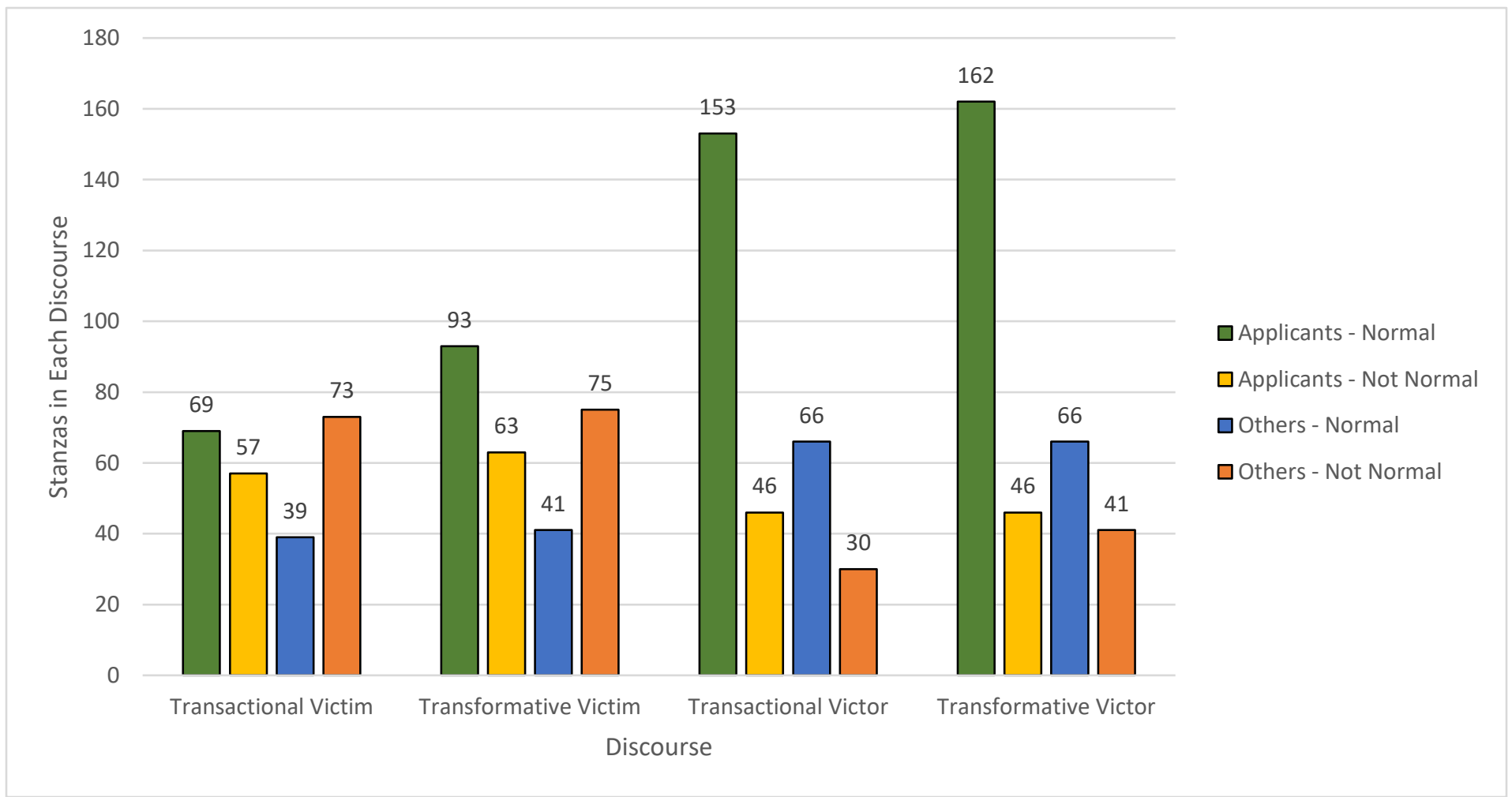

Figure 11. Discourses by Each Analytical Group 
Figure 11: Discourses by Each Analytical Group illustrates how each of the four Discourses was represented among the four groups for analysis: applicants in normallyfigured worlds, applicants in dis-figured worlds, others in normally-figured worlds, and others in dis-figured worlds. This chart compared the number of stanzas within each comparison group that fell into each of the four Discourse Blocks. For example, in the sections of the essays describing applicants in their normally-figured worlds, there were 69 stanzas that fell within the "Transactional Victim" Discourse. In comparison, there were only 39 stanzas within this Discourse referring to others in normally-figured worlds. These comparisons provided insight into the relative importance of each Discourse for applicants and for the others in their lives, as well as their applicability to normally-figured or disfigured worlds. This comparison of relative importance was important given the rather large difference in stanzas that applied to applicants (60\%) vs. others (40\%), and the almost 50\%$50 \%$ ratio of normally-figured and dis-figured worlds across all of the application essays. It shows the overwhelming focus of the essays on discussing the applicants as "victors" in normally-figured worlds - highlighting their assumption that they would be (or already had been) victorious. Figures $12-15$ in the Appendix 1 illustrate the differences among each analytical group for each of the four Discourses.

Transactional Victim Discourse. The Transactional Victims Discourse was identified by grouping together four categories: Economics, Academic-Financial, Victims, and Villains. This Discourse typically referred to an applicant's financial barriers to accessing education. In proportion to other distribution patterns, this was more closely aligned with discussions about others than about the applicants. This focus on others may be illustrated by the discussion around family members (especially parents) not being able to 
provide financial support to the applicant. Only $40 \%$ of all 435 stanzas referred to others. However, a larger percentage (47\%) of the stanzas in this specific Discourse applied to others. Additionally, the stanzas within this Discourse were more closely associated with disfigured worlds (55\%) than the average stanza (38\%). This focus on others in dis-figured worlds may be illustrated by Moza's explanation: "The financial condition for my family is not stable these days as my father lost his job recently."

Transformational Victim Discourse. The Transformational Victims Discourse was comprised of the 272 stanzas with Building Task Codes in at least one of these three categories: Academics, Victims, and/or Villains. This Discourse considered the relationship between academics and victimization. Within the essays, this discussion often referred to the suffering needlessly caused by others. The suffering described was more emotional than utilitarian - for example, feeling hopeless (emotional) as compared to simply not having funding (utilitarian). The stanzas within this Discourse were (slightly) more likely to refer to others in dis-figured worlds than expected. Instead of comprising $40 \%$ of the stanzas about others, those in this Discourse comprised 43\%. Likewise, instead of making up only $50 \%$ of all stanzas about dis-figured worlds, they made up 54\%. The difference in distribution between normal and abnormal worlds for others was more substantial. Instead of being equally distributed (50\%-50\%), only $35 \%$ referred to normally-figured worlds, while $65 \%$ referred to dis-figured worlds - meaning a greater focus on others in dis-figured worlds. Layan expressed the need to support "students who are in desperate need...in order to receive their education rights" with the term "desperate" being used to emphasize the abnormal nature of the situation. 
Transactional Victor Discourse. The categories of Agency, Economics, and Academic-Financial were used to identify stanzas within the Transactional Victors Discourse. These 295 Transactional Victor stanzas were often focused on building careers and seeking financing for education. This Discourse represented slightly more than its expected share of all stanzas as it accounted for $68 \%$ rather than the $64 \%$ of all stanzas. It was also more likely to refer to applicants in normally-figured worlds (77\%) than expected (70\%). This illustrates the importance of the applicants' assumptions that their victories regarding the transactional aspects of education were normal, representing the way the world should be. The stanzas comprising the Transactional Victors Discourse also referred to others. The stanzas discussing others represented a larger proportion of normal scenarios than expected. The 66 stanzas referring to others in normally-figured worlds represented $69 \%$ of all those referring to others, whereas overall, only $50 \%$ of stanzas referring to others also referred to normally-figured worlds.

Transformational Victor Discourse. As anticipated, the most prominent of the four was the Transformational Victors Discourse. The categories used to identify stanzas in this block included both Agency and Academics. Discussions in this Discourse revolved around the ways in which education could transform a society. A common theme was that of applicants sharing how their educational success would lead to positive change in their communities. Unlike the "transactional" discourses, this change was constructed as having meaning, and/or as having positive ripple effects beyond that of simple economic development, or the ability to earn more money. Laleh's desire "to overcome illiteracy in [her] family" was one simple example. 
The 315 stanzas comprising this final Discourse represented $72 \%$ of all 435 stanzas and were much more common in scenarios discussing applicants in normal situations than would be expected given the general distribution of stanzas. When focused on applicants, over three-fourths $(78 \%)$ of the stanzas referred to their normally figured worlds (vs. $70 \%$ for all stanzas), leaving only $22 \%$ referring to their dis-figured worlds (vs. $30 \%$ ). However, there were also more statements that were more clearly "transformational" as outlined in Chapter Two. These include Amara's goal to become highly specialized in her medical field and thus “adding [her] knowledge to [that] field." Laleh wrote that her attainment of a college degree would "be the first of its kind in the history of [her] family" thereby becoming transformative.

Although the stanzas in this Discourse were not nearly as focused on others (only $34 \%$ ), the applicants still discussed the transformative potential for their families and communities. Layan explained that education "defines one's future." Amara suggested that for her war-ravaged community, "education is the key factor that can help us to cope with the conflict and instill a sense of purpose in [the] future." Applicants discussed the potential transformative power of education beyond that of economic and psychological improvements in their references to education as a (human) right. Amara, Layan, Nifa, and Rada all referred to education as a right for others (as well as for themselves).

Four Discourses in Context. The Discourses described here reflect debates (Gee's "Conversations") about the role of education and the identities of students: Transactional Victims, Transformative Victims, Transactional Victors, and Transformative Victors. This section will illustrate the ways in which these Discourses were shared via the stories of three groups of women. These three groups each consist of two-three women whose trajectories 
described in their essays were quite similar to each other: 1) Gaeti and Moza, 2) Mahin and Rayna, and 3) Laleh, Lawan, and Rada. Each group of women was approximately the same age, from the same country, and had similar distributions of engagement with the Four Discourses.

Gaeti \& Moza. The first group was Gaeti and Moza. They were among the younger applicants and were both forcibly displaced from the same country in West Asia: Yemen. As conflict continued to worsen, their home country's economic situation deteriorated to the point that it was re-categorized from a lower-middle-income country to a low-income country. Both women were seeking degrees in the field of Architecture \& Design and sought to obtain these degrees in an upper-middle-income country in East Asia. The programs they sought were offered in English - meaning that they would be in a different cultural and linguistic environment.

Gaeti and Moza were much more likely to focus on Discourses about victory than about victimhood with almost two-thirds (an average of 63\%) of their essays engaging in either the Transactional Victors or Transformational Victors Discourse. Gaeti and Moza both referenced the Transactional Victor Discourse - as illustrated by Moza's stated goals which included completion of her current baccalaureate degree, obtaining a master's degree, after which she would then "work and search a lot to have enough experience to start [her] own business and be a successful person." They both also mentioned the economic considerations of their choice of academic program and university.

"Dreams" were central to their discussions, with variants of the term being used 10 times. As dreaming is generally not thought of in utilitarian terms, it meant that Gaeti and Moza focused a lot on the transformational aspects of their experiences. For example, Gaeti 
noted: "I hope that my dream will become true," and that she wanted "to get a grant to achieve [her] dream." Likewise, Moza shared that she had "a future plan and many dreams to make it true." When combined with discussions about agency, these two women engaged in the Transformational Victor Discourse. For example, Moza shared:

I am trying to put all my effort in my studies and always trying to learn new things to reach to the successful future that I always dream about, I do also have a future plan and many dreams to make it true. I do have a lot of aims and dreams that this scholarship would really help me to reach...I will improve my studies and experience to be something important in the future.

Gaeti shared that all she wanted was "to get this scholarship that will completely change my life, and that will make me feel more like a person with a special vision and help me to make my country and the whole world a better place." Like Gaeti, Moza also focused on her ability to transform her community with her education. She shared:

My future is not only about me and my family - I would never forget my country and one of my biggest dreams [is] to go back to my country after when I am ready with my degrees and experience to help rebuild it again, helping to improve it, and making it look like before and better especially after the big damages that were caused by the war there which demolished most of the buildings in my country and me as an [Architect \& Designer] will help to make it all better and designed in a great way soon.

However, their essays were far from completely focused on success. Both women had been forcibly displaced from their homes and found themselves in unfortunate financial and emotional situations. They engaged in Discourses about Transactional Victimization - 
primarily focused on their lack of funding to attend school. In contrast to many of the applicants, these two women engaged in this Discourse when discussing others, primarily their parents' reduced ability to financially support their education.

They engaged in Discourses around Transformational Victimization in two ways. The first was by explaining how they were suffering as they were not able to achieve their dreams. As Gaeti explained, "I have suffered over the last three years because of the years that I have wasted [while some of my friends have graduated] and I am still wasting time and [need] to get a grant to achieve my dream." The second way was in reference to their future goals. Moza pointed out the ongoing destruction of "most of the buildings in [her] country." As both women were seeking degrees in Architecture \& Design, their goals included returning home to Yemen to help rebuild (literally) once the war was over. These goals were highlighted through their more substantial emphasis on Discourses focused on victory.

Mahin \& Rayna. Mahin and Rayna comprised the second group. Both women were older and had both financial and familial obligations. They both grew up in Liberia, where ongoing conflict had significantly impacted their lives in a multitude of ways. Despite this conflict, they both remained in Liberia - a low-income country in Sub-Saharan Africa and had goals to help alleviate some of the suffering in their local communities.

In contrast to Gaeti and Moza, Mahin and Rayna were much more likely to focus on Discourses about victimization than victory, with an average of $57 \%$ of their essays focused on victimization. Both women chose to highlight the many traumatic experiences and ongoing challenges they had faced since childhood. By the age of seven, Mahin had begun to suffer in multiple ways due to the ongoing conflict in her country. She had been abused by both her caretakers and via a forced marriage to a man over three times her age when she was 
a teenager. During this time, she described the ways in which she had been both exploited and enslaved. Rayna had been kidnapped and enslaved by rebel forces at the age of six. She lost her family when these forces staged a surprise attack on her home town. Once freed, she was taken care of by a surrogate mother. Unfortunately, this older woman was a widow, impoverished, and perished in the Ebola epidemic. Mahin and Rayna both sought education for its economic opportunities as well as for the resources it would provide them to help support those in their communities who were suffering.

Given the situations within their country, discussions within the Transactional Victim Discourse were prevalent. They discussed both themselves and their communities as victims. For example, Rayna shared that she had "been making attempts since the completion of high school to seek opportunity for college or university education. All of [her] efforts [had] not materialized up to the date of this application." She explained the financial difficulties she had faced once she escaped captivity and attempted to resettle. In addition to her enslavement, her adopted mother was a widow "faced with serious financial situations" who then died, leaving Rayna alone without any assistance or support. Mahin described the weak job market and explained that she needed higher levels of education to be able to obtain "reasonable employment." Mahin noted that in her community there were:

no basic social services such as school, clinic and safe drinking water. Children as early as 6-7 years old are compelled to leave their parents to go elsewhere for schooling and those without relations outside the community live with acute illiteracy, pregnant women and children have to be taken in hammocks on a very long distance only to get to the clinic and a frequent outbreak of diarrhea [occurs] due to the lack of safe drinking water. 
Mahin began her essay with the statement, "I gr[e]w up under a very challenging condition." Within her first paragraph alone, she mentions seven different traumatic events that caused her great suffering as well as delaying and interrupting her schooling. The use of terms such as "challenging" and "suffering" indicate that this victimhood involves more than simple utilitarian issues (i.e. funding). Through their explanations of the various challenges they had survived and faced, both Mahin and Rayna engaged deeply with the Transformational Victim Discourse.

Engagement with Discourses around victory were minimal and often tied closely to victimization. As an example, Rayna stated that she had "been accepted for enrollment to start in September" (Transactional Victor), but she was unable to attend due to her lack of funds (Transactional Victim). These two women also engaged with the Transformational Victor Discourse. Mahin shared that in her teens, she began to stand up to a parental figure who had been abusing her. As a result, within a year, she had been forced into an abusive marriage. Finally, after many years of abuse by multiple people in her family and community, she "escaped from the village to renew [her] life." Both women engaged in this Discourse when discussing how they hoped to help their communities. Rayna explained that she wanted "to spend the rest of [her] life working for the welfare of orphans and less privileged children." Mahin shared that her dream was "develop capacity which will give me the prospect to give to the development of my community, focusing [on] women and children who are disadvantaged in life like I am." Rayna also stated that her receipt of the scholarship would "not only build my capacity and offer opportunity for me; but I am also determined to have the benefits from this second chance to wriggle down to my community and eventually 
the larger society through voluntary community services to address the issues of orphans and youths involved in drug...abuse.”

Laleh, Lawan, \& Rada. Three women from South Sudan comprised the third group. Laleh, Lawan, and Rada were all older, and shared that they were originally from South Sudan. Despite the country's inaugural classification as a lower-middle-income country (in 2011), it had been down-graded to a low-income country by the time these women applied for the Asherah Foundation scholarship. Laleh and Rada both had financial and familial obligations. Laleh and Lawan were both going to school in different Sub-Saharan countries, meaning that their educational experiences involved different cultural environments. These women were more balanced in their engagement with the various Discourses than the previous two groups.

Their engagement with the Transactional Victim Discourse included Lawan's explanation that she was "not able to [pay] my tuition on time and sometime [sic] am being chased from class because of the tuition fee." Laleh shared that she had not been able to begin her program "due to lack of financial support" and "had found it very hard to be able to afford a semester and all the other requirements that come with the award of admission into a university." Due to the "constant war and insecurity" in her country, she had to abandon her “job and flee the Country for [her] safety and that of [her] children." Rada noted that her educational journey had been difficult as she had spent her entire life in a refugee camp. She was "unable to pay for [her] higher studies or get a good job that would enable [her] to pay for [her] higher education."

This Discourse was also present in discussions about others. Laleh mentioned that the deteriorating situation in her country had "also worsen[ed] things for [her] parents in meeting 
high tuition fees for higher institutions of learning." Rada shared that her country had been plagued by war for decades, "leaving thousands dead and million[s] displaced."

The Transformational Victim Discourse was less prevalent and was predominantly engaged in by Rada. She highlighted the ways in which the violent "ethnic and tribal conflicts in South Sudan represents not only a significant barrier to health development; it also wipes out efforts in improving the situation and finally inflict a lot of suffering on the people and the entire country." The violence she describes impacted complex systems and caused a great deal of suffering. She illustrates the consequences of ongoing conflict which were:

worse than anybody can imagine; naked violation of Human Rights, a complete breakdown of law and order, stalled economic activities; famine, rape, high rate of illiteracy, an abject poverty, lack of political order, proliferation of small arms in the hands of civilians that has resulted into uncontrolled insecurity in the Country and so on.

Rada was also descriptive about the utilitarian ways she was going to improve her life and her community via education - thus engaging in the Transactional Victor Discourse. Her program of study would provide her with "up-to-date knowledge and skills in public health." After completing the degree and working professionally in the field for a few years, she explained that she would work to address her "country's shortage of qualified personnel" in the field by engaging in advocacy, research, and teaching. Simple statements such as Laleh's announcement that she had been "promoted after six months to [management] effective from...2015 to...2016." were also components of this Discourse. 
Rada also engaged with the Transformational Victor Discourse as she explained her goals for the future. She expressed that she was "confident that [she would] acquire knowledge that [would] enable [her] to contribute towards the transformation of [her] community and [it was her] wish to make it come true." She also noted that her educational success would allow her to "to contribute significantly to the transformation of [her] country and also become a source of inspiration for others." Finally, she was:

convinced that this scholarship [would] make [her] feel proud and at the same time obliged because [she was] aware of the community [she was] aspiring to be part and parcel of and this is where [her] real undergraduate studies will work, our contemporary society is full of challenges and equally full of opportunities, it [would be her] responsibility to harvest opportunity hidden in these challenges that our contemporary society possess and make the best of these opportunities to bring a change in [her] community in order to establish a community of service and character...[she was] confident that [she would] acquire knowledge that [would] enable [her] to contribute towards the transformation of [her] community and it [was her] wish to make it come true.

Laleh shared that she had the "opportunity to become the first person in [her] family to attend college [and thus] to realize what has been a long-term goal for [her] and a dream for [her] parents. She believed that attaining her university degree would inspire her "relatives and the entire community to eventually value girl child education after seeing [her] achievements $[s i c]$." She also sought to "be exemplary and a role model for many young girls and women [in her] Community.” Finally, Lawan explained that her ability to access education (via the scholarship) would enable her to "be able to stand to advocate for the 
voiceless [e]specially women and children who are the most vulnerable people in our community" in the context of their human rights having been disrespected.

\section{Findings for Part III: Wider Societal Context (What Might Be?)}

So far, this chapter has answered the central question guiding this study about "What is?": What do nontraditional women from conflict-affected, lower income regions say about their journeys to higher education despite tremendous obstacles including violence and poverty? Identifying applicants' assumptions about education and its role in their lives provided insight. Despite their obstacles, these women identified themselves as individuals and as members of communities with agency. They exercised agency in fighting for their education, and in seeking to help their communities. They identified the role of education in their experiences as both transactional and transformational. It was transactional in that it required money to access it, and in that it would help develop their careers and professional skills. It was transformational as it provided opportunities to help the victims in their families and communities - both practically and emotionally. It was also transformational as their ability to access it would inspire others to seek out education as well.

The secondary research question, "What Might Be?” was also addressed through examination of the ways in which the application essays were aligned with Conversations and Discourses about the purposes of education and the role of women in relation to these purposes. It sought to answer the question, "How do these discourses compare to those of women in similar situations?" This analytical question was asked to address Gee's concepts of "agreement" and "coverage" as they pertain to the validity of the findings.

Per Fairclough (2013), Critical Discourse Analysis seeks to critique existing Discourses by reflecting on the wider social contexts within which they were created, in 
order to answer the question of "what might be?", this research used two additional Building Tasks for this reflection: Sign Systems \& Knowledges and Connections. Looking at how these two Building Tasks were both used and not used provided insight into what else might be possible for these 10 women. Answering this question also provided insight into areas of future research, as well as potential implications for IOs and the Asherah Foundation.

Connections Building Task. What were the key connections among identities, practices, and social goods? Earlier parts of this chapter illustrated how the applicants connected education with agency, victimization, finance, and their communities. The stanzas within these applications highlighted connections that those concerned with global educational goals should consider. For example, the women within this study connected conflict with employment. They were women whose lives had been upended by conflict, yet they still assumed that they would, and should, have careers. They also assumed that they would have a leadership role in helping their communities.

Identifying what was not connected was also informative. These applicants strongly connected the economic aspects of education with normally-figured worlds. There were no instances where a stanza focused totally on the economic aspects of education was presented in a dis-figured world. The literature reviewed in Chapter Two highlighted connections among women, education, nontraditional students, and conflict - not all of which were reflected in these applications. For example, there was little discussion about the impact of their culturally and linguistically diverse backgrounds in terms of their journey to higher education. Although the majority were attending schools in a country different than their own, the potential barriers of a different culture and/or linguistic background were not discussed. For many nontraditional students in the Global North, the obligations of family 
and dependents often are a barrier to success. These obligations were barely mentioned even though many of the women had family responsibilities.

The UN Sustainable Development Goals connected improved access to education with a number of related development goals, many of which were not addressed by these applicants. The 2016 GEM Report highlighted (for example) "more sustainable farming methods" improved health outcomes in terms of "early mortality, reproductive health, the spread of disease...better energy conservation and uptake of renewable energy sources," improvement in "social and economic inequality," understanding of climate change, skills to develop more sustainable lifestyles, and capacity building "to understand and promote sustainable development policies and practices." (see Table 1: How Education is Typically Linked with Other Sustainable Development Goals). These connections were made throughout the GEM Reports and were highlighted by other IO Discourses and academic research critiquing global education goals discussed in Chapter Two. However, these applicants did not discuss their goals in terms of environmental sustainability. Their discussions about development were focused on re- building their war-ravaged communities, not developing more environmentally-friendly or resilient communities as recommended by the Global North. Although there were two applicants pursuing education in health-related fields, there was no discussions around either reducing early mortality or communicable diseases. Although two women described sexual assault, they did not discuss matters around reproductive health.

Sign Systems and Knowledges. This Building Task uses languages (sign systems) and claims of knowing and believing (knowledges) to create worlds. The neo-colonial critiques discussed in Chapter Two highlight the importance of understanding who is 
claiming to know something, and how they communicate it. The applications used in this research were all submitted in English, privileging those who speak this language. The applications were for programs in accredited institutions of higher education. This focus privileges formal systems of education.

Looking at the two alternate groups provided insight into what Sign Systems \& Knowledges were not used by the 10 women who were the focus of this study. As an example, the students within the graduate group were much more likely to focus on academics and economics than these 10 women, perhaps because they were in graduate programs. This makes sense as academics and economics pertaining to their education had already been a substantial and successful part of their lives. The women in the undergraduate alternate group were also more likely to discuss issues around health. As many of them were enrolled in healthcare-related programs, this also makes sense. Finally, the main population of this study also discussed victimization much more than the two alternate groups. Although these findings are not surprising, they highlight other sign systems and ways of knowing. For example, how did the academic discipline of each applicant influence what she wrote about? Why did they and the graduate group highlight their experiences with conflict when those in the undergraduate group did not? Why did the 10 women at the heart of this research focus so much on victimization when compared to the other two groups? Despite being in conflictaffected and fragile situations, were the women in the two alternate groups simply more privileged? Were there socio-economic factors that should have been taken into account?

\section{Findings for Part VI: What else is possible?}

The final part of this analysis sought to understand what else was possible, and to highlight ways in which critiques regarding inequities might be addressed. In order to 
understand "what else was possible" the analysis first needed to understand "what [already] is" in terms of the wider social context within which these applicants submitted their applications. Critical discourse analysis enables a researcher to critically examine the social realities that are constructed through discourses. This enables identification of possible structures of power that are responsible for these constructions, and that inhibit other social realities from being created. These structures of power will be examined as components of the Wider Societal Context of their applications. These structures of power are tied to the Discourses of IOs such as the UN and the World Bank, the Asherah Foundation, and of this research.

Throughout, this research has analyzed the discourses created by a group of women applying for an academic scholarship. It has discussed how their discourses aligned with larger Discourses about the role of education and about the role of women regarding education. This section seeks to highlight structures of power undergirding these Discourses.

Saarinen highlighted the "persuasive presuppositions" of Discourses engineered by organizations such as the UN. She noted that "[p]resuppositions set the assumed common ground, which in turn sets the frame of interpretation of texts" (2008, p. 341). Discourses created by IOs are often built via specific contributions to the working vocabulary and through "sharing best practices, highlighting innovative policy developments, establishing common definitions, and setting the frameworks through which state actors operate" (Shahjahan \& Madden, 2015, p. 708) (see also Antunes, 2006; King, R. 2009; Lebeau \& Sall, 2011; and Wende, 2011).

Why does all of this matter? Critiques of global goals for education revolve around those assumptions, interpretations, and definitions that are developed and promoted via these 
Discourses. As discussed in Chapter Two, neoliberal critiques focus on the damage caused by narrow definitions of what education should be. Neo-colonial critiques focus on the ways in which the Global North has influenced these Discourses at the expense of the Global South. All of these critiques focus on the lack of diversity in the definitions, interpretations, and assumptions about the purpose of education and the identities of students.

This section will begin to answer the question "What else is possible?" through highlighting the assumptions, interpretations and definitions in global Discourses about education that have been discussed throughout this dissertation. These assumptions are seen by looking at what is being connected through the lens of Gee's Building Task: Connections. Interpretations and definitions are delineated by the Sign Systems and Knowledges that are privileged. Understanding better "what is" is essential to identifying structures of power and addressing how resulting inequities may be addressed. This understanding will better illuminate "what else is possible" for applicants, for the Asherah Foundation, and IOs. Additionally, addressing these questions will provide insight into the context of this research and to implications for future research. Discussion about "what might be" and "what else is possible" will be examined through the "Implications" section of Chapter Five. These implications include answers to the question: How might critiques regarding inequities be addressed?

\section{International Organizations (IOs)}

What is? Gee's Building Tasks, Connections and Sign Systems \& Knowledges, are key components of the worlds that IOs such as the UN are constructing through the discourses they produce, and the Discourses they engage in. These organizations connect education and students in ways that shape how policies are made, who is included in the 
policy-making, and how resources (i.e. funding) are distributed. As outlined in Chapter Two, there are several key ways in which education and students are connected. There are also Sign Systems and Knowledges that are privileged.

Education is connected to sustainable development. It is connected to long term economic growth, including improvements in decent work outcomes and labor markets. It is also connected to achieving social development goals, particularly regarding health outcomes. Education is "an enabling right, i.e. it enables other human rights" (UNESCO, 2016a, p. 8) which are essential to the success of global goals such as the SDGs.

Women are connected to education in a variety of ways. As described earlier, education for women is tied to achieving all 17 of the SDGs. Women who are educated are able to improve the health of their children and enhance the capacity of these children to achieve higher levels of education. Women who have access to education can improve their economies, improve civic engagement, and reduce corruption.

These organizations privilege certain Sign Systems and Knowledges in their discourses. As described in Chapter Two, neoliberal Discourses are often privileged. These Discourses use "specific language to establish 'facts' and give meaning to the workings of the economy...[they] predispose various modes of theoretical thought and methodological inquiry that shape what truths can be known about the economy" (2017, p. 18). These might include: "economic deregulation, complete privatization, free trade and a reduction in government size and spending for the creation of a strong private sector" as well as "the valorising of individual agency" (p. 19).

Structures of power. As critics argue, the global goals for education were created by IOs in the Global North that have vested interests in maintaining the global status quo. This 
means these global goals focus more on the neoliberal aspects of education and less on the role of education as a potent tool for transformation. The neoliberal focus puts the onus on accessing education on the student and removes it from society (Barton, 2005; Briant Carant, 2017). Thus, educational systems in the Global South remain underdeveloped as resources are put into scholarships and efforts to further develop the "better" systems of higher education in the Global North. Those in the Global North control the Discourses, and the purse strings, enabling them to decide what knowledge "counts" and who gets to access it, how they can access it, and for what purposes. The knowledge that "counts" is generally knowledge developed by experts and institutions in the Global North. As this knowledge "counts" it is able to receive financial, political, and intellectual resources. Although attempts are made to bring this knowledge (and related resources) to those in the Global South, the attempts often fail - either as the knowledge is inappropriate for local contexts, or as it draws away valuable resources from those who need it the most (Cummings, Regeer, de Haan, Zweekhorst, \& Bunders, 2017; McCormick, 2014; Mundy, \& Verger, 2015; Shahjahan, \& Madden, 2015; Stein, 2017b; Zapp, 2017). This failure helps maintain neo-colonial structures of power, with "developed" countries maintaining their dominance over "developing" countries.

\section{What is: The Asherah Foundation}

The Asherah Foundation also makes Connections and privileges certain Sign Systems and Knowledges over others. The Connections are highlighted by its application essay prompt: "Please attach an essay illustrating how this scholarship will give you a second chance and how it will benefit your community. Essay shall be no less than 500 words and no more than 1000 words." 
There are several key connections within these two sentences. For example, this prompt connects the scholarship to both "a second chance" and to benefiting their communities. The presence of this prompt in a scholarship application connects the scholarship to education. It connects education to benefiting a community. It connects the applicant to education and to benefiting her community. Through these connections, the organization highlights the purpose of education as something to benefit a community. It focuses on the student as 1) someone needing a "second chance" and 2) as someone who can benefit her community.

The Asherah Foundation also privileges certain Sign Systems and Knowledges. For example, the language of a scholarship application is privileged (over, for example, a piece of dramatic art). It also privileges the knowledge of a certain type of education. By providing scholarships to those attending accredited higher education institutions, it privileges the knowledge gained via the formal higher education sector.

Structures of power. This organization operates in the Global North in order to help those in the Global South through the offering of financial support to underserved women to access higher education. The focus of its work is on helping individuals financially, not on addressing structural causes of inequities in access. Thus, it might be said that it implicitly supports a neoliberal view of higher education. As the provider of funds, the organization (in the Global North) maintains a form of power over constituents in the Global South. This organization seeks to help those in the Global South by providing financial support to certain types of educational institutions, thereby influencing what types of knowledges "count" (those procured from accredited higher education institutions) as well as "appropriate" ways to get this knowledge (via attending these institutions). 


\section{What Is: This Research}

This research made many connections and clearly and systematically privileged certain sign systems and knowledges over others. Key connections in this research included the relationships among applicants, international organizations, and global educational goals. It also connected empirical research on access to education for nontraditional students, students from lower income, and from fragile and conflict-affected states. This research connected the Asherah Foundation to underserved students and to global educational agendas.

As a dissertation submitted in partial fulfillment of the requirements of a Doctor of Philosophy degree, this research privileged sign systems and knowledges associated with formal higher education in the Global North. Sign systems included: English, American Psychological Association (APA) formats, and more formal academic language. Knowledges included empirical research from peer-reviewed academic journals published by large publishing agencies in the Global North that are often written primarily by academics in the Global North as well.

This research relied on official documents published by International Organizations. Its key theoretical and methodological framework (CDA) was developed by scholars in the Global North and applied to applications submitted to another international organization located in the Global North. It chose to highlight concepts developed by academics and policymakers working for institutions in the Global North and that were part of the knowledges important to these groups.

Structures of power. As with the Asherah Foundation, this research was conducted in the Global North, by a researcher from the Global North as part of a formal academic 
graduate program in the Global North. In some ways, this dissertation contributes to the hegemony of knowledge production as dictated by the Global North and its capitalist and colonialist power structures (Cummings, Regeer, de Haan, Zweekhorst, \& Bunders, 2017; McCormick, 2014; Mundy, \& Verger, 2015; Shahjahan, \& Madden, 2015; Stein, 2017b; Zapp, 2017).

\section{Conclusion}

This chapter has answered the central question guiding this study about "What is?": What do nontraditional women from conflict-affected, lower income regions say about their journeys to higher education despite tremendous obstacles including violence and poverty? It illustrated how they identified themselves and the role of education in their experiences, as well as noting power dynamics they appeared to operate within.

The secondary research question, "What Might Be?" was partially addressed through examination of the ways in which the application essays were aligned with Conversations and Discourses about the purposes of education and the role of women in relation to these purposes. These women very clearly positioned themselves as having agency. They had agency to fight for access to education despite the ways in which they had been victimized by conflict and related issues (i.e. poverty). They had agency to help their families and communities rebuild and heal from conflict. However, they themselves were victims. They had their own financial obstacles to overcome in order to access the education that would enable them to help others. They also had to contend with the barriers of protracted conflict and systemic poverty about which they said they had little control.

Finally, this chapter began to answer the question: "What else is possible?" 
by pointing out the complexity of their experiences and advocating for those involved with discourses and Discourses around global goals for education, and with IOs, to consider this complexity. Chapter Five will provide a brief summary, followed by more detailed answers to "What else is possible?" in terms of IOs, the Asherah Foundation, and the women themselves. 


\section{Chapter}

\section{DISCUSSION \& CONCLUSION}

This study began in the context of a global shift in discourses and Discourses around education. The study was inspired by the release of the 2016 Global Education Monitoring (GEM) Report. This report was the first annual report on progress made towards the United Nations' Sustainable Development Goals. It was released in the midst of what was becoming a global migration crisis. Earlier in 2016, this author had started a non-profit, the Asherah Foundation, to provide scholarships to women around the world - many affected by these global shifts. A significant portion of these scholarship seekers were not reflected in the 2016 GEM Report. This prompted discussion about how, and why, these women could be reflected in future reports, leading to the development of this study. Along the way, the author presented aspects of this research at international conferences focused on education and development, while simultaneously continuing to develop the nonprofit.

Discussions about how applicants to the Asherah Foundation could be better reflected in the GEM Reports led to important questions for both research and for the development of this organization. These questions included: "Why should these women be represented in the GEM Reports?", "How would these women want to be represented in these reports?", and finally "What do these women actually say about the role of education in their lives?"

In order to learn more about what these women actually said, this research identified select applicants to the Asherah Foundation Second Chance Scholarship and analyzed how they portrayed themselves and discussed education via their scholarship applications. While the Asherah Foundation has had many applicants, this study sought out those who represented intersecting and overlapping characteristics of underserved student populations: 
adult females, nontraditional, conflict-affected, and from lower income countries. These characteristics included their geographic region, age, level of education, country income levels, and whether or not conflict was involved in their educational journeys. Subsequently, three groups of women were selected. The primary population for this study was composed of 10 undergraduate women from low- and lower-middle-income countries who self-reported that their educational journeys had been affected by conflict. To better understand the context of this group of women, two additional alternative groups (samples) were identified. The first consisted of women with the same demographic characteristics, but with the difference that they had not self-reported that conflict had affected their educational journeys. The second consisted of women with the same profile as the primary sample, but with the difference that they were pursuing graduate degrees.

Gee's recommendations for critical discourse analysis provided the foundation for this study. The application essays of the primary sample were analyzed through identifying six Building Tasks and two Theoretical (Building) Tools. Codes were created, applied, and categorized to highlight patterns of discourse within the application essays of the 10 women in the main population of study. These patterns were further analyzed to understand if, and how, applicants engaged in Conversations aligned with those around the UN's SDGs.

\section{What Can We Learn?}

This research began with the basic question: What do adult women from conflictaffected, lower income regions say about their journeys to higher education despite tremendous obstacles including violence and poverty? In this study, the question was addressed by identifying how a specific subset of applicants to the Asherah Foundation 
Second Chance Scholarship talked about their educational experiences and what Discourses they represented (or not). For this analysis, the specific questions were focused on:

- What is: How do the women identify themselves and the role of education in their experiences?

- What might be: How do these discourses compare to women in similar situations?

- What else is possible: How might critiques regarding inequities be addressed?

\section{What Were Key Findings?}

The analyses demonstrated that applicants engaged in the same Conversations around their access to education as IOs and as critiques of the global educational agendas (Brissett \& Mitter, 2017). Specifically, the applicants highlighted both the transactional and transformative roles of education in their lives. They also highlighted related structures of power through identifying both themselves and others as victims, victors, and even saviors.

To summarize, applicants from the main population of study illustrated the importance of the transactional nature of education. Without funding, women could not access higher education. Without higher education, they could not develop skills, find jobs, and build their careers. Without these essential (neoliberal) resources, they could not help anyone in their communities. They could not have jobs that would financially support their families. They could not save lives, educate and inspire others, or help rebuild war-ravaged communities.

Critics have argued that the SDGs pertaining to education focused efforts on its transactional and neo-capitalist potential at the expense of its transformative role (Briant Carant, 2017; Brissett \& Mitter, 2017). However, these women discussed how the transformative potential of education could not be filled without the transactional aspects 
being realized. While their discussion noted that education could transform their societies, they made it clear that it could only happen once the transactional potential was achieved. In response to these critics, the Discourses of these women highlighted their multifaceted identities. They were complex individuals who could be victims, but who could also achieve victory over obstacles and help lead others to success.

\section{Interpretation of Findings}

There are many barriers hindering underserved students such as Mahin, Lawan, and Rayna from accessing higher education. These involve practical considerations (poverty, bombed-out universities). They also involve more esoteric things, such as the hegemony of knowledge production. These are interrelated, and thus should be of interest to those seeking to improve access to higher education. The following "Implications" section will follow with recommendations to consider "what might be" and even "what else is possible" for International Organizations (IOs) such as the United Nations, for the Asherah Foundation, and for the women who are the focus of this study.

\section{Implications}

\section{How might critiques regarding inequities be addressed?}

Critiques about inequities perpetuated by global educational goals revolve around the lack of diverse perspectives in the development and implementation of these goals, which leads to further entrenchment of inequities. Many of the critics tend towards polarity in their critiques, highlighting one perspective (i.e. the SDGs are too neoliberal) at the expense of others (the potential for a neoliberal focus to be helpful). In order to address these critiques, it is important to appreciate the complexity of each student's experience. As has been illustrated throughout, the women who were the focus of this study have many barriers 
keeping them from accessing higher education. The barriers they identified included both ongoing civil conflict and poverty that was often related to the conflict. These 10 women all had multiple characteristics of what would be termed a "nontraditional" student in the Global North. These characteristics presumably made accessing higher education even more difficult. They included familial and financial responsibilities, different cultural and/or linguistic backgrounds than those of their institutions and being the first in their family to attend higher education (Schatzel, et al., 2011; Suarez-Orozco, Teranishi, Suarez-Orozco, 2015).

These women very clearly positioned themselves as having agency. However, this agency was not absolute. They had agency to fight for access to education despite the ways in which they had been victimized by conflict and related issues (i.e. poverty). They had agency to help their families and communities rebuild and heal from conflict. However, they themselves were victims. They had their own financial obstacles to overcome in order to access the education that would enable them to help others. They also had to contend with the barriers of protracted conflict and systemic poverty about which they said they had little control.

Critiques of global educational goals tend towards polarity. Education is either utilitarian and transactional or it is transformative. It either develops the economy and human capital, or it transforms a society via enhanced human rights and more inclusive political structures. Women, nontraditional students, forcibly displaced individuals, and other underserved groups are either victims who desperately need assistance, or they are exemplars of strength and resilience. As the essays of these 10 women illustrate, the reality is much more complex. For them education was both utilitarian (helping them get a job) and 
transformative. That job would enable them to help others both transactionally (providing financial support) and transformatively (creating new knowledge, inspiring others). They were both victims (of conflict, poverty) and victors - saviors even. They had suffered, but they were still fighting, and were determined to continue to do so until they were able to reach their educational goals and help those around them.

When looking at the structures of power upholding inequities, critics should take into account these complexities. Those hoping to support nontraditional students might focus on how their resilience might help them overcome the obstacles they actually face. Those hoping to support students affected by conflict might focus on ways in which motivations to help their communities may provide resilience. Those hoping to support women might focus on how education can benefit these women personally and transactionally as well as how it might benefit and transform their communities.

\section{Considerations for International Organizations (IOs) (i.e. the United Nations)}

What might be? These findings should ideally encourage more Conversations about underserved populations in education such as women from conflict-affected areas. The barriers these women face should be acknowledged. Their resiliency should also inspire (Baker, et al., 2018; Mangan \& Winter, 2017; Tecle et al., 2017). The pivotal role these women play in their communities should be recognized and highlighted. Their access to higher education is an indication of their privilege in these communities as most of their peers can't even consider such levels of educational attainment. Their perseverance is also a testament to their resilience and their ability to fight for something better. The characteristics of these women should be included in efforts to collect data on access for this particular group of underserved students, as well as for their peers. 
What else is possible? Given the pivotal role these women play in their communities, their voices should also be sought more (Briant Carant, 2017). Critics of the SDGs pointed out that the voices of underserved populations were not included in their development, despite great efforts and despite the publicity created to highlight it. These women, although greatly underserved, have managed to persevere and access higher education despite the tremendous odds against them. They were able to connect with a new Washington, DC-based nonprofit and put together complex scholarship applications. They have much they can share about the complexities of seeking access to higher education in their part of the globe (Cummings et al., 2017) and much they can share about resilience and strength in the place of significant obstacles (Mangan \& Winter, 2017). However, they also are a part of some of the most underserved populations in the world: those from low- and lower-middle-income countries and conflict-affected states. Their communities are those that the UN SDGs are trying to help, but too often they are still neglected or missed.

These women have the ability to bring the voice of their communities into these global conversations around higher education. They also have the ability to support progress towards these goals in ways that work for these communities (which may be different from what a policymaker in Washington, DC thinks). The impetus behind this study was to learn more about this unique population so that it could be included in efforts to develop and achieve global goals for education. The ability for these women to access higher education via an international scholarship program means that they have more stability than others who have been forcibly displaced. Although these women currently have this stability, that was not always their case. Likewise, the international connections they demonstrated through 
their applications may also be new to them. They overcame substantial obstacles to get to the place where they could apply for an international higher education scholarship.

Involving these women in IO Discourses about access to higher education would emphasize the need to consider the complexity of a student's experience. They would highlight the importance of mitigating conflict to ensure progress towards educational goals. They would emphasize the need for financial support for individual students. They would remind policymakers that women of all ages need access to higher education - not just youth. Adult women are capable of re-entering the formal educational system and succeeding. They are interested in professional credentials and in having careers - not just basic skills and jobs.

As critics have suggested, the IOs should re-consider the accuracy and appropriateness of the assumptions undergirding their Discourses. The neoliberal vision of education assumes that accessing education will, in a linear fashion, 1) lead to the development of skills, that will 2) lead to a job, that will then 3) develop the economy. As Andersson and Hatakka (2017), Brissett and Mitter (2017), and Cummings et al., (2017) illustrate, education has many potential outcomes. The development of skills can improve the health of one's family and community, can make one a better parent, and can lead to gainful employment. Education can also lead to increased political participation and civic engagement (Wodon et al., 2018).

\section{Considerations for the Asherah Foundation}

What might be? These findings will help inform the continued development of the Asherah Foundation in several ways. One significant way will be increased scrutiny on communication with applicants. It was disheartening to discover how much applicants described themselves (and others) as victims. Akyüz and Coşkun (2014), Andersson and 
Hatakka (2017), and Freedman (2017) all caution against describing women (especially refugee women) as "victims." Such characterization removes their agency and minimizes their opportunities. It also can distract from the need to address larger systemic issues, such as economic and cultural norms around gender, lack of public services, etc. The organization might investigate ways in which it might be unintentionally encouraging applicants to identify themselves as victims.

Additionally, much of the literature on nontraditional students suggests that a strengths-based approach is more helpful than a victimization focus to such students (Collis \& Reed, 2016; Crea, 2016). One of the most important qualities noted about nontraditional students is their resilience. The women who have applied for the Asherah Foundation's scholarship are generally quite resilient. Finding ways to help highlight this aspect of their experiences should be considered.

What else is possible? Relatedly, the critical discourse analysis framework focuses on giving "voice" to others - especially those who have not traditionally had a voice. This may be done both structurally and conceptually. From a structural perspective, the Asherah Foundation might work with constituents to identify resources beyond money that could support their educational goals. The organization may consider ways to encourage and support applicants seeking additional sources of funds. While the Asherah Foundation already seeks to highlight the voices of these women through its blog literally called "Voices" and its outreach materials, those with these voices could be more integrated into the organization to help improve communication and strategies to better serve these women. One of the founding members of this organization had been the recipient of a second chance scholarship from a different, local organization. Her input had been extremely helpful, but 
since she rotated off the Executive Board (and onto the less formal Advisory Board) her voice has not been as widely heard. One of the first Asherah Foundation scholarship recipients was invited to join the organization's Advisory Board upon her graduation in 2018. She helped review scholarship applications in 2018 and 2019, sharing her insight with the rest of the reviewers. More conceptually, the Asherah Foundation might investigate additional venues to integrate women from conflict areas and graduates of the program into the organization. The organization might continue to identify various opportunities to refine its own assumptions, and to incorporate diverse perspectives (especially from applicants) into its operations.

\section{Considerations for Applicants}

What might be? As the applicants featured in this dissertation illustrated, there are many possible paths to accessing higher education. There are also many barriers. By bringing together research strands focused on conflict-affected students, women, and "nontraditional" students (as defined by literature in the Global North), many possible Conversations became apparent. How similar or different are older female students in the Global North vs. the Global South? How do familial and financial responsibilities impact their ability to access higher education? Familial responsibilities (i.e. child care) did not figure heavily in the application essays analyzed here. However, these discussions are common in literature focused on nontraditional students in the Global North. Do applicants worry about indebtedness for higher education in the Global South to the same extent that students do in the Global North (especially in the United States)?

It was also interesting to consider the many issues that the applicants did not discuss that are often tied with education. Despite the emphasis on the "sustainable" part of the SDGs 
and maintaining the environment, the women featured in this study hardly mentioned it. Was the topic not relevant to them? Are concerns about "sustainable" development just one more idea from the Global North that is inappropriate or irrelevant to those in the Global South? Perhaps when one is concerned about getting shot (for example), the concept of environmental sustainability seems unimportant?

What else is possible? The Discourses about women accessing higher education include women as victims, as victors, as mothers, as human capital, and even as "saviors" as they use their education to "transform" their communities. It was notable that the women in these essays assumed that they would use their education to develop their careers, despite ongoing conflict. There did not seem to be much concern about gendered expectations regarding their capacity to become working, and highly educated, professionals. Going a step further, where were Discourses about women becoming leaders in both business and government? Where were discussions about women working to become wealthy? Where were discussions about women using education to seek political power? Also, where were discussions about men taking on familial responsibilities? Where were discussions about men "transforming" their communities and improving human rights? "What else is possible" is that these additional Discourses need to be developed and shared. These additional Discourses may lead to improvements in gender-related structural inequities (Briant Carant, 2017).

\section{Considerations for this Research}

What might be? As will be discussed more below in the section "Reflection on Researcher's Experience," there are many other ways in which this research could have been done. There are many, many other Connections that could have been made and other Sign 
Systems and Knowledges that could have been privileged. What else is possible? There are also many future possibilities for research as articulated in the section "Recommendations for Further Study." A future iteration of this research could more directly involve the applicants featured here. They might recommend more pertinent topics for research, more relevant Connections to be made, and Sign Systems and Knowledges that are more reflective of their experiences.

\section{Recommendations for Action}

\section{Who Should Care?}

The findings of this research should be of interest to many. The Executive Board of the Asherah Foundation may consider it in strategic planning efforts. International organizations such as the United Nations should be aware of these women's experiences. Both UNESCO and UNHCR are interested in improving educational attainment for conflictaffected people and may learn from the experiences of these women. Relatedly, organizations such as the World Bank may also find this research of interest. The ways in which these women discuss their access to education may shape methods of data collection, inform analysis of data, and provide insight into potential funding decisions.

\section{Dissemination of Results}

The results of this analysis will be shared with the Executive Board of the Asherah Foundation. Some elements may be used to inform communication with potential applicants. Other elements may inform outreach to potential supporters and donors. Data around the underserved populations these women represent are regularly used in social media and fundraising campaigns. Future use of this data may be better contextualized as a result of this research. 
Elements of this research have already been shared with global audiences. In 2014, the researcher spoke at the United Nations about the potential role of international higher education in what would become the SDGs. In 2017, three presentations about this research were given at international conferences concerned with education and sustainable development, with two papers published as a result. Also, in 2017, an early version of this research was shared with developers of the GEM Reports in efforts to help shape what became the 2019 GEM Report focused on education for forcibly displaced populations. Although no specific presentations or academic publications are currently planned, it is expected that the results of this research will be shared in a variety of ways.

\section{Recommendations for Further Study}

All research has its limitations. There are always additional questions to be asked and new information to incorporate. As outlined above, much of the discussion around education for underserved populations like these 10 women has changed since this study formally began in 2016. The UNHCR has since developed significant resources to help refugees access education. The publication of the 2019 GEM Report undoubtedly has shaped this research and these discussions. On a more practical note, the income status of various countries has shifted due to economic changes. Migration continues to both increase and change due to policies, economics, and climate changes. When this study began in 2016 , the world was experiencing unprecedented levels of forced displacement, with 65 million people having been driven from their homes. Since then, the numbers have continued to climb to 70.8 million, with around " 37,000 people a day being forced to flee their homes because of conflict and persecution" at a rate of one person every two seconds (UNHCR, 2016a, 2019). 
As discussed earlier, there are many connections that were not made, and ways of knowing that were not highlighted. For example, what role does socio-economic status play in the ways in which these women seek to access education? As many of them have chosen universities in a new country, how do culture and language impact their options? Future research might investigate how their experiences are aligned with (or not!) research on international student integration into their universities. There is growing research highlighting the practical resources and supports that nontraditional students in the Global North need to succeed in higher education (Collis \& Reed, 2016). How do the findings of this research apply to these women? How do these lessons from the Global North translate into the Global South? What can these nontraditional women in the Global South teach researchers in the Global North?

For this particular research focus, a next step may be to more fully analyze the application essays of the two alternate groups used to help identify the context of the main population of study. As English was not the first language of many of these women, it would be good to bring in others with fluency in other languages. Given the explosion of academic research, white papers, conference proceedings, and reports since 2016, additional literature reviews would be useful (Myklebust, 2019). An analysis of this explosion of data would also be informative on its own. For example, who is doing the research? Who is doing the publishing? How have critiques about the predominance of research from the Global North been addressed? Has there been a corresponding increase in the number of publications from researchers and experts in the Global South (Mwangi et al., 2018)?

The ability to focus closely on the discourses of these 10 women had both strengths and limitations. The strengths included the ability to analyze how broad, global Discourses 
and Conversations were, or were not, a part of their lives. For example, seeing how an applicant could describe herself as both a victim of a regime and a savior of her community was instructive. Limitations included the lack of information about the actual socioeconomic-political context each applicant was living in. How did her socio-economicpolitical situation influence her educational trajectory? How did it help or how did it hinder her educational journey? How important were her culture, her religion, and her language abilities to her success?

Critical Discourse Analysis (CDA) is a powerful framework and method for understanding the complexity of a situation and of an individual. It is also a powerful framework and method for understanding one's own discourses (and Discourses) as it raises awareness of the many subconscious choices that are made throughout the research process. Despite this, it is limited in its capacity to identify how closely a discourse matches the actual intentions of the person creating it. For example, how accurate and/or honest were these applicants about their situations? What did they leave out? What did they over-emphasize? What word choices did they make to try to persuade the scholarship reviewers to award them the funds?

There are three key considerations for those engaging in CDA: counter-arguments, triangulation, and ongoing reflection. Seeking counter-arguments is an essential component of both triangulation and reflection. Looking for data that contradicts an idea is important in illustrating the strength of that idea. Triangulation helps to verify the strength (or not) of an argument. Reflection on the context within which the piece of discourse was produced provides insight into what may, or may not be, prominent. Why (and when) a woman decided to write an application for an international scholarship matters to how the application is 
analyzed. Reflections on the institutional context helps identify why a scholarship is important. Reflections on the wider societal context illustrate why the scholarship might have been offered, why the woman was seeking out higher education, and why she chose to tell certain parts of her story over others. Reflections on the research process itself helps outline why certain analytical choices are made, or not made. Why does the topic matter to the researcher? What Discourses is (s)he invoking? What Conversations is (s)he engaging in by doing the research? Ongoing reflections on the research process are key to uncovering potential subconscious bias, and to helping seek out contradictory perspectives.

\section{Reflection on Researcher's Experience}

\section{Possible Bias of Researcher}

Throughout this study, I have sought to recognize any personal biases or preconceived ideas that may have influenced the steps of analysis and the analysis itself. In efforts to mitigate any influence from such bias, I tried to quantify results in ways that "the numbers would tell the story" so that my voice would be less present. Earlier versions of this research had a multitude of charts and graphs that were inserted to highlight possible patterns in the data (and to remove a bit of the focus on the individual applicant). Obviously, the desire to quantify results and rely on numbers is itself a bias. Likewise, the selection of Discourses to be focused on was a result of what I thought would be of value in this research.

Ongoing reflection on this research helped ensure the validity of the findings. This was helped by looking at the data in a variety of ways, by seeking out additional data, and by soliciting ongoing feedback from multiple sources. As discussed in Chapter Three, the analysis consisted of nine concrete steps meant to look at the data from a variety of perspectives. The 10 women in the main population of study were identified after analyzing a 
large number of applications. The Building Tasks decided on were identified after using all of them to analyze several application essays. Additional data was sought out through engaging with two alternative groups, and through ongoing reflection about the selection of all three groups as additional empirical literature was published and GEM Reports were released. Feedback was solicited from multiple sources. These included my gracious dissertation committee, members of the Executive and Advisory Boards of the Asherah Foundation, colleagues in the PhD program, and colleagues through my professional work in international education.

There are many, many other ways in which this research could have been done. Additional research might involve a closer analysis of the stanzas in the two alternative groups. It could engage with applications in other languages. Future research might explore relations among an applicant's academic discipline, her socio-economic-political status, her family structure, and her culture, religion, and language(s). Sharing research on nontraditional students in the Global North with applicants from the Global South could be an interesting project. How would these applicants view this research? Would they think it was applicable to them in their context? What would they recommend to their peers in the Global North?

\section{Possible Effects of the Research on the Participants}

Telling the stories of these underserved women through this dissertation helps share their experiences with others around the world. Women in similar situations might be able to realize they are not alone in their experiences. Hopefully, the resilience demonstrated by those featured in this research will inspire others confronted with obstacles to education. In a less direct way, this research will help articulate the need for more to be done to identify and 
assist underserved populations - particularly nontraditional women dealing with both conflict and poverty. Hearing about the experiences of actual people can give meaning to abstract datasets, put a human face on otherwise de-humanized policies, and provide insight into the various nuances of actual experience "on the ground." In communicating about these women, it is essential to highlight their strengths - particularly their resiliency. It is also important to ensure that their voices are being heard, and their complex realities appreciated.

The Asherah Foundation focuses on providing financing for formal and accredited higher education, thereby encouraging continued investment within this sector. Research on these applicants brings more attention to the topic. Women are encouraged to attain credentials from these institutions, without questioning the actual value of their degree. Will they learn skills that will enable them to transform their lives in the ways that they want? Will their degree enable them to obtain the employment they seek? Is the financial burden they are taking on worth it? Will they be able to repay any loans and/or make up for lost time in the workforce? Does their attendance at their institution of choice harm the educational prospects of their community? For example, does it divert funds from a poorer community (without a university) to a more developed one (with the university)?

Another critique is the neo-colonial hegemony of knowledge production. How does this research contribute to the maintenance of harmful power structures? Does this research, which privileges the English language and "Northern" scholars take away from focus on knowledge in other languages and "Southern" scholars? Does the seeking of a formal graduate degree from a university in the Global North take away from universities in the Global South? 
Finally, there are critiques about the focus on women in this research. For example, by focusing on women, does this research maintain the status quo of women as "victims" in some way? Did they need to have research done about them? By focusing on their relationships - particularly on how they might "help" others - does this further entrench notions around women existing to serve others? What if their educational goals were to make themselves happy and/or to make themselves wealthier? De Jong's identification of "complicit sisters" has been instructive throughout. These "complicit sisters" are "women who share certain gendered experiences with the women they seek to support and as women whose subjectivities and positionalities are intertwined with the material inequalities and power structures that have marginalized others" (De Jong, 2017, p. 191). How can this work provide voice despite the structures of power involved?

\section{Changes in Researcher Thinking}

As a researcher pursuing a $\mathrm{PhD}$ at an $\mathrm{R} 1$ university about an international topic, who works in the professional international education sector, and who operates an international nonprofit focused on higher education, I exist in a very privileged and homogenous bubble. The majority of people I interact with, the research I seek, and the questions I ask are in a world where 1) English is the dominant language, 2) higher education is regarded as very important and generally positive, 3) appreciation for diversity is essential. In addition, concerns about damage caused by our hegemony of knowledge production are common. Discussing these concerns signals both one's "virtue" and one's erudition. Development of policies, research, and programs to address global issues like "refugees" and "underserved populations in the Global South" are central to our work. However, this development generally takes place in climate-controlled offices in cities where ongoing, disruptive civil 
conflict is not a threat, where those involved are not too concerned about access to food, clean water, reliable electricity, and legal protections. This environment separates the researchers and policymakers from the reality of those they seek to serve.

In conducting this research, I was surprised by the importance applicants gave to things that academic critics of the SDGs either didn't address or didn't treat as important. For example, the primacy of Discourses around the "transactional" nature of education was unexpected. In addition, the "structures of power" that kept applicants from transforming their lives were things like bombing of schools, kidnapping, slavery, and poverty resulting from conflict. The idea of a "hegemony of knowledge production" being problematic seemed laughable in that context. This was an important reminder about the privilege of being able to think about such ideas, and the power dynamics that have created that privilege (De Jong, 2017). Getting education to develop skills and get jobs (transactional) was of much more immediate importance than vague notions of "empowering" their children or developing "local" knowledge (transformative).

\section{Conclusion}

This research has sought to highlight the ways in which women in an underserved population discuss the role of education in their lives. As organizations like the Asherah Foundation continues to offer scholarships, and the UN continues to urge progress towards the SDGs, they would be wise to listen to these women, and to reflect on how educational goals are discussed by them. How can these resilient women be brought more into the conversations to share about their experiences? How can their resilience and ability to lead become more of a focus than their victimhood? More practically, how can more funding go to support these women? How can international organizations help remove the barriers of 
war and poverty so that they can access higher education? How can their voices become more integral to Discourses about the role of education for women around the world? 


\section{BIBLIOGRAPHY}

Ahmed, N. (2015). UN plan to save Earth is "fig leaf" for big business: Why the new sustainable development agenda is "fundamentally compromised" by corporate interests. INSURGE intelligence - Medium. Retrieved from https://medium.com/insurge-intelligence/un-plan-to-save-earth-is-fig-leaf-for-bigbusiness-insiders-2b91c106bb03

Akyüz, S., \& Coşkun, B. B. (2014). Gendered (In) Securities: Refugee Camps in Southeastern Turkey. Journal of Conflict Transformation \& Security, 4(1-2), 722.

Altbach, P. G. (2016). Global perspectives on higher education. Baltimore, MD: JHU Press.

Amin, S. (2006). Review of the month: The millennium development goals: A critique from the South. Monthly Review-New York, 57(10), 1. doi:10.14452/mr-057-102006-03_1

Andersson, A., \& Hatakka, M. (2017). Victim, mother, or untapped resource? Discourse analysis of the construction of women in ICT policies. Information Technologies \& International Development, 13, 72-86.

Antunes, F. (2006). Globalization and Europeification of education policies: Routes, processes and metamorphoses. European Education Research Journal, 5(1), 3855. doi:10.2304/eerj.2006.5.1.38

Baaz, M. E. (2005). The paternalism of partnership: A postcolonial reading of identity in development aid. London, UK: Zed Books. 
Baker, S., Irwin, E., Freeman, H., Nance, S., \& Coleman, J. (2018). Building cultural and linguistic bridges: Reflections on a program designed to support adult students from refugee backgrounds' transitions into university. Journal of Academic Language and Learning, 12(1), A64-A80.

Barton, C. (2005). Where to for women's movements and the MDGs? Gender \& Development, 13(1), 25-34. doi:10.1080/13552070512331332274

Bassett, R., \& Maldonado-Maldonado, A. (2009). International organizations and higher education policy: Thinking globally, acting locally. New York, NY: Routledge.

Benavot, A. (2016). Assuring quality education and learning: Lessons from education for all. Prospects, 46(1), 5-14. doi:10.1007/s11125-016-9386-1

Berg, J. (2018). A new aspect of internationalisation? Specific challenges and support structures for refugees on their way to German higher education. European Higher Education Area: The Impact of Past and Future Policies, 219-235. doi:10.1007/978-3-319-77407-7_15

Beyani, C. (2014). Improving the protection of internally displaced women: Assessment of progress and challenges. Washington, DC: Brookings Institution.

Biermann, F., Kanie, N., \& Kim, R. E. (2017). Global governance by goal-setting: The novel approach of the UN Sustainable Development Goals. Current Opinion in Environmental Sustainability, 26, 26-31. doi:10.1016/j.cosust.2017.01.010

Big Future. (2017). Scholarship Search. Retrieved from https://bigfuture.collegeboard.org/scholarship-search 
Boliver, V. (2017). Misplaced optimism: How higher education reproduces rather than reduces social inequality. British Journal of Sociology of Education, 38(3), 423432. doi:10.1080/01425692.2017.1281648

Bonal, X. (2016). Education, poverty and the "missing link": The limits of human capital theory as a paradigm for poverty reduction. The handbook of global education policy. New Jersey: Wiley-Blackwell, 97-110. doi:10.1002/9781118468005.ch5

Brennan, J., Cochrane, A., Lebeau, Y., \& Williams, R. (2018). Universities, social change and transformation: Global perspectives. The University in Its Place, 13-31. doi:10.1007/978-94-024-1296-3_2

Briant Carant, J. (2017). Unheard voices: A critical discourse analysis of the Millennium Development Goals' evolution into the Sustainable Development Goals. Third World Quarterly, 38(1), 16-41. doi:10.1080/01436597.2016.1166944

Brissett, N., \& Mitter, R. (2017). For function or transformation? A critical discourse analysis of education under the sustainable development goals. Journal for Critical Education Policy Studies (JCEPS), 15(1), 181-204.

Bromley, P. (2016). Policy and administration as culture: Organizational sociology and cross-national education trends. The Handbook of Global Policy-making in Education, 470-489. doi:10.1002/9781118468005.ch26

The Brookings-LSE Project on Internal Displacement. (2014). Improving the Protection of Internally Displaced Women: Assessment of Progress and Challenges. Washington, DC: Brookings Institution.

Bucken-Knapp, G., Fakih, Z., \& Spehar, A. (2018). Talking about integration: The voices of Syrian refugees taking part in introduction programmes for integration into 
Swedish society. International Migration, 57(2), 221-234.

doi:10.1111/imig. 12440

Bye, D., Pushkar, D., \& Conway, M. (2007). Motivation, interest, and positive affect in traditional and nontraditional undergraduate students. Adult education quarterly, 57(2), 141-158. doi:10.1177/0741713606294235

Campbell, A. C., \& Mawer, M. (2018). Clarifying mixed messages: International scholarship programmes in the sustainable development agenda. Higher Education Policy, 32(2), 167-184. doi:10.1057/s41307-017-0077-1

Chancel, L., Hough, A., \& Voituriez, T. (2018). Reducing inequalities within countries: Assessing the potential of the sustainable development goals. Global Policy, 9(1), 5-16. doi:10.1111/1758-5899.12511

Chung, B. G., Jeon, I. S., Lee, R. H., Lee, I., \& Yoo, S. S. (2018). Global governance of education and training: As reviewed from Jomtien via Incheon to New York. Asia Pacific Education Review, 19(3), 319-336. doi:10.1007/s12564-018-9544-7

Clegg, S. (2011). Cultural capital and agency: Connecting critique and curriculum in higher education. British Journal of Sociology of Education, 32(1), 93-108. doi: $10.1080 / 01425692.2011 .527723$

Collins, C. S. (2017). Development labs: University knowledge production and global poverty. The Review of Higher Education, 41(1), 113-139. doi:10.1353/rhe.2017.0035

Collins, C. S., \& Rhoads, R. A. (2010). The World Bank, support for universities, and asymmetrical power relations in international development. Higher Education, 59(2), 181-205. doi:10.1007/s10734-009-9242-9 
Collis, R., \& Reed, M. (2016, November). Non-traditional students, non-traditional teaching: Pathways to academic success include resourcefulness and adaptation skills. Paper presented at the Higher Education in Transformation Symposium, Oshawa, Ontario, Canada.

Cotton, D. R., Nash, T., \& Kneale, P. (2017). Supporting the retention of non-traditional students in Higher Education using a resilience framework. European Educational Research Journal, 16(1), 62-79. doi:10.1177/1474904116652629

Crea, T. M. (2016). Refugee higher education: Contextual challenges and implications for program design, delivery, and accompaniment. International Journal of Educational Development, 46, 12-22. doi:10.1016/j.ijedudev.2015.11.005

Crisp, N., \& Chen, L. (2014). Global supply of health professionals. New England Journal of Medicine, 370(10), 950-957. doi:10.1056/nejmra1111610

Cummings, S., Regeer, B., de Haan, L., Zweekhorst, M., \& Bunders, J. (2018). Critical discourse analysis of perspectives on knowledge and the knowledge society within the Sustainable Development Goals. Development Policy Review, 36(6), 727-742. doi:10.1111/dpr.12296

De Jong, S. (2017). Complicit sisters: Gender and women's issues across North-South divides. International Feminist Journal of Politics, 21(1), 159-161. doi:10.1080/14616742.2018.1552526

Doyle, M. W., \& Stiglitz, J. E. (2014). Eliminating extreme inequality: A sustainable development goal, 2015-2030. Ethics \& International Affairs, 28(1), 5-13. doi:10.1017/s0892679414000021 
Dryden-Peterson, S. (2016a). Policies for education in conflict and post-conflict reconstruction. The Handbook of Global Education Policy, 189-205. doi:10.1002/9781118468005.ch10

Dryden-Peterson, S. (2016b). Refugee education in countries of first asylum: Breaking open the black box of pre-resettlement experiences. Theory and Research in Education, 14(2), 131-148. doi:10.1177/1477878515622703

Dryden-Peterson, S. (2016c). Refugee education: The crossroads of globalization. Educational Researcher, 45(9), 473-482. doi:10.3102/0013189x16683398

Dryden-Peterson, S. (2017). Refugee education: Education for an unknowable future. Curriculum Inquiry, 47(1), 14-24. doi:10.1080/03626784.2016.1255935

Dryden-Peterson, S., \& Giles, W. (2010). Higher education for refugees. Refuge: Canada's Journal on Refugees, 27(2), 3-9.

Eppel, E. A. (2009). The contribution of complexity theory to understanding and explaining policy processes: A study of tertiary education policy processes in New Zealand (Unpublished doctoral thesis). Victoria University of Wellington, Wellington, NZ.

Escobar, A. (2012). Encountering development: The making and unmaking of the third world. Princeto, NJ: Princeton University Press.

Esser, D. E., \& Ha, Y. (2015). Sustaining development as we know it: Limits to downward accountability in Post-2015 International Development Policy. SSRN Electronic Journal. doi:10.2139/ssrn.2640297

Fairclough, N. (1992). Discourse and social change. Cambridge, UK: Polity Press. 
Fairclough, N. (1995). Critical Discourse Analysis: The Critical Study of Language. Harlow, UK: Longman.

Fairclough, N. (2001). Language and Power. Harlow, UK: Longman.

Fairclough, N. (2013). Critical discourse analysis: The critical study of language. New York, NY: Routledge.

Fantom, N., Khokhar, T., \& Purdie, E. (2016). The 2016 edition of World Development Indicators is out: Three features you won't want to miss. Retrieved from https://blogs.worldbank.org/opendata/2016-edition-world-developmentindicators-out-three-features-you-won-t-want-miss

Fantom, N., Khokhar, T., \& Purdie, E. (2016). The 2016 edition of World Development Indicators is out: Three features you won't want to miss. World Bank Blogs. Retrieved from https://blogs.worldbank.org/opendata/2016-edition-worlddevelopment-indicators-out-three-features-you-won-t-want-miss

Faul, M. V. (2014). Future-perfect/present-imperfect: Contemporary global constraints on the implementation of a post-2015 education agenda. International Journal of Educational Development, 39, 12-22. doi:10.1016/j.ijedudev.2014.07.011

Freedman, J. (2017). Women's experience of forced migration. In J. Freedman, N. O. Baklacıoglu, and Z. Kıvılcım (Eds.), A Gendered Approach to the Syrian Refugee Crisis (pp. 125-141). New York, NY: Routledge.

Fruja Amthor, R. (2017). "If only i did not have that label attached to me": Foregrounding self-positioning and intersectionality in the experiences of immigrant and refugee youth. Multicultural Perspectives, 19(4), 193-206.

doi:10.1080/15210960.2017.1366862 
Gebreiyosus, Y. B. (2018). Being a Refugee Student in Higher Education: Exploring the Challenges and Coping Strategies, A Case Study of Mekelle University, Ethiopia (Master's thesis). Retrieved from UIO Duo Research Archive.

Gee, J. P. (2014a). An introduction to discourse analysis: Theory and method. New York, NY: Routledge.

Gee, J. P. (2014b). How to do discourse analysis: A toolkit. New York, NY: Routledge.

Guinée, N. (2014). Empowering women through education: Experiences from Dalit women in Nepal. International Journal of Educational Development, 39, 173-180. doi:10.1016/j.ijedudev.2014.07.007

Hamid, M. O., Mundy, K., Green, A., Lingard, B., \& Verger, A. (2016). The politics of language in education in a global polity. The handbook of global education policy, 259-274. doi:10.1002/9781118468005.ch14

Hartmann, E. (2010). The United Nations educational, scientific and cultural organisation: Pawn or global player? Globalisation, Societies and Education, 8(2), 307-318. doi:10.1080/14767721003780645

Hirsch, A. \& Maylea, C. (2016). Education denied: People seeking asylum and refugees trapped in limbo. New Community Quarterly, 14(3), 19-24.

Holden, E., Linnerud, K., \& Banister, D. (2016). The imperatives of sustainable development. Sustainable Development, 25(3), 213-226. doi:10.1002/sd.1647

Holden, E., Linnerud, K., Banister, D., Schwanitz, V. J., \& Wierling, A. (2017). The Imperatives of Sustainable Development: Needs, Justice, Limits. London, UK: Routledge. 
Institute of International Education. (2017, October). Retrieved from https://www.iie.org/programs

Jules, T. D., \& Jefferson, S. S. (2016). The next educational bubble-educational brokers and education governance mechanisms: Who governs what! In The Global Educational Policy Environment in the Fourth Industrial Revolution: Gated, Regulated and Governed (pp. 123-147). Bingley, UK: Emerald Group Publishing Limited.

Khoja-Moolji, S. S. (2017). Envisioning an alternative to the neoliberalization of education in the Global South: The Aga Khan's philosophies of education. Discourse: Studies in the Cultural Politics of Education, 38(4), 542-560. doi:10.1080/01596306.2015.1113508

King, K. (2016). The global targeting of education and skill: Policy history and comparative perspectives. Compare: A Journal of Comparative and International Education, 46(6), 952-975. doi:10.1080/03057925.2016.1216781

King, K. (2017). Lost in translation? The challenge of translating the global education goal and targets into global indicators. Compare: A Journal of Comparative and International Education, 47(6), 801-817. doi:10.1080/03057925.2017.1339263

King, R. (2009). Governing universities globally: Organizations, regulation and ranking. Cheltenham, UK: Edward Elgar Publishing Ltd.

King, R., Marginson, S., \& Naidoo, R. (Eds.). (2011). Handbook on globalization and higher education. Northampton, MA: Edward Elgar Publishing. 
Knutsson, B., \& Lindberg, J. (2017). Studying "the political" in international aid to education: Methodological considerations. Comparative Education Review, 61(4), 701-725. doi:10.1086/693924

Lebeau, Y., \& Sall, E. (2011). Global institutions, higher education and development. In R. King, S. Marginson, \& R. Naidoo (Eds.), Handbook on globalization and higher education (pp. 129-147). Northampton, MA: Edward Elgar Publishing.

MacNaughton, G. (2017). Vertical inequalities: Are the SDGs and human rights up to the challenges? The International Journal of Human Rights, 21(8), 1050-1072. doi:10.1080/13642987.2017.1348697

Macpherson, I. (2016). An analysis of power in transnational advocacy networks in education. The Handbook of Global Education Policy, 401-418. doi:10.1002/9781118468005.ch22

Maldonado-Maldonado, A. (2018). The expansion of markets and the rise of skills: Two roads leading to the same place-higher education in the current agendas of the international organisations. In Sin C., Tavares O., Cardoso S., J. Rosa M. (Eds.), European Higher Education and the Internal Market (pp. 193-228). Cham, Switzerland: Palgrave Macmillan.

Mangan, D., \& Winter, L. A. (2017). (In) validation and (mis)recognition in higher education: The experiences of students from refugee backgrounds. International Journal of Lifelong Education, 36(4), 486-502. doi:10.1080/02601370.2017.1287131

Marginson, S. (2016). The global construction of higher education reform. Handbook of Global Education Policy, 291-311. doi:10.1002/9781118468005.ch16 
McCormick, A. (2014). Who are the custodians of Pacific 'post-2015'education futures? Policy discourses, education for all and the millennium development goals. International Journal of Educational Development, 39, 163-172. doi:10.1016/j.ijedudev.2014.07.009

McEwan, C. (2001). Postcolonialism, feminism and development: Intersections and dilemmas. Progress in Development Studies, 1(2), 93-111. doi:10.1177/146499340100100201

McEwan, C. (2009). Postcolonialism and development. London and New York: Routledge. McGrath, S., \& Powell, L. (2016). Skills for sustainable development: Transforming vocational education and training beyond 2015. International Journal of Educational Development, 50, 12-19. doi:10.1016/j.ijedudev.2016.05.006

Menashy, F. (2018). Multi-stakeholder aid to education: Power in the context of partnership. Globalisation, Societies and Education, 16(1), 13-26. doi:10.1080/14767724.2017.1356702

Milton, S. (2018). Higher education in emergencies. In Higher Education and Post-Conflict Recovery (pp. 121-139). Cham, Switzerland: Palgrave Macmillan.

Mollett, S. (2017). Irreconcilable differences? A postcolonial intersectional reading of gender, development and human rights in Latin America. Gender, Place \& Culture, 24(1), 1-17. doi:10.1080/0966369x.2017.1277292

Moutsios, S. (2009). International organisations and transnational education policy. Compare, 39(4), 469-481. doi:10.1080/03057920802156500

Mundy, K., \& Menashy, F. (2014). Investing in private education for poverty alleviation: The case of the World Bank's International Finance Corporation. International 
Journal of Educational Development, 35, 16-24.

doi:10.1016/j.ijedudev.2012.06.005

Mundy, K., \& Verger, A. (2015). The World Bank and the global governance of education in a changing world order. International Journal of Educational Development, 40, 9-18. doi:10.1016/j.ijedudev.2014.11.021

Mwangi, C. A. G., Latafat, S., Hammond, S., Kommers, S., Thoma, H. S., Berger, J., \& Blanco-Ramirez, G. (2018). Criticality in international higher education research: A critical discourse analysis of higher education journals. Higher Education, 76(6), 1091-1107. doi:10.1007/s10734-018-0259-9

Myklebust, J. P. (2019, April 5). Research is more focused on Sustainable Development Goals. University World News. Retrieved from https://www.universityworldnews.com/post.php?story=20190405090658546

Naidoo, L., Wilkinson, J., Adoniou, M., \& Langat, K. (2018). Refugee background students transitioning into higher education: Navigating complex spaces. Singapore: Springer.

Naidoo, R. (2008). Entrenching international inequality: Higher education as a global commodity and its impact on developing countries. In W. Shumar \& J. Canaan (Eds.), Structure and agency in the Neoliberal university (pp. 84-100). New York, NY: Routledge.

Naylor, R., \& Ndarhutse, S. (2015). Non-government organizations as donors to education. (Background paper for EFA Global Monitoring Report 2015). 
Nijenhuis, G., \& Leung, M. (2017). Rethinking migration in the 2030 Agenda: Towards a de-territorialized conceptualization of development. Forum for Development Studies, 44(1), 51-68. doi:10.1080/08039410.2016.1276958

Nussbaum, M. C. (2001). Women and human development: The capabilities approach (Vol. 3). Cambridge, UK: Cambridge University Press.

Organisation for Economic Co-operation and Development (OECD) (2011). Divided we stand: Why inequality keeps rising. Paris, France: OECD Publishing.

Owens, T. L. (2017). Higher education in the sustainable development goals framework. European Journal of Education, 52(4), 414-420. doi:10.1111/ejed.12237

Ramirez, F. O., Meyer, J. W., \& Lerch, J. (2016). World society and the globalization of educational policy. The handbook of global education policy, 43-63. doi:10.1002/9781118468005.ch2

Rizvi, F., \& Lingard, B. (2010). Globalizing education policy. New York, NY: Routledge. Robertson, S. (2009). Market multilateralism, the World Bank, and the asymmetries of globalizing higher education: Toward a critical political economy analysis. In R. Bassett \& A. Maldonado-Maldonado (Eds.), International organizations and higher education policy: Thinking globally, acting locally? (pp. 113-131). New York, NY: Routledge.

Robertson, S. L., \& Komljenovic, J. (2016). Non-state actors, and the advance of frontier higher education markets in the global south. Oxford Review of Education, 42(5), 594-611. doi:10.1080/03054985.2016.1224302 
Rogers, R., \& Wetzel, M. M. (2013). Designing critical literacy education through critical discourse analysis: Pedagogical and research tools for teacher-researchers. New York, NY: Routledge.

Rugg, D. (2016). The role of evaluation at the UN and in the new sustainable development goals: Towards the future we want. Global Policy, 7(3), 426-430.

doi:10.1111/1758-5899.12346

Saarinen, T. (2007). Quality on the move: Discursive construction of higher education policy from the perspective of quality (Unpublished dissertation). University of Jyväskylä, Finland.

Saarinen, T. (2008). Persuasive presuppositions in OECD and EU higher education policy documents. Discourse Studies, 10(3), 341-359. doi:10.1177/1461445608089915

Sachs, J. D. (2012). From millennium development goals to sustainable development goals. The Lancet, 379(9832), 2206-2211. doi:10.1016/s0140-6736(12)60685-0

Saith, A. (2006). From universal values to millennium development goals: Lost in translation. Development and change, 37(6), 1167-1199. doi:10.1111/j.1467-7660.2006.00518.x

Salmi, J., Hopper, R., \& Bassett, R. (2009). Transforming higher education in developing countries: The role of the World Bank. In R. Bassett \& A. Maldonado-Maldonado (Eds.), International organizations higher education policy: Thinking globally, acting locally? (pp. 99-112). New York, NY: Routledge.

Samoff, J., \& Carrol, B. (2003). From manpower planning to the knowledge era: World Bank policies on higher education in Africa. UNESCO Forum on Higher Education, Research and Knowledge, Division of Higher Education. 
Sayed, Y., \& Ahmed, R. (2015). Education quality, and teaching and learning in the post2015 education agenda. International Journal of Educational Development, 40, 330-338. doi:10.1016/j.ijedudev.2014.11.005

Schatzel, K., Callahan, T., Scott, C. J., \& Davis, T. (2011). Reaching the non-traditional stopout population: A segmentation approach. Journal of Marketing for Higher Education, 21(1), 47-60. doi:10.1080/08841241.2011.569590

Schulte, M. (2015). Stopout, swirl, double-dip, and dropout: Attempting to understand student enrollment patterns. The Journal of Continuing Higher Education, 63(2), 133135. doi:10.1080/07377363.2015.1043001

Sen, G. (2013). Gender equality in the Post-2015 development agenda: Lessons from the MDGs. IDS Bulletin, 44(5-6), 42-48.

Shahjahan, R. A. (2012). The roles of international organizations (IOs) in globalizing higher education policy. In J. Smart \& M. Paulsen (Eds.), Higher Education: Handbook of Theory and Research (Vol. 27, pp. 369-407). Dordrecht, Netherlands: Springer.

Shahjahan, R. A., \& Madden, M. (2015). Uncovering the images and meanings of international organizations (IOs) in higher education research. Higher Education, 69(5), 705-717. doi:10.1007/s10734-014-9801-6

Spring, J. (2009). Globalization of education: An introduction. New York, NY: Routledge. Spring, J. (2014). Globalization of education: An introduction. New York, NY: Routledge. Stambach, A. (2016). Ethnography and the localization of global education policy. The handbook of global education policy, 490-503. doi:10.1002/9781118468005.ch27 
Stein, S. (2017a). Internationalization for an uncertain future: Tensions, paradoxes, and possibilities. The Review of Higher Education, 41(1), 3-32.

doi:10.1353/rhe.2017.0031

Stein, S. (2017b). The persistent challenges of addressing epistemic dominance in higher education: Considering the case of curriculum internationalization. Comparative Education Review, 61(S1), S25-S50. doi:10.1086/690456

Steiner-Khamsi, G., \& Waldow, F. (2012). World yearbook of education 2012: Policy borrowing and lending in education. New York, NY: Routledge.

Streitwieser, B., Brueck, L., Moody, R., \& Taylor, M. (2017). The potential and reality of new refugees entering German higher education: The case of Berlin Institutions. European Education, 49(4), 231-252. doi:10.1080/10564934.2017.1344864

Stromquist, N. P. (2015). Women's Empowerment and Education: Linking knowledge to transformative action. European Journal of Education, 50(3), 307-324. doi:10.1111/ejed.12137

Suarez-Orozco, M., Teranishi, R., Suarez-Orozco, C. (2015). In the shadows of the ivory tower: Undocumented undergraduates and the liminal state of immigration reform. The UndocuScholars Project, UCLA. Retrieved from http://www.undocuscholars.org/undocuscholars-2015-report/

Talbot, C. (2013). Education in conflict emergencies in light of the post-2015 MDGs and EFA Agendas. Network for international policies and cooperation in education and training (NORRAG). Retrieved from 
https://www.norrag.org/fileadmin/Working_Papers/Education_in_conflict_emerg encies_Talbot.pdf

Tampio, N. (2018). What if neoliberalism captures the human rights establishment? Sustainable Development Goal 4 and the Global Education Reform Movement. Human Rights Review, 19(3), 379-383. doi:10.1007/s12142-018-0521-7

Tecle, A. S., Ha, A. T., \& Hunter, R. (2017). Creating a continuing education pathway for newly arrived immigrants and refugee communities. Journal of Teaching in Social Work, 37(2), 171-184. doi:10.1080/08841233.2016.1211463

Teferra, D. (2009). Higher education in Africa: The dynamics of international partnerships and interventions. In R. Bassett \& A. Maldonado (Eds.), International organizations and higher education policy: Thinking globally, acting locally? (pp. 155-173). New York, NY: Routledge.

The World Bank. (n.d.). Data: How does the World Bank classify countries? Retrieved from https://datahelpdesk.worldbank.org/knowledgebase/articles/378834-howdoes-the-world-bank-classify-countries

The World Bank. (n.d.). Data: World Bank country and lending groups. Retrieved from https://datahelpdesk.worldbank.org/knowledgebase/articles/378834-how-doesthe-world-bank-classify-countries

The World Bank. (2000). World Development Report, 2000/01. Washington, DC: World Bank.

The World Bank. (2018a). Fragile and conflict affected situations. Retrieved from https://data.worldbank.org/region/fragile-and-conflict-affectedsituations? view=chart 
The World Bank. (2018b). Higher education. Retrieved from https://www.worldbank.org/en/topic/tertiaryeducation\#2

The World Bank. (2018c). New country classifications by income level: 2018-2019.

Retrieved from https://blogs.worldbank.org/opendata/new-country-classifications$\underline{\text { income-level-2018-2019 }}$

Titscher, S., Meyer, M., Wodak, R., \& Vetter, E. (2000). Methods of text and discourse analysis: In search of meaning. Thousand Oaks, CA: SAGE.

Unangst, L., \& Streitwieser, B. (2018). Inclusive practices in response to the German refugee influx: Support structures and rationales described by university administrators. In European Higher Education Area: The Impact of Past and Future Policies (pp. 277-292). Cham, Switzerland: Springer.

UNESCO-UNEVOC. (2014). UNESCO-UNEVOC at Global education and skills forum. Retrieved from https://unevoc.unesco.org/bulletin/bulletin_full.php?bull=26en United Nations Educational, Scientific and Cultural Organization (n.d.). Milestones. Retrieved from http://www.unesco.org/new/en/unesco/about-us/who-we$\underline{\text { are/history/milestones/ }}$

United Nations Educational, Scientific and Cultural Organization (UNESCO). (2016a). Global education monitoring report: Education for people and planet. Paris, France.

United Nations Educational, Scientific and Cultural Organization (UNESCO). (2016b). Global education monitoring report gender review: Creating sustainable futures for all. Paris, France. 
United Nations Educational, Scientific and Cultural Organization (UNESCO). (2017a).

Collective consultation of NGOs on education 2030 (CCNGO/Education 2030). Retrieved from www.en.unesco.org/education2030sdg4/coordination/education

United Nations Educational, Scientific and Cultural Organization (UNESCO). (2017b). Global education monitoring report: Accountability in education: Meeting our commitments. Paris, France.

United Nations Educational, Scientific and Cultural Organization (UNESCO). (2018). Global education monitoring report gender review: Meeting our commitments to gender equality in education. Paris, France.

United Nations Educational, Scientific and Cultural Organization (UNESCO). (2017).

Collective consultation of NGOs on education 2030 (CCNGO/Education 2030). Retrieved from www.en.unesco.org/education2030sdg4/coordination/educationnngos

United Nations High Commissioner for Refugees (UNHCR). (n.d.). Left behind: Refugee education in crisis. Retrieved from http://www.unhcr.org/left- behind/. United Nations High Commissioner for Refugees (UNHCR). (1967). Convention and protocol relating to the status of refugees. Paris, UNHCR.

United Nations High Commissioner for Refugees (UNHCR). (2004). Guiding principles on internal displacement. Retrieved from http://www.unhcr.org/en-us/43ce1cff2.

United Nations High Commissioner for Refugees (UNHCR). (2014). Woman alone: The fight for survival by Syria's refugee women. Paris, UNHCR.

United Nations High Commissioner for Refugees (UNHCR). (2016a). Figures at a glance. Retrieved from http://www.unhcr.org/en-us/figures-at-a-glance.html. 
United Nations High Commissioner for Refugees (UNHCR). (2016b). Missing out:

Refugee education in crisis. Paris, UNHCR.

United Nations High Commissioner for Refugees (UNHCR). (2016c). UNHCR viewpoint: 'Refugee' or 'migrant' - Which is right? Retrieved from http://www.unhcr.org/enus/news/latest/2016/7/55df0e556/unhcr-viewpoint-refugee-migrant-right.html.

United Nations High Commissioner for Refugees (UNHCR). (2019). Figures at a glance. Retrieved from http://www.unhcr.org/en-us/figures-at-a-glance.html.

United Nations High Commissioner for Refugees (UNHCR). (2017). Global Report 2016. Geneva, Switzerland: UNHCR.

United Nations High Commissioner for Refugees (UNHCR). (2018a). Scholarship opportunities for refugee students. Retrieved from http://help.unhcr.org/scholarships/\#_ga=2.81269663.987433657.1532438967692738253.1531519121

United Nations High Commissioner for Refugees (UNHCR). (2018b). Tertiary Education. Retrieved from http://www.unhcr.org/en-us/tertiary-education.html

United Nations. (2013). United Nations Millennium Goals. Retrieved from http://www.un.org/millenniumgoals/bkgd.shtml

United Nations. (2015). Transforming our world: The 2030 agenda for sustainable development. General Assembly 70 session.

United Nations. (2017). Sustainable Development Goal 4. Retrieved from https://sustainabledevelopment.un.org/sdg4. 
Unterhalter, E. (2015). Concept paper prepared for London workshop beyond parity: Measuring gender inequality and equality in education. Paper for beyond parity: Measuring gender equality in education, London, 18-19 September.

Unterhalter, E. (2016). Gender and education in the global polity. The Handbook of Global Education Policy, 111-127. doi:10.1002/9781118468005.ch6

Unterhalter, E. (2017). A review of public private partnerships around girls' education in developing countries: flicking gender equality on and off. Journal of International and Comparative Social Policy, 33(2), 181-199.

doi:10.1080/21699763.2017.1328612

Veltmeyer, H., \& Bowles, P. (Eds.). (2017). The essential guide to critical development studies. New York, NY: Routledge.

Verger, A., Lubienski, C., \& Steiner-Khamsi, G. (Eds.). (2016). World yearbook of education 2016: The global education industry. New York, NY: Routledge

Walker, M., \& Fongwa, S. (2017). Graduate employability, global shifts and local realities. Universities, Employability and Human Development, 29-51. doi:10.1057/978-1-137-58452-6_2

Webb, S., Burke, P. J., Nichols, S., Roberts, S., Stahl, G., Threadgold, S., \& Wilkinson, J. (2017). Thinking with and beyond Bourdieu in widening higher education participation. Studies in Continuing Education, 39(2), 138-160. doi:10.1080/0158037x.2017.1302926

Wende, M. (2011). Global institutions: The organization for economic co-operation and development. In R. King, S. Marginson, \& R. Naidoo (Eds.), Handbook of 
globalization and higher education (pp. 95-113). Cheltenham, England: Edward Elgar Publishing.

Wilson, K. (2017). Worlds beyond the political? Post-development approaches in practices of transnational solidarity activism. Third World Quarterly, 38(12), 2684-2702. doi:10.1080/01436597.2017.1354694

Wodon, Q., Montenegro, C., Nguyen, H., Onagoruwa, A. (2018). Missed Opportunities: The high cost of not educating girls. The cost of not educating girls notes series. Washington, DC: World Bank.

Wong, B. (2018). By chance or by plan? The academic success of nontraditional students in higher education. AERA Open, 4(2). doi:10.1177/2332858418782195

Zapp, M. (2017). The World Bank and education: Governing (through) knowledge. International Journal of Educational Development, 53, 1-11. doi:10.1016/j.ijedudev.2016.11.007 
APPENDICES 
Appendix 1: Figures and Tables 


\section{Figures}

Figure 1: 2016 Gross Enrolment Ratio: Tertiary, Female (\%)

Figure 2. Building Task Codes by Top Categories - Normal Scenarios

Figure 3. Top Categories by Building Task - Applicants in Normal Scenarios

Figure 4. Normal Scenarios: Applicants vs. Others

Figure 5. Top Categories of Building Task Codes for Others in Normal Scenarios

Figure 6. Top Categories for Building Tasks in Dis-figured Worlds - Both Applicants and Others

Figure 7. Top Categories for Three Building Tasks - Applicants' Dis-figured Worlds

Figure 8 Top Categories for Others in Dis-figured Worlds

Figure 9. Total Stanzas in Each Discourse

Figure 10. Discourse Ratios: Percentage of Normal : Not Normal

Figure 11. Discourses by Each Analytical Group

Figure 12. Transactional Victim Discourse Distribution

Figure 13. Transformative Victim Discourse Distribution

Figure 14. Transactional Victor Discourse Distribution

Figure 15. Transformative Victor Discourse Distribution 


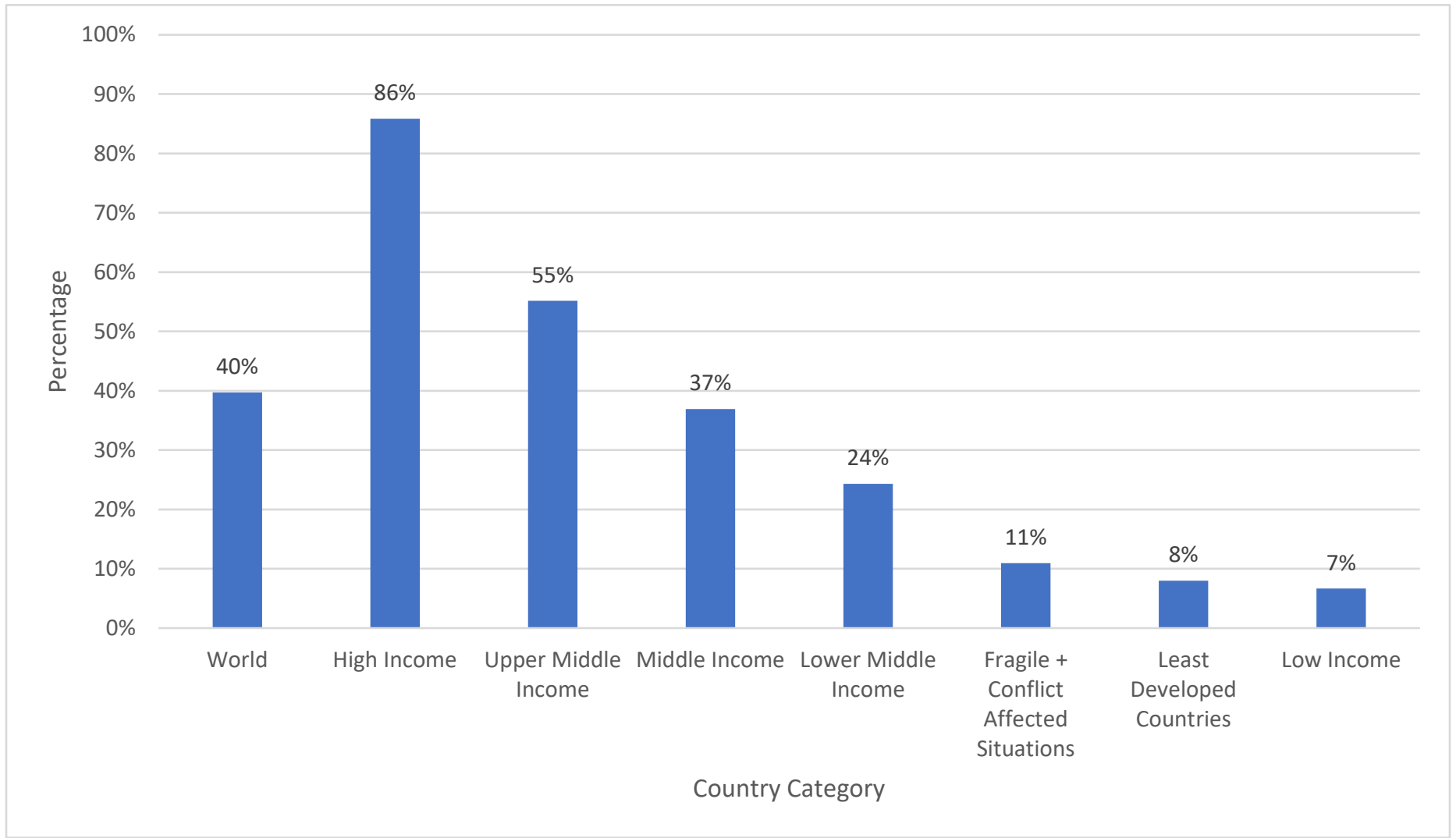

Figure 1: 2016 Gross enrolment ratio, tertiary, female (\%)

Indicator Name: Gross enrolment ratio, tertiary, female (\%)

Long definition: Total female enrollment in tertiary education (ISCED 5 to 8), regardless of age, expressed as a percentage of the total female population of the five-year age group following on from secondary school leaving.

Source: UNESCO Institute for Statistics via World Bank Database 9.14.19 


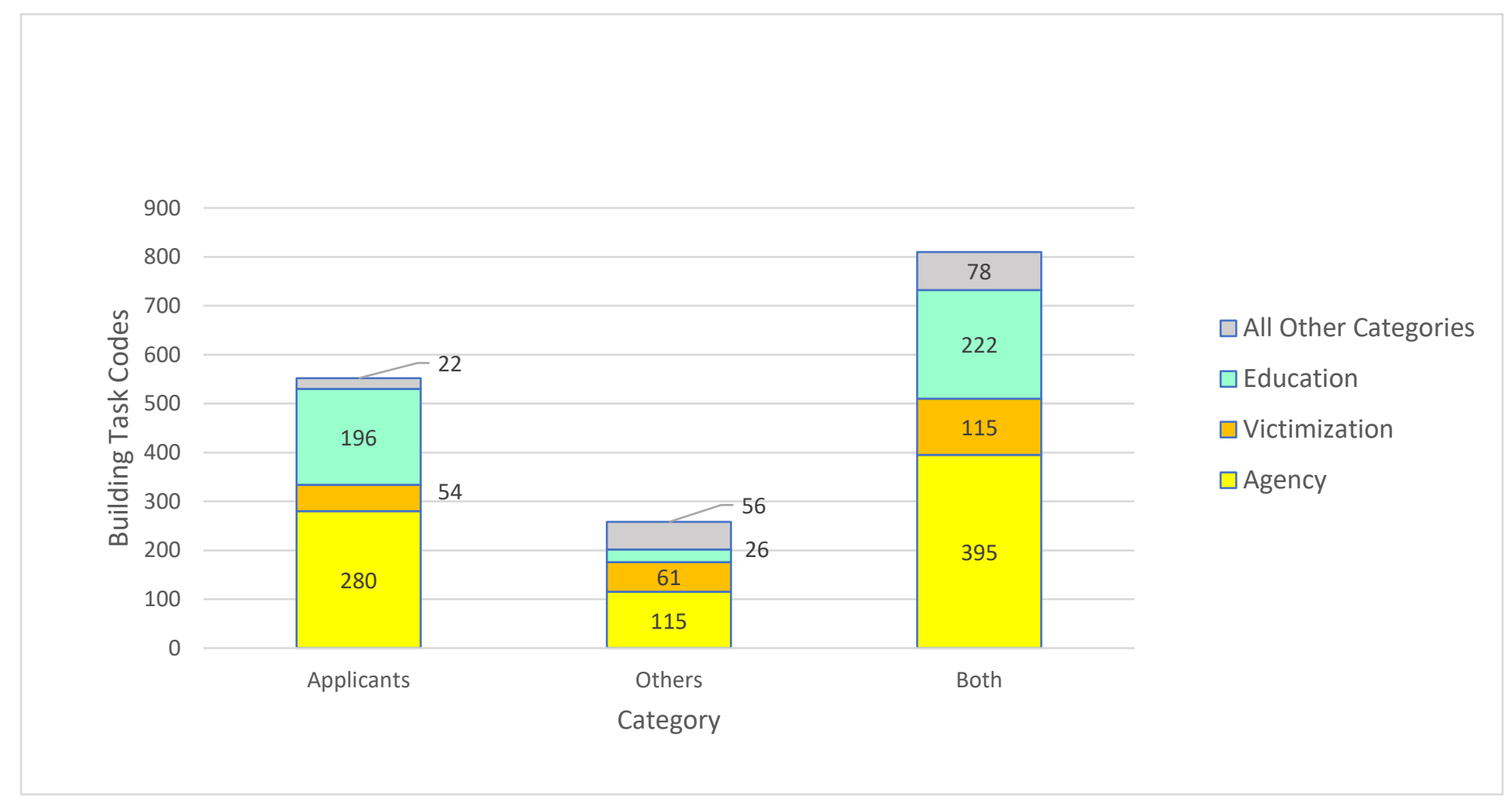

Figure 2. Building Task Codes by Top Categories - Normal Scenarios 


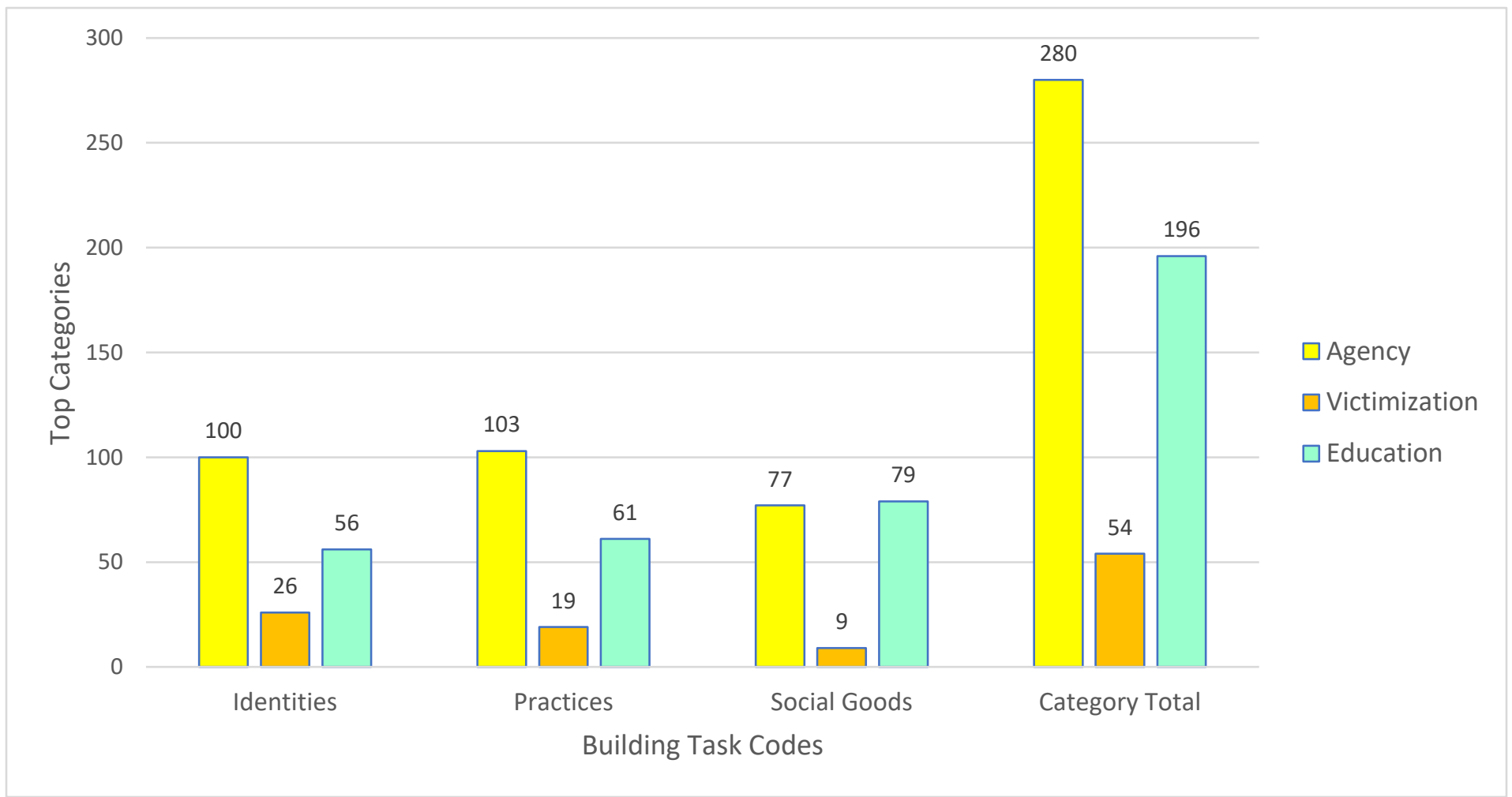

Figure 3. Top Categories by Building Task - Applicants in Normal Scenarios 


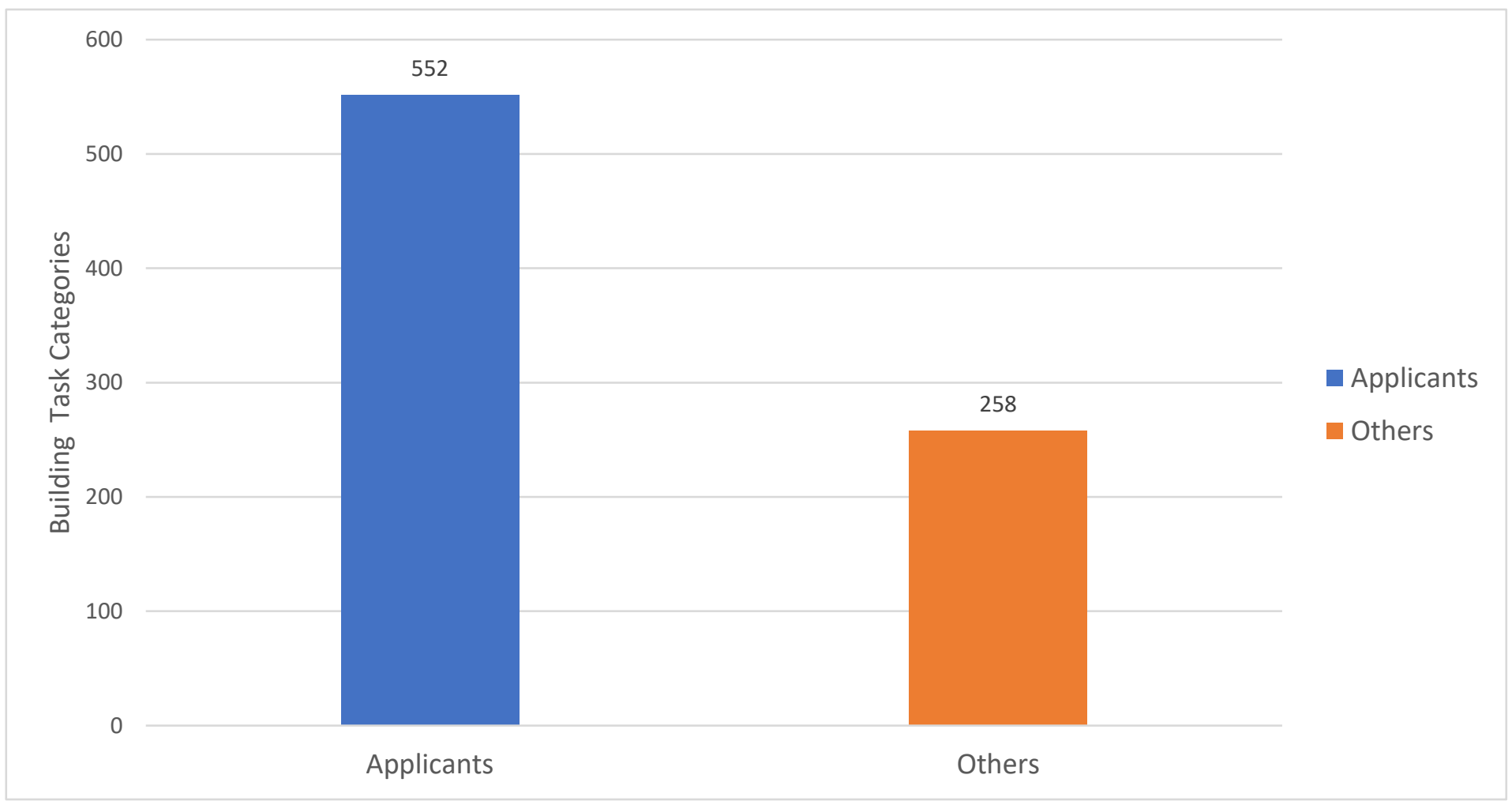

Figure 4. Normal Scenarios: Applicants vs. Others 


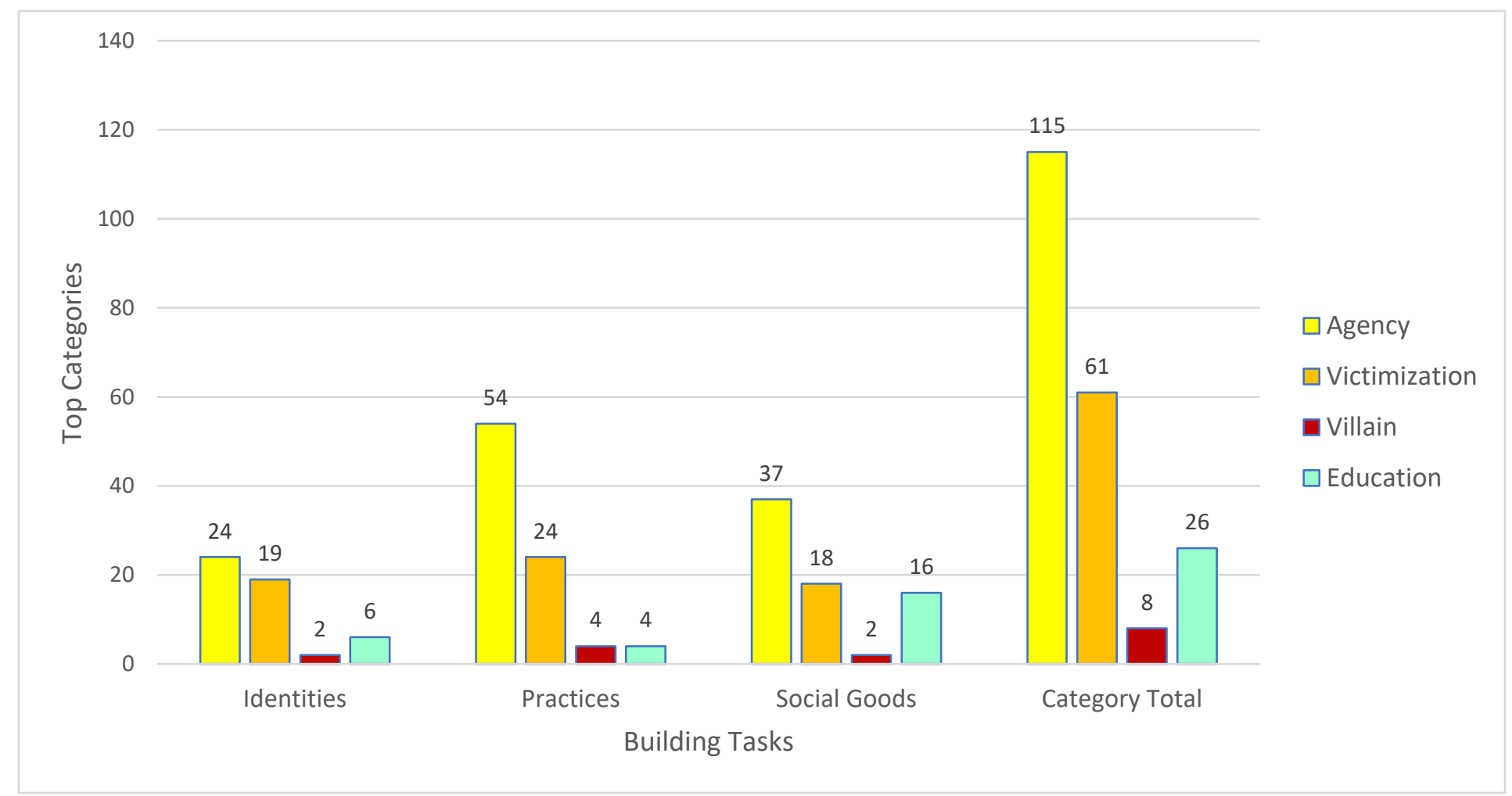

Figure 5. Top Categories of Building Task Codes for Others in Normal Scenarios 


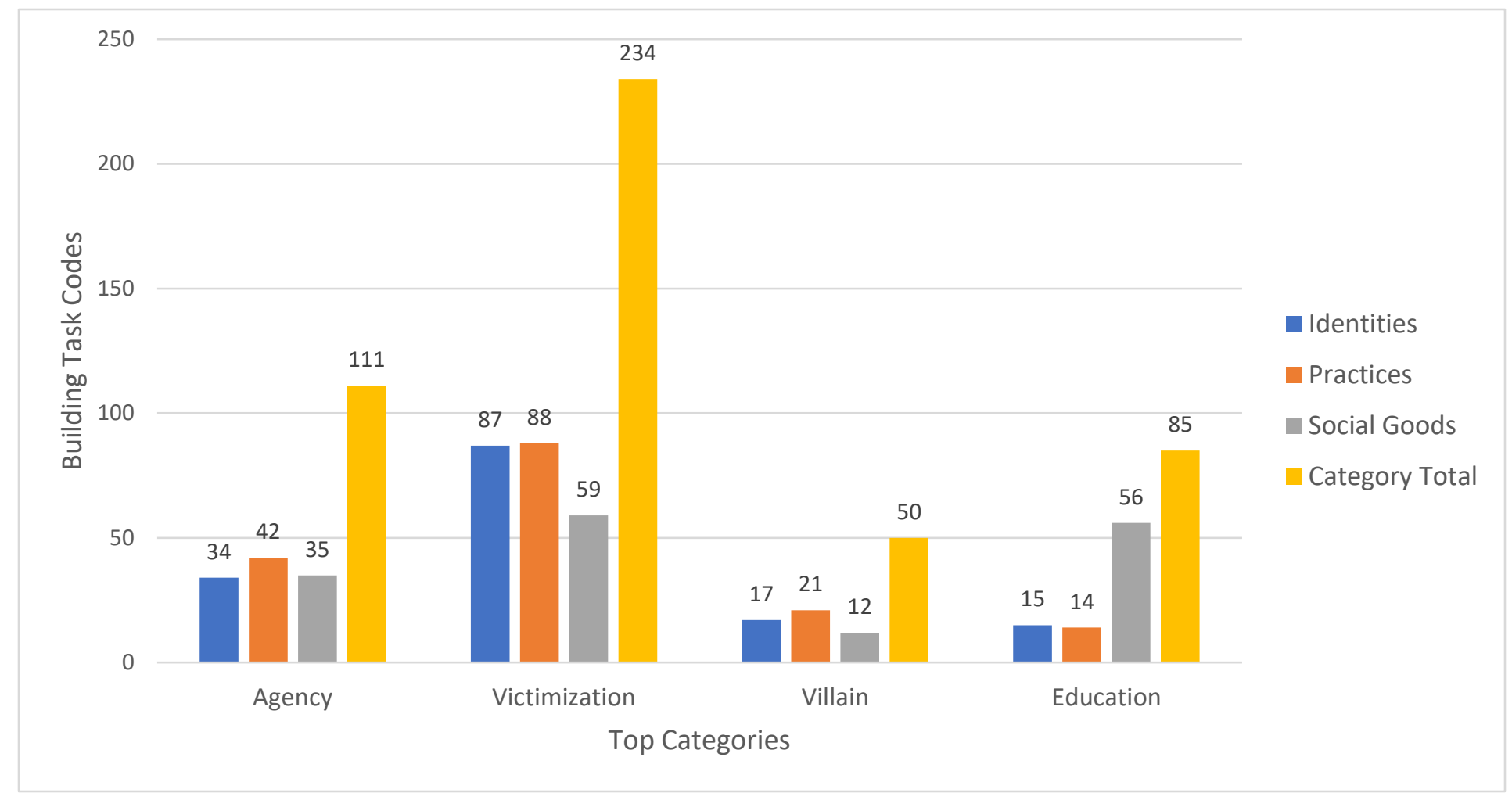

Figure 6. Top Categories for Building Tasks in Dis-figured Worlds - Both

Applicants and Others 


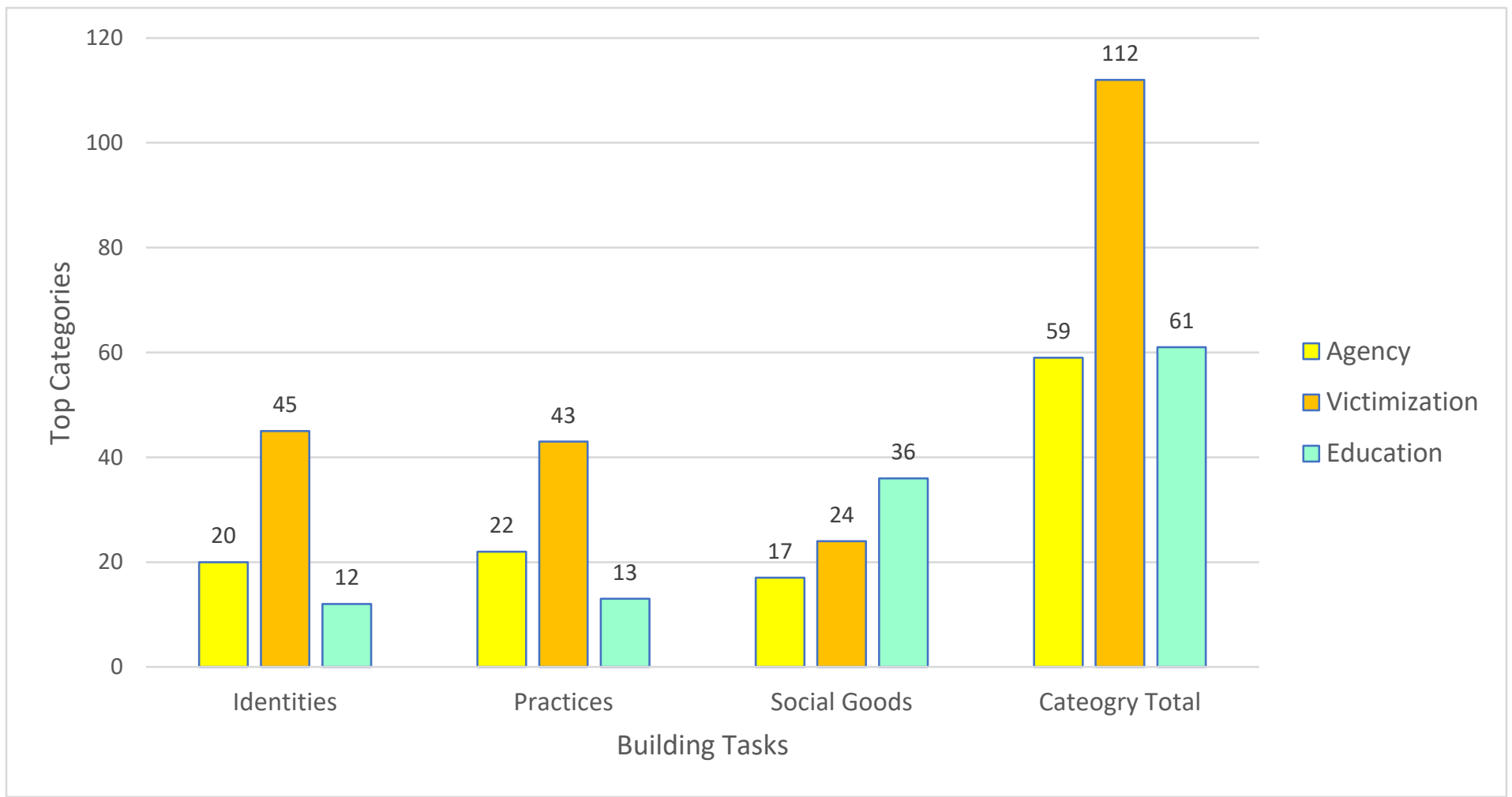

Figure 7. Top Categories for Three Building Tasks - Applicants' Dis-figured

Worlds 


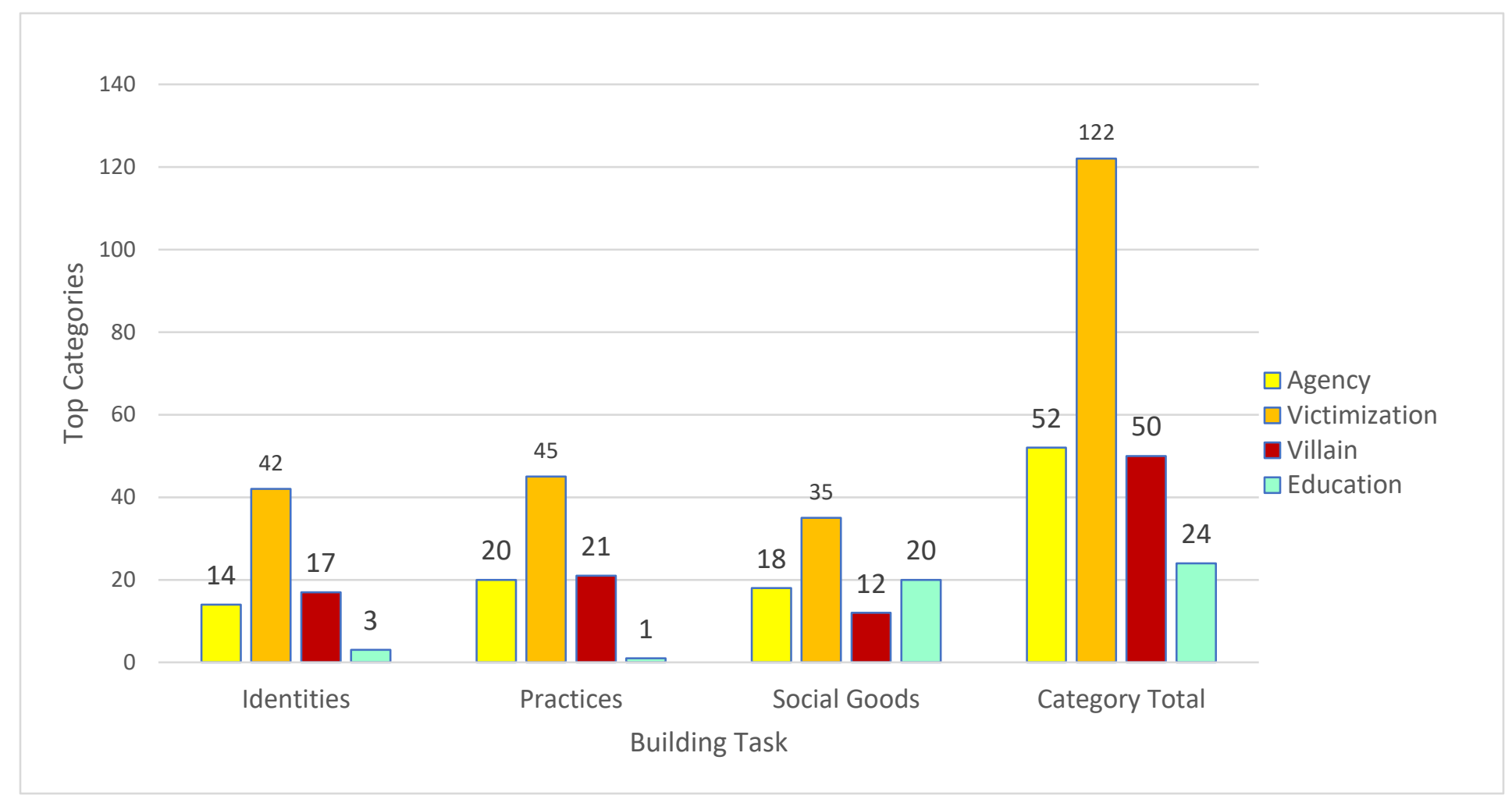

Figure 8 Top Categories for Others in Dis-figured Worlds 


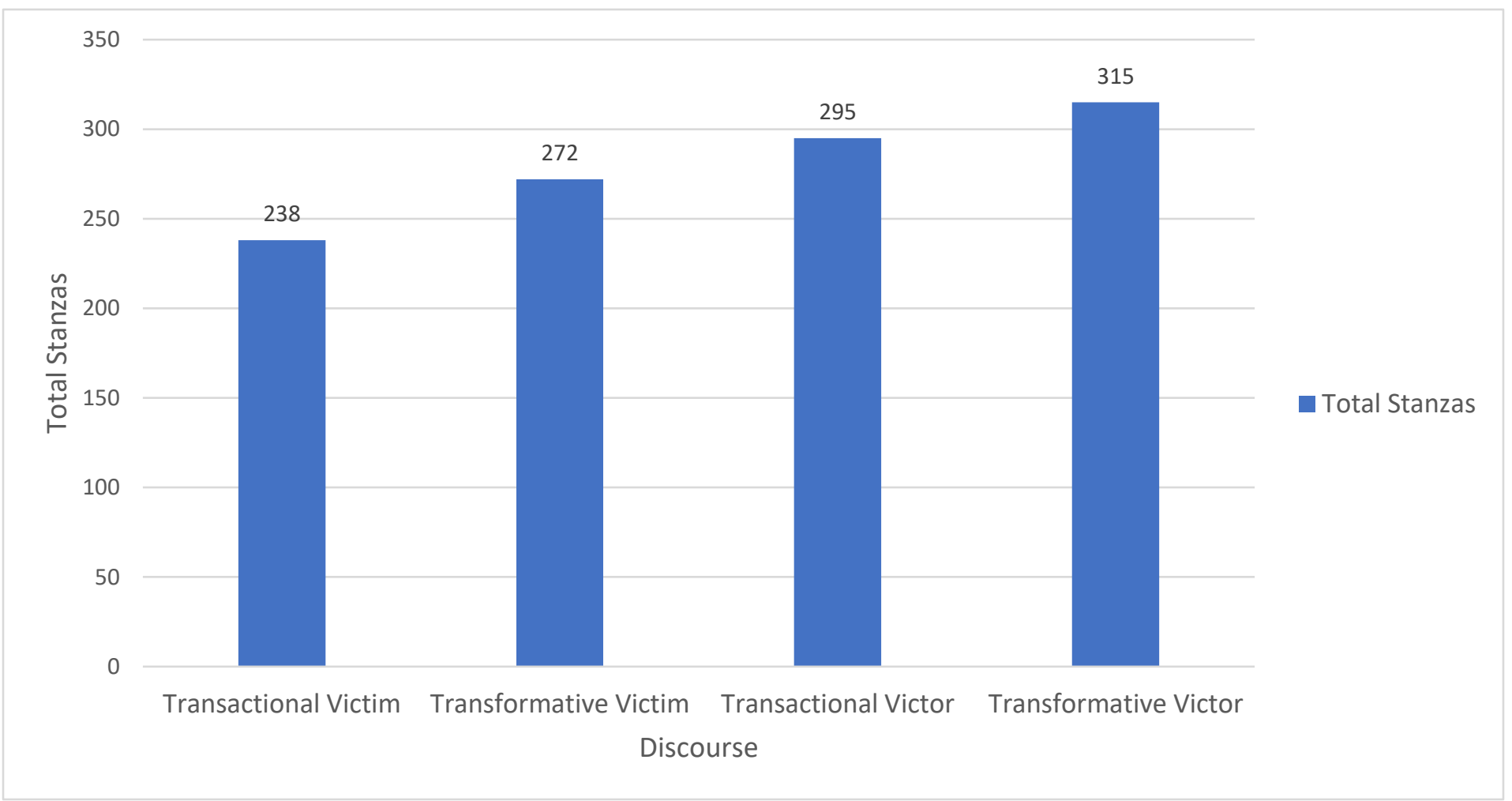

Figure 9. Total Stanzas in Each Discourse 


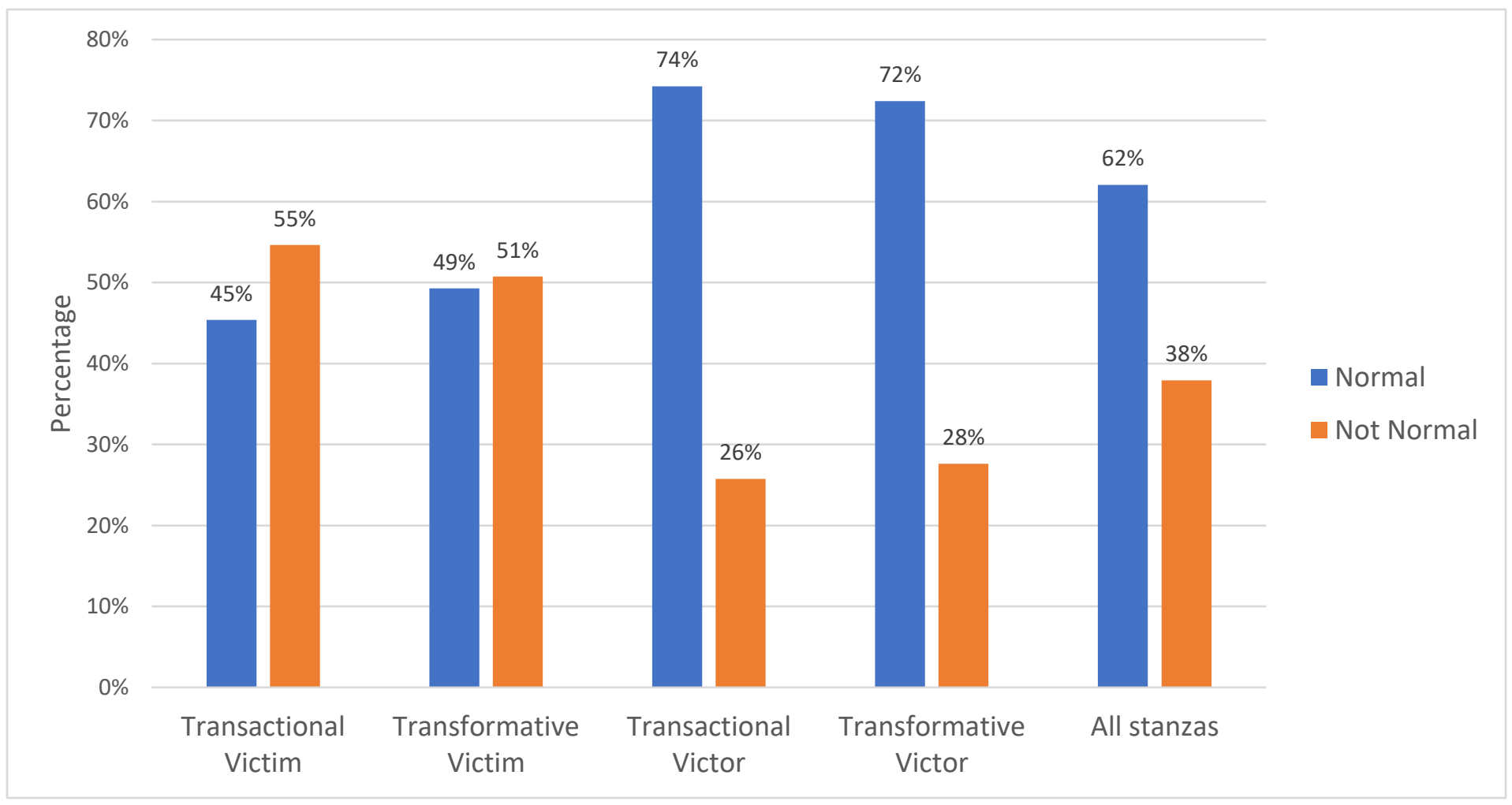

Figure 10. Discourse Ratios: Percentage of Normal : Not Normal 


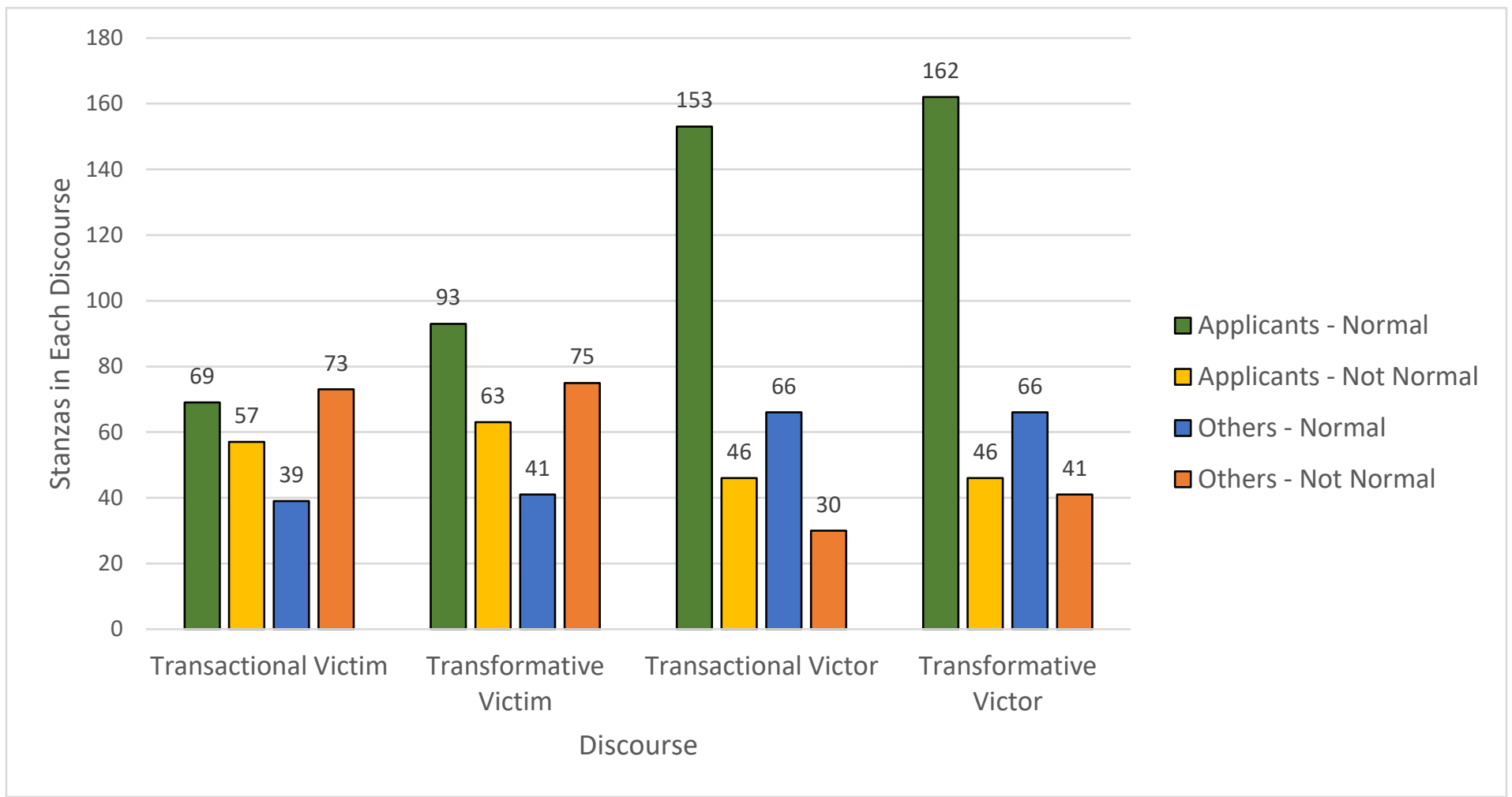

Figure 11. Discourses by Each Analytical Group 


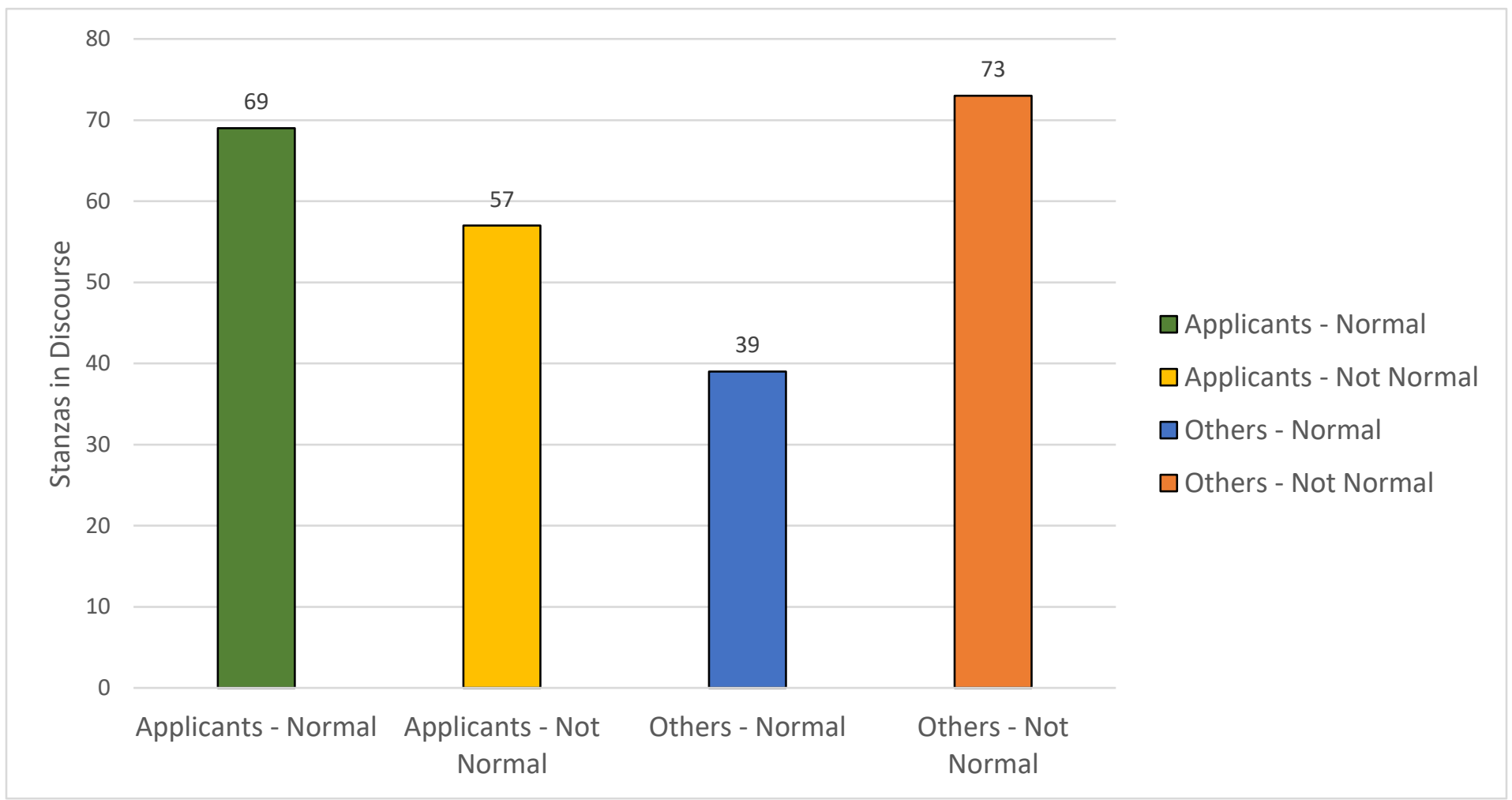

Figure 12. Transactional Victim Discourse Distribution 


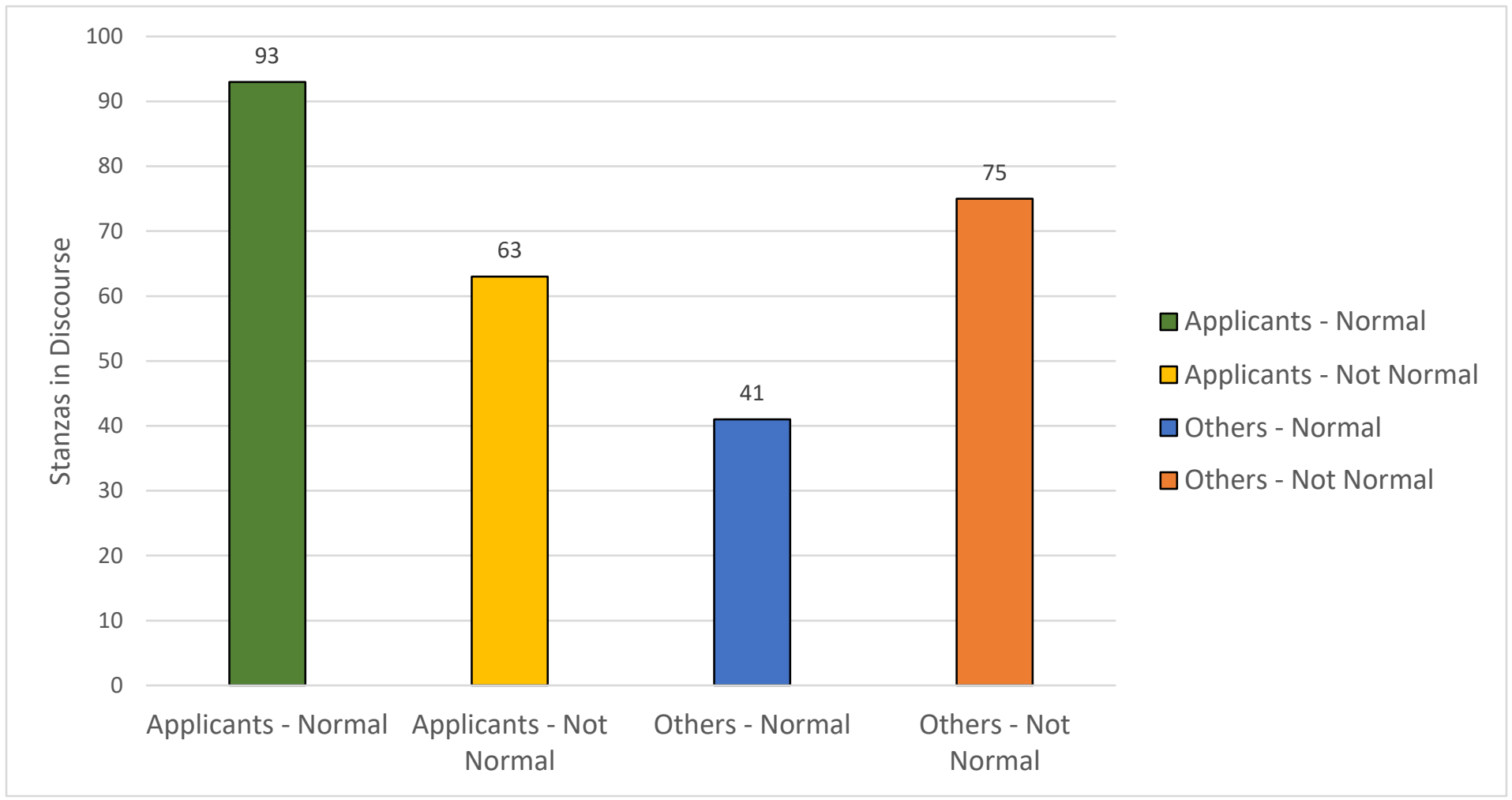

Figure 13. Transformative Victim Discourse Distribution 


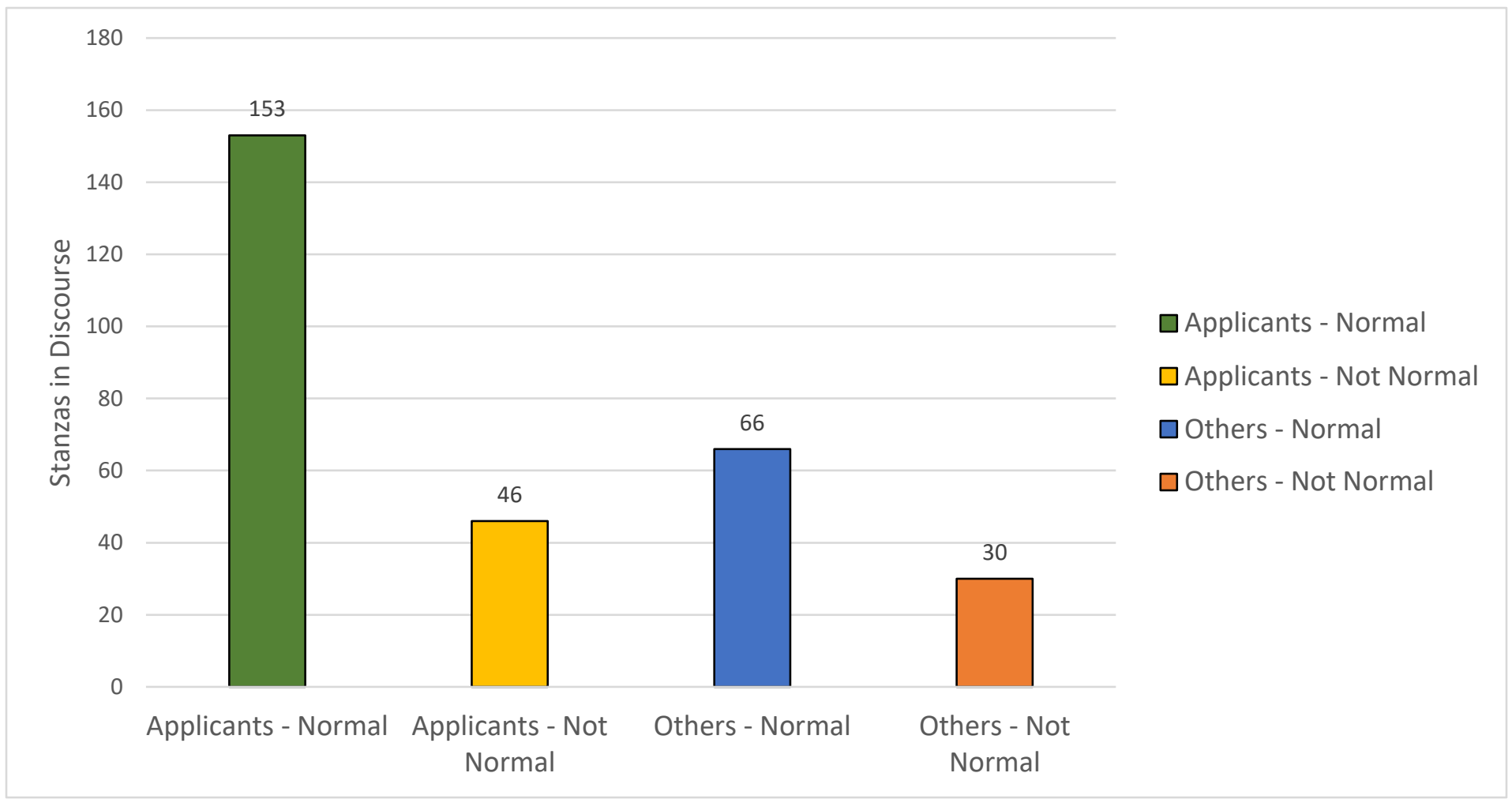

Figure 14. Transactional Victor Discourse Distribution 


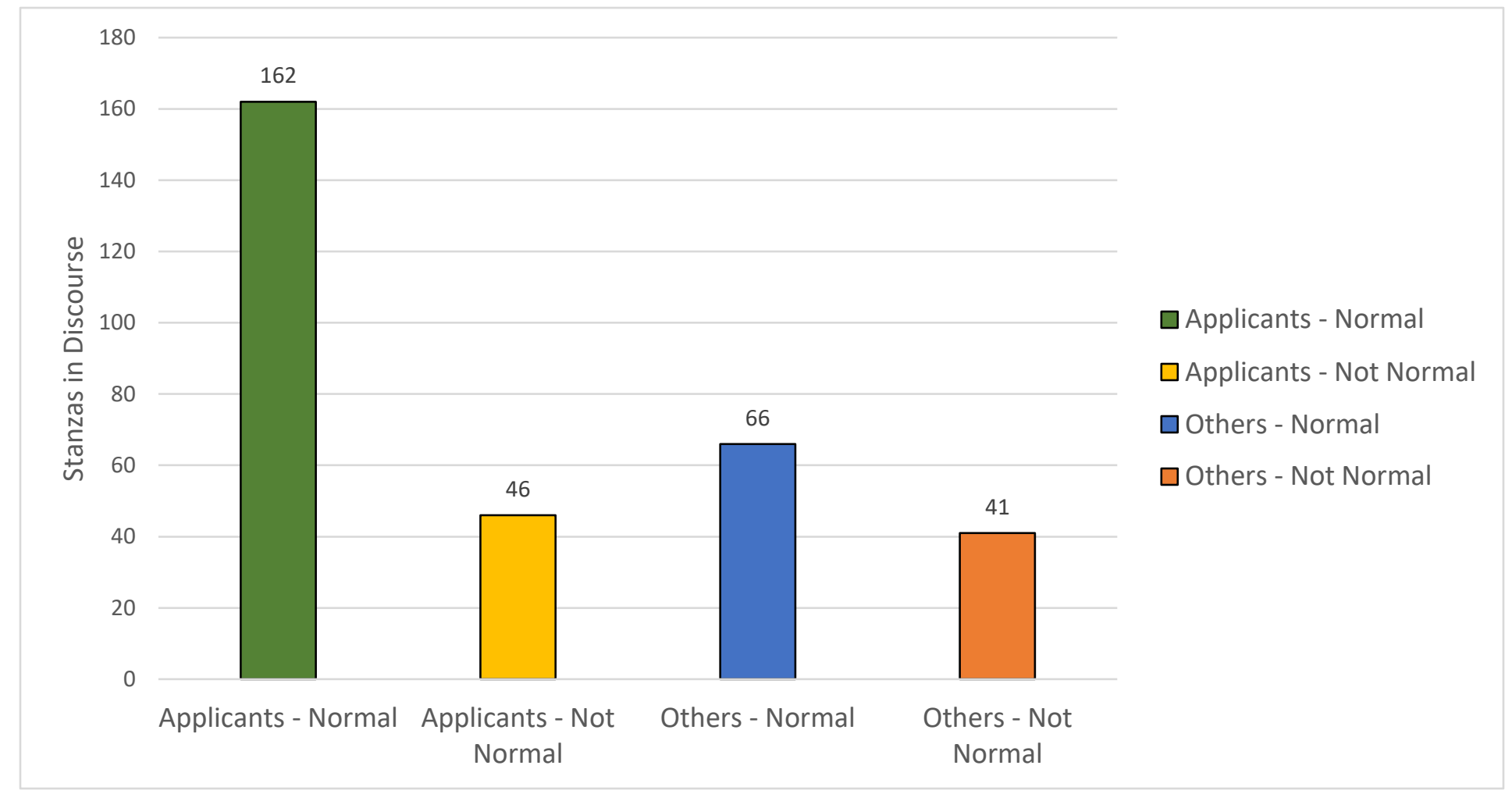

Figure 15. Transformative Victor Discourse Distribution 


\section{Tables}

- Table 1: How Education is Typically Linked with Other Sustainable Development Goals

- Table 2: Completion rates by education level, income group, sex and wealth, 2008$2014(\%)$

- Table 3: Tertiary education participation indicators

- Table 4: Definitions and Components of D/discourse and Critical Discourse Analysis (CDA)

- Table 5: Characteristics of Inaugural Executive Board

- Table 6: Applicants by Region

- Table 7: Applicants by Income Classification Level

- Table 8: Applicants by UIS Level of Development

- Table 9: Primary and Alternative Samples

- Table 10: Characteristics of Primary Population of Study

- Table 11: Components of Discourse, CDA, and Parts of Analysis

- Table 12: Building Tasks \& Theoretical Tools: Analysis Round Two

- Table 13: Chart of Codes

- Table 14: Distribution of Building Task Codes

- Table 15: Additional Codes

- Table 16: Building Task Code Distribution

- Table 17: Categories

- Table 18: Overview of Stanza Distribution

- Table 19: Categories for Each Building Task in Example Stanzas

- Table 20: Category Distribution

- Table 21: Categories in each Discourse Block 


\section{Table 1: How Education is Typically Linked with Other Sustainable Development Goals}

\section{Table 1}

How Education is Typically Linked with Other Sustainable Development Goals How Education is Typically Linked with Other Sustainable Development Goals

\begin{tabular}{|c|c|c|c|}
\hline Goal 1 & $\begin{array}{l}\text { Education is critical to } \\
\text { lifting people out of poverty. }\end{array}$ & Goal 10 & $\begin{array}{l}\text { Where equally accessible, } \\
\text { education makes a proven } \\
\text { difference to social and } \\
\text { economic inequality. }\end{array}$ \\
\hline
\end{tabular}

Goal 2 Education plays a key role in Goal 11 Education can give people
helping people move towards more sustainable farming methods, and in the skills to participate in shaping and maintaining understanding nutrition. more sustainable cities, and to achieve resilience in disaster situations.

\begin{tabular}{|c|c|c|c|}
\hline Goal 3 & $\begin{array}{l}\text { Education can make a } \\
\text { critical difference to a range } \\
\text { of health issues, including } \\
\text { early mortality, reproductive } \\
\text { health, spread of disease, } \\
\text { healthy lifestyles and well- } \\
\text { being. }\end{array}$ & Goal 12 & $\begin{array}{l}\text { Education can make a critical } \\
\text { difference to production } \\
\text { patterns (e.g. with regard to } \\
\text { the circular economy) and to } \\
\text { consumer understanding of } \\
\text { more sustainably produced } \\
\text { goods and prevention of } \\
\text { waste. }\end{array}$ \\
\hline Goal 5 & $\begin{array}{l}\text { Education for women and } \\
\text { girls is particularly important } \\
\text { to achieve basic literacy, } \\
\text { improve participative skills } \\
\text { and abilities, and improve } \\
\text { life chances. }\end{array}$ & Goal 13 & $\begin{array}{l}\text { Education is key to mass } \\
\text { understanding of the impact } \\
\text { of climate change and to } \\
\text { adaptation and mitigation, } \\
\text { particularly at the local level. }\end{array}$ \\
\hline Goal 6 & $\begin{array}{l}\text { Education and training } \\
\text { increase skills and the } \\
\text { capacity to use natural } \\
\text { resources more sustainably } \\
\text { and can promote hygiene. }\end{array}$ & Goal 14 & $\begin{array}{l}\text { Education is important in } \\
\text { developing awareness of the } \\
\text { marine environment and } \\
\text { building proactive consensus } \\
\text { regarding wise and } \\
\text { sustainable use. }\end{array}$ \\
\hline
\end{tabular}




\begin{tabular}{|c|c|c|c|}
\hline Goal 7 & $\begin{array}{l}\text { Educational programmes, } \\
\text { particularly non-formal and } \\
\text { informal, can promote better } \\
\text { energy conservation and } \\
\text { uptake of renewable energy } \\
\text { sources. }\end{array}$ & Goal 15 & $\begin{array}{l}\text { Education and training } \\
\text { increase skills and capacity } \\
\text { to underpin sustainable } \\
\text { livelihoods and to conserve } \\
\text { natural resources and } \\
\text { biodiversity, particularly in } \\
\text { threatened environments. }\end{array}$ \\
\hline Goal 8 & $\begin{array}{l}\text { There is a direct link among } \\
\text { such areas as economic } \\
\text { vitality, entrepreneurship, } \\
\text { job market skills and levels } \\
\text { of education. }\end{array}$ & Goal 16 & $\begin{array}{l}\text { Social learning is vital to } \\
\text { facilitate and ensure } \\
\text { participative, inclusive and } \\
\text { just societies, as well as } \\
\text { social coherence. }\end{array}$ \\
\hline Goal 9 & $\begin{array}{l}\text { Education is necessary to } \\
\text { develop the skills required to } \\
\text { build more resilient } \\
\text { infrastructure and more } \\
\text { sustainable industrialization. }\end{array}$ & Goal 17 & $\begin{array}{l}\text { Lifelong learning builds } \\
\text { capacity to understand and } \\
\text { promote sustainable } \\
\text { development policies and } \\
\text { practices. }\end{array}$ \\
\hline
\end{tabular}


Table 2: Completion rates by education level, income group, sex and wealth, 2008-2014 (\%)

Table 2

Completion rates by education level, income group, sex and wealth, 2008-2014 (\%)

\begin{tabular}{|c|c|c|c|c|c|c|c|c|c|c|}
\hline & \multicolumn{3}{|l|}{ Primary } & \multicolumn{4}{|c|}{ Lower Secondary } & \multicolumn{3}{|c|}{ Upper Secondary } \\
\hline & $\begin{array}{l}\text { Low } \\
\text { income } \\
\text { countries }\end{array}$ & $\begin{array}{l}\text { Lower } \\
\text { middle } \\
\text { income } \\
\text { countries }\end{array}$ & $\begin{array}{l}\text { Upper } \\
\text { middle } \\
\text { income } \\
\text { countries }\end{array}$ & $\begin{array}{l}\text { Low } \\
\text { income } \\
\text { countries }\end{array}$ & $\begin{array}{l}\text { Lower } \\
\text { middle } \\
\text { income } \\
\text { countries }\end{array}$ & $\begin{array}{l}\text { Upper } \\
\text { middle } \\
\text { income } \\
\text { countries }\end{array}$ & $\begin{array}{l}\text { Low } \\
\text { income } \\
\text { countries }\end{array}$ & $\begin{array}{l}\text { Lower } \\
\text { middle } \\
\text { income } \\
\text { countries }\end{array}$ & $\begin{array}{l}\text { Upper } \\
\text { middle } \\
\text { income } \\
\text { countries }\end{array}$ & $\begin{array}{l}\text { High } \\
\text { income } \\
\text { countries }\end{array}$ \\
\hline Total & 51 & 84 & 92 & 27 & 68 & 79 & 14 & 38 & 43 & 84 \\
\hline Female & 49 & 83 & 93 & 24 & 67 & 80 & 12 & 36 & 44 & 87 \\
\hline Male & 53 & 84 & 90 & 31 & 70 & 77 & 18 & 40 & 43 & 82 \\
\hline Poorest $20 \%$ & 28 & 69 & 86 & 10 & 50 & 63 & 2 & 20 & 27 & 76 \\
\hline *Female & 25 & 67 & 87 & 7 & 47 & 65 & 1 & 17 & 29 & 79 \\
\hline *Male & 30 & 71 & 85 & 13 & 52 & 60 & 4 & 23 & 23 & 75 \\
\hline Richest $20 \%$ & 77 & 95 & 96 & 52 & 88 & 87 & 34 & 66 & 60 & 93 \\
\hline *Female & 75 & 96 & 95 & 48 & 88 & 91 & 30 & 67 & 60 & 95 \\
\hline *Male & 79 & 95 & 96 & 58 & 88 & 84 & 39 & 65 & 60 & 91 \\
\hline
\end{tabular}

Source: UNESCO, 2016a, p. 185 
Table 3: Tertiary education participation indicators

Table 3

Tertiary education participation indicators

\begin{tabular}{lllllll}
\hline & \multicolumn{2}{c}{ Enrolment (000) } & \multicolumn{2}{c}{$\begin{array}{c}\text { Gross enrolment } \\
\text { ratio (\%) }\end{array}$} & \multicolumn{2}{c}{ Gender parity index } \\
\hline World & 2000 & 2014 & 2000 & 2014 & 2000 & 2014 \\
\hline Low income & 99516 & 207272 & 19 & 34 & 0.99 & 1.11 \\
\hline Lower middle income & 1237 & 4460 & 3 & 8 & 0.43 & 0.53 \\
\hline Upper middle income & 24996 & 58642 & 11 & 22 & 0.79 & 0.97 \\
\hline High income & 24798 & 78729 & 14 & 41 & 0.94 & 1.16 \\
\hline Caucasus and Central Asia & 48485 & 65441 & 55 & 74 & 1.17 & 1.25 \\
\hline Eastern and South-eastern Asia & 24213 & 67351 & 15 & 39 & 0.83 & 1.11 \\
\hline Europe and Northern America & 39940 & 51870 & 56 & 75 & 1.25 & 1.28 \\
\hline Latin America and the Caribbean & 11318 & 23845 & 22 & 44 & 1.17 & 1.29 \\
\hline Northern Africa and Western Asia & 6854 & 15261 & 20 & 37 & 0.83 & 0.99 \\
\hline Pacific & 1044 & 1748 & 46 & 62 & 1.26 & 1.39 \\
\hline Southern Asia & 12162 & 38097 & 9 & 23 & 0.66 & 0.93 \\
\hline Sub-Saharan Africa & 2557 & 7145 & 4 & 8 & 0.66 & 0.70 \\
\hline Source: (UNESCO, $2016 a$, p. 229$)$ & & & 22 & 24 & \\
\hline
\end{tabular}

Source: (UNESCO, 2016a, p. 229) 


\section{Table 4: Definitions and Components of D/discourse and Critical Discourse}

\section{Analysis (CDA)}

Table 4

Definitions and Components of D/discourse and Critical Discourse Analysis (CDA)

\begin{tabular}{llllll}
\hline Component & Fairclough & Gee & Gee CDA & Fairclough CDA & $\begin{array}{l}\text { Contextual } \\
\text { Considerations }\end{array}$ \\
\hline Data & $\begin{array}{l}\text { Text (spoken or } \\
\text { written language) }\end{array}$ & Text (discourse) & Piece of data & $\begin{array}{l}\text { Analysis of } \\
\text { language texts }\end{array}$ & $\begin{array}{l}\text { Context of } \\
\text { Situation }\end{array}$ \\
\hline Action & $\begin{array}{l}\text { An instance } \\
\text { of discourse } \\
\text { practice involving } \\
\text { the production and } \\
\text { interpretation of } \\
\text { text }\end{array}$ & $\begin{array}{l}\text { Communicative } \\
\text { Event (uses text to } \\
\text { communicate) }\end{array}$ & $\begin{array}{l}\text { Six Theoretical } \\
\text { (Building) Tools }+ \\
\text { Seven Building } \\
\text { Tasks }\end{array}$ & $\begin{array}{l}\text { Analysis of the } \\
\text { processes of text } \\
\text { production }\end{array}$ & $\begin{array}{l}\text { Institutional } \\
\text { Context }\end{array}$ \\
& $\begin{array}{l}\text { A piece of social } \\
\text { practice }\end{array}$ & $\begin{array}{l}\text { Meta-narratives } \\
\text { (Discourse) }\end{array}$ & $\begin{array}{l}\text { Reflection on } \\
\text { Context }\end{array}$ & $\begin{array}{l}\text { Analysis of the } \\
\text { events of discourse } \\
\text { as a form of } \\
\text { sociocultural } \\
\text { practice }\end{array}$ & Context \\
\hline Context & & & & Wider Societal \\
& & & & & \\
\end{tabular}

Sources: Fairclough, 1992, 1995, 2001, 2013; Gee, 2014a, 2014b 
Table 5: Characteristics of Inaugural Executive Board

Table 5

Characteristics of Inaugural Executive Board

\begin{tabular}{lccccc}
\hline Board Member & $\begin{array}{c}\text { Professional }- \\
\text { International } \\
\text { Higher }\end{array}$ & $\begin{array}{c}\text { University } \\
\text { Professor } \\
\text { Education Field }\end{array}$ & $\begin{array}{c}\text { Earned } \\
\text { Doctorate }\end{array}$ & $\begin{array}{c}\text { Significant } \\
\text { International }\end{array}$ & $\begin{array}{c}\text { Multiple } \\
\text { Languages } \\
\text { Travel / Personal } \\
\text { Connections } \\
\text { (pluent) }\end{array}$ \\
\hline Chair & $\mathrm{x}$ & $\mathrm{xbroad}$ & $\mathrm{x}$ & $\mathrm{x}$ \\
\hline Chair Elect & $\mathrm{x}$ & $\mathrm{x}$ & $\mathrm{x}$ & $\mathrm{x}$ & $\mathrm{x}$ \\
\hline Treasurer $/$ & $\mathrm{x}$ & & $\mathrm{x}$ & $\mathrm{x}$ \\
Secretary & & $\mathrm{x}$ & $\mathrm{x}$ & $\mathrm{x}$ & $\mathrm{x}$ \\
\hline At-large & & & & $\mathrm{x}$ \\
\hline At-large & & & & $\mathrm{x}$ \\
\hline
\end{tabular}


Table 6: Applicants by Region

Table 6

Applicants by Region

\begin{tabular}{lclc}
\hline World Bank Region & Number of Applicants & UIS Region & Number of Applicants \\
\hline East Asia and Pacific & 3 & Caribbean & 5 \\
\hline Europe \& Central Asia & 11 & Caucasus and Central Asia & 5 \\
\hline $\begin{array}{l}\text { Latin America \& the } \\
\text { Caribbean }\end{array}$ & 7 & Europe & 2 \\
\hline Middle East \& North Africa & 75 & Latin America & 28 \\
\hline North America & 6 & North Africa & 6 \\
\hline South Asia & 7 & North America & 8 \\
\hline Sub-Saharan Africa & 44 & Southern Asia & 3 \\
\hline & & Southeast Asia & 39 \\
\hline NA & 22 & Sub-Saharan Africa & 76 \\
\hline
\end{tabular}




\section{Table 7: Applicants by Income Classification Level}

Table 7

Applicants by Income Classification Level

\begin{tabular}{lclc}
\hline World Bank Income & Number of Applicants & UIS Income & Number of Applicants \\
Classification & & Classification & \\
\hline High Income & 21 & High Income & 21 \\
\hline Upper Middle Income & 25 & Upper Middle Income & 34 \\
\hline Lower Middle Income & 85 & Lower Middle Income & 98 \\
\hline Low Income & 22 & Low Income & 22 \\
\hline
\end{tabular}


Table 8: Applicants by UIS Level of Development

Table 8

Applicants by UIS Level of Development

\begin{tabular}{lc}
\hline UIS Development Level & Number of Applicants \\
\hline Developed & 12 \\
\hline Transitioning & 4 \\
\hline Developing & 159 \\
\hline
\end{tabular}


Table 9: Primary and Alternative Samples

Table 9

Primary and Alternative Samples

\begin{tabular}{|c|c|c|c|c|c|}
\hline Group & Size & $\begin{array}{c}\text { Lower } \\
\text { Income } \\
\text { Country }\end{array}$ & $\begin{array}{c}\text { Conflict- } \\
\text { affected / } \\
\text { Fragile State }\end{array}$ & $\begin{array}{c}\text { Interrupted } \\
\text { Educational } \\
\text { Journey }\end{array}$ & $\begin{array}{c}\text { Undergradu } \\
\text { ate Degree }\end{array}$ \\
\hline
\end{tabular}

\begin{tabular}{llllll}
\hline Primary & 10 & Yes & Yes & Yes & Yes
\end{tabular}

Sample

\begin{tabular}{lccccc}
\hline $\begin{array}{l}\text { Alternative } \\
\text { Sample One }\end{array}$ & 13 & Yes & Yes & No & Yes \\
\hline $\begin{array}{l}\text { Alternative } \\
\text { Sample Two }\end{array}$ & 9 & Yes & Yes & Yes & No \\
\end{tabular}


Table 10: Characteristics of Primary Population of Study

Table 10

Characteristics of Population of Study

\begin{tabular}{|c|c|c|c|c|c|c|}
\hline $\begin{array}{l}\text { Applicant } \\
\text { (Pseudonym) }\end{array}$ & Age & UIS Region & $\begin{array}{l}\text { Origin: } \\
\text { World } \\
\text { Bank } \\
\text { Income } \\
\text { Level }^{4}\end{array}$ & $\begin{array}{l}\text { School } \\
\text { Location: } \\
\text { World } \\
\text { Bank } \\
\text { Income } \\
\text { Level }\end{array}$ & $\begin{array}{l}\text { Degree } \\
\text { Field }\end{array}$ & $\begin{array}{l}\text { Non-Traditional Student } \\
\text { Characteristics }\end{array}$ \\
\hline Amara & 19 & S. Asia & $\begin{array}{l}\text { Lower- } \\
\text { middle }\end{array}$ & $\begin{array}{l}\text { Lower- } \\
\text { middle }\end{array}$ & Medicine & First-in-family \\
\hline Gaeti & 19 & W. Asia & Low* & $\begin{array}{l}\text { Upper- } \\
\text { middle }\end{array}$ & $\begin{array}{l}\text { Architecture } \\
\text { \& Design }\end{array}$ & $\begin{array}{l}\text { Culturally \& Linguistically Diverse } \\
\text { (CLD) } \\
\text { Refugee-background }\end{array}$ \\
\hline Layan & 19 & W. Asia & $\begin{array}{l}\text { Lower- } \\
\text { middle }\end{array}$ & $\begin{array}{l}\text { Upper- } \\
\text { middle }\end{array}$ & Health & $\begin{array}{l}\text { Culturally \& Linguistically Diverse } \\
\text { (CLD) } \\
\text { Refugee-background }\end{array}$ \\
\hline Laleh & 27 & SS Africa & Low* & Low & Business & $\begin{array}{l}\text { First-in-family } \\
\text { Age: } 24+ \\
\text { Familial responsibilities } \\
\text { Financial responsibilities } \\
\text { Culturally \& Linguistically Diverse } \\
\text { (CLD) }\end{array}$ \\
\hline Lawan & 27 & SS Africa & Low* & $\begin{array}{l}\text { Lower- } \\
\text { middle }\end{array}$ & Law & $\begin{array}{l}\text { Age: } 24+ \\
\text { Culturally \& Linguistically Diverse } \\
\text { (CLD) }\end{array}$ \\
\hline
\end{tabular}

${ }^{4}$ Note: Income level per World Bank FY2020 classification. World Bank data used as UIS does not have detailed classification parameters. 


\begin{tabular}{|c|c|c|c|c|c|c|}
\hline Mahin & 27 & SS Africa & Low & Low & STEM & $\begin{array}{l}\text { Age: } 24+ \\
\text { First-in-family } \\
\text { Familial responsibilities } \\
\text { Financial responsibilities }\end{array}$ \\
\hline Moza & 19 & W. Asia & Low* & $\begin{array}{l}\text { Upper- } \\
\text { middle* }\end{array}$ & $\begin{array}{l}\text { Architecture } \\
\text { \& Design }\end{array}$ & $\begin{array}{l}\text { Culturally \& Linguistically Diverse } \\
\text { (CLD) }\end{array}$ \\
\hline Nifa & 27 & W. Asia & Low* & $\begin{array}{l}\text { Upper- } \\
\text { middle* }\end{array}$ & Finance & $\begin{array}{l}\text { Age: } 24+ \\
\text { Culturally \& Linguistically Diverse } \\
\text { (CLD) } \\
\text { Familial responsibilities } \\
\text { Financial responsibilities }\end{array}$ \\
\hline Rada & 27 & SS Africa & Low* & Low & Public Health & $\begin{array}{l}\text { Refugee-background } \\
\text { Familial responsibilities } \\
\text { Financial responsibilities }\end{array}$ \\
\hline Rayna & 27 & SS Africa & Low & Low & Economics & $\begin{array}{l}\text { Age: } 24+ \\
\text { Financial responsibilities }\end{array}$ \\
\hline
\end{tabular}

Note: * Income level of country was downgraded within the time period of this research (2016-2019) 
Table 11: Components of Discourse, CDA, and Parts of Analysis

\section{Table 11}

\section{Components of Discourse, CDA, and Parts of Analysis}

\begin{tabular}{|c|c|c|c|c|c|c|c|c|}
\hline $\begin{array}{l}\text { Parts of } \\
\text { Analysis }\end{array}$ & $\begin{array}{l}\text { Analytical } \\
\text { Considerations }\end{array}$ & $\begin{array}{l}\text { Research } \\
\text { Questions }\end{array}$ & $\begin{array}{l}\text { Phase of } \\
\text { Analysis }\end{array}$ & $\begin{array}{l}\text { Analytic } \\
\text { Questions }\end{array}$ & Sample & Data & Tools of Analysis & $\begin{array}{l}\text { Rounds of } \\
\text { Analysis }\end{array}$ \\
\hline $\begin{array}{l}\text { Part I: Context of } \\
\text { Situation } \\
\text { What is? - } \\
\text { Preliminary } \\
\text { Content Analysis }\end{array}$ & $\begin{array}{l}\text { Data } \\
\text { Analysis of } \\
\text { language texts }\end{array}$ & $\begin{array}{l}\text { How do the } \\
\text { women identify } \\
\text { themselves and the } \\
\text { role of education } \\
\text { in their } \\
\text { experiences? }\end{array}$ & Phase 1 & $\begin{array}{l}\text { What are the key } \\
\text { terms? } \\
\text { How do these terms } \\
\text { fit with Discourses? }\end{array}$ & $\begin{array}{l}\text { All three } \\
\text { applicant groups }\end{array}$ & $\begin{array}{l}\text { Application } \\
\text { Essays }\end{array}$ & 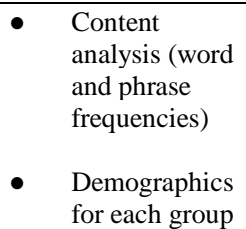 & $\begin{array}{l}\text { Round 1 - } \\
\text { Identification of } \\
\text { Content (all } 3 \\
\text { groups) }\end{array}$ \\
\hline \multirow[t]{2}{*}{$\begin{array}{l}\text { Part II: } \\
\text { Institutional } \\
\text { Context } \\
\text { What is? Examine } \\
\text { what applicants } \\
\text { are } \\
\text { communicating }\end{array}$} & \multirow[t]{2}{*}{$\begin{array}{l}\text { Action } \\
\text { Analysis of the } \\
\text { processes of text } \\
\text { production (use of } \\
\text { applications to } \\
\text { communicate) }\end{array}$} & $\begin{array}{l}\text { What is? } \\
\text { How did they } \\
\text { discuss } \\
\text { themselves? } \\
\text { How did they } \\
\text { discuss the role of } \\
\text { education in their } \\
\text { lives?" }\end{array}$ & Phase 2 & $\begin{array}{l}\text { What are the } \\
\text { applicants } \\
\text { communicating via } \\
\text { these Theoretical } \\
\text { Tools? } \\
\text { - Figured } \\
\text { Worlds } \\
\text { - Conversations } \\
\text { and Building Tasks? } \\
\text { - Identities } \\
\text { - Practices } \\
\text { Patterns? Outliers }\end{array}$ & \multirow[t]{2}{*}{ Primary sample } & \multirow[t]{2}{*}{$\begin{array}{l}\text { Application } \\
\text { Essays }\end{array}$} & \multirow{2}{*}{$\begin{array}{ll}\text { Building Tasks } \\
\text { - } & \text { What } \\
& \text { Identities? } \\
\text { - } & \text { What } \\
& \text { Relationships? } \\
\text { - } & \text { What } \\
& \text { Practices? } \\
\text { - } & \text { What Politics } \\
& \text { (Social } \\
& \text { Goods)? } \\
\text { Theoretical } \\
\text { (Building) Tools } \\
\text { - Figured } \\
\quad \text { Worlds } \\
\quad \text { (assumptions } \\
\text { about reality) } \\
\text { - Conversations } \\
\text { (role of } \\
\text { identity) }\end{array}$} & $\begin{array}{l}\text { Rounds 2-3 } \\
\mathbf{2} \text { - Development of } \\
\text { Building Task Codes } \\
\text { 3-Analysis of } \\
\text { Building Task Codes }\end{array}$ \\
\hline & & $\begin{array}{l}\text { What is? What } \\
\text { power dynamics } \\
\text { do they operate } \\
\text { within? }\end{array}$ & Phase 3 & $\begin{array}{l}\text { How do these essays } \\
\text { align with } \\
\text { Discourses? }\end{array}$ & & & & $\begin{array}{l}\text { Round 4-6 } \\
\mathbf{4}-\text { Development of } \\
\text { Categories } \mathbf{5}- \\
\text { Analysis of } \\
\text { Categories } \\
\mathbf{6} \text { - Analysis of } \\
\text { Categories - by } \\
\text { Discourses }\end{array}$ \\
\hline
\end{tabular}




\begin{tabular}{|c|c|c|c|c|c|c|c|c|}
\hline & & $\begin{array}{l}\text { What is? What } \\
\text { power dynamics } \\
\text { do they operate } \\
\text { within? }\end{array}$ & Phase 4 & $\begin{array}{l}\text { How do these essays } \\
\text { align with } \\
\text { Conversations about } \\
\text { the role of education } \\
\text { in their lives? }\end{array}$ & & & & $\begin{array}{l}\text { Round } 7-\text { Analysis } \\
\text { of Categories - by } \\
\text { Conversations }\end{array}$ \\
\hline $\begin{array}{l}\text { Part III: Wider } \\
\text { Societal Context } \\
\text { What might be? }\end{array}$ & $\begin{array}{l}\text { Context } \\
\text { Analysis of the } \\
\text { events of } \\
\text { discourse as a } \\
\text { form of } \\
\text { sociocultural } \\
\text { practice }\end{array}$ & $\begin{array}{l}\text { What might be? } \\
\text { How do these } \\
\text { discourses } \\
\text { compare to } \\
\text { women in similar } \\
\text { situations? }\end{array}$ & Phase 5 & $\begin{array}{l}\text { What are the key } \\
\text { Connections? (What } \\
\text { are missed } \\
\text { Connections?) } \\
\text { What Sign Systems } \\
\text { \& Knowledge are } \\
\text { privileged? (What } \\
\text { Sign Systems \& } \\
\text { Knowledges are not } \\
\text { privileged?) }\end{array}$ & $\begin{array}{l}\text { Primary sample } \\
\text { with supporting } \\
\text { documentation } \\
\text { from two } \\
\text { alternate groups }\end{array}$ & $\begin{array}{l}\text { Application } \\
\text { Essays }\end{array}$ & 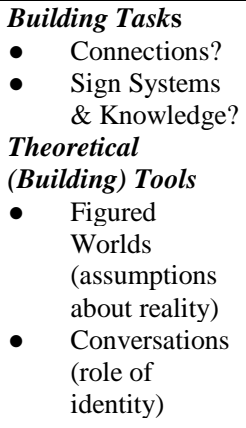 & $\begin{array}{l}\text { Round 8- } \\
\text { Reflection on } \\
\text { Context }\end{array}$ \\
\hline $\begin{array}{l}\text { Part VI: } \\
\text { Reflection o } \\
\text { Context } \\
\text { Critique of Power } \\
\text { Structures } \\
\text { (Reflections on } \\
\text { Context) }\end{array}$ & & $\begin{array}{l}\text { What else is } \\
\text { possible? How } \\
\text { might critiques } \\
\text { regarding } \\
\text { inequities be } \\
\text { addressed? }\end{array}$ & Phase 6 & $\begin{array}{l}\text { What are the key } \\
\text { Connections? (What } \\
\text { are missed } \\
\text { Connections?) } \\
\text { What Sign Systems } \\
\text { \& Knowledge are } \\
\text { privileged? (What } \\
\text { Sign Systems \& } \\
\text { Knowledges are not } \\
\text { privileged?) }\end{array}$ & Researcher & $\begin{array}{l}\text { Research } \\
\text { Journal }\end{array}$ & 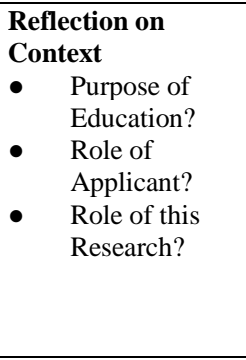 & $\begin{array}{l}\text { Round 9- } \\
\text { Reflection on } \\
\text { Context } \\
\text { (Researcher) }\end{array}$ \\
\hline
\end{tabular}


Table 12: Building Tasks \& Tools: Analysis Round Two

Table 12

Building Tasks \& Tools: Analysis Round Two

\begin{tabular}{ll}
\hline $\begin{array}{l}\text { Task (What part of "Reality" is } \\
\text { being built) }\end{array}$ & $\begin{array}{l}\text { Tool (How Language is Used to } \\
\text { Build "Reality") }\end{array}$ \\
\hline Significance & Situated meaning \\
\hline Practices & Social languages \\
\hline Identities & Figured worlds \\
\hline Relationships & Intertextuality \\
\hline & Discourses \\
\hline & Conversations \\
\hline
\end{tabular}




\section{Table 13: Chart of Codes}

Table 13

Chart of Codes

\begin{tabular}{llll}
\hline Category & $\begin{array}{l}\text { Identities } \\
\text { Person/Entity (Identities) } \\
\text { (PID) }\end{array}$ & Practices & $\begin{array}{l}\text { Social Goods } \\
\text { Noun (social good) (NSG) }\end{array}$ \\
\hline Education & PID: [Acad. Amin.] & Practice: To do Acad. Work & NSG: [Acad. Degree/Credential] \\
\hline & PID: [Acad. Prof.] & Practice: To be Credentialed (graduated) & NSG: [Acad. Exam / Test] \\
\hline PID: [Acad. Colleague] & $\begin{array}{l}\text { Practice: To be Examined (for } \\
\text { credentials) }\end{array}$ & NSG: [Acad. Finances] \\
\hline PID: [Skilled Professional] & Practice: To Educate (teach others) & NSG: [Acad. Institution] \\
\hline PID: [Acad. STUDENT] & Practice: To Have Career (pro work) & $\begin{array}{l}\text { NSG: [Acad. Program } \\
\text { (education)] }\end{array}$ \\
\hline PID: [Acad. GRADUATE] & Practice: To Seek Education & NSG: [Acad. Work] \\
\hline PID: Asherah Fdn. & Practice: To Seek Finances & NSG: [Career] \\
\hline & & NSG: [Asherah Fdn. Scholarship] \\
\hline
\end{tabular}

\begin{tabular}{llll}
\hline $\begin{array}{l}\text { Family/ } \\
\text { Community }\end{array}$ & PID: Self & Practice: Strengthen Fam. & NSG: Trauma (social bad) \\
\hline & PID: Fam. 1 & Practice: Weaken Fam. & NSG: Burden/Adversity \\
\hline PID: Fam 2. & & NSG: Challenge (social bad) \\
\hline PID: Dependents & & NSG: Safety (state of equanimity) \\
\hline PID: Com. 1 & Practice: Strengthen Com. & NSG: Support \\
\hline PID: Com. 2 & Practice: Weaken Com. & NSG: Success! \\
\hline & & NSG: Savior Status \\
\hline
\end{tabular}




\begin{tabular}{llll}
\hline Discourses & PID: Villain 1 - Evil & Practice: Injure / be villainous 1 & NSG: Trauma (social bad) \\
\hline & PID: Villain 2 & Practice: Injure / be villainous 2 & $\begin{array}{l}\text { NSG: Burden/Adversity (social } \\
\text { bad) }\end{array}$ \\
\hline Po Agency & PID: Victim & Practice: Be Victimized & NSG: Challenge \\
\hline & PID: Recipient of Being Saved & Practice: Being Saved & NSG: Safety \\
\hline & PID: Survivor & Practice: Survive & NSG: Support \\
\hline PID: Fighter & Practice: Fight (demonstrates agency) & NSG: Success! \\
\hline
\end{tabular}

Table 14: Distribution of Building Task Codes

Table 14

Distribution of Building Task Codes

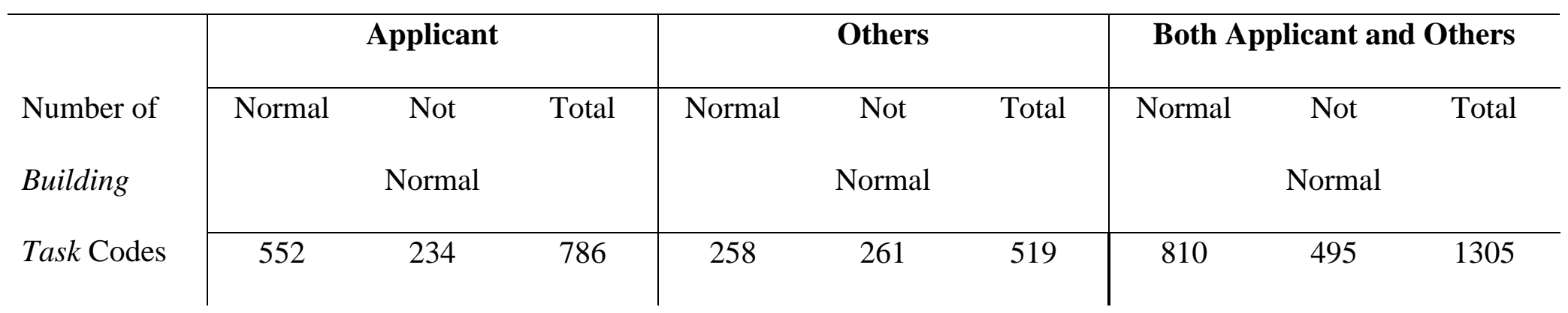




\section{Table 15: Additional Codes}

Table 15

Additional Codes

\begin{tabular}{lll}
\hline Identities (Person/Entity (Identities) & Practices & Social Goods (Noun (social good) \\
(PID)) & & (NSG)) \\
\hline PID: [Acad. GRADUATE] & Practice: To do Acad. Work & NSG: [Asherah Fdn. Scholarship] \\
\hline PID: Asherah Fdn. & Practice: To Seek Education & \\
\hline & Practice: To Seek Finances & NSG: Safety \\
\hline PID: Recipient of Being Saved & Practice: Being Saved & \\
\hline PID: Fighter & Practice: Fight (demonstrates agency) \\
\hline
\end{tabular}


Table 16: Building Task Code Distribution

Table 16

Building Task Code Distribution

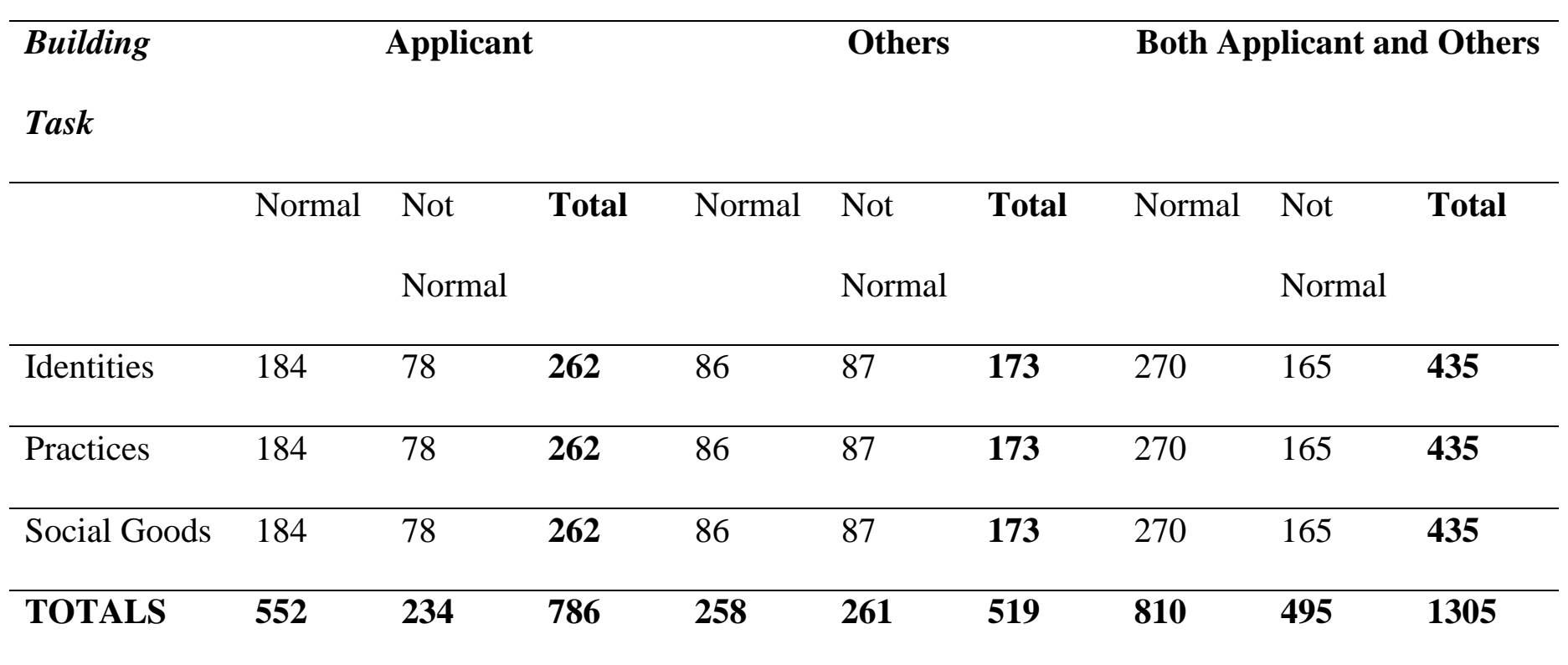




\section{Table 17: Categories}

\section{Table 17}

\section{Categories}

\begin{tabular}{ll}
\hline Category & Code used in Analysis \\
\hline Academic-Financial & ACAD-\$\$ \\
\hline Academics & ACAD \\
\hline Agency (victory) & S_Acy \\
\hline Asherah Foundation & A Fdn \\
\hline Education (Comprehensive) & ACAD\$\$ $\$$ \\
\hline Financial & \$\$\$ \\
\hline Social (generic) & SOCIAL \\
\hline Victimization & S Vctm \\
\hline
\end{tabular}

Table 18: Overview of Stanza Distribution

Table 18

Overview of Stanza Distribution

\begin{tabular}{lrcr}
\hline Subject of Stanza & Normal & Not Normal & Total \\
\hline Self (Applicant) & 184 & 78 & $\mathbf{2 6 2}$ \\
\hline Other & 86 & 87 & $\mathbf{1 7 3}$ \\
\hline Total & $\mathbf{2 7 0}$ & $\mathbf{1 6 5}$ & $\mathbf{4 3 5}$
\end{tabular}


Table 19: Categories for Each Building Task in Example Stanzas

Table 19

Categories for Each Building Task in Example Stanzas

\begin{tabular}{lll}
\hline Building Task (BT) 1 & Building Task $($ BT) 2 & Building Task (BT) 3 \\
\hline Identities & Practices & Social Goods \\
\hline ACAD\$\$ & ACAD\$\$ & ACAD\$\$ \\
\hline Social & S_Vctm & S_Vctm \\
\hline Villain & Villain & S_Vctm \\
\hline
\end{tabular}




\section{Table 20: Category Distribution}

Table 20

Category Distribution

\begin{tabular}{|c|c|c|c|c|c|c|c|c|c|c|}
\hline \multirow{2}{*}{$\begin{array}{l}\text { Building } \\
\text { Task (BT) }\end{array}$} & \multirow[t]{2}{*}{ Category } & \multicolumn{3}{|c|}{ Applicant } & \multicolumn{3}{|c|}{ Others } & \multicolumn{3}{|c|}{ Both Applicant and Others } \\
\hline & & Normal & $\begin{array}{c}\text { Not } \\
\text { Normal }\end{array}$ & Total & Normal & $\begin{array}{c}\text { Not } \\
\text { Normal }\end{array}$ & Total & Normal & $\begin{array}{c}\text { Not } \\
\text { Normal }\end{array}$ & Total \\
\hline \multirow[t]{6}{*}{ Identities } & Education* & 56 & 12 & 68 & 6 & 3 & 9 & 62 & 15 & 77 \\
\hline & Asherah Fdn. & 0 & 0 & 0 & 21 & 3 & 24 & 21 & 3 & 24 \\
\hline & Agency & 100 & 20 & 120 & 24 & 14 & 38 & 124 & 34 & 158 \\
\hline & Social & 2 & 1 & 3 & 14 & 8 & 22 & 16 & 9 & 25 \\
\hline & Villain & 0 & 0 & 0 & 2 & 17 & 19 & 2 & 17 & 19 \\
\hline & Totals & 184 & 78 & 262 & 86 & 87 & 173 & 270 & 165 & 435 \\
\hline
\end{tabular}




\begin{tabular}{|c|c|c|c|c|c|c|c|c|c|c|}
\hline \multirow[t]{7}{*}{ Practices } & Education* & 61 & 13 & 74 & 4 & 1 & 5 & 65 & 14 & 79 \\
\hline & Asherah Fdn. & 0 & 0 & 0 & 0 & 0 & 0 & 0 & 0 & 0 \\
\hline & Agency & 103 & 22 & 125 & 54 & 20 & 74 & 157 & 42 & 199 \\
\hline & Victimization & 19 & 43 & 62 & 24 & 45 & 69 & 43 & 88 & 131 \\
\hline & Social & 1 & 0 & 1 & 0 & 0 & 0 & 1 & 0 & 1 \\
\hline & Villain & 0 & 0 & 0 & 4 & 21 & 25 & 4 & 21 & 25 \\
\hline & Totals & 184 & 78 & 262 & 86 & 87 & 173 & 270 & 165 & 435 \\
\hline Social & Education* & 79 & 36 & 115 & 16 & 20 & 36 & 95 & 56 & 151 \\
\hline \multirow[t]{6}{*}{ Goods } & Asherah Fdn. & 18 & 1 & 19 & 13 & 2 & 15 & 31 & 3 & 34 \\
\hline & Agency & 77 & 17 & 94 & 37 & 18 & 55 & 114 & 35 & 149 \\
\hline & Victimization & 9 & 24 & 33 & 18 & 35 & 53 & 27 & 59 & 86 \\
\hline & Social & 1 & 0 & 1 & 0 & 0 & 0 & 1 & 0 & 1 \\
\hline & Villain & 0 & 0 & 0 & 2 & 12 & 14 & 2 & 12 & 14 \\
\hline & Totals & 184 & 78 & 262 & 86 & 87 & 173 & 270 & 165 & 435 \\
\hline All & TOTAL & 552 & 234 & 786 & 258 & 261 & 519 & 810 & 495 & 1305 \\
\hline \multicolumn{11}{|l|}{ Building } \\
\hline Tasks & & & & & & & & & & \\
\hline
\end{tabular}

*Comprehensive Education composed of the three categories: Academics, Academic-Financial, and Financial 
Table 21: Categories in each Discourse Block

Table 21

Categories in each Discourse Block

\begin{tabular}{|c|c|c|c|c|}
\hline \multirow[t]{2}{*}{ Category (Code) } & \multicolumn{2}{|c|}{ Transactional } & \multicolumn{2}{|c|}{ Transformational } \\
\hline & Victim & Victor & Victim & Victor \\
\hline Academic-Financial (ACAD-\$\$) & $(\mathrm{ACAD}-\$ \$)$ & $(\mathrm{ACAD}-\$ \$)$ & & \\
\hline Academics (ACAD) & & & (ACAD) & (ACAD) \\
\hline Agency (victory) (S_Acy) & & (S_Acy) & & (S_Acy) \\
\hline \multicolumn{5}{|c|}{ Comprehensive Education (ACAD\$\$ } \\
\hline Financial $(\$ \$ \$)$ & $(\$ \$ \$)$ & $(\$ \$ \$)$ & & \\
\hline \multicolumn{5}{|l|}{ Social (generic) (SOCIAL) } \\
\hline Victimization (S_Vctm) & $\left(S_{-}\right.$Vctm) & & $\left(S_{-}\right.$Vctm $)$ & \\
\hline Villainy (VILLAIN) & (VILLAIN) & & (VILLAIN) & \\
\hline
\end{tabular}




\section{Appendix 2: SDG \#4 Targets}

\section{Sustainable Development Goal (SDG) \#4}

Ensure inclusive and equitable quality education and promote lifelong learning opportunities for all

\begin{tabular}{|c|c|c|c|}
\hline \multicolumn{2}{|c|}{ Targets } & \multicolumn{2}{|c|}{ Indicators } \\
\hline 4.1 & $\begin{array}{l}\text { By } 2030, \text { ensure that all girls } \\
\text { and boys complete free, } \\
\text { equitable and quality primary } \\
\text { and secondary education } \\
\text { leading to relevant and } \\
\text { effective learning outcomes }\end{array}$ & 4.1.1 & $\begin{array}{l}\text { Proportion of children and } \\
\text { young people: (a) in grades } \\
2 / 3 \text {; (b) at the end of primary; } \\
\text { and (c) at the end of lower } \\
\text { secondary achieving at least a } \\
\text { minimum proficiency level in } \\
\text { (i) reading and } \\
\text { (ii) mathematics, by sex }\end{array}$ \\
\hline \multirow[t]{2}{*}{4.2} & \multirow[t]{2}{*}{$\begin{array}{l}\text { By } 2030, \text { ensure that all girls } \\
\text { and boys have access to } \\
\text { quality early childhood } \\
\text { development, care and pre- } \\
\text { primary education so that they } \\
\text { are ready for primary } \\
\text { education }\end{array}$} & 4.2.1 & $\begin{array}{l}\text { Proportion of children under } 5 \\
\text { years of age who are } \\
\text { developmentally on track in } \\
\text { health, learning and } \\
\text { psychosocial well-being, by } \\
\text { sex }\end{array}$ \\
\hline & & 4.2 .2 & $\begin{array}{l}\text { Participation rate in organized } \\
\text { learning (one year before the } \\
\text { official primary entry age), by } \\
\text { sex }\end{array}$ \\
\hline 4.3 & $\begin{array}{l}\text { By } 2030, \text { ensure equal access } \\
\text { for all women and men to } \\
\text { affordable and quality } \\
\text { technical, vocational and } \\
\text { tertiary education, including } \\
\text { university }\end{array}$ & 4.3 .1 & $\begin{array}{l}\text { Participation rate of youth and } \\
\text { adults in formal and non- } \\
\text { formal education and training } \\
\text { in the previous } 12 \text { months, by } \\
\text { sex }\end{array}$ \\
\hline 4.4 & $\begin{array}{l}\text { By } 2030, \text { substantially } \\
\text { increase the number of youth } \\
\text { and adults who have relevant } \\
\text { skills, including technical and } \\
\text { vocational skills, for } \\
\text { employment, decent jobs and } \\
\text { entrepreneurship }\end{array}$ & 4.4 .1 & $\begin{array}{l}\text { Proportion of youth and adults } \\
\text { with information and } \\
\text { communications technology } \\
\text { (ICT) skills, by type of skill }\end{array}$ \\
\hline
\end{tabular}




\begin{tabular}{|c|c|c|c|}
\hline 4.5 & $\begin{array}{l}\text { By } 2030, \text { eliminate gender } \\
\text { disparities in education and } \\
\text { ensure equal access to all } \\
\text { levels of education and } \\
\text { vocational training for the } \\
\text { vulnerable, including persons } \\
\text { with disabilities, indigenous } \\
\text { peoples and children in } \\
\text { vulnerable situations }\end{array}$ & 4.5 .1 & $\begin{array}{l}\text { Parity indices (female/male, } \\
\text { rural/urban, bottom/top wealth } \\
\text { quintile and others such as } \\
\text { disability status, indigenous } \\
\text { peoples and conflict-affected, } \\
\text { as data become available) for } \\
\text { all education indicators on this } \\
\text { list that can be disaggregated }\end{array}$ \\
\hline 4.6 & $\begin{array}{l}\text { By } 2030 \text {, ensure that all youth } \\
\text { and a substantial proportion of } \\
\text { adults, both men and women, } \\
\text { achieve literacy and numeracy }\end{array}$ & 4.6.1 & $\begin{array}{l}\text { Percentage of population in a } \\
\text { given age group achieving at } \\
\text { least a fixed level of } \\
\text { proficiency in functional (a) } \\
\text { literacy and (b) numeracy } \\
\text { skills, by sex }\end{array}$ \\
\hline 4.7 & $\begin{array}{l}\text { By } 2030, \text { ensure that all } \\
\text { learners acquire the } \\
\text { knowledge and skills needed } \\
\text { to promote sustainable } \\
\text { development, including, } \\
\text { among others, through } \\
\text { education for sustainable } \\
\text { development and sustainable } \\
\text { lifestyles, human rights, } \\
\text { gender equality, promotion of } \\
\text { a culture of peace and non- } \\
\text { violence, global citizenship } \\
\text { and appreciation of cultural } \\
\text { diversity and of culture's } \\
\text { contribution to sustainable } \\
\text { development }\end{array}$ & 4.71 & $\begin{array}{l}\text { Extent to which (i) global } \\
\text { citizenship education and (ii) } \\
\text { education for sustainable } \\
\text { development, including } \\
\text { gender equality and human } \\
\text { rights, are mainstreamed at all } \\
\text { levels in: (a) national } \\
\text { education policies, (b) } \\
\text { curricula, (c) teacher } \\
\text { education and (d) student } \\
\text { assessment }\end{array}$ \\
\hline 4.A & $\begin{array}{l}\text { Build and upgrade education } \\
\text { facilities that are child, } \\
\text { disability and gender sensitive } \\
\text { and provide safe, non-violent, } \\
\text { inclusive and effective } \\
\text { learning environments for all }\end{array}$ & 4.A.1 & $\begin{array}{l}\text { Proportion of schools with } \\
\text { access to: (a) electricity; (b) } \\
\text { the Internet for pedagogical } \\
\text { purposes; (c) computers for } \\
\text { pedagogical purposes; } \\
\text { (d) adapted infrastructure and } \\
\text { materials for students with } \\
\text { disabilities; (e) basic drinking } \\
\text { water; (f) single-sex basic } \\
\text { sanitation facilities; and (g) } \\
\text { basic handwashing facilities } \\
\text { (as per the WASH indicator } \\
\text { definitions) }\end{array}$ \\
\hline
\end{tabular}




\begin{tabular}{|l|l|l|l|}
\hline 4.B & $\begin{array}{l}\text { By 2020, substantially expand } \\
\text { globally the number of } \\
\text { scholarships available to } \\
\text { developing countries, in } \\
\text { particular least developed } \\
\text { countries, small island } \\
\text { developing States and African } \\
\text { countries, for enrolment in } \\
\text { higher education, including } \\
\text { vocational training and } \\
\text { information and } \\
\text { communications technology, } \\
\text { technical, engineering and } \\
\text { scientific programmes, in } \\
\text { developed countries and other } \\
\text { developing countries }\end{array}$ & $\begin{array}{l}\text { Volume of official } \\
\text { development assistance flows } \\
\text { for scholarships by sector and } \\
\text { type of study }\end{array}$ \\
\hline 4.C & $\begin{array}{l}\text { By 2030, substantially } \\
\text { increase the supply of } \\
\text { qualified teachers, including } \\
\text { through international } \\
\text { cooperation for teacher } \\
\text { training in developing } \\
\text { countries, especially least } \\
\text { developed countries and small } \\
\text { island developing States }\end{array}$ & $\mathbf{4 . C . 1}$ & $\begin{array}{l}\text { Proportion of teachers in: (a) } \\
\text { pre-primary; (b) primary; (c) } \\
\text { lower secondary; and (d) } \\
\text { upper secondary education } \\
\text { who have received at least the } \\
\text { minimum organized teacher } \\
\text { training (e.g. pedagogical } \\
\text { training) pre-service or in- } \\
\text { service required for teaching } \\
\text { at the relevant level in a given } \\
\text { country }\end{array}$ \\
\hline
\end{tabular}

Source: https://sustainabledevelopment.un.org/sdg4 


\section{Appendix 3: Education Levels (ISCED levels 4-8)}

Education levels in the GEM Report follow "the International Standard Classification of Education (ISCED), which is the classification system designed to serve as an instrument for assembling, compiling and presenting comparable indicators and statistics of education both within countries and internationally" (UNESCO, 2016a, p. 493). Much of the discourse relied upon for this research is about tertiary education (levels 5-8 in the GEM Report). It should be noted that the Asherah Foundation uses post-secondary to refer to levels 4-8. To avoid confusion, this paper will refer to ISCED levels 4-8 as "higher education" in general. When discussing specific aspects of the GEM Report or Asherah Foundation policies, tertiary education and post-secondary education will be used as appropriate. Throughout this paper, "higher" education is used to refer to all post-secondary education (levels 4-8). This is done, in large part, as one of the goals of this research is to inform the dialogue about access for women to tertiary education including post-secondary education opportunities (level 4).

\section{Education Levels (ISCED levels 4-8)}

Education levels according to the International Standard Classification of Education (ISCED), which is the classification system designed to serve as an instrument for assembling, compiling and presenting comparable indicators and statistics of education both within countries and internationally. The system, introduced in 1976, was revised in 1997 and 2011.

- Post-secondary non-tertiary education (ISCED level 4). It provides learning experiences building on secondary education, preparing for labour market entry as well as tertiary education. 
- Tertiary education (ISCED levels 5-8): It builds on secondary education, providing learning activities in specialized fields of education. It aims at learning at a high level of complexity and specialization. It comprises:

- Level 5: Short-cycle tertiary education, often designed to provide participants with professional knowledge, skills and competencies. It is practically based, occupationallyspecific and prepares students to enter the labour market.

- Level 6: Bachelor's, often designed to provide participants with intermediate academic and/or professional knowledge, skills and competencies, leading to a first degree or equivalent qualification.

- Level 7: Master's or equivalent level, often designed to provide participants with advanced academic and/or professional knowledge, skills and competencies, leading to a second degree or equivalent qualification.

- Level 8: Doctoral or equivalent level, designed primarily to lead to an advanced research qualification.

Source: UNESCO, 2016a, pp. 493-494. 


\section{Appendix 4: Comparison of World Bank and UIS Country Classifications}

This chart highlights the region and income level of the countries/states of origin for applicants.

\begin{tabular}{|l|c|l|l|l|l|l|l|}
\hline $\begin{array}{l}\text { Applicant } \\
\text { Home }\end{array}$ & $\begin{array}{l}\text { Number of } \\
\text { Applicants }\end{array}$ & $\begin{array}{l}\text { WB } \\
\text { Region }\end{array}$ & $\begin{array}{l}\text { UIS } \\
\text { Region }\end{array}$ & $\begin{array}{l}\text { WB Income } \\
\text { Level }\end{array}$ & $\begin{array}{l}\text { UIS Income } \\
\text { Level }\end{array}$ & $\begin{array}{l}\text { UIS } \\
\text { Development } \\
\text { Level }\end{array}$ & $\begin{array}{l}\text { Conflict - } \\
\text { Affected/ } \\
\text { Fragile State }\end{array}$ \\
\hline Algeria & 4 & MENA & N. Africa & Upper-Middle & Upper-Middle & Developing & Yes \\
\hline Belgium & 1 & ECA & Eur. & High & High & Developed &.. \\
\hline Belize & 1 & LAC & Carib. & Upper-Middle & Upper-Middle & Developing &.. \\
\hline Bosnia & 1 & ECA & Eur. & Upper-Middle & Upper-Middle & Transition &.. \\
\hline Cameroon & 5 & SS Africa & SS Africa & Lower-Middle & Lower-Middle & Developing &.. \\
\hline Canada & 1 & N. America & N. America & High & High & Developed &.. \\
\hline Chile & 2 & LAC & LA & High & High & Developing &.. \\
\hline $\begin{array}{l}\text { Comoros } \\
\text { Islands* }\end{array}$ & 1 & SS Africa & SS Africa & Low & Low & Developing & Yes \\
\hline Cyprus & 1 & ECA & N/A & High & N/A & Developed &.. \\
\hline Egypt & 10 & MENA & N. Africa & Lower-Middle & Lower-Middle & Developing &.. \\
\hline
\end{tabular}




\begin{tabular}{|l|c|l|l|l|l|l|l|}
\hline Ethiopia & 1 & SS Africa & SS Africa & Low & Low & Developing & Yes \\
\hline Ghana & 3 & SS Africa & SS Africa & Lower-Middle & Lower-Middle & Developing &.. \\
\hline India & 4 & S. Asia & S. Asia & Lower-Middle & Lower-Middle & Developing & Yes \\
\hline Iran & 1 & MENA & S. Asia & Upper-Middle & Upper-Middle & Developing & Yes \\
\hline Israel & 1 & MENA & W. Asia & High & High & Developed &. \\
\hline Italy & 2 & ECA & Europe & High & High & Developed &.. \\
\hline Jamaica & 3 & LAC & Carib. & Upper-Middle & Upper-Middle & Developing &.. \\
\hline $\begin{array}{l}\text { Jerusalem } \\
\text { (West Bank }\end{array}$ & 1 & MENA & W. Asia & High & High & Developed & Yes \\
\hline Jordan & 8 & MENA & W. Asia & Lower-Middle & Lower-Middle & Developing &.. \\
\hline Kenya & 5 & SS Africa & SS Africa & Lower-Middle & Lower-Middle & Developing &.. \\
\hline Kyrgyzstan & 1 & ECA & CCA & Lower-Middle & Lower-Middle & .. &.. \\
\hline Lebanon & 5 & MENA & W. Asia & Upper-Middle & Upper-Middle & Developing & Yes \\
\hline Liberia & 2 & SS Africa & SS Africa & Low & Low & Developing & Yes \\
\hline Libya & 4 & MENA & N. Africa & Upper-Middle & Upper-Middle & Developing & Yes \\
\hline
\end{tabular}




\begin{tabular}{|l|c|l|l|l|l|l|l|}
\hline Malawi & 3 & SS Africa & SS Africa & Low & Low & Developing &.. \\
\hline Malaysia & 2 & EAP & SE Asia & Upper-Middle & Upper-Middle & Developing &.. \\
\hline Morocco & 4 & MENA & N. Africa & Lower-Middle & Lower-Middle & Developing &.. \\
\hline Nigeria & 2 & SS Africa & SS Africa & Lower-Middle & Lower-Middle & Developing & Yes \\
\hline Pakistan & 3 & S. Asia & S. Asia & Lower-Middle & Lower-Middle & Developing & Yes \\
\hline Palestine & 22 & N/A & W. Asia & N/A & Lower-Middle & Developing & Yes \\
\hline Philippines & 1 & EAP & SE Asia & Lower-Middle & Lower-Middle & Developing & Yes \\
\hline Rwanda & 2 & SS Africa & SS Africa & Low & Low & Developing & Yes \\
\hline Saudi Arabia & 6 & MENA & W. Asia & High & High & Developing &.. \\
\hline South Sudan & 5 & SS Africa & SS Africa & Low & Low & Developing & Yes \\
\hline Sudan & 5 & SS Africa & N. Africa & Lower-Middle & Lower-Middle & Developing & Yes \\
\hline Syria & 21 & MENA & W. Asia & Lower-Middle & Lower-Middle & Developing & Yes \\
\hline Tajikistan & 1 & ECA & CCA & Lower-Middle & Lower-Middle & Transition &.. \\
\hline
\end{tabular}




\begin{tabular}{|l|c|l|l|l|l|l|l|}
\hline $\begin{array}{l}\text { Trinidad \& } \\
\text { Tobago }\end{array}$ & 1 & LAC & Carib. & High & High & Developing &.. \\
\hline Tunisia & 1 & MENA & N. Africa & Lower-Middle & Upper-Middle & Developing &.. \\
\hline Turkey & 3 & ECA & W. Asia & Upper-Middle & Upper-Middle & Developing & Yes \\
\hline Turkmenistan & 1 & ECA & CCA & Upper-Middle & Upper-Middle & Transition &.. \\
\hline Uganda & 5 & SS Africa & SS Africa & Low & Low & Developing & Yes \\
\hline USA & 5 & N. America & N. America & High & High & Developed &.. \\
\hline Yemen & 9 & MENA & W. Asia & Lower-Middle & Lower-Middle & Developing & Yes \\
\hline Zambia & 2 & SS Africa & SS Africa & Lower-Middle & Lower-Middle & Developing & .. \\
\hline
\end{tabular}

\begin{tabular}{|l|l|l|l|}
\hline Abbreviation & Region & Abbreviation & Region \\
\hline Carib. & Caribbean & MENA & Middle East \& North Africa \\
\hline CCA & Caucasus \& Central Asia & N. Africa & North Africa \\
\hline EAP & East Asia and Pacific & N. America & North America \\
\hline Eur. & Europe & S. Asia & South Asia \\
\hline ECA & Europe \& Central Asia & SE Asia & Southeast Asia \\
\hline LA & Latin America & SS Africa & Sub-Saharan Africa \\
\hline LAC & $\begin{array}{l}\text { Latin America \& the } \\
\text { Caribbean }\end{array}$ & W. Asia & West Asia \\
\hline
\end{tabular}




\section{Appendix 5: Fragile and Conflict-affected Situations}

Conflict-affected country. For a given year, any country with 1,000 or more battlerelated deaths (including fatalities among civilians and military actors) over the preceding 10-year period and/or more than 200 battle related deaths in any one year over the preceding 3-year period, according to the Uppsala Conflict Data Program Battle-Related Deaths Dataset. (2017 GEM Report p. 427)

\section{Fragile and conflict affected situations}

- Long Name: Fragile and conflict affected situations

- Special Notes: Fragile and conflict affected situations aggregate. Countries with fragile situations are primarily International Development Association-eligible countries and nonmember or inactive countries and territories with a 3.2 or lower harmonized average of the World Bank's Country Policy and Institutional Assessment rating and the corresponding rating by a regional development bank, or that have had a UN or regional peacebuilding and political mission (for example by the African Union, European Union, or Organization of American States) or peacekeeping mission (for example, by the African Union, European Union, North Atlantic Treaty Organization, or Organization of American States) during the last three years. The group excludes IBRD countries (for which the CPIA scores are not publicly disclosed); unless there is the presence of a peace-keeping or political/peacebuilding mission. This definition is pursuant to an agreement between the World Bank and other multilateral development banks at the start of the International Development Association 15 round in 2007. The list of countries and territories with fragile 
situations is imperfect and used here to reflect a complex concept. The World Bank continues to work with partners and client countries to refine the concept.

World Bank https://data.worldbank.org/region/fragile-and-conflict-affected-

situations?view=chart (accessed 7.17.18)

\section{List of Fragile \& Conflict-Affected Situations: Both UN and World Bank}

\begin{tabular}{|c|c|c|}
\hline $\begin{array}{ll}\text { - } & \text { Afghanistan } \\
\text { - } & \text { Algeria } \\
\text { - } & \text { Burundi } \\
\text { - } & \text { Rentral African } \\
\text { - } & \text { Chad } \\
\text { - } & \text { Comoros } \\
\text { - } & \text { Colombia } \\
\text { - } & \text { Democratic } \\
& \text { Republic of the } \\
& \text { Congo } \\
\text { - } & \text { Cote D'Ivoire } \\
\text { - } & \text { Djibouti (Republic } \\
\text { - } & \text { Ef) } \\
\text { - } & \text { Eritrea } \\
\text { - } & \text { Gambia, The } \\
\text { - } & \text { Guinea-Bissau } \\
\text { - } & \text { Haiti } \\
\text { - } & \text { Indonesia } \\
\text { - } & \text { Iran (Islamic } \\
& \text { Republic of) }\end{array}$ & $\begin{array}{ll}\text { - } & \text { Iraq } \\
\text { - Kiribati } \\
\text { - Kosovo } \\
\text { - Lebanon } \\
\text { - Liberia } \\
\text { - } \text { Madaga } \\
\text { - Mali } \\
\text { - Marshall Islands } \\
\text { - Micronesia } \\
\text { - Myanmar } \\
\text { - Nepal } \\
\text { - Paperia } \\
\text { - Pakistan } \\
\text { - Palestine } \\
\text { - Philippines } \\
\text { - Russian Federation } \\
\text { - Rwanda }\end{array}$ & $\begin{array}{l}\text { - Sierra Leone } \\
\text { - Solomon Islands } \\
\text { - Somalia } \\
\text { - South Sudan } \\
\text { - Sri Lanka } \\
\text { - Sudan } \\
\text { - Syrian Arab } \\
\text { - Republic } \\
\text { - Thailand } \\
\text { - Togo } \\
\text { - Turkey } \\
\text { - Uganda } \\
\text { - West Bank and } \\
\text { - Gaza } \\
\text { - Zimen }\end{array}$ \\
\hline
\end{tabular}




\section{Appendix 6: Scholarship Policy \& Application Form}

\section{Second Chance Scholarship \\ Policies and Requirements:}

The Asherah Foundation, a global organization of professional women, has instituted a scholarship program to benefit females who have a high school diploma or equivalent and who desire to begin or continue a postsecondary education or technical training program with the intent of acquiring the skills necessary to enter or advance her status in the workplace.

The recipient shall be a female who will receive benefits under the Scholarship, subject to the terms and conditions set out below.

Recipients shall be chosen by the Foundation based strictly on the following criteria:

- Must be 24 years of age or older. (removed in 2017)

- Must be committed to the pursuit of postsecondary education and/or training.

- Must demonstrate financial inability to attain further education/training without the Scholarship.

- Must provide a copy of the last two years income tax return (Form 1040). (removed in 2017)

- Must have high school diploma or equivalent.

- Must provide high school transcript, GED OR current transcript from current school.

- Must demonstrate personal discipline and perseverance.

- Must complete Foundation current essay requirement: "Why This Scholarship will Give Me A Second Chance," to be no less than 500 words and no more than 1000 words.

- Must provide two letters of recommendation. 
- Must provide two references with phone numbers included.

- Must have been accepted into an accredited college or university degree program or a vocational or training institution located in the community of the program.

- Must live, work, or attend college in the community of the program.

\section{The Scholarship will include the following:}

The monetary dollar amount of this award shall be up to (US) $\$ 2,500.00$ per semester and may be renewable for the next consecutive semester. This award shall be applied to expenses pertaining to a four-year college degree, associate degree or an accredited vocation/training program, for the payment of costs relating to the recipient's registration costs, tuition and related expenses for books, lab fees, and other classroom supplies and fees required under the recipient's school curriculum.

A member of the Foundation shall be a mentor to the student and will be a liaison between the recipient and the Foundation.

All of the foregoing amounts shall be payable to the Financial office of the school chosen by the student or to the training program chosen by the student. The funds shall be disbursed solely for the purposes outlined above.

Each recipient, while receiving Scholarship benefits, shall fulfill the following obligations or will lose eligibility for participation in the Scholarship program:

- Must complete a minimum of 9 hours a semester (16 week period) unless having prior approval of Foundation mentor.

- Must submit any changes in writing from one program to another for prior approval of the Foundation.

- Must maintain a cumulative GPA of 2.50 in such postsecondary programs. 
- Must report to the Foundation in writing, the status of her educational/training efforts each semester or term.

- Must turn in copy of grades to mentor before receiving funds for the next semester or term.

- Must be committed to the mentor program and be receptive to being contacted.

- Must be free of substance abuse.

- Must have financial status reviewed on a semester basis. 


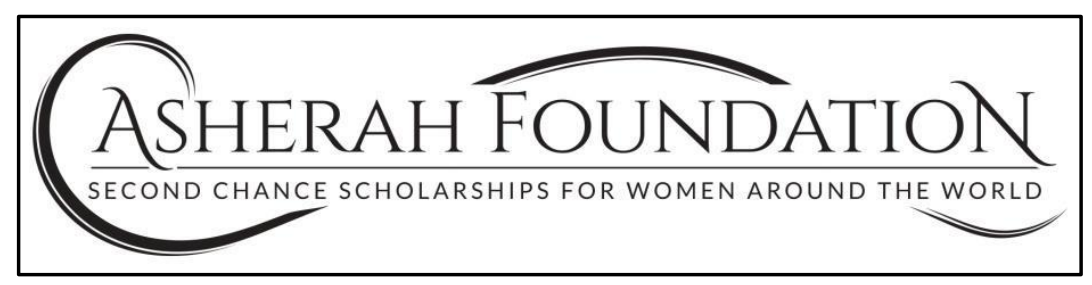

\section{WOMEN'S SECOND CHANCE SCHOLARSHIP PROGRAM STUDENT APPLICATION FORM}

I hereby apply for The Asherah Foundation's Second Chance Scholarship to assist in the payment of my education and/or training expenditures.

THIS APPLICATION MUST BE COMPLETED INCLUDING ALL REQUESTED INFORMATION AND SUPPORTING DOCUMENTS i.e. TRANSCRIPTS, TAX RETURNS, LETTERS OF REFERENCE AND ESSAY.

COMPLETED APPLICATIONS ARE DUE JULY 1, 2016.

\section{PERSONAL INFORMATION}

NAME:

Last

First

MI

HOME ADDRESS:

Street Number

City,

State/Province Postal (Zip) Code

Country

Home Phone:

Work Phone: Cell Phone: 
EMAIL ADDRESS:

DATE OF BIRTH: SOCIAL SECURITY \#:

Have you been convicted of a felony?

Yes No

NAMES AND AGES OF DEPENDENTS:

Name Date of Birth

Name Date of Birth

Name Date of Birth

Name Date of Birth

\section{WORK EXPERIENCE}

Current Employer

Employer's Address

Name of Contact Person

Employer's Phone Number

Average Number of Hours Worked Each Week

\section{RECOMMENDATIONS}

TWO LETTERS OF RECOMMENDATION FROM NON-RELATIVES ARE REQUIRED TO BE SENT TO THE FOUNDATION AT THE ADDRESS AT THE END OF THIS APPLICATION.

\section{REFERENCES}

PLEASE GIVE NAMES AND ADDRESSES OF TWO OTHER PERSONS WHO HAVE KNOWN YOU FOR FIVE YEARS OR MORE:

First and Last Name

Street Number 
City, State \& Zip

Phone: Email: Relationship:

First and Last Name

Street Number

City, State \& Zip

Phone:

Email:

Relationship:

\section{EDUCATION EXPERIENCE}

\section{Name of School}

Street Number

City, State \& Zip

Year of Completion Degree

\section{Name of School}

Street Number

City, State \& Zip

Year of Completion Degree

IMPORTANT NOTE: IT IS THE APPLICANT'S RESPONSIBILITY TO FORWARD TO THE ASHERAH FOUNDATION AN OFFICIAL COPY OF HER MOST RECENT TRANSCRIPT OR GED IF APPLICABLE. INCOMPLETE APPLICATIONS WILL NOT BE ACCEPTED.

\section{EXPENSES AND INCOME}

A COPY OF THE LAST TWO INCOME TAX RETURNS (FORM 1040 in United States) MUST BE ATTACHED.

Number of Weeks in Class 
Number of Classes in 16 week period

\section{EXPENSES}

Tuition \& Required Fees

$\$$

Books \& Materials

$\$$

Child Care

$\$$

Transportation

$\$$

Other

$\$$

Total

$\$$

\section{INCOME}

Amount you will contribute to your

tuition and education expenses

$\$$

Other Scholarships

$\$$

Grants

$\$$

Loans

$\$$

Other Sources

$\$$

Total

$\$$

TOTAL EXPENSES SHOULD EQUAL TOTAL INCOME

Does your employer reimburse all or a portion of your tuition fees? Please explain. 
VII. PLEASE ATTACH AN ESSAY ILLUSTRATING HOW THIS

SCHOLARSHIP WILL GIVE YOU A SECOND CHANCE AND HOW IT

WILL BENEFIT YOUR COMMUNITY. ESSAY SHALL BE NO LESS

THAN 500 WORDS AND NO MORE THAN 1000 WORDS.

VIII. APPLICANT'S CERTIFICATION STATEMENTS

\section{Financial Statement:}

I hereby state that I need financial assistance to help pay for my education and that the scholarship will be used for that purpose.

Name of School Attending or Accepted to:

Degree being pursued: Projected Graduation Date

\section{Accuracy:}

I hereby state that all information contained in this application and all supporting materials is correct to the best of my knowledge.

\section{Use of Application Materials:}

I understand that the attached essay and a photo of myself may be used for promotional and research purposes. I also understand that I may request that my name and other identifying details be changed for all outreach, research, and promotional purposes to protect my identity. However, I understand that the scholarship will be given in my legal name and that all identifying information will be available to those involved in the scholarship selection and awarding process, including the institution to which the scholarship funds will be paid. I waive any right to damages that may result as a consequence of applying for this scholarship. Obligations of the Scholarship Recipient:

I understand that upon acceptance of this scholarship that I: 
- Must complete a minimum of 9 hours a semester (16 week period) unless having prior approval of Foundation mentor.

- Must submit any changes in writing from one program to another for prior approval of the Foundation.

- Must maintain a cumulative GPA of 2.50 (on a 4 point scale) in such postsecondary programs.

- Must report to the Foundation in writing, the status of my educational/training efforts each semester or term; including the ways in which this scholarship has been helpful in providing a second chance.

- Status update \#1 will be due December 1, 2016

- Status update \#2 will be due June 1, 2017

- Must turn in copy of grades to mentor before receiving funds for the next semester or term.

- Must be committed to the mentor program and be receptive to being contacted.

- Must be free of substance abuse.

- Must have financial status reviewed on a semester basis.

Applicant's Signature: Date:

\section{APPLICATION CHECKLIST}

Before you mail your application, please verify the following items are completed and enclosed.

- Completed and signed application

- Two letters of recommendation (The writer may mail the letter directly to the address above or may be enclosed with your application) 
O Official copy of your latest transcript

- Copies of your completed tax return (or comparable information) for the two latest years
○ Essay
○ Photo (optional)

Thank you and good luck! 


\section{Appendix 7: Building Task Codes - Comparisons of Major Categories}
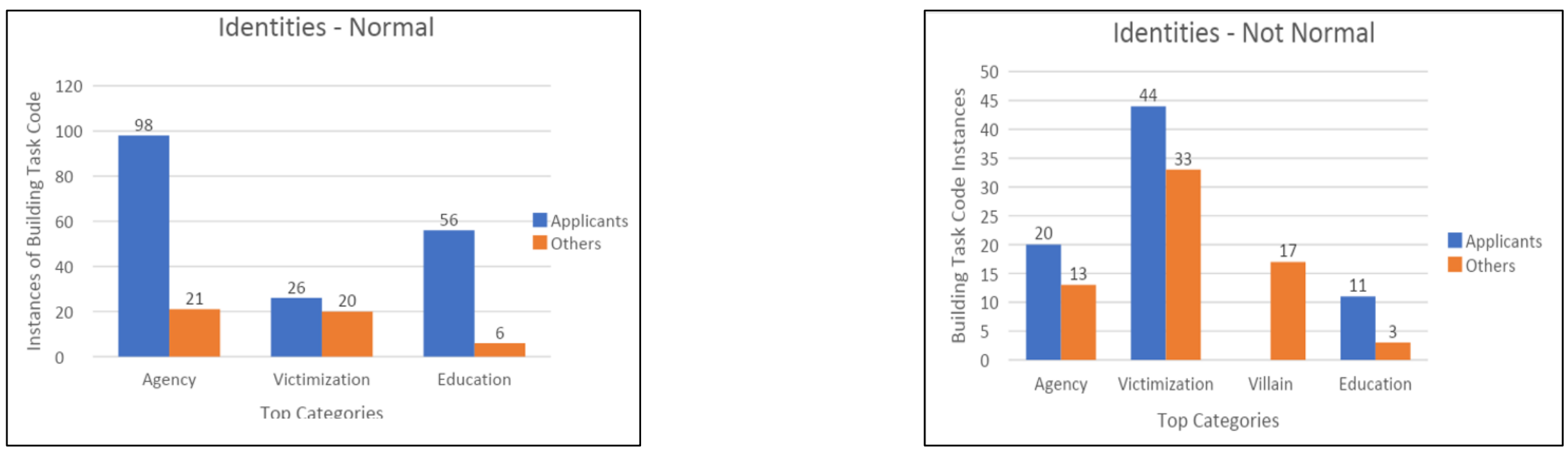

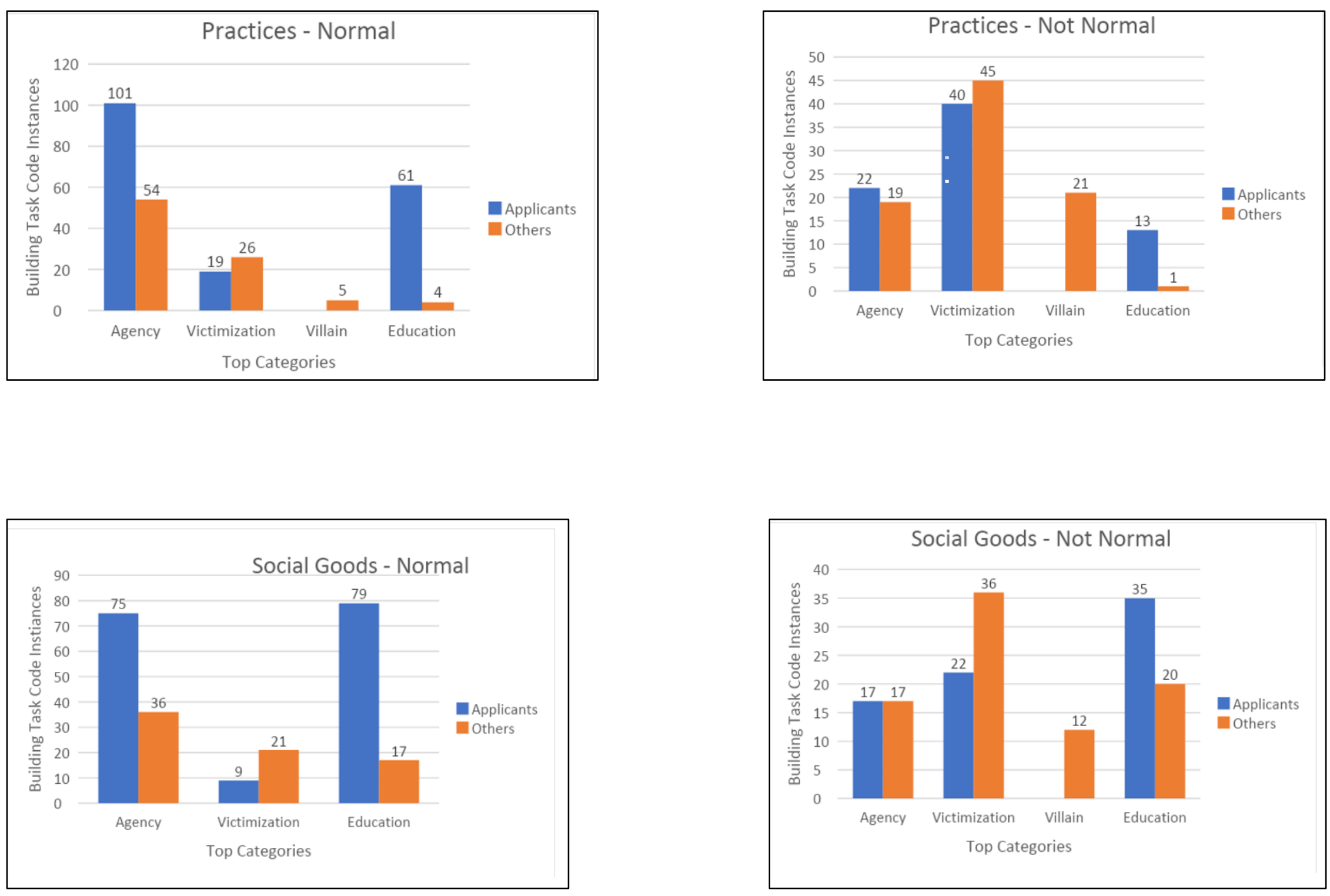


\section{Appendix 8: Chart of Four Discourses: Applicants vs. Others}

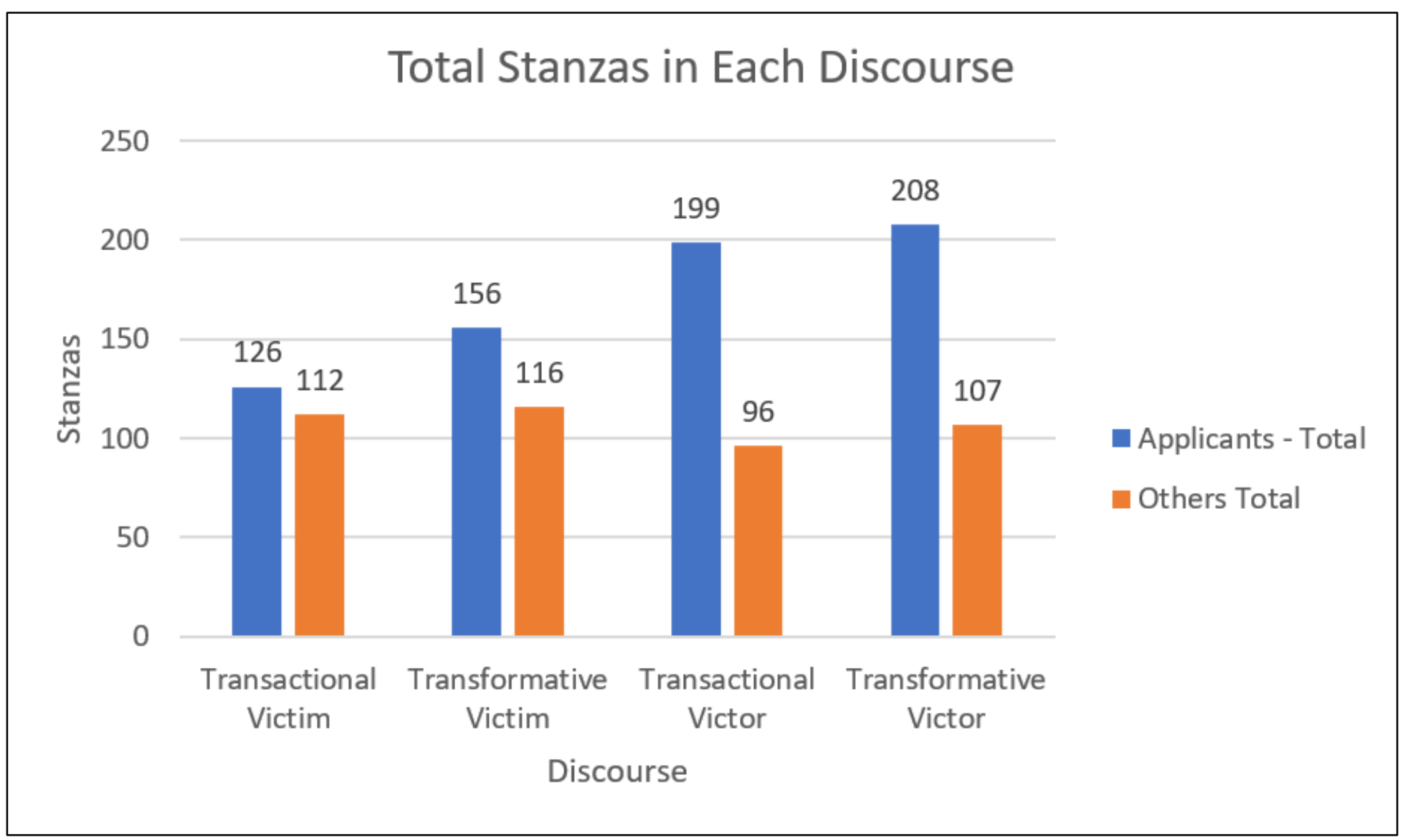




\section{VITA}

Heather MacCleoud has worked in the international higher education field for

over a decade. Through her work at NAFSA: Association of International Educators and at the Asherah Foundation, she leads the development of strategic international partnerships so students and employers can mutually benefit from the increased availability of post-secondary education around the world.

She works with higher education institutions, business communities, NGOs and governments to develop international partnerships as well as to internationalize curriculum and programming so that graduates are prepared to enter a diverse workforce and succeed in a global environment.

She has extensive experience leading international collaborative partnerships. This includes leading an international nonprofit to provide scholarships to under-served students and through the Asherah Foundation. It also currently includes oversight of the development of global learning opportunities for higher education institutions around the world.

She previously oversaw accreditation and quality assurance processes for higher education programs as well as assisted government-led tasks forces in developing financing strategies and in creating policies and legislation to improve education services. She developed and directed public-private partnerships to increase international trade of higher education and developed a nonprofit organization to support this work. She has experience in leadership, strategic planning, grants management, coalition building, market development, policy development, policy implementation, and in quality assurance for both the public and private sectors. 